Kolja Möller

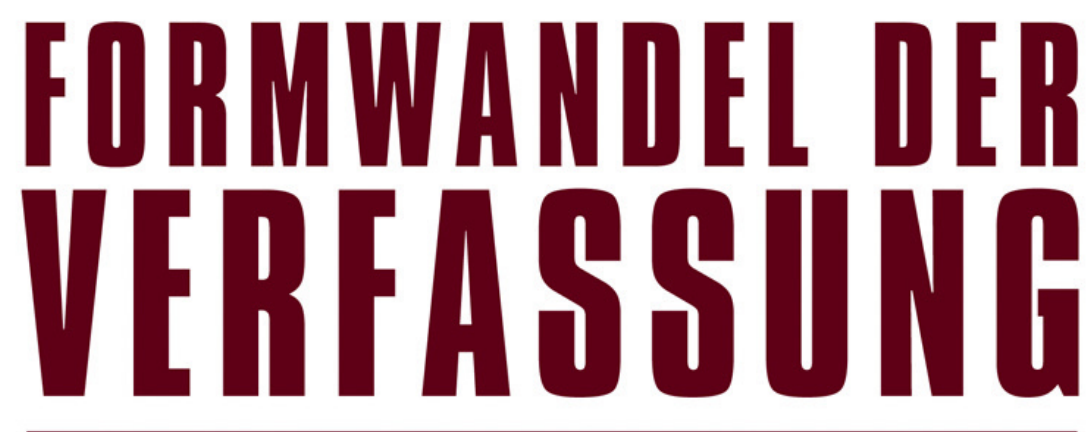

Die postdemokratische Verfasstheit des Transnationalen

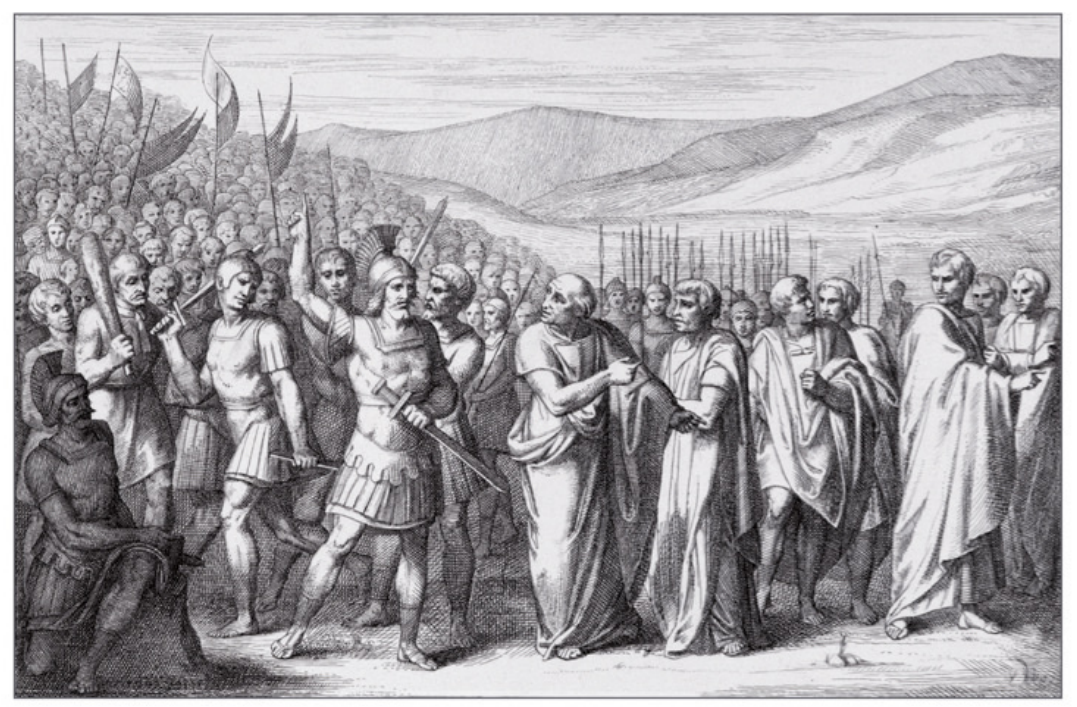

[transcript] Edition Politik 
Kolja Möller

Formwandel der Verfassung

Edition Politik | Band 23 
Kolja Möller (Dr.) ist wissenschaftlicher Mitarbeiter am Exzellenzcluster »Normative Ordnungen « der Universität Frankfurt am Main. Er forscht zu Fragen internationaler politischer Theorie, Soziologie und Rechtstheorie. 
Kolja MÖLleR

\section{Formwandel der Verfassung}

Die postdemokratische Verfasstheit des Transnationalen

[transcript] 
Diese Publikation geht hervor aus dem DFG-geförderten Exzellenzcluster »Die Herausbildung normativer Ordnungen« an der Goethe-Universität Frankfurt am Main.

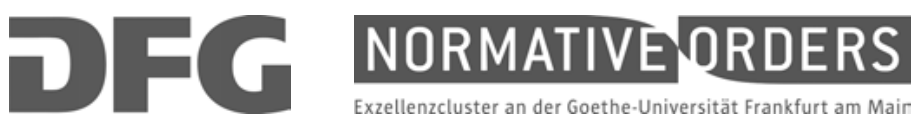

\section{(c) (1) $\Theta \Theta$}

Dieses Werk ist lizenziert unter der Creative Commons Attribution-NonCommercial-NoDerivs 4.0 Lizenz (BY-NC-ND). Diese Lizenz erlaubt die private Nutzung, gestattet aber keine Bearbeitung und keine kommerzielle Nutzung. Weitere Informationen finden Sie unter https://creativecommons.org/licenses/by-nc-nd/4.o/deed.de/. Um Genehmigungen für Adaptionen, Übersetzungen, Derivate oder Wiederverwendung zu kommerziellen Zwecken einzuholen, wenden Sie sich bitte an rights@transcript-verlag.de

\section{(C) 2015 transcript Verlag, Bielefeld}

\section{Bibliografische Information der Deutschen Nationalbibliothek}

Die Deutsche Nationalbibliothek verzeichnet diese Publikation in der Deutschen Nationalbibliografie; detaillierte bibliografische Daten sind im Internet über http://dnb.d-nb.de abrufbar.

Umschlagkonzept: Kordula Röckenhaus, Bielefeld

Umschlagabbildung: The Secession of the People to the Mons Sacer, engraving by B. Barloccini, 1849. Perkins, C.C (19th century) (after) Fotocredit: Private Collection/Bridgeman Images

Druck: Majuskel Medienproduktion GmbH, Wetzlar

Print-ISBN 978-3-8376-3093-0

PDF-ISBN 978-3-8394-3093-4

Gedruckt auf alterungsbeständigem Papier mit chlorfrei gebleichtem Zellstoff. Besuchen Sie uns im Internet: $h t t p: / / w w w . t r a n s c r i p t-v e r l a g . d e$ Bitte fordern Sie unser Gesamtverzeichnis und andere Broschüren an unter: info@transcript-verlag.de 


\section{Inhalt}

\section{ERSter TEIL - KONStitutionalismus ALS WidERSPRÜCHLICHE FORM $\mid 9$}

I. Die globale Verfassungsfrage |9

II. Reflexivität $\mid 15$

III. Der Widerspruch der Verfassung mit sich selbst. Anschlüsse an Hegel und Marx $\mid 21$

IV. Verfassungssoziologie $\mid 28$

\section{Zweiter Teil - Formwandel des Konstitutionalismus: Die Weltgesellschaft als fRAgmentierte HEGEMONIEKONSTELLATION $\mid 33$}

I. Das Weltwirtschaftsregime und der politikwissenschaftliche Legitimismus | 34

1. Das Weltwirtschaftsregime $\mid 34$

2. Legitimismus $\mid 44$

II. Weltgesellschaft $\mid 48$

1. Dominanz kognitiver Erwartungsstile $\mid 51$

2. Inklusion/Exklusion als Leitdifferenz $\mid 54$

3. Das Herrschaftsproblem $\mid 59$

III. Hybride Regime | 62

IV. Eigenrationalitätsmaximierung $\mid 73$

1. Kollisionen und Paradoxien $\mid 76$

2. Grenzen der Regimediagnose $\mid 80$ 
v. Hegemonie $\mid 82$

1. Marktliberale Hegemonie |83

2. Antagonismus und das Außen der Regime 192

3. Das Politische $\mid 96$

4. Leere und Kritik $\mid 98$

VI. Formwandel des Konstitutionalismus | 105

1. Regimeverfassungen $\mid 106$

2. Substantialisierung $\mid 109$

3. Antagonistische Verfassungen | 112

\section{DRITTER TEIL - KRITIK ZEITGENÖSSISChER VERFASSUNGSTHEORIE | 115}

I. Die Konstitutionalisierung des Völkerrechts 116

1. Nachordnung der hegemonialen Regime $\mid 120$

2. Verfassung der Form der Herrschaftsausübung | 128

a. Kelsen oder Schmitt? | 128

b. Policey und Verfassung | 131

c. Die Politik des internationalen Rechts 138

3. Menschenrechte $\mid 143$

a. Repressive Toleranz | 144

b. Platzhalterfunktion $\mid 147$

4. Dr. Jekyll and Mr. Hyde | 151

II. Zwischen Verselbstständigung und Emanzipation: Transnationaler gesellschaftlicher Konstitutionalismus $\mid 153$

1. Zivile Verfassungstheorie $\mid 155$

a. Gesellschaftsverfassung im Nationalstaat | 157

b. Antagonismus 160

c. Evolution und Revolution 165

2. Soziale Demokratie $\mid 166$

a. Responsivität | 168

b. Reflexivität | 170

c. Das Politische $\mid 172$

3. Grund- und Menschenrechte 174

4. Systemkritik im System | 177 


\section{Vierter Teil - Von der kONStituierenden Macht ZUR DESTITUIERENDEN MACHT | 179}

I. Volkssouveränität $\mid 181$

1. Vertrag statt Verfassung $\mid 182$

2. Formwandel der Demokratie | 186

3. Abschied von der Volkssouveränität? | 188

II. Destituierende Macht | 193

1. Konstitution und Destitution | 195

2. Paradoxe Verfassung | 197

3. Staat und Zivilgesellschaft | 200

III. Ein demokratisches Dispositiv für die Regime $\mid 201$

1. Leere 202

2. Opposition und Kontestation | 203

\section{EPILOG: VeRfassungSKÄMPfE LANGER DAUER} Und die Wiederkehr des Plebejischen | 207

Literaturverzeichnis | 211

Danksagung | 239 



\section{Erster Teil - Konstitutionalismus als widersprüchliche Form}

\section{Die globale Verfassungsfrage}

Die jüngeren Diskussionen in der internationalen politischen Theorie und der Rechtstheorie erheben die globale Verfassungsfrage zur »zentralen Herausforderung für internationale Philosophen im 21. Jahrhundert«1. Im alltagsverständlichen Sinne erscheint das erst einmal irritierend, wird der Begriff der Verfassung doch in der Regel vor allem verwendet, um nationale Staatsverfassungen - beispielsweise das Grundgesetz - zu bezeichnen. Allerdings erlebt die Diskussion um die Verfassung seit den $1990 e r$ Jahren eine zunehmende Verschiebung in den inter- und transnationalen Raum. ${ }^{2}$ Der Übergang in die Weltgesellschaft, das Anwachsen von Institutionen jenseits des Nationalstaats, die Globalisierung der Wirtschaft, die Verrechtlichung kontinentaler Integrationsprozesse - all diese Entwicklungen deuten auf ein verändertes Terrain hin, auf dem sich Verfassungsfragen stellen. Jedenfalls gerät die ausschließliche Identifizierung von Nationalstaat und Verfassung zunehmend unter Druck; ja, es wird immer deutlicher, dass der moderne Konstitutionalismus, der im Nationalstaat seinen Ausdruck gefunden hat, nur ein Kapitel in einer vielfältigeren Verfassungsevolution abgibt, deren Zukunft in der Weltgesellschaft eventuell vollkommen neuartige Facetten hervorbringen wird. Insgesamt ist es fraglich, ob Staatsverfassungen unter Bedingungen globaler Vernetzung überhaupt noch in der Lage sind, ihre Funktionen zu erfüllen. Man mag der Staatssouveränität noch die Rolle eines Schutzes nationaler Demokratie vor demokratischen Defiziten zuschreiben. Selbst dann bleibt sie oft machtlos. ${ }^{3}$ Sie findet

1 | Allott, Philip: "The Emerging Universal Legal System", in: International Law Forum du Droit International 3 / 1 (2001), S. 12-17, hier S. 16.

2 | Vgl. den Überblick bei Schwöbel, Christine J.: "Situating the Debate on Global Constitutionalism ", in: International Journal of Constitutional Law 8/3 (2010), S. 611-635. 3 | Die Souveränität ist dann eher defensiver Demokratieschutz bei Grimm, Dieter: Souveränität. Herkunft und Zukunft eines Schlüsselbegriffs, Berlin: Berlin University 
keinerlei Rückendeckung mehr, wenn wichtige Entscheidungen von der Fiskalpolitik bis zum Grundrechtsschutz längst von inter- und transnationalen Institutionen vereinnahmt oder wenigstens massiv mitbestimmt werden.

Deshalb gewinnen zwischenzeitlich Überlegungen an Bedeutung, die den Verfassungsbegriff vom Nationalstaat lösen. Sie zeichnen eine folgenreiche Konstitutionalisierung jenseits des Staates nach und binden sie an die Entwicklungen der Weltgesellschaft an. So werden der Übergang des internationalen Völkerrechts zu einem kosmopolitischen Weltbürgerrecht, die Tendenz zur Verrechtlichung der Weltwirtschaft oder auch Verfassungsprozesse in den unterschiedlichsten Sozialbereichen der Weltgesellschaft wie Weltgesundheit, Technikregulierung oder Weltbildung zu Anhaltspunkten für eine Wende: ${ }^{4}$ Der Konstitutionalismus erhält eine starke transnationale Dimension.

So unterschiedlich die Prämissen innerhalb dieser neueren Diskussion sein mögen, so fallen doch wenigstens Familienähnlichkeiten in der Herangehensweise auf. Zumeist verallgemeinern die vorliegenden Überlegungen einzelne Strukturmerkmale der nationalen Staatsverfassung. In einem nächsten Schritt versuchen sie in der Regel zu zeigen, wie und ob solche Strukturmerkmale auch jenseits des Nationalstaats aufzufinden sind. Dies ruft einzelne entgegenkommende Beispiele der Weltgesellschaft auf. Die Annahme besteht darin, dass sich Strukturmerkmale der modernen Nationalstaatsverfassung im transnationalen Raum, wenn auch in veränderter, verschobener Art, aufspüren lassen. Insofern - und hier besteht ein Kontrast zu den jüngeren Forschungsschwerpunkten der zeitgenössischen Politikwissenschaft - findet in dieser Perspektive nicht nur eine Transformation politischer Steuerung statt; vielmehr wird das Blickfeld über die »Global Governance « hinaus erweitert und in gewisser Weise radikalisiert. ${ }^{5}$ Nicht nur politische Institutionen rücken in den Fokus. In Konstitutionalisierungsprozessen sind Wechselbeziehungen zwischen Politik, Recht, Wirtschaft und Gesellschaft wirksam, die weit über die enge Sphä-

Press 2009, S. 123; vgl. zur Souveränität als politischer Widerstandsstrategie auch: Koskenniemi, Martti: "What Use for Sovereignty Today? ", in: Asian Journal of International Law $1 / 1$ (2011), S. 61-70.

4 | Exemplarisch für den Bereich des Völkerrechts: Habermas, Jürgen: "Hat die Konstitutionalisierung des Völkerrechts noch eine Chance?", in: ders., Der gespaltene Westen, Frankfurt a. M.: Suhrkamp 2004, S. 113-193; für den Welthandel: Petersmann, Ernst-Ulrich: "The WTO-Constitution and Human Rights", in: Journal of International Economic Law $3 / 1$ (2000), S. 19-25; für die transnationalen Sozialbereiche: Teubner, Gunther: Verfassungsfragmente. Gesellschaftlicher Konstitutionalismus in der Globalisierung, Berlin: Suhrkamp 2012.

5 | Siehe dazu auch die Problematisierung bei Bogdandy, Armin von/Dann, Philipp/ Goldmann, Matthias: "Völkerrecht als öffentliches Recht: Konturen eines rechtlichen Rahmens für Global Governance", in: Der Staat 49/ 1 (2010), S. 23-50. 
re der internationalen Politik hinausreichen. Die Verfassungsfrage aufzuwerfen, sie zu stellen, macht einen Unterschied ums Ganze aus. In der Rede (und nicht zuletzt im Schreiben) über die Verfassung schwingt schließlich ein normativer Anspruch mit. Auf dem Spiel steht nicht einzig die Verfassung als Institution, sondern genauso ihre Normativität: Kann die Normativität der Verfassung, können ihre herrschaftsbegrenzenden und herrschaftskonstituierenden Ambitionen in die Weltgesellschaft verlängert werden? Und wenn ja, inwiefern leisten Verfassungsordnungen einen Beitrag dazu, den Krisen- und Gefährdungslagen der Weltgesellschaft zu begegnen?

Zwischenzeitlich hat die Diskussion um die Verfassungsbildung jenseits des Staates ein hohes Differenzierungsniveau erreicht. So liegen unterschiedliche Definitionsversuche vor, die darauf zielen den Verfassungsbegriff zu verallgemeinern. Im Kern scheint jedoch alles auf drei grundlegende Strukturmerkmale hinauszulaufen, die im Mittelpunkt der Kontroversen stehen.

Erstens ist davon auszugehen, dass der Verfassungsbegriff stets auf eine höherrangige Ordnung verweist, die Recht und Politik aufeinander bezieht. ${ }^{6}$ Die Verfassung ist der Ort, an dem sich Recht und Politik überschneiden. Dort regeln sie ihre gegenseitigen Einflussnahmen. In den Worten Niklas Luhmanns reagiert die Verfassung historisch auf »eine Differenzierung von Recht und Politik [...] und auf den damit gegebenen Verknüpfungsbedarf « ${ }^{7}$. Dabei unterwirft sie als höherrangige Ordnung beide Seiten einem »Zwang zur Form ${ }^{8}$. Sie gibt das Recht der Rechtserzeugung vor. Sie regelt, in welchen politischen Verfahren Recht gesetzt und verändert wird. Dies gilt auch für die Änderungsregeln der Verfassung selbst. Darüber hinaus stattet sie unterschiedliche Organe mit Kompetenzen aus und unterwirft sie gleichermaßen dem Recht der Verfassung. Damit formt die Verfassung beide Seiten, Recht und Politik. Die Politik wird in die Form der Gesetzgebung überführt und an das Recht gebunden. Das Recht selbst wird dem höherrangigen Recht der Verfassung unterworfen. Der

6 | Zu diesem Motiv einer höherrangigen Koppelung von Recht und Politik durch Verfassung vgl. so unterschiedliche Ansätze wie Luhmann, Niklas: "Verfassung als evolutionäre Errungenschaft", in: Rechtshistorisches Journal 9 (1990), S. 176-220, hier S. 180; Vorländer, Hans: Die Verfassung. Idee und Geschichte, München: C. H. Beck 1999, S. 9; Möllers, Christoph: "Verfassunggebende Gewalt - Verfassung - Konstitutionalisierung", in: Armin von Bogdandy / Jürgen Bast (Hg.): Europäisches Verwaltungsrecht, Heidelberg: Springer 2009, S. 227-277, hier S. 238. Nowotny/Raunig führen den Verfassungsbegriff begriffsgeschichtlich auf die "Zusammen-Stellung von mehreren Komponenten" zurück, vgl. Nowotny, Stefan/Raunig, Gerald: Instituierende Praxen. Bruchlinien der Institutionskritik, Wien: Turia + Kant 2008, S. 37.

7 | N. Luhmann, Verfassung als evolutionäre Errungenschaft, S. 180.

8 | Preuss, Ulrich K.: "Der Begriff der Verfassung“, in: ders. (Hg.), Zum Begriff der Verfassung. Die Ordnung des Politischen, Frankfurt a. M.: Fischer 1994, S. 7-36, hier S. 12. 
Rechtstheoretiker H. L. A. Hart hat solche Regeln als secondary rules bezeichnet, also sekundäre Regeln, die einfache primäre Regeln hervorbringen. ${ }^{9}$ Es geht also um die Normierung von Normierungen, um die Regeln der Regelerzeugung. Im Nationalstaat, wie er in umkämpften Prozessen der Territorialisierung seit der Frühen Neuzeit entstanden ist, hat das staatliche Gewaltmonopol sich diese höherrangige Setzungskompetenz zunehmend angeeignet. ${ }^{10}$ Nun ist die Leistung der Verfassung so zu verstehen, dass sie als Verknüpfungsinstanz in doppelter Weise wirksam ist. Sie hat die Herrschaftsausübung im Territorialstaat zum einen ermöglicht, indem sie Recht und Politik dauerhaft verknüpft und vonseiten des Staates her vereinheitlicht hat. So sind legale Veränderungen der Herrschaftsstrukturen durchführbar geworden. Zum anderen hat die Verfassung eine begrenzende Wirkung entfaltet, da sie die Herrschaftsausübung einem höherrangigen Recht unterworfen und rechtlich formalisiert hat. ${ }^{11}$

Im Übergang zur Weltgesellschaft gerät dieses Amalgam aus Herrschaftskonstitution und Herrschaftsbegrenzung, das idealtypisch in den Staatsverfassungen ablesbar ist, unter massiven Druck. Die Weltgesellschaft bringt zunehmend Strukturen hervor, die der Staatsverfassung ihre Zentralstellung rauben. Dies gilt schon für das klassische Völkerrecht, das die Souveränität der Nationalstaaten eingrenzen soll, vielleicht aber noch mehr für die supranationale politische Integration wie in der Europäischen Union (EU) oder in der sich abzeichnenden Verfassung des Welthandels. Der Staat verliert hier zunehmend sein Rechtsetzungsmonopol. Seine Verfassung wird übertrumpft und kann sich nicht mehr einfach als höchste Ordnung darstellen. Denn auch jenseits des Staates sind höherrangige Ordnungen identifizierbar, die Recht und Politik in neuer Weise miteinander verbinden.

Zweitens halten Verfassungen in der Regel eine Regierungsart fest - oder, um klassisch mit Aristoteles zu sprechen, ein Prinzip der »Staatslenkung « ${ }^{12}$. Obliegt die Regierung einem, mehreren oder vielen, dem Mächtigsten, den Besten oder den Mittellosen? Weist die Verfassung ein monarchisches, aristokra-

9 | Vgl. Hart, H. L. A.: The Concept of Law (1961), Oxford: Oxford University Press 2012, S. $79 \mathrm{ff}$.

10 | Vgl. Kriegel, Blandine: The State and the Rule of Law, Princeton: Princeton University Press 1995.

11 | Diese Formulierung greift die gängige Unterscheidung zwischen einer herrschaftskonstituierenden und einer herrschaftsbegrenzenden Dimension der Verfassung auf. Sie wird sich zu einem späteren Zeitpunkt der Argumentation als problematisch erweisen (siehe insbes. den dritten Teil, I, ab S. 116). Jon Elster analysiert diesen Aspekt der Verfassung als Strategie des precommitment, vgl. Elster, Jon: Ulysses and The Sirens. Studies in Rationality and Irrationality, Cambridge: Cambridge University Press 1979, S. $94 \mathrm{ff}$.

12 | Aristoteles: Politik. Schriften zur Staatstheorie, Stuttgart: Reclam 2010, S. 170. 
tisches oder demokratisches Regierungsprinzip auf? Seit den demokratischen Revolutionen des 18. Jahrhunderts in Amerika und Frankreich hat sich zunehmend ein Verständnis durchgesetzt, das dem Volk die konstituierende Macht zuschreibt. Es ist das Volk, das sich sowohl das Recht der Verfassungsgebung als auch die Wahl der Regierung aneignet. Demokratische Verfahren und Mechanismen der Gewaltengliederung sollen gewährleisten, dass sich die Adressaten der Rechtssetzung als ihre Autoren verstehen können. Heutzutage wird der Verfassungsbegriff sogar oft direkt mit dem Demokratieprinzip gleichgesetzt. Viele zeitgenössische Kritiker des neueren Verfassungswandels weisen darauf hin, dass die Ordnungsmuster der Weltgesellschaft einer demokratischen Regierungsart vollkommen entbehren und deshalb nicht als Verfassungen zu bezeichnen sind - wo kein demos ist, könne von einer Verfassung im modernen Sinne keine Rede sein. ${ }^{13}$ Sie halten an der Idee der demokratischen Verfassung fest, die für die bürgerlich-demokratischen Revolutionen charakteristisch war.

Auf der anderen Seite üben die inter- und transnationalen Vernetzungen selbst Druck auf die nationalstaatliche Demokratie aus. Es scheint so, als ob die gegenseitige Bezogenheit von territorial gebundenen Rechtsunterworfenen und Rechtsautoren nur um den Preis des nationalen Autismus aufrechtzuerhalten ist. Schließlich sind regelmäßig bei Entscheidungen im Nationalstaat weite Teile der Weltbevölkerung massiv betroffen, haben jedoch im Gegenzug kaum Chancen, überhaupt Einfluss zu nehmen. ${ }^{14}$ Die demokratische Regierungsart in ihrer staatlich gebundenen Form ist zunehmend durch eigene Legitimationsdefizite gekennzeichnet. Es ist fraglich, ob transnationale Institutionen dabei sind, Mechanismen auszubilden, die diese demokratischen Defizite kompensieren. Dies betrifft etwa die Beteiligung von Nichtregierungsorganisationen (NGOs) an Entscheidungsprozessen oder die Entstehung transnationaler Öffentlichkeiten. Gleichzeitig liegen weitreichende Legitimationsprobleme der vorliegenden Konstitutionalisierungsprozesse selbst vor. In diesem Umfeld kann sogar zugespitzt von einer Krise der Verfassungsevolution ausgegangen werden, wenn der Souveränitätsverlust des Nationalstaats mit einer schleichenden Tilgung des zweiten Strukturmerkmals, der demokratischen

13 | Vgl. Maus, Ingeborg: Über Volkssouveränität. Elemente einer Demokratietheorie, Berlin: Suhrkamp 2011, S. 375 ff., oder Grimm, Dieter: "The Achievement of Constitutionalism in a Changed World", in: Petra Dobner/Martin Loughlin (Hg.): The Twilight of Constitutionalism?, New York: Oxford University Press 2010, S. 3-22, hier S. 21.

14 | Dies ruft die Frage auf, wie "Betroffenheit" unter Globalisierungsbedingungen zu fassen ist; für eine Diskussion des "all-affected-principle" unter Globalisierungsbedingungen vgl. Fraser, Nancy: Scales of Justice. Reimagining Political Space in a Globalized World, New York: Columbia University Press 2010, S. 40 ff. 
Regierungsart, einhergeht. ${ }^{15}$ Die neuere Rede über einen postdemokratischen Herrschaftszustand hätte so auch eine Verfassungsdimension: ${ }^{16}$ transnationaler Konstitutionalismus ohne Demokratie.

Drittens schließlich enthalten Verfassungen in der Regel einen umfassenden Katalog an Grundrechten, der soziale Kommunikationssphären voneinander abgrenzt. ${ }^{17}$ Sie sollen Individuen und gesellschaftliche Teilbereiche (Öffentlichkeit, Wissenschaft, Religion etc.) vor Übergriffen schützen und ihre Autonomie ermöglichen. Im Übergang zur Weltgesellschaft erlebt dieses Strukturmerkmal einen Wandel. Das schillerndste Beispiel dafür ist die gewachsene Bedeutung des Menschenrechtsschutzes, der immer stärker von inter- und transnationalen Institutionen geprägt ist. Die Erklärung der Menschenrechte wird zunehmend als globaler Grundrechtskatalog verstanden, auf den sich alle Weltbürger, unabhängig von ihrem Wohnort, berufen können. ${ }^{18}$ In der Responsibility-to-Protect-Doktrin etwa, die auf dem UN World Summit 2005 von fast allen Staaten der Welt anerkannt wurde, ist festgehalten, dass die internationale Staatengemeinschaft auf innerstaatliche Menschenrechtsverletzungen reagiert. ${ }^{19}$ Der Schutz der Menschenrechte wird gerade nicht den Einzelstaaten überlassen. Diese Entwicklung ist widersprüchlich und umkämpft. Militärische Interventionen der letzten Jahre haben kriegführende Staatenallianzen zumeist als Friedensmissionen tituliert, die weltweit kosmopolitischen Weltbürgerrechten zur Geltung verhelfen. ${ }^{20}$ Aber auch globale soziale Bewegungen übersetzen ihre Anliegen in die Sprache der Menschenrechte. Sie bündeln ihre Forderungen in einen Aktivismus, der die transnationale lex humana

15 | So etwa die Beobachtung bei Hirschl, Ran: Towards Juristocracy. The Origins and Consequences of New Constitutionalism, Cambridge/London: Harvard University Press 2004, und Bellamy, Richard: Political Constitutionalism. A Republican Defence of the Constitutionality of Democracy, Cambridge: Cambridge University Press 2007.

16 | Vgl. die Postdemokratiethese bei Crouch, Colin: Post-democracy, Cambridge: Polity Press 2005.

17 | Dies ist die sozialtheoretische Lesart der subjektiven Rechte bei Luhmann, Niklas: Grundrechte als Institution (1965), Berlin: Duncker \& Humblot 1999; Willke, Helmut: Stand und Kritik der neueren Grundrechtstheorie. Schritte zu einer normativen Systemtheorie, Berlin: Duncker \& Humblot 1975 sowie Thornhill, Chris: A Sociology of Constitutions. Constitutions and State Legitimacy in Historical-Sociological Perspective, Cambridge: Cambridge University Press 2011.

18 | Vgl. Fassbender, Bardo: The United Nations Charta as the Constitution of the International Community, Leiden/Boston: Martinus Nijhoff Publishers 2009.

19 | UN Generalversammlung, Resolution der UN Generalversammlung A/Res/60/ 1.

20 | Siehe zu dieser Verbindung von kosmopolitischen Weltbürgerrechten und kriegerischer Intervention Eberl, Oliver: Demokratie und Frieden. Kants Friedensschrift in den Kontroversen der Gegenwart, Baden-Baden: Nomos 2008. 
dazu treibt, neue Themenbereiche in den Horizont grundlegender Menschenrechte zu übernehmen. ${ }^{21}$ Wieder steht die Zentralstellung der Staatsverfassung in Frage. Angesichts vielfältiger Mechanismen des Grund- und Menschenrechtsschutzes, die von unterschiedlichen Konventionen und Arenen bestimmt sind, durchläuft auch diese letzte Komponente tiefgreifende Veränderungen.

Betrachtet man alle drei Strukturmerkmale, wird deutlich, dass der Übergang zur Weltgesellschaft mit einem Verfassungswandel einhergeht. Interund transnationale Institutionen, globale Sozialdynamiken und ökonomische Verkehrsverhältnisse sind schon längst dabei, Strukturmerkmale auszubilden, die bisher im Regelfall der Staatsverfassung vorbehalten waren. Nicht zuletzt wird sie wiederum durch jene Prozesse einem rückwirkenden Funktionswandel ausgesetzt. Die Staatsverfassung ist nicht mehr der einzige höherrangige Lokus, sondern Teil eines pluralen Kontinuums von rechtlich-politischen Formen, das sich einer zentralen Steuerung entzieht. ${ }^{22}$ Insofern verschiebt der Übergang zur Weltgesellschaft die Verfassungsfrage von der Staatsverfassung hin zur Frage nach den beobachtbaren Konstitutionalisierungsprozessen jenseits des Staates und ihren Folgen für diejenigen Strukturmerkmale, die im Zentrum der modernen Verfassungsevolution stehen.

\section{RefLeXIVItät}

Es ist deshalb nur konsequent, wenn der Verfassungsbegriff wesentlich stärker als Prozessbegriff verstanden wird. Weder besteht eine einheitliche Weltverfassung noch existieren schon vollständig etablierte Ordnungen, die in vollem Sinne einem herkömmlichen, am Beispiel der Staatsverfassung geschulten Verständnis entsprechen. Erst recht kann man nicht davon ausgehen, dass eine solche Verfassung die beiden Funktionssysteme Recht und Politik - etwa im Zuge eines klar erkennbaren Gründungsaktes oder einer nachträglichen Erzählung über einen solchen Gründungsakt - ins Werk setzt und von dort aus formt. Die Verfassungsbildung jenseits des Staates besteht ja gerade nicht in der autoritativen Setzung einer Globalverfassung mit klarer Normenhierarchie, sondern in den teils untergründigen Prozessen, in denen in Völkerrecht, in transnationalen Sozialbereichen und internationalen Organisationen schritt-

21 | Vgl. Fischer-Lescano, Andreas: Globalverfassung: Die Geltungsbegründung der Menschenrechte, Weilerswist: Velbrück 2005.

22 | Zum damit zusammenhängenden "Kontinuum " politischer Legitimation: Ley, Isabelle: Opposition im Völkerrecht. Ein Beitrag zur Legitimation internationaler Rechtserzeugung, Heidelberg u. a.: Springer 2015, S. 180; zum Pluralismus des transnationalen Rechts: Krisch, Nico: Beyond Constitutionalism. The Pluralist Structure of Postnational Law, Oxford: Oxford University Press 2010. 
weise Ordnungen mit konstitutionellen Merkmalen entstehen. Die transnationale Verfassungsbildung vollzieht sich vor allem inkrementell, insbesondere durch die Aktivität internationaler Gerichtsbarkeiten oder durch die Eigendynamik internationaler Institutionen. Es liegen zumindest Indizien für eine höherrangige Formgebung vor, wenn Gerichte damit beginnen, die Menschenrechte als einklagbare individuelle Grundrechte der Weltbürger zu begreifen, wenn das internationale Staatensystem zu einer übergeordneten internationalen Gemeinschaft avanciert oder die WTO-Verträge ihre Mitglieder auf eine Freihandelspolitik festlegen. Die Vielfalt der Phänomene sowie ihre gegenseitigen Einflussnahmen werden dadurch erfasst, dass der Verfassungsbegriff eher im englischen Wortsinn als breitere Tradition des constitutionalism, als Prozess der Konstitutionalisierung oder als constitutional mindset verwendet wird. ${ }^{23}$

Dieser veränderte Zugriff macht noch einen weiteren Abstraktionsschritt erforderlich. Schließlich müssen die genannten Strukturmerkmale der transnationalen Verfassungsbildung als Teil eines umfassenderen Vorgangs darstellbar sein. Einerseits können sie sozusagen nicht nur für sich stehen. Denn internationales Recht, internationale Politik und der Schutz von Grund- und Menschenrechten deuten noch nicht zwingend auf eine Verfassungsbildung hin. Andererseits scheint in den tiefgreifenden Veränderungen im Übergang zur Weltgesellschaft tatsächlich eine konstitutionelle Dimension enthalten zu sein, die schon an den allgegenwärtigen Jurisdiktionskonflikten zwischen unterschiedlichen Gerichtsbarkeiten ablesbar ist.

Um den prozessualen Charakter der Verfassungsbildung jenseits des Staates herauszuarbeiten, ist verstärkt das Kriterium der Reflexivität eingeführt worden. ${ }^{24}$ Demnach sind Verfassungen als reflexive Strukturbildungen $\mathrm{zu}$ kennzeichnen. Sie entstehen dort, wo die Frage nach dem Selbstbezug eines Sozialbereiches oder einer Institution aufgeworfen wird. Die Reflexivität der Verfassung ist auf beiden Seiten wirksam. Die eingangs erwähnte Dimension eines höherrangigen Rechts kann als reflexiv verstanden werden, da es dem einfachen Recht ein Recht der Rechtserzeugung überordnet. In der Verfassung entsteht ein Recht, das in Distanz zum einfachen Recht ein höherrangiges Recht begründet. Man sollte jedoch nicht nur das Recht in den Blick nehmen. Die Pointe der Verfassung liegt genau darin, dass sie auch auf der anderen Seite, der Politik, eine reflexive Strukturbildung aufweist. Im Zuge einer Verfas-

23 | Vgl. Koskenniemi, Martti: "Constitutionalism as Mindset. Reflections on Kantian Themes about International Law and Globalization ", in: Theoretical Inquiries in Law 8/ 1 (2007), S. 9-36.

24 | Vgl. u. a. G. Teubner, Verfassungsfragmente, S. 158 ff.; siehe auch Lindahl, Hans: "Constituent Power and Reflexive Identity. Towards an Ontology of Collective Selfhood", in: Martin Loughlin/Neil Walker (Hg.), The Paradox of Constitutionalism. Constituent Power and Constitutional Form, Oxford: Oxford University Press 2007, S. 9-24. 
sungsbildung wird auch die Frage nach dem politischen und sozialen Selbstbezug aufgeworfen. Die Reichweite der jeweiligen Ordnung, ihre Grenzen und Zwecke werden festgelegt. Und nicht zuletzt erfahren die Machtverhältnisse eine Institutionalisierung und Verrechtlichung. ${ }^{25}$ Auf diese Weise entsteht ein höherrangiger Selbstbezug, der seine Beobachtung am Code »verfassungsgemäß/verfassungswidrig « ausrichtet. ${ }^{26}$ Insofern erscheint es geboten, von einer doppelten Reflexivität auszugehen. Dabei kommt ein »Zusammenspiel von autonomen Sozialprozessen und autonomen Rechtsprozessen zustande«, das »auf Dauer gestellte strukturelle Koppelungen von teilbereichsspezifischen Ordnungsmustern und Rechtsregimes ${ }^{27}{ }^{27}$ herstellt. Diese Generalisierung verortet die konstitutionelle Dimension der genannten Strukturmerkmale vor allem darin, dass sie den Selbstbezug der jeweiligen Ordnungen festlegen und eine Eigendynamik entfalten, die ihnen Dauer und eine gewisse Selbstständigkeit ermöglichen.

An dieser Stelle soll nicht verschwiegen werden, dass ein solcher prozessorientierter Verfassungsbegriff durchaus Kritik erfährt. ${ }^{28}$ Der Vorwurf lautet, dass die Konstitutionalisierungsdiskussion dazu neige, einfache Rechtsphänomene überzustrapazieren, indem sie das einfache Recht als konstitutionell auflädt. Der Verfassungsbegriff sei zu amorph und letztlich eine rein semantische Strategie. Die Schwäche dieser Einwände ist dort zu suchen, wo sie die transnationale Sozialstruktur weiterhin aus dem Nationalstaat ableiten oder ihm nachordnen. Wenn es sich nicht um Konstitutionalisierungsprozesse handelt, bieten sich im Grunde nur noch zwei Optionen an: (1) Entweder ist die Ära der Verfassungsbildung beendet und die neuartigen Ordnungen entziehen sich den klassischen Versuchen der politischen und juridischen Begriffsbildung vollständig. ${ }^{29}$ Dem widerspricht die ausufernde Verrechtlichung der Weltgesell-

25 | Zur Funktion von Verfassungen, politische und soziale Macht zu aggregieren und handhabbar zu machen, vgl. C. Thornhill, A Sociology of Constitutions, S. $372 \mathrm{ff}$.

26 | Luhmann, Niklas: Das Recht der Gesellschaft, Frankfurt a. M.: Suhrkamp 1993, S. 95.

27 | Fischer-Lescano, Andreas/Teubner, Gunther: Regime-Kollisionen. Zur Fragmentierung des globalen Rechts, Frankfurt a. M.: Suhrkamp 2006, S. 55.

28 | Vgl. Neves, Marcelo: Transconstitutionalism, Portland/Oxford: Hart Publishing 2013, S. 5 ff., im Hinblick auf die Dissemination in die Sozialbereiche; mit stärker staatszentrierten Argumenten vgl. etwa Haltern, Ulrich: "Internationales Verfassungsrecht? Anmerkungen zu einer kopernikanischen Wende", in: Archiv des Öffentlichen Rechts 128/4 (2003), S. 511-557.

29 | In diese Richtung weist etwa Luhmanns Spekulation, wonach die "Prominenz des Rechtssystems" nichts weiter "als eine europäische Anomalie" sei, "die sich in der Evolution der Weltgesellschaft abschwächen wird", N. Luhmann, Das Recht der Gesellschaft, S. 586. 
schaft genauso wie die zunehmende Verbreitung des Konstitutionalismus. ${ }^{30}$ Internationale Institutionen greifen in der Regel auf Mechanismen rechtlicher Selbstbindung, der Festlegung politischer Kompetenzen und der Regulierung von Kommunikationssphären zurück. Oder aber (2), das ist die zweite Option, die nationalstaatliche Verfassung bleibt vollkommen intakt und bildet nur eine inter- und transnationale Rechtsschicht aus. Dies würde letztlich auf die Wiederbelebung eines dualistischen Modells hinauslaufen, das die inter- und transnationale Sphäre auf die vertraglichen Vereinbarungen zwischen Staaten zurückführt. ${ }^{31}$ Doch sowohl die Tendenzen zu einer Ordnungsbildung jenseits des Staates, die Teile der zeitgenössischen Politikwissenschaft als "globale Herrschaft « $^{32}$ konturieren, als auch die vielfältigen Diagnosen zum Niedergang der nationalstaatlichen Demokratie legen einen Einwand nahe: Die Kritik an der Konstitutionalisierungsthese tendiert dazu, die folgenreiche Ordnungsbildung jenseits des Staates letztlich doch als eine Garnitur zu betrachten, die keine tiefgreifenden und auch konstitutionellen Folgen in den Nationalstaaten zeitigt. Die Legitimationsprobleme der Weltgesellschaft bleiben so recht beschränkt und sind durch verstärkte rechtliche Kooperation, Rückbindung an parlamentarische Entscheidungsverfahren oder die Herausbildung transnationaler Öffentlichkeiten zu beheben. Dies steht in einem Spannungsverhältnis zu den drastischen Diagnosen, die gerade im Hinblick auf die politische Seite der Verfassung gestellt werden. Hier ist vom Funktionsverlust der Demokratie die Rede, von Postdemokratie, von demokratischen Defiziten und transnationaler Klassenherrschaft. ${ }^{33}$ Letztlich geht es um die Frage, wie stark man die Veränderungen erachtet. Es handelt sich schließlich nicht nur um die idiosynkratische Verrechtlichung im Sinne eines verstärkten Dualismus, sondern um Verhältnisse der Koevolution des Rechts mit transnationalen Funktionssystemen. Genau dieser Umstand wird am ehesten im Verfassungsbegriff abgebildet. Denn die neuen Spielarten der Verrechtlichung können nicht sinnvoll als bloße internationale Rechtsschicht erfasst werden, ohne auf die Rolle

30 | Dazu jüngst Brunkhorst, Hauke: Critical Theory of Legal Revolutions. Evolutionary Perspectives, New York u. a.: Bloomsbury 2014, S. 319 ff.

31 | Vgl. zur Aktualisierung des Dualismus: Cohen, Jean L.: Globalization and Sovereignty. Rethinking Legality, Legitimacy, and Constitutionalism, New York: Cambridge University Press 2012.

32 Daase, Christopher/Deitelhoff, Nicole: Zur Rekonstruktion globaler Herrschaft aus dem Widerstand, Frankfurt a. M.: Working-Paper Projekt "Internationale Dissidenz" $1 / 2014$.

33 | Einen Überblick über die Diskussionslage gibt Volk, Christian: "Zwischen Entpolitisierung und Radikalisierung. Zur Theorie von Demokratie und Politik in Zeiten des Widerstands", in: Politische Vierteljahresschrift 54/1 (2013), S. 75-110. 
des Rechts für die Erwartungsstabilisierung in anderen transnationalen Funktionssystemen einzugehen.

Demnach bleibt auch die verbreitete These einer verstärkten Politisierung durch Global Governance allzu sehr auf die Sphäre der internationalen Politik beschränkt. ${ }^{34}$ Sie verliert den Umstand aus dem Blickfeld, dass schon längst eine Verrechtlichung im Gange ist, die massiven Einfluss auf die Rahmenbedingungen politischen Handelns ausübt oder aber schon in Bereiche vorgedrungen ist, die weit vom Staatensystem entfernt liegen. Ein passendes Beispiel dafür ist sicherlich die Verrechtlichung der Weltwirtschaft. ${ }^{35}$ Insofern irritiert die Konstitutionalisierungsthese einerseits eine Rechtswissenschaft, die stets geneigt ist, doch in allen Phänomenen nur (internationales) Recht zu sehen, und andererseits eine Politikwissenschaft, die das internationale Recht den politischen Machtbeziehungen der Staatenwelt nur nachordnet.

Demgegenüber macht das hier angeführte Kriterium der Reflexivität einen Zugriff erforderlich, der in den neueren Diskussionen als verfassungssoziologisch ausgewiesen wird. ${ }^{36}$ Hier wird die Verschränkung von weltgesellschaftlichen Strukturbildungen und rechtlichen Normen in den Mittelpunkt gestellt. Die Verbindung der Diskussionen um Verrechtlichung, Weltgesellschaft und Global Governance verspricht nicht nur eine innovative analytische Perspektive, sie soll ebenso in die Lage versetzen, normative Fragestellungen besser herauszuarbeiten zu können. ${ }^{37}$

Schließlich hängen die diagnostischen Fragen auch direkt mit normativen Problemlagen zusammen. Einzelne Momente der Höherrangigkeit, der Regierungsweise oder des Menschenrechtsschutzes dienen in der Regel als entschei-

34 | Vgl. Zürn, Michael/Binder, Martin/Ecker-Ehrhardt, Matthias: "International Authority and its Politicization", in: International Theory - A Journal of International Politics, Law and Philosophy 4 / 1 (2012), S. 69-106; vgl. für einen Zugriff auf die Politisierung, die auch eine innerrechtliche Politisierung nachvollzieht: Liste, Philip: Völkerrecht-Sprechen. Die Konstruktion demokratischer Völkerrechtspolitik in den USA und der Bundesrepublik Deutschland, Baden-Baden: Nomos 2012.

35 | Vgl. nur für den Bereich des Investitionsschutzrechts: Schneiderman, David: Constitutionalizing Economic Globalization. Investment Rules and Democracy's Promise, Cambridge: Cambridge University Press 2008.

36 | Dazu: H. Brunkhorst, Critical Theory of Legal Revolutions; C. Thornhill, A Sociology of Constitutions; Kjaer, Poul F.: Constitutionalism in the Global Realm. A Sociological Approach, London / New York: Routledge 2014; Holmes, Pablo: Verfassungsevolution in der Weltgesellschaft. Differenzierungsprobleme des Rechts und der Politik im Zeitalter der Global Governance, Baden-Baden: Nomos 2013.

37 | So das Programm einer "Triangulation" bei Wiener, Antje: "Zur normativen Wende in den IB: Triangulation of a Different Kind ", in: Zeitschrift für internationale Beziehungen 17 / 2 (2010), S. 335-354, hier S. 338. 
dende Indizien dafür, dass sich der demokratische Rechtsstaat doch als historische Universalie in die Weltgesellschaft verlängert. Dabei entstehen jedoch auf beiden Seiten - Faktizität und Normativität - massive blinde Flecken. Man mag die Menschenrechtsentwicklung zum Kernbestandteil für eine kosmopolitische Konstitutionalisierung erheben. Dass die Menschenrechte jedoch im Übergang zur Weltgesellschaft eine andere Rolle einnehmen, indem sie von ihrer Verbindung zum Demokratieprinzip entkoppelt werden und so eher eine Sprache bereitstellen, in der sich konkurrierende politische Projekte ausdrücken, kommt selten in den Blick. ${ }^{38}$ Ähnliches gilt beispielsweise auch für die Rechtsprechung des Europäischen Gerichtshofs (EuGH) und die damit zusammenhängenden Grundfreiheiten der Europäischen Verträge. In der Euphorie für die sich längst abzeichnende Konstitutionalisierung der EU scheint allzu selten auf, dass sie vor allem das Binnenmarktprojekt absichert. Die einstweilige europäische Verfassung entbehrt bisher ein Äquivalent zu den sozialen Rechten der jeweiligen nationalen Grundrechtskataloge. ${ }^{39}$ Auch im Bereich transnationaler Institutionen führt die Suche nach einzelnen Strukturelementen der Nationalverfassungen zu folgenreichen Kategorienfehlern. Der Basler Bankenausschuss beispielsweise organisiert Governancedialoge und Bürgerbeteiligungsverfahren. ${ }^{40}$ Solche Mechanismen, von Teilen der zeitgenössischen Governanceforschung zum Ersatz für das Demokratieprinzip geadelt, versorgen die Entscheidungsträger nur zu oft mit diskursiven Schmiermitteln für ihre Eigeninteressen. ${ }^{41}$ Sie sind von einer demokratischen Regierungsart, die tatsächliche Entscheidungs- und Kontrollbefugnisse beinhaltet, oft weit entfernt.

Bei allen kursorisch eingeführten Beispielen besteht die Gefahr darin, dass mit der Annahme von konstitutionellen Strukturmerkmalen gleichzeitig davon ausgegangen wird, dass die Normativität des demokratischen Rechtstaats in den transnationalen Raum übertragbar ist und nur in disaggregierter Form verwirklicht wird. Demgegenüber soll hier eine Herangehensweise im Mittelpunkt stehen, die voraussetzt, dass der Übergang in die Weltgesellschaft mit einem Verfassungswandel einhergeht. Eventuell zeichnet sich dann in der Verfassungsbildung jenseits des Staates eine andere Form der Verfassung, ein an-

38 | Vgl. I. Maus, Über Volkssouveränität, S. 359 ff.

39 | Zur Kritik der marktliberalen Konstitutionalisierung siehe jüngst nur Joerges, Christian: "Recht und Politik in der Krise Europas", in: Merkur 66/ 11 (2012), S. 1013-1024. 40 | Zur Partizipation der Zivilgesellschaft: Barr, Michael S./ Miller, Geoffrey P.: "Global Administrative Law. The View from Basel«, in: European Journal of International Law 17 / 1 (2006), S. 15-46.

41 | Vgl. Kohler-Koch, Beate/Quittkat, Christine: Die Entzauberung partizipativer Demokratie. Zur Rolle der Zivilgesellschaft bei der Demokratisierung von EU-Governance, Frankfurt a. M. / New York: Campus 2010. 
derer Typ der Konstitutionalisierung ab, der die genannten Strukturmerkmale neu arrangiert und die Normativität der Verfassung massiv verändert. Indem die transnationale Verfassung ausschließlich mit der Verfassung des demokratischen Rechtsstaats erklärt wird, bleibt die spannende Frage offen: Welche beobachtbaren Sozialdynamiken der Weltgesellschaft rufen neuartige Formen der Verfassungsbildung hervor? Und vor allem: Von welchen Verfassungskämpfen und Widerspruchskonstellationen ist der transnationale Konstitutionalismus geprägt? Im Folgenden soll die Frage nach dem konstitutionellen Terrain des Transnationalen und dem damit verbundenen Formwandel des Konstitutionalismus im Mittelpunkt der Diskussion stehen.

\section{Der Widerspruch der Verfassung mit Sich Selbst. Anschlüsse an Hegel und MarX}

Das hier aufscheinende Grundmotiv, also die Frage nach dem Formwandel der Verfassung, entstammt einer theoretischen Traditionslinie, die auf die Kritik des Hegel'schen Staatsrechts durch den jungen Karl Marx zurückgeht. ${ }^{42}$ Hier hatte Marx ein Problem identifiziert, das sich wie ein roter Faden von der Hegel'schen Verfassungstheorie bis in die Weltgesellschaft zieht. Der Versuch, die Verfassungsbildung einfach dadurch aufzuklären, dass sie die schon bestehende Verfassungsbildung verlängert, muss scheitern, da die gesellschaftlichen Dynamiken, die sich in sie einschreiben, unberücksichtigt bleiben. In seinem Vorwort zur »Kritik der politischen Ökonomie« rekapituliert Marx seine Auseinandersetzung mit dem Hegel'schen Konstitutionalismus wie folgt:

"Meine Untersuchung [Kritik der Hegel'schen Rechtsphilosophie - d. Verf.] mündete in dem Ergebnis, daß Rechtsverhältnisse wie Staatsformen weder aus sich selbst zu begreifen sind noch aus der sogenannten allgemeinen Entwicklung des menschlichen Geistes, sondern vielmehr in den materiellen Lebensverhältnissen wurzeln, deren Gesamtheit Hegel, nach dem Vorgang der Engländer und Franzosen des 18. Jahrhunderts, unter dem Namen ıbürgerliche Gesellschaft zusammenfaßt, daß aber die Anatomie der bürgerlichen Gesellschaft in der politischen Ökonomie zu suchen sei. «43

In dieser kurzen Passage verweist Marx auf ein Argument, das für seinen verfassungstheoretischen Standpunkt charakteristisch ist. Wenn »Rechtsverhältnisse und »Staatsformen« nicht einfach aus Recht und Staat heraus ableitbar

42 | Vgl. Marx, Karl: "Kritik des Hegelschen Staatsrechts" (1843), in: ders./Engels, Friedrich: Werke. Band 1, Berlin: Dietz 1976, S. 203-333.

43 | Marx, Karl: "Zur Kritik der politischen Ökonomie" (1859), in: ders./Friedrich Engels, Werke. Band 13, Berlin: Dietz 1971, S. 3-160, hier S. 8. 
sind (und auch nicht den Weltgeist säkularisieren), folgt daraus eine gegenseitige Verwiesenheit von Verfassung und Gesellschaft. Erst eine Untersuchung der »bürgerlichen Gesellschaft« und ihrer »politischen Ökonomie « ermöglicht eine hinreichend fundierte Diskussion ihrer Verfassung. Die Verfassung tritt als Verfassung einer spezifischen Gesellschaftsformation auf die Bühne der Geschichte, nicht als ewiges Prinzip. Selbst »universalistische Bewusstseinsstrukturen «, die in Verfassungen verankert sein mögen, sind immer Bestandteil einer spezifischen Form der Verfassung. ${ }^{44}$ Nicht die Staatsverfassung als abstrakte Idee bringt die Gesellschaft hervor, sondern umgekehrt: In der Gesellschaft und ihren materiellen Lebensverhältnissen entstehen politisch-rechtliche Formen mit Verfassungscharakter. Man kann den Marx'schen Hinweis auf die politische Ökonomie als Einfallstor für vermeintlichen Ökonomismus lesen. Davon bleibt die grundlegende Einsicht allerdings, auch unter Verzicht auf die Zentralstellung der politischen Ökonomie, unberührt und hochgradig aktuell. Denn der Vorwurf an die klassische Verfassungstheorie lautet: Der Verzicht darauf, die eigenen Überlegungen an eine Analytik der materiellen Lebensverhältnisse anzubinden, die Verfassung also vom Staat und nicht von der Gesellschaft her zu denken, neigt dazu, ideologisch zu werden. Indem sie die politisch-rechtlichen Formen autonom stellt, mystifiziert die klassische Verfassungstheorie den Zusammenhang von Verfassung und Gesellschaft. Sie tut so, als ob es die Staatsverfassung selbst ist, die sich eine Gesellschaft nach ihrem Bilde formt. Deshalb fragt sie nicht danach, in welchem Verhältnis Verfassung und Gesellschaft zueinander stehen. Sie nimmt an, dass eine vernünftige Staatsidee die gesellschaftliche Realität immer schon vorgängig zu strukturieren vermag.

Obgleich Hegels bürgerliche Gesellschaft der Einsatz ist, an dem Marx zeigen kann, wie ihre Grundzüge in die Verfassung eingehen, kritisiert er doch scharf Hegels Entwurf einer konstitutionellen Monarchie, der in der Rechtsphilosophie vorliegt. ${ }^{45}$ Der Fortschritt der Hegel'schen Gesellschaftstheorie wird gewissermaßen sofort wieder dadurch zunichtegemacht, dass er die bürgerliche Gesellschaft einem Verfassungsmodell unterstellen will, das auf eine sittlichkeitsverbürgende Staatssouveränität hinausläuft. ${ }^{46}$ Die Integration gesell-

44 | Zur Einschätzung, dass sich schon im frühen bürgerlichen Privatrecht solche universalistischen Bewusstseinsstrukturen "verkörpern«: Habermas, Jürgen: Zur Rekonstruktion des historischen Materialismus, Frankfurt a. M.: Suhrkamp 1976, S. 260.

45 | Vgl. Hegel, Georg W. F.: Grundlinien der Philosophie des Rechts (1821) (= Werke. Band 7), Frankfurt a. M.: Suhrkamp 1986.

46 | Freilich kann die Hegel'sche Rechtsphilosophie nicht auf die bloße Verteidigung des Obrigkeitsstaates reduziert werden; vgl. nur jüngst die Anschlüsse bei Honneth, Axel: Das Recht der Freiheit. Grundriß einer demokratischen Sittlichkeit, Berlin: Suhrkamp 2011. Darüber hinaus wird in der Kritik des Hegel'schen Staatsrechts deutlich, 
schaftlicher Sphären, die das Hegel'sche Modell prägt, steht unter Führung und Letztentscheidungskompetenz der fürstlichen Gewalt. ${ }^{47}$ Marx bringt an dieser Stelle seine schon angedeutete Kritik am Staatsfetischismus ins Spiel: dass nämlich Hegel »den sich selbst wissenden und wollenden Geist« zur »Substanz des Staates « erklärt, was durch die Souveränität der fürstlichen Gewalt, das heißt des Staates selbst, ausgedrückt wird. ${ }^{48}$ So schwinge sich der Monarch zum »Gottmenschen « als »wirkliche Verkörperung der Idee « ${ }^{49}$ auf.

Bei Hegel, so lautet die Marx'sche Kritik, schleicht sich auf diese Weise die schon angemahnte Transsubstantiation im Verhältnis von Staatsverfassung und bürgerlicher Gesellschaft ein. Die Idee eines Staatsgedankens, der die Gesellschaft vernünftig von oben ordnet, wird zum Subjekt erhoben und nicht umgekehrt als Teil der Lebensverhältnisse kontextualisiert. Das staatssouveränistische Verfassungsdenken ruft verzerrende Effekte hervor, indem es den Staat zu einer Verwirklichungsinstanz der Vernunft erhebt, statt ihn aus der sozialen Evolution der modernen Gesellschaft heraus zu begreifen. Dies gilt für die Mystifizierung des Staates und seiner »Kraft zur Versöhnung « ${ }^{50}$ genauso wie für die im Hegel'schen Entwurf angelegte Gliederung der Gesellschaft in unterschiedliche Sphären. Sie folgen einem jeweils eigenen, begrenzten Zweck, dem sie nur im Hinblick auf das Staatsganze nachkommen können. Als naturalisierende Festschreibung der bürgerlichen Verkehrsverhältnisse bleiben sie einer gesellschaftlichen Befragung entzogen. Die Gesellschaft regiert sich nicht im Medium der Verfassung selbst. Sie wird einer Vernunftregierung von oben unterworfen. Dabei strukturiert die Verfassung als Vermittlungsinstanz die Herrschaftsausübung des modernen Staates und sichert gleichzeitig als »Verfassung des Privateigentums« die Verkehrsverhältnisse der bürgerlichen Ge-

dass sich Marx durchaus eingehend mit Verfassungsfragen beschäftigt und dabei Recht und Verfassung nicht kategorisch zurückweist (siehe demgegenüber die stark rechtskritische Lesart des jungen Marx bei Abensour, Miguel: Democracy against the State. Marx and the Machiavellian Moment, Cambridge: Polity Press 2011). Vgl. auch für einen Versuch, die Marx'schen Frühschriften für Fragen des internationalen Rechts fruchtbar zu machen: Koskenniemi, Martti: "What Should International Lawyers Learn from Karl Marx?", in: Leiden Journal of International Law 17 / 2 (2004), S. 229-246; im Hinblick auf den Republikanismus beim frühen Marx: Isaac, Jeffrey C.: "The Lion's Skin of Politics. Marx on Republicanism«, in: Polity 22/3 (1990), S. 59-85.

47 | Vgl. G. W. F. Hegel, Rechtsphilosophie, S. $441 \mathrm{ff}$.

48 | K. Marx, "Kritik der Hegelschen Staatsrechts", S. 215.

49 | Ebenda, S. 225.

50 | So H. Brunkhorst in seinem Kommentar zu Marx' "18. Brumaire" mit Blick auf den Hegel'schen Etatismus, siehe ders.: "Kommentar", in: ders. (Hg.), Karl Marx, Der 18. Brumaire des Louis Bonaparte, Frankfurt a. M.: Suhrkamp 2007, S. 133-328, hier S. 160. 
sellschaft ab. ${ }^{51}$ Der Hegel'sche Konstitutionalismus ist vor allem eines: eine etatistische Herrschaftsform.

In der Kritik des Hegel'schen Staatsrechts endet der junge Marx ausdrücklich nicht mit einer kategorischen Zurückweisung. Hatte er die staatssouveränistische Verfassung kritisiert, so nicht, um den modernen Konstitutionalismus nur auf seine herrschaftliche Faktizität zurückzuführen. Im radikaldemokratischen Verfassungsverständnis der Französischen Revolution entdeckt der junge Marx nämlich ein emanzipatives Gegenprinzip, für das er beherzt Partei ergreift. Marx entpuppt sich als radikaler Demokrat. Denn die Idee einer demokratischen Verfassung und ihrer Volkssouveränität, das heißt der konstituierenden Macht des Volkes, sich eine Verfassung zu geben und sich in ihrem Rahmen selbst zu regieren, erscheint als qualitativ vollkommen anderes Moment, als ein der Staatssouveränität »ganz entgegengesetzter Begriff der Souveränität $\aleph^{52}$. Das Lob des revolutionären Demokratieprinzips findet viele Formeln. Die demokratische Verfassung sei »das aufgelöste Rätsel aller Verfassungen«, das »Wesen aller Staatsverfassungen« und noch die »Wahrheit der Monarchie ${ }^{53}$. Was Marx mit diesen Formulierungen im Blick hat, ist der Umstand, dass die demokratische Volkssouveränität eine doppelte historische Chance enthält. Sie trägt zur Entmystifizierung des Verfassungsdenkens bei und legt eine emanzipatorische Entgrenzung des Demokratieprinzips nahe, die tendenziell alle Herrschaftsverhältnisse der Kritik aussetzt. Im Gegensatz zu Hegel, der

"die moderne Entwicklungsgeschichte mit dem, was 1814 als Erbschaft Napoleons übrig geblieben war [...] beginnen lässt, geht Marx auf die gründende Verfassung der parlamentarischen Demokratie, die zwischen 1789 und 1794 mit Macht zur Wirklichkeit drängt, zurück « ${ }^{54}$.

Indem die Französische Revolution die Forderung nach der Identität von Rechtsautoren und Rechtsadressaten erhoben und dem Volk die verfassungsgebende Kompetenz übereignet hatte, ist nicht nur eine andere Regierungsart in den Vordergrund getreten, sondern eine viel weitergehende gesellschaftliche Wahrheit: dass die rechtlich-politischen Formen aus den gesellschaftlichen Lebensverhältnissen entspringen, von Menschen "gemacht« werden und damit veränderbar sind. Es ist weniger die Verfahrensgerechtigkeit, die Marx zum Anhänger der Volkssouveränität macht; eher ist es die historische Wahrheit, dass hier endlich eine nichtmystifizierende Perspektive auf gesellschaftli-

$\mathbf{5 1} \mid$ K. Marx, "Kritik des Hegelschen Staatsrechts", S. 303.

52 | Ebenda, S. 230.

53 | Ebenda, S. $230 \mathrm{ff}$.

54 | H. Brunkhorst, "Kommentar", S. 162. 
che Verhältnisse eingerichtet wird. Die konstituierende Macht des Volkes wirft schließlich nicht nur die Frage auf, inwieweit sich die Menschen als Autoren ihrer eigenen Rechtsverhältnisse verstehen, sondern sie eröffnet darüber hinaus zumindest die Möglichkeit, diese Befragung auf die Gesamtheit der gesellschaftlichen Verhältnisse auszuweiten. Denn offen ist, ob sich die Menschen auch als Autoren ihrer eigenen Lebensverhältnisse verstehen können. Insofern enthält die demokratische Verfassung ein emanzipatives Moment der Entgrenzung, das über den Staat hinausgetrieben werden kann.

Ausgehend von der konstituierenden Macht des Volkes zeichnet sich eine Tendenz zu weitergehenden Idealen gesellschaftlicher Emanzipation ab. In der Kritik des Hegel'schen Staatsrechts und in seinem Text »Zur Judenfrage« klingt das Projekt einer »wahren Demokratie ${ }^{55}$ an, in der die verselbstständigte Staatsform in die Gesellschaft zurückgenommen wird und der »Mensch seine forces propres als gesellschaftliche Kräfte erkannt und organisiert hat und daher die gesellschaftliche Kraft nicht mehr in Gestalt der politischen Kraft von sich trennt ${ }^{56}$. Marx korrigiert diesen Optimismus schnell wieder dadurch, dass er ebenso zeigt, wie die demokratische Verfassung mit ihrer Begrenzung auf die politische Sphäre zu einer »Halbheit der Emanzipation «"57 führt, wenn die Forderung nach Selbstregierung auf den Staat begrenzt bleibt. Trotzdem ist festzuhalten, dass in der demokratischen Verfassung, dort, wo die konstituierende Macht des Volkes zum Prinzip avanciert, ein gänzlich anderes Moment der modernen Verfassung aufscheint. Versucht der restaurative Konstitutionalismus Hegels die Gesellschaft als Organismus zu ordnen, ist es hier das »Regime der Unruhe ${ }^{58}$, das seine Selbstregierungsambitionen sogar über den politischen Staat hinaustreiben kann.

Folglich gibt es nicht die eine Verfassung, die durch begriffliche Arbeit eindeutig zu identifizieren ist. In der Verfassungsevolution liegt ein Widerspruch, eine Spaltung vor. Dies wird vor allem deutlich, wenn der junge Marx das Hegel'sche Zugeständnis an die demokratische Verfassung diskutiert. Hegel hatte in seinem Verfassungsentwurf eine »gesetzgebende Gewalt« eingeführt, die auf ständische Mitbestimmungsmechanismen hinausläuft. ${ }^{59} \mathrm{Ihr}$ charakte-

55 | K. Marx, "Kritik des Hegelschen Staatsrechts", S. 232.

56 | Marx, Karl: "Zur Judenfrage" (1843), in: ders./Engels: Werke. Band 1 (1976), S. 347-377, hier S. 370; siehe für eine Rekonstruktion der Marx'schen Kritik am bürgerlichen Recht jüngst Menke, Christoph: "Die randre Formı der Herrschaft. Marx’ Kritik des Rechts", in: Rahel Jaeggi / Daniel Loick (Hg.), Nach Marx. Philosophie, Kritik, Praxis, Berlin: Suhrkamp 2013, S. 273-295.

57 | K. Marx, "Zur Judenfrage", S. 351.

58 | Marx, Karl: „Der achtzehnte Brumaire des Louis Bonaparte" (1852), in: ders. / Friedrich Engels, Werke. Band 8, Berlin: Dietz 1960, S. 111-207, hier S. 153.

59 | G. W. F. Hegel, Rechtsphilosophie §298 ff., S. 465. 
ristisches Merkmal ist es aber, dass sie der Staatssouveränität als Teilmoment untergeordnet ist. Sie kann nur Gesetze im Rahmen der Verfassung und dort in Übereinstimmung mit der fürstlichen Gewalt erlassen. Die Kompetenz der Verfassungsgebung und demokratischen Selbstregierung - das pouvoir constituant - erhält das Volk ausdrücklich nicht. Marx spürt hier einen irreduziblen Widerspruch auf:

"Die Kollision zwischen der Verfassung und der gesetzgebenden Gewalt ist nichts als ein Konflikt der Verfassung mit sich selbst, ein Widerspruch im Begriff der Verfassung. [...] Sie ist daher notwendig in sich selbst ein Traktat wesentlich heterogener Gewalten. " ${ }^{60}$

Die Verfassung ist der Schauplatz eines Widerspruchs zweier kollidierender Gewalten. Zwar bleibt die gesetzgebende Gewalt bei Hegel noch durch die staatssouveränistische Verfassung gezähmt. Allerdings kann sich diese konservative Verfassungsarchitektur nicht als einheitlicher Aufbau präsentieren. Die Aufnahme einer gesetzgebenden Gewalt, die nicht unmittelbar dem Staat, sondern der Gesellschaft zugeordnet ist, gilt als Zeichen dafür, dass selbst das restaurative Denken am Beginn des 19. Jahrhunderts zu Zugeständnissen an die Volkssouveränität gezwungen ist. Im Fahrwasser der Französischen Revolution wird noch Hegels Entwurf als Traktat heterogener Gewalten lesbar, also als Ensemble widersprüchlicher Momente, die Marx sogleich - der Verfassungstheorie der Französischen Revolution folgend - als pouvoir constituant und pouvoir constitué ${ }^{61}$ bezeichnet. Selbst der herrschaftliche Konstitutionalismus kann unter gewissen historischen Umständen zum Austragungsort von sozialen Konflikten und antagonistischen Widersprüchen werden.

Die eine Traditionslinie des Konstitutionalismus generiert im Grunde zwei kollidierende Subverfassungen: eine Verfassung der Herrschaftsausübung und eine Verfassung der Herrschaftskritik. Die Verfassung erscheint in zwei heterogene Teile gespalten, die jedoch beide ihre Haltepunkte in der einen Verfassung finden. Scheint die konstituierende Macht des Volkes in der Verfassung auf, wird es möglich, den herrschaftlichen Konstitutionalismus am Maßstab der Demokratie zu befragen. Verfassungskämpfe sind die notwendige Folge dieser Teilung der einen Verfassung in zwei konkurrierende Momente des Konstitutionalismus. Dann wird das Terrain der Verfassung zu dem Ort, der es ermöglicht, Herrschaftskonflikte in den Widerspruch der beiden Subverfassungen der einen Verfassung zu übersetzen. ${ }^{62}$ Der moderne Konstitutiona-

60 | K. Marx, "Kritik des Hegelschen Staatsrechts", S. 260.

61 | Bzw. als assemblée consitutante und assemblée constituée, ebenda.

62 | Abensours Rekonstruktion der Marx'schen Demokratie- und Staatskritik weist zwar plausibel die noch weiter auszuführenden Parallelen (vgl. den vierten Teil, ab S. 179) zu radikalen Demokratietheorien nach, die Verfassung, also das Terrain, auf dem sich 
lismus wird zur Bühne des Konflikts zwischen »zwei bereits >existierenden< (Hegel), also geschichtlich wirksamen Verfassungsbegriffen, die miteinander konkurrierten $\ll^{63}$.

Auf diese Weise scheiden allzu lineare Perspektiven auf den eigentlichen Sinn des Konstitutionalismus aus: Weder ist er der Anknüpfungspunkt für eine einseitige Fortschrittsgeschichte und per se aufs Demokratische gerichtet noch die bloße Hülle einer sich ausweitenden staatlichen Repressionsgewalt. Als Traktat heterogener Gewalten entzieht er sich einer einseitigen Zuordnung zur demokratischen oder zur herrschaftlichen Verfassung. Er hat zwei Seiten.

Genau jener »Widerspruch der Verfassung mit sich selbst« (Marx) gibt das Leitmotiv der folgenden Untersuchungen vor. Die Annahme ist dabei, dass die transnationale Konstitutionalisierung den Widerspruch zwischen herrschaftlicher und demokratischer Verfassung erbt. Dabei erfahren die beiden Seiten nicht einfach eine Verlängerung. Im Prozess der Transnationalisierung werden sie umgearbeitet. Das Terrain für mögliche Verfassungskonflikte verschiebt sich. Die vorliegende Studie fragt danach, (1) wie diejenigen (welt-)gesellschaftlichen Verhältnisse zu fassen sind, mit denen ein Formwandel des Konstitutionalismus einhergeht (zweiter Teil, ab S. 33), (2) wie zeitgenössische Verfassungstheorien den diagnostizierten Formwandel und seine Widersprüche bearbeiten (dritter Teil, ab S. 115) und schließlich (3) wo das demokratische Moment in der Weltgesellschaft noch Ansatzpunkte finden könnte (vierter Teil, ab S. 179).

\section{VerfassungsSOZIOLOGIE}

Aus der Rekonstruktion der Verfassungstheorie des jungen Marx folgen zwei weitere Weichenstellungen: Die erste besteht darin, dass eine Diskussion der

Herrschaftskritik und Herrschaftsausübung treffen, bleibt eine Leerstelle. Für Abensour beginnt die Marx'sche "wahre Demokratie" überhaupt erst jenseits des Staates, siehe M. Abensour: Democracy against the State, insbes. S. $47 \mathrm{ff}$. Die Annahme der beiden Subverfassungen weist eher Parallelen zu Balibars Unterscheidung zwischen einer "Politik der Verfassung" und einer "Politik der Insurrektion" auf, vgl. Balibar, Etienne: Die Grenzen der Demokratie, Hamburg: Argument-Verlag 1993, S. 113. Aber auch diese Unterscheidung schlägt das Recht und die Verfassung eher der herrschaftlichen Seite zu. Im Laufe der Argumentation wird sich zeigen, dass gerade auch die "revolutionäre" Seite nicht vollständig auf die Form verzichten kann (vgl. Epilog, ab S. 207).

63 | H. Brunkhorst, "Kommentar", S. 163; vgl. auch die Analyse der Verwendungsweise des Demokratiebegriffs in den sozialen Bewegungen des frühen und mittleren 19. Jahrhunderts bei Draper, Hal: Karl Marx's Theory of Revolution III. The "Dictatorship of the Proletariat", New York: Monthly Review Press 1986, S. 59 ff. 
Verfassungsfrage nur sinnvoll als Bestandteil einer Theorie der Gesellschaft erfolgen kann. Wenigstens muss sie gesellschaftstheoretische Anleihen vornehmen, um nicht in Zirkelschlüsse zurückzufallen oder die Verfassung zu einer vorsozialen Entität zu verdinglichen. Um diese gegenseitige Verwiesenheit von Gesellschaft und Verfassung zu kennzeichnen, bietet sich eine Perspektive an, die nicht in der Analyse politisch-rechtlicher Verfahren verharrt, sondern sie als Bestandteil spezifischer Gesellschaftsformationen ausleuchtet. In der jüngeren Diskussion ist in diesem Zusammenhang zunehmend von einer Verfassungssoziologie die Rede.$^{64}$ Diese Herausforderung ruft sogleich einen Ersetzungsbedarf auf. Während Marx und Hegel ihre verfassungstheoretischen Überlegungen im Hinblick auf die nationalstaatlich eingehegte bürgerliche Gesellschaft entwickelten, stellt sich die Verfassungsfrage heute in der funktional ausdifferenzierten Weltgesellschaft. ${ }^{65}$ Der zweite Teil (ab S. 33) der vorliegenden Arbeit versucht diesen Ersetzungsschritt zu leisten. Er fragt nach den charakteristischen Merkmalen der postnationalen Konstellation, nach ihren Sozialdynamiken und Konfliktverhältnissen. Dabei soll die systemtheoretische Weltgesellschaftsdiagnose mit der postmarxistischen Hegemonietheorie so verbunden werden, dass die offensichtlichen Mängel einer bloßen Ausdifferenzierungsthese eingeholt werden. Erst als fragmentierte Hegemoniekonstellation wird die Weltgesellschaft wirklich lesbar; erst vor diesem Hintergrund kann der Formwandel des Konstitutionalismus erhellt werden.

Schließlich geht es nicht einzig um die neuartige Koppelung zwischen Recht und Politik. Zumeist tauchen hintergründige Beschreibungen auf, die den Zustand der Weltgesellschaft als Ganze betreffen: Seien es die funktionale Differenzierung und ihre negativen Externalitäten, sei es die neoliberale Weltwirtschaft, die sich eine rechtlich-politische Verfassung nach ihrem Bilde schafft oder sei es das dezisionistische Machthandeln einzelner Nationalstaaten, dem durch eine Konstitutionalisierung des Völkerrechts begegnet werden soll. Eine angemessene Diskussion der Verfassungsfrage muss sich bestimmter Grundzüge der Weltgesellschaft versichern. Sie sollte zeigen, wie es zu einer Weltgesellschaft kommt, welche grundlegenden Konflikte auftauchen, wie die neuen Ordnungsmuster zu charakterisieren sind. Gefragt ist eine Perspektive,

64 | Vgl. C. Thornhill, A Sociology of Constitutions; Teubner, Gunther: "Das Projekt der Verfassungssoziologie. Irritationen des nationalstaatlichen Konstitutionalismus", in: Zeitschrift für Rechtssoziologie 32 / 2 (2011), S. 189-204; P. F. Kjaer, Constitutionalism in the Global Realm.

65 | Vgl. Luhmann, Niklas: "Die Weltgesellschaft" (1971), in: ders., Soziologische Aufklärung 2. Aufsätze zur Theorie der Gesellschaft, Wiesbaden: VS-Verlag 2005, S. 63-88. 
die an der Grenze von Politik, Recht und Sozialwissenschaft generiert wird. ${ }^{66}$ Sie steht vor der Herausforderung,

"real ablaufende Konstitutionalisierungsprozesse außerhalb der Nationalstaaten empirisch zu untersuchen, eine Theorie des transnationalen gesellschaftlichen Konstitutionalismus zu entwerfen [und schließlich] soziologische Problemvorgaben für normative Perspektiven in Politik und Recht zu entwickeln “67.

Hier taucht eine Schwierigkeit auf. Die empirische Untersuchung von Verfassungsphänomenen ist fraglos notwendig. Sie ruft jedoch ebenso die Gefahr einer Rücknahme der Verfassungsdiskussion in den Zirkel von Beispiel und Gegenbeispiel hervor. Die einen beobachten eine Konstitutionalisierung der digitalen Welt im Bereich der Internet Corporation for Assigned Names and Numbers (ICANN). Sie regelt die Adressvergabe im Internet. ${ }^{68}$ Die anderen beschreiben solche Prozesse weder als Verfassungsbildung noch erachten sie diese neuartigen Verrechtlichungsmechanismen für konstitutionell. ${ }^{69}$ Für diejenigen, die sowieso daran festhalten, dass die Nationalstaaten das »Monopol physischer Gewaltsamkeit« (Weber) - trotz Globalisierung - vereinnahmen, ${ }^{70}$ ist die ICANN vielleicht interessant, als Gegenstand einer Verfassung jedoch ungeeignet und ohne jeden prognostischen Charme für die Weltgesellschaft als Ganze. Von ordoliberaler und neomarxistischer Seite wird eingewendet: It's the economy stupid. Nur Fälle aus Weltwirtschaft, Finanzmärkten oder europäischer Binnenmarktintegration erhalten hier die nötige Verfassungsdignität. Sicherlich ist die Untersuchung empirischer Beispiele aufschlussreich. Man kommt allerdings auch hier ohne eine Klärung sozialtheoretischer Grundfragen nicht aus. Wie sich der Übergang zur Weltgesellschaft darstellt, wel-

66 | Vgl. zu den Erfordernissen einer "transdisziplinären“ Methode: A. Wiener, Zur normativen Wende in den IB, insbes. S. 338; Niesen, Peter: "Internationale Politische Theorie: Eine disziplinengeschichtliche Einordnung", in: Zeitschrift für internationale Beziehungen 17/2 (2010), S. 267-277.

67 | G. Teubner, "Das Projekt der Verfassungssoziologie", S. 190.

68 | Karavas, Vagias: "Governance of Virtual Worlds and the Quest for a Digital Constitution «, in: Christoph Beat Graber/Mira Burri-Nenova (Hg.), Governance of Digital Game Environments and Cultural Diversity. Transdisciplinary Enquiries, Cheltenham: Edward Elgar 2009, S. 153-169.

69 | Vgl. D. Grimm, "The Achievement of Constitutionalism in a Changed World".

70 | Vgl. u. a. Müller, Harald: "Staatlichkeit ohne Staat? Ein Irrtum aus der europäischen Provinz", in: Nicole Deitelhoff/Jens Steffek (Hg.), Was bleibt vom Staat? Demokratie, Recht und Verfassung im globalen Zeitalter, Frankfurt a. M.: Campus 2009, S. 221-258; Ten Brink, Tobias: Geopolitik. Geschichte und Gegenwart kapitalistischer Staatenkonkurrenz, Münster: Westfälisches Dampfboot 2008. 
che neuartigen Interaktionsverhältnisse von Recht, Politik und Gesellschaft entstehen, welche Widersprüche auftauchen, welche Fälle von prognostischer Relevanz sind und welche nicht - all diese Fragen machen ein Verständnis derjenigen Prozesse notwendig, die überhaupt die globale Verfassungsfrage aufwerfen. Deshalb widmet sich das erste Kapitel der Frage nach der Weltgesellschaft. Die dabei zugrundeliegende These lautet: Die Weltgesellschaft ist als fragmentierte Hegemoniekonstellation zu begreifen, in der sich ein Formwandel des Konstitutionalismus vollzieht.

Die nächste, zweite Umstellung, die sich aus der Rekonstruktion der Verfassungstheorie des jungen Marx gewinnen lässt, zielt auf den Widerspruch in der Verfassungsevolution. Demnach gibt es nämlich keinen eindeutigen »richtigen« Begriff der Verfassung, der über seine historischen Ausprägungen erhaben ist. Was vorliegt, sind spezifische Beziehungen zwischen Recht, Politik und Gesellschaft, die in der Form der Verfassung bestehende Muster der Herrschaftsausübung absichern und ermöglichen. Unter Formwandel wäre also zu verstehen, dass ein Veränderungsprozess stattfindet, der bestimmte Strukturmerkmale des Konstitutionalismus in die Weltgesellschaft fortschreibt. Diese werden aber so grundlegend transformiert, dass man von einer anderen Form des Konstitutionalismus ausgehen muss. ${ }^{71}$

Dies betrifft natürlich auch das Verhältnis von Herrschaftsausübung und Herrschaftskritik. Zwar fand mit der konstituierenden Macht des Volkes eine entgrenzte Herrschaftskritik ihren gründenden Eingang in die Verfassungsevolution, jedoch entzieht sie sich einer eindeutigen Zuordnung zu einer der beiden Seiten; vielmehr ist zu betrachten, wie beide Seiten aufeinander bezogen sind. Im dritten Teil (ab S.115) soll diesem Problem nachgespürt werden. Die Annahme ist, dass die Weltgesellschaft den Widerspruch zwischen herrschaftlichem und demokratischem Konstitutionalismus erbt, die vorliegenden Reflexionen allerdings noch keine Mittel dafür gewonnen haben, den Widerspruch adäquat zu bearbeiten.

Dies hängt nicht zuletzt damit zusammen, dass es zu einseitig wäre, den Formwandel nur für die eine, herrschaftliche Seite anzunehmen. Auch die andere Seite, das Prinzip der demokratischen Verfassung, erlebt eine Veränderung, wenn es dem Übergang in die Weltgesellschaft ausgesetzt ist. Im zweiten Teil wird deshalb demonstriert, dass zeitgenössische Verfassungstheorien daran scheitern, diesen Formwandel hinreichend auszuarbeiten. Neuere Diskussionen um die Konstitutionalisierung des Völkerrechts berücksichtigen die Transformation der Verfassung zu wenig. Der transnationale gesellschaftliche Konstitutionalismus legt dagegen eine ausführliche Betrachtung zu den

71 | Davon bleibt die Annahme, dass die Verfassung als höherrangige Form zu verstehen ist, unberührt. 
Veränderungen vor. ${ }^{72}$ Ihm gelingt es jedoch nicht, den Formwandel als Herrschaftsproblem so zu reformulieren, dass die demokratische Verfassung noch eine Rolle in der Weltgesellschaft spielen kann.

Deshalb schlägt der vierte Teil (ab S.179) prognostische Überlegungen zum Problem der demokratischen Verfassung vor. Die Aussichten sind dabei düster. Bisher sind diejenigen großen Geschichtszeichen und radikaldemokratischen Verfassungsrevolutionen, wie sie Marx in der Französischen Revolution für die bürgerliche Gesellschaft ausgemacht hat, in der Weltgesellschaft ausgeblieben. Die erste, herrschaftliche Seite der Verfassungsevolution gewinnt an Dominanz. Die konstituierende Macht des Volkes taucht zumeist gar nicht mehr auf und wenn, dann in korrumpierter Fassung, als Governance - ein Problem, das Marx schon in Hegels Ständeverfassung angelegt sah: »Das Volk ist hier schon so zubereitet, wie es in dem betrachteten Organismus zubereitet sein muß, um keinen entschiedenen Charakter zu haben. ${ }^{73}$ Unter diesen Bedingungen bleibt es dem pouvoir constituant vorbehalten, sich negativ als »absetzende Macht«, als pouvoir destituant, zu artikulieren. Um überhaupt wieder eine Einschreibung der demokratischen Verfassung in den transnationalen Konstitutionalismus zu erreichen, wird es erst einmal negativ ansetzen müssen. Nicht gesetz- und verfassungsgebend, sondern in Bezug auf die Verfassungsbildung jenseits des Nationalstaats: $a b$ - bzw. ent-setzend. ${ }^{74}$ Erst im Zuge einer Entleerung des transnationalen Konstitutionalismus von seinen ihn bisher bestimmenden Programmen und Politiken kann sich der Raum für eine erneute Einschreibung des Widerspruchs in den Konstitutionalismus öffnen. Dabei tritt der einheitliche populus der Staatsverfassung als Träger der konstituierenden Macht zu Gunsten von eher plebejischen Handlungsformen zurück, die darauf zielen, das herrschaftskritische Moment noch präsent zu halten.

72 | Zur Konstitutionalisierung des Völkerrechts vgl. J. Habermas, "Hat die Konstitutionalisierung des Völkerrechts noch eine Chance? «; zum gesellschaftlichen Konstitutionalismus: G. Teubner, Verfassungsfragmente.

73 | K. Marx, "Kritik des Hegelschen Staatsrechts", S. 273.

74 | Dazu ausführlicher im vierten Teil, ab S. 179; vgl. auch für die freilich etwas anders geartete, von innen her im Rechtsprozess ansetzende Figur einer Ent-Setzung des Rechts im Anschluss an Walter Benjamins "Kritik der Gewalt»: Menke, Christoph: Recht und Gewalt, Berlin: August-Verlag 2011, S. 59 ff. 



\section{Zweiter Teil - Formwandel des Konstitutionalismus: Die Weltgesellschaft als fragmentierte Hegemoniekonstellation}

Die Verfassungsbildung jenseits des Staates ist nur angemessen zu begreifen, wenn sie die Verbindungslinien zur Gesellschaftstheorie einzieht. Dies ist ein zentraler methodologischer Impuls, der aus der Diskussion des Marx'schen Verfassungsdenkens folgte. Das zeitigt Folgen für den Argumentationsgang. Zuerst wendet er sich nicht zeitgenössischen Verfassungstheorien im engeren Sinne zu; vielmehr versucht er den Transformationsprozessen nachzugehen, die den Übergang zur Weltgesellschaft prägen, und schlägt einen Weg vor, wie sie auszuleuchten sind. Wenigstens sollten die groben Umrisse der transnationalen Problemstellungen erkennbar sein, die schließlich so in die Verfassungsdiskussion hineinreichen, dass Konstitutionalisierung auch als normative Antwort nachvollziehbar werden kann. Als prägendes Beispiel steht erst einmal das Weltwirtschaftsregime im Mittelpunkt der Überlegungen. Das Ziel besteht darin, in einem kursorischen Durchgang zu umreißen, welche Gegenstandsbereiche auf dem Spiel stehen, wenn von Verfassungsbildung und Formwandel die Rede ist. Nicht zuletzt ist das Weltwirtschaftsregime vor allem deshalb von Interesse, da spätestens seit der globalen Wirtschafts- und Finanzkrise deutlich wurde, wie stark das Zusammenspiel von Politik, Recht und kapitalistischer Weltwirtschaft die Situation der Weltgesellschaft als Ganze bestimmt. Der Durchgang versucht sodann nachzuweisen, dass zeitgenössische Überlegungen aus den Politikwissenschaften mit ihrem Schwerpunkt auf den staatlichen Institutionen und dem weitgehenden Verzicht auf gesellschaftstheoretische Grundierungen dem Übergang zur Weltgesellschaft oft nicht gerecht werden (I, ab S. 34).

In einem nächsten Schritt soll deshalb die schon angeklungene Ersetzung der sozialtheoretischen Perspektive erfolgen. Die für die Argumentation leitende Diagnose wird in einer Auseinandersetzung mit der Weltgesellschaftsthese Niklas Luhmanns entwickelt (II, ab S.48), um schließlich mit der Dimension eines Formwandels der Verfassung eine Erweiterung zu erfahren: In 
der Weltgesellschaft liegen transnationale Regime vor, in denen Recht, Politik und unterschiedliche Rationalitäten sozialer Teilbereiche damit beginnen, einen Prozess der Verfassungsbildung zu durchlaufen (III, ab S. 62). Die Darstellung ist daran orientiert bestimmte Aspekte der systemtheoretischen Überlegungen aufzunehmen, sie aber gleichsam in eine gewisse Distanz zu einer geschlossenen Theoriearchitektur zu bringen. Schon in der Aufarbeitung wird kritisiert, dass die Systemtheorie zwar die Ausdifferenzierung von transnationalen Regimen aussichtsreich ausleuchtet. Demgegenüber verliert sie jedoch die neuartigen Hegemonieverhältnisse der Weltgesellschaft aus dem Blick. Um dann solche Phänomene, wie sie etwa für das Beispiel des Weltwirtschaftsregimes bestimmend sind, zu begreifen, ist eine Umschrift nötig. Es erscheint notwendig die Systemtheorie mit der postmarxistischen Hegemonietheorie zu verbinden. Differenz und Hegemoniebildung bilden so zwei gleichursprüngliche Strukturmerkmale der postnationalen Konstellation. Dadurch erscheinen die Regime in einem veränderten Licht. Sie sind nicht nur Ausdruck allgemeiner funktionaler Differenzierung, sondern genauso von Dominanzverhältnissen, sozialen Kräftekonstellationen wie Kämpfen, geprägt. Dies wiederum legt eine stärkere Historisierung der Analyseperspektive nahe: Als »hegemonische Regime« ist es gerade den Institutionen der Weltwirtschaftsregime seit den 1970er Jahren gelungen, ihr marktliberales Esperanto zu verallgemeinern (IV, ab S. 73). ${ }^{1}$ Aus der postmarxistischen Umschrift erwächst schließlich eine veränderte Perspektive auf die Verfassungsbildung jenseits des Staates. Sie ist durch einen Formwandel im Hinblick auf die Ordnungsbildung (Regimeverfassungen), auf das Recht und die Politik (Hybridisierung/Substantialisierung) sowie auf der Bearbeitung sozialer Widersprüche (antagonistische Regimeverfassungen) geprägt (V, ab S. 82).

\section{Das Weltwirtschaftsregime UND DER POLITIKWISSENSCHAFTLICHE LEGITIMISMUS}

\section{Das Weltwirtschaftsregime}

Die Hoffnungen darauf, dass die globale Verallgemeinerung eines marktliberalen Kapitalismusmodells für Frieden und Wohlfahrt sorgt, haben sich gründ-

1 | Vgl. zum hegemonialen Charakter der Regimes: Koskenniemi, Martti: "Hegemonic Regimes", in: Margaret A. Young (Hg.), Regime Interaction in International Law, Cambridge: Cambridge University Press 2012, S. 305-324, und ders.: "International Law and Hegemony. A Reconfiguration «, in: Cambridge Review of International Affairs 17 / 2 (2004), S. 197-218. 
lich zerstreut. Das ändert wiederum nichts am »befremdlichen « ${ }^{2}$ Überleben des Neoliberalismus. Die Krisenreaktionen, nicht zuletzt in der EU, sind oft weiterhin an einseitiger Austeritätspolitik orientiert. ${ }^{3}$ Die Krisensituation weist immer wieder darauf hin, dass transnationale Vernetzungen von Wirtschaft, Politik und Recht vorliegen, die zwischenzeitlich die Steuerungskompetenzen der Nationalstaaten weit übersteigen. Regelmäßig unterlaufen sie die althergebrachten Institutionen der nationalen Verfassungen. Längst ist die EU auf dem Weg in eine supranationale Verfasstheit, die den wirtschaftspolitischen Handlungsspielraum nationalstaatlicher Demokratien einschränkt; längst richtet die Streitschlichtungseinheit der Welthandelsorganisation (WTO) über das wirtschaftspolitische Handeln der Mitgliedsstaaten; längst legt der Basler Ausschuss für Bankenaufsicht diejenigen Eigenkapitalstandards fest, die Banken für ihre Geschäfte gegenhalten müssen; längst sind Mechanismen privater Standardsetzung wirksam; längst gewinnen transnationale Schiedsgerichtsbarkeiten im Bereich des Investitionsschutzrechts an Unabhängigkeit. ${ }^{4}$ An dieser Aufzählung wird schon deutlich, dass die moralische Empörung über die Macht der Ökonomie über die Politik zu kurz greift. Nicht unmoralische Manager und ihre gierigen Charakterzüge haben ursächlich zur Weltwirtschaftskrise beigetragen. Rechtliche und politische Strukturbildungen haben das finanzialisierte Akkumulationsregime von Beginn an begleitet. ${ }^{5}$

Wenn man versucht, diesen Umstand fassbar zu machen, taucht sogleich ein Problem auf. Zwischenzeitlich hat sich ein dichtes Netz an weltwirtschaftlichen und finanzmarktbezogenen Institutionen etabliert. Aber weder gibt es

2 | Crouch, Colin: Das befremdliche Überleben des Neoliberalismus, Frankfurt a. M.: Suhrkamp 2011.

3 | Vgl. C. Joerges, "Recht und Politik in der Krise Europas«; für die Durchsetzung des Austeritätsmodells: Streeck, Wolfgang: Gekaufte Zeit. Die vertage Krise des demokratischen Kapitalismus, Berlin: Suhrkamp 2013; Kennedy, David: "Law and the Political Economy of the World «, in: Leiden Journal of International Law 26/ 1 (2013), S. 7-48.

4 | Vgl. in der Reihenfolge der Beispiele: Habermas, Jürgen: Zur Verfassung Europas, Berlin: Suhrkamp 2011; Trachtman, Joel P.: "The Constitutions of the WTO ", in: European Journal of International Law 17 (2006), S. 623-646; Wood, Duncan R.: Governing Global Banking. The Basel Committee and the Politics of Financial Globalisation, Aldershot: Ashgate 2005.

5 | Der Begriff des Akkumulationsregimes entstammt der französischen Regulationsschule. So wird ein Zusammenspiel von Ökonomie, Gesellschaft und Politik in kapitalistischen Gesellschaftsformationen konzeptualisiert. Vgl. Aglietta, Michel: Ein neues Akkumulationsregime. Die Regulationstheorie auf dem Prüfstand, Hamburg: VSA-Verlag 2000; zur Kritik an einem Zugang, der Wirtschaft und Politik einfach nur gegenüberstellt: Biebricher, Thomas/Vogelmann, Frieder: "Die Zukunft Europas zwischen Demokratie und Kapitalismus", in: Politische Vierteljahresschrift 55/ 1 (2014), S. 1-17. 
eine transnationale »Super«-Organisation der Weltwirtschaft noch einen eindeutigen Gründungsmoment, auf den man die Regulierung der Weltwirtschaft zurückführen könnte. Eher liegen eine Vielzahl von Institutionen und Rechtskreisen vor, die sich einer zentralen Steuerung entziehen. ${ }^{6}$ Was sich abzeichnet, ist ein in sich heterogenes, aber in der inhaltlichen Orientierung auf Freihandel und Finanzialisierung doch relativ kohärentes Netzwerk, das die marktliberale Dominanz mit rechtlich-politischen Strukturbildungen unterfüttert. Ohne dieses Netz, das hier vorläufig als Weltwirtschaftsregime firmieren soll, wäre die Krise der Weltwirtschaft nicht möglich gewesen. ${ }^{7}$ Insbesondere der Forschungszweig der »Internationalen Politischen Ökonomie« hat in den letzten Jahren immer wieder darauf hingewiesen, dass der Trend zur Liberalisierung und Finanzialisierung sehr wohl von einer förderlichen rechtlich-politischen Einbettung gestützt wurde. ${ }^{8}$ Denn in allen Bereichen des Weltwirtschaftsregimes sind nicht nur ökonomische Steigerungszwänge, sondern auch folgenreiche Koppelungen zwischen Recht und Politik zu beobachten. Global Governance, von vielen als regulatorisches Gegengift zur Weltwirtschaft verstanden, ${ }^{9}$ erweist sich als problematisches Unterfangen: Die Governance der Weltwirtschaft war bisher nicht der Sand, zumeist war sie das Öl im Getriebe eines neuartigen, transnationalen Konstitutionalismus des Freihandels. ${ }^{10}$ Dies lässt sich an einigen Beispielen darstellen.

Das wohl schillerndste Element des Weltwirtschaftsregimes ist die WTO. Mit ihrer Gründung sollte 1995 ein globaler Rahmen für den wirtschaftlichen

6 | Vgl. Renner, Moritz: "Transnationale Wirtschaftsverfassung", in: Rabels Zeitschrift für ausländisches und internationales Privatrecht 78/4 (2014), S. 750-783.

7 | Zur Aufnahme des Regimekonzepts siehe ausführlich III, ab S. 62.

8 | Vgl. Gill, Stephen: "New Constitutionalism, Democratisation and Global Political Economy“, in: Pacifica Review: Peace, Security \& Global Change 10/1 (1998), S. 2338. Das Konzept der embeddedness, also der Modalitäten gesellschaftlicher "Einbettung" von Marktprozessen, geht auf den Wirtschaftshistoriker Karl Polanyi zurück: ders.: The Great Transformation (1944), Boston: Beacon Press 2001; zu rechtlichen Implikationen vgl. Kreide, Regina: "Re-embedding the Market Through Law? in: Christian Joerges / Josef Falke (Hg.), Karl Polanyi. Globalization and the Potential of Law in Transnational Market, Oxford/Portland: Hart Publishing, S. 42-64.

9 | Zusammenfassend siehe: Behrens, Maria: "Global Governance", in: Arthur Benz (Hg.), Governance - Regieren in komplexen Regelsystemen, Wiesbaden: VS-Verlag 2010, S. 104-124.

10 | Zugespitzt zur Verallgemeinerung eines "disziplinierenden Neoliberalismus", vgl. Gill, Stephen: "Constitutionalizing Inequality and the Clash of Globalizations", in: International Studies Review 4/ 2 (2002), S. 47-65; für eine Aktualisierung: Cutler, Claire A. / Gill, Stephen (Hg.): New Constitutionalism and World Order, Cambridge: Cambridge University Press 2014. 
Freihandel geschaffen werden. Die Anzahl der WTO-Mitglieder ist zwischenzeitlich auf 160 Nationalstaaten angewachsen. In Abschnitt 1 des »Übereinkommens zur Errichtung der Welthandelsorganisation« (v. 15.4.1994) verständigten sich die Vertragsparteien auf einen »wesentlichen Abbau der Zölle und anderer Handelsschranken sowie auf die Beseitigung der Diskriminierung in den internationalen Handelsbeziehungen«. Theoreme neoklassischer Wirtschaftstheorie spielten dabei eine einflussreiche Rolle. Die Dominanz des Freihandelsprinzips war nicht nur eine Schlussfolgerung der weltpolitischen Entwicklung. Sie war auch davon getrieben, dass eine Wohlstandssteigerung maßgeblich auf der Ebene des Außenhandels sowie komparativer Kostenvorteile angesiedelt wurde. ${ }^{11}$ In der Folge forcierte die WTO im Zusammenspiel mit dem IWF und der Weltbank zunehmend Liberalisierungs- und Marktöffnungspolitiken, die teils erhebliche Konfliktlagen mit der Gewährleistung sozialer Menschenrechte provozierten. ${ }^{12}$

Eigentlich ist die WTO als intergouvernementale Organisation konzipiert. Sie beruht auf der Mitgliedschaft von Einzelstaaten. Der Schritt zu ihrer Konstitutionalisierung wird nun maßgeblich darauf zurückgeführt, dass sie zu einer höherrangigen Ordnung der Weltwirtschaft wird, die sich wenigstens teilweise von einem rein intergouvernementalen Vertrag abhebt und die Mitglieder in einem starken Sinne bindet. ${ }^{13}$ Wiederum ist in diesem Zusammenhang auf die Rolle von Gerichten zurückzukommen. Der WTO-interne Streitschlichtungsmechanismus und seine Spruchpraxis haben eine Eigendynamik gewonnen, die auch immer wieder neue Themenbereiche, wie Ökologie, Umwelt oder Menschenrechte, in den Regelungsbereich der WTO einordnet. ${ }^{14}$ Diese Entwicklung rückt die WTO-Verträge zunehmend in den Status eines höherrangigen Rechts, das über den nationalstaatlichen Vertragsparteien steht. ${ }^{15}$ Dabei ist auch zu beobachten, dass neue Akteurskonstellationen entstehen. Im Shrimp-

11 | Vgl. Krajewski, Markus: Verfassungsperspektiven und Legitimation des Rechts der Welthandelsorganisation, Berlin: Duncker \& Humblot 2001, S. 132.

12 | Siehe etwa die Aufarbeitung der Strukturanpassungsprogramme bei Abouharb, M. Rodwan/Cingranelli, David: Human Rights and Structural Adjustment, Cambridge: Cambridge University Press 2007.

13 | Vgl. die Aufarbeitung der Verfassungsdiskussion bei Cass, Deborah Z.: The Constitutionalization of the World Trade Organisation. Legitimacy, Democracy, and Community in the International Trading System, New York: Oxford University Press 2005.

14 | Zur Analyse der diesbezüglichen interpretativen Techniken: Lang, Andrew: World Trade after Neoliberalism. Reimagining the Global Economic Order, Oxford: Oxford University Press 2011, S. 165 ff.

15 | Vgl. u. a. Petersmann, Ernst-Ulrich: The GATT/WTO Dispute Settlement System, London/Den Haag/ Boston: Kluwer Law International 1997, S. 53; M. Krajewski, Verfassungsperspektiven und Legitimation des Rechts der Welthandelsorganisation, S. 21. 
Turtle-Verfahren ${ }^{16}$ genehmigte der appellate body das Einreichen von sogenannten Amicus-curie-Schriftsätzen. Dabei haben Dritte, nicht am Streitschlichtungsverfahren Beteiligte, die Möglichkeit, zum Fall Stellung zu beziehen. ${ }^{17}$ So können private Akteure Einfluss auf die Verfahren ausüben. Wenigstens sind mit den Amicus-curie-Schriftsätzen und einer intensiveren Kooperation der WTO mit Unternehmen »mittelbare Beteiligungsmöglichkeiten ${ }^{18}$ nichtstaatlicher Akteure entstanden. Damit rücken Konfliktlagen ins Blickfeld, die nicht auf zwischenstaatliche Handelskonflikte beschränkt bleiben. Bei den zwischenzeitlich langandauernden Konflikten um die Agrarsubventionen wird dies besonders deutlich: In den letzten Jahren blockierten die Länder des globalen Südens die sogenannte Doha-Runde, da sie negativ von den Agrarsubventionen des Nordens betroffen sind. Dabei geht es nicht nur um zwischenstaatliche Machtkonflikte. Genauso ist die Frage nach ökonomischen Entwicklungswegen und sozialem Ausgleich aufgeworfen, die allerdings im Rahmen einer Freihandelsverfassung nur sehr verzerrt thematisiert werden kann - hier steht das Privileg der Liberalisierung erst einmal fest. ${ }^{19}$ Zwischenzeitlich liegen Untersuchungen vor, die unterstreichen, dass die WTO in der Folge der Wirtschaftsund Finanzkrise in eine postneoliberale Phase eingetreten sei. ${ }^{20}$ Zwar haben sich einige Veränderungen durch das Stocken der Doha-Runde ergeben, die Kompromissbildung im Bereich der Agrarsubventionen beispielsweise deu-

16 I Indien, Malaysia, Thailand und Pakistan klagten gegen ein Importverbot ihrer Shrimps auf den US-Markt: WTO DSU, DS 58, United States - Import Prohibition of Certain Shrimp and Shrimp Products.

17 | Zu diesem Fall: D. Z. Cass, The Constitutionalization of the World Trade Organisation, S. 182.

18 | Nowrot, Karsten: Normative Ordnungsstruktur und private Wirkungsmacht. Konsequenzen aus der Beteiligung transnationaler Unternehmen im internationalen Wirtschaftssystem, Berlin: Berliner Wissenschaftsverlag 2006, S. 406.

19 | Klagen gegen die Agrarsubventionen müssen die Sprache des Freihandels und des kategorischen Subventionsabbaus sprechen, vgl. dazu etwa die Klagen Brasiliens, Thailands und Australiens gegen die EU-Zuckersubventionen bei der WTO: WTO DSU, DS 265, 266 und 283 European Communities - Export Subsidies on Sugar; siehe auch Danvivathana, Pornchai: "Thailand's Experience in the WTO Dispute Settlement System, Challenging the WTO Sugar Regime", in: Gregory C. Shaffer/Ricardo Meléndez-Ortiz (Hg.), Dispute Settlement in the WTO. The Developing Country Experience, New York: Cambridge University Press 2010, S. 210-229. Für eine optimistische Einschätzung, die den Waiver-Mechanismus nach Art. IX (3) der WTO-Verträge als Einfallstor für eine Öffnung der WTO betrachtet, vgl. Feichtner, Isabel: The Law and Politics of WTO Waivers. Stability and Flexibility in Public International Law, Cambridge: Cambridge University Press 2011.

20 | Vgl. A. Lang, World Trade after Neoliberalism. 
tet allerdings nicht auf einen Bruch mit der Freihandelsorientierung hin, sondern im Gegenteil auf seine Fortschreibung - auch wenn sich die Rahmenbedingungen und Konfliktkonstellationen tatsächlich von der Phase nach der WTO-Gründung 1995 abheben. Trotzdem wird die WTO noch 2010 von ihrem Generaldirektor als marktliberale »rampart against totalitarianism ${ }^{21}$ charakterisiert. Die Zugeständnisse an die Länder des globalen Südens sind Ausnahmeregeln, die über die Zeit natürlich dem Freihandelsideal angenähert werden sollen. Nun kann man nicht davon ausgehen, dass die WTO die ökonomische Superinstitution der Weltgesellschaft ist. Schließlich tragen auch der Internationale Währungsfonds (IWF) und die Weltbank maßgeblich zur Wirtschaftsverfassung bei. Darüber hinaus haben sich Entwicklungen im Bereich der Finanzmärkte, der Banken und des Bankensektors ergeben, die man wohl ebenso in das breitere Bild eines Weltwirtschaftsregimes einordnen muss. Nicht zuletzt hat die Entwicklung der Weltwirtschaft in den letzten Jahren maßgeblich auf der Grundlage einer stark finanzialisierten Akkumulation stattgefunden. Insofern ist die inter- und transnationale lex financaria durchaus als Teil des Weltwirtschaftsregimes zu begreifen und nicht als separate Sphäre.

Durch die Wirtschafts- und Finanzkrise ist der Basler Ausschuss für Bankenaufsicht zunehmend ins öffentliche Interesse gerückt. Er trägt mit Eigenkapitalvorschriften und Transparenzpflichten zur Regulierung des Bankensektors bei. ${ }^{22}$ Der Basler Ausschuss für Bankenaufsicht wurde 1974 unter dem Dach der Bank for International Settlements (BIS) von den Zentralbanken und Aufsichtsbehörden der G1o gegründet. Um den neuen Problemlagen eines internationalisierten Bankensektors zu begegnen, wurde 1974 unter dem Dach der BIS ein ständiges Committee on Banking Regulations and Supervisory Practices eingerichtet, das schließlich 1989 zum Basel Committee on Banking Supervision umbenannt wurde. Zwischenzeitlich sind im Basler Ausschuss insgesamt 28 nationale Zentralbanken bzw. Finanzaufsichtsbehörden vertreten. Zwar spielt der Basler Bankenausschuss eventuell eine »wichtigere Rolle in der Integration der Finanzmärkte als der IWF [...] und übersteigt wahrscheinlich den Einfluss der Weltbank « ${ }^{23}$, aber die Bankenregulierung vermochte es seit den $1990 e r$ Jahren nicht, problematische Geschäftspraktiken zu verhindern. Im Ge-

21 Zit. nach Joseph, Sarah: Blame it on the WTO? A Human Rights Critique, Oxford: Oxford University Press 2011, S. 84; für die Strategien der Länder des globalen Südens: Santos, Alvaro: "Carving Out Policy Autonomy for Developing Countries in the World Trade Organization. The Experience of Brazil and Mexico", in: Virginia Journal of International Law 52/3 (2012), S. 551-632.

22 | Zur Entwicklung des Ausschusses siehe insbes. D. R. Wood, Governing Global Banking.

23 | Underhill, Geoffrey: „Foreword«, in: D. R. Wood, Governing Global Banking (2005), S. VI. 
genteil sprechen unterschiedliche Indizien dafür, dass gerade die Basel-II-Vereinbarungen aus dem Vorfeld der Finanzkrise die Rolle von Ratingagenturen gestärkt und mithin prozyklische, krisenverschärfende Effekte erzielt haben. ${ }^{24}$

Das institutionelle Design des Ausschusses hat sich über die letzten 30 Jahre hinweg verschoben. Bestand der Basler Ausschuss in den 1970er Jahren noch aus dem exklusiven Club der Gio-Zentralbanken, ist der Teilnehmerkreis auf zwischenzeitlich 28 Mitglieder angewachsen. ${ }^{25}$ Schon damals basierte die Regulierung auf Verhandlungen zwischen staatlichen Aufsichtsbehörden und dem Bankensektor, auf einem Zusammenspiel zwischen konsensuellen Regeln und der Bereitschaft des Bankensektors zur Selbstbindung an diese Regeln. Darüber hinaus hat sich der Bankenausschuss bei den Verhandlungen zum Basel-II-Abkommen um einen Dialog mit Zivilgesellschaft und Interessengruppen bemüht. Er hat sie in ein Kommentierungsverfahren eingebunden, das sich über mehrere Jahre von 1999 bis 2003 erstreckt hat. Hier konnten Kritikpunkte zu den vorgeschlagenen Richtlinien eingereicht werden. ${ }^{26}$ Deshalb gehen unterschiedliche Untersuchungen davon aus, dass der Baseler Bankenausschuss als Governancestruktur par excellence zur effizienten Problemlösung führt und sogar mit den neuen Partizipationsverfahren für die Zivilgesellschaft die accountability der Institution erhöht. ${ }^{27}$ Dies ändert wiederum nichts an seiner hohen Selektivität für die Interessen des Bankensektors, die im Vorfeld der globalen Wirtschaftskrise prozyklische Effekte erzielt hat. ${ }^{28}$ Auf der Internetsei-

24 | So auch Bieling, Hans-Jürgen / Jäger, Johannes: "Global Finance and the European Economy. The Struggle over Banking Regulation«, in: Bastian Apeldoorn/Jan Drahokoupil/ Laura Horn (Hg.), Contradictions and Limits of Neoliberal European Governance. From Lisbon to Lisbon, London: Palgrave Macmillan 2008, S. 87-105; Crotty, James: "Structural Causes of the Global Financial Crisis. A Critical Assessment of the New Financial Architecture", in: $33 / 4$ (2009), S. 563-580; Illing, Marc/Paulin, Graydon: "Basel II and the Cyclicality of Bank Capital«, in: Canadian Public Policy $31 / 2$ (2005), S. 161-180; Kessler, Oliver: Die internationale Politische Ökonomie des Risikos. Eine Analyse am Beispiel der Diskussion um die Reformierung der Finanzmärkte, Wiesbaden: VS-Verlag 2008, S. 217; King, Michael R./ Sinclair, Timothy J.: "Private Actors and Public Policy. A New Requiem for the New Basel Accord «, in: International Political Science Review 24/3 (2003), S. 345-362.

25 | Vgl. http://www.bis.org/about/factbcbs.htm (letzter Zugriff: 19.3.2013).

26 | Vgl. M. S. Barr/G. P. Miller, "Global Administrative Law".

27 | Ebenda; siehe auch Slaughter, Anne-Marie: A New World Order, Princeton: Princeton University Press 2004, S. 54.

28 Kapstein hatte schon in einer frühen Analyse gezeigt, dass die Politik des Basler Ausschusses mit neuen finanzialisierten Geschäftspraktiken einhergeht, vgl. Kapstein, Ethan B.: "Resolving the Regulator's Dilemma. International Coordination of Banking Regulations", in: International Organization 43/2 (1989), S. 323-347, hier S. 324 ff. 
te www.nakedcapitalism.com warfen im Nachgang der Subprime-Krise in den USA einige Blogger die spannende Frage auf: »what kind of idiots would let the banks determine their own capital requirements (by allowing them to rig their own risk models)? ${ }^{29}$

Stellen in der WTO die Mitgliedsstaaten die Hauptversammlung und im Basler Bankenausschuss die Zentralbanken, so tauchen im internationalen Investitionsschutzrecht dagegen vor allem Konfliktkonstellationen zwischen Unternehmen und Staaten auf. Hier werden Streitigkeiten zwischen Unternehmen und Staaten beigelegt, in denen sich eine der Konfliktparteien auf bilaterale Investitionsschutzabkommen berufen kann. Seit den $1990 e r$ Jahren ist die Zahl der bilateralen Investitionsschutzabkommen auf über 2833 angestiegen. ${ }^{30}$ Zumeist verpflichten sich die Staaten in diesen Abkommen, den Investoren aus dem jeweiligen Partnerland ihre Eigentumsrechte zu sichern. Die zentrale Arena, die über die Einhaltung der jeweiligen Abkommen wacht, ist das bei der Weltbank angesiedelte International Centre for Settlement of Investment Disputes (ICSID). Das Kernprojekt des internationalen Investitionsschutzes ist der Schutz privatwirtschaftlicher Unternehmen vor Enteignungen. ${ }^{31}$ Ausländische Investoren sollen mit Rechtssicherheit versorgt werden. Zwischenzeitlich hat die steigende Anzahl der bilateralen Abkommen und die Spruchpraxis des ICSID eine Art investment rule regime hervorgebracht, das eine bestimmte, substantielle Auffassung davon hat, worin Einschränkungen der Eigentumsfreiheit bestehen..$^{32}$ Demnach sind Eingriffe in das Eigentumsrecht der Investoren als Enteignungen zu werten. Besonders tritt dieser Umstand bei der Rechtsprechungslinie hervor, die das ICSID in Konflikten von Unternehmen mit lateinamerikanischen Ländern vorgenommen hat. In unterschiedlichen Fallkonstellationen in Bolivien und Argentinien hatten Großkonzerne öffentliche Güter wie beispielsweise Wasser und Gas bereitgestellt. Dadurch haben sich insbesondere preisliche Verteuerungen und schlechtere Versorgungslagen ergeben.

29 | Zit. nach Moosa, Imad A.: "Basel II as a Casualty of the Global Financial Crisis", in: Journal of Banking Regulation 11/ 2 (2010), S. 95-114, hier S. 102.

30 | Siehe die Zahl für 2012 in UNCTAD (Hg.): World Investment Report. Towards a New Generation of Investment Policies 2012, S. XX; zu dem Anstieg der letzten Jahre auch Krajewski, Markus: Wirtschaftsvölkerrecht, Heidelberg: C. F. Müller 2009, S. 170.

31 | Vgl. ebenda, S. 190; siehe auch Dolzer, Rudolf/Stevens, Margarete: Bilateral Investment Treaties, Den Haag: Martinus Nijhoff Publishers 1995, S. 97 ff.

32 | Vgl. D. Schneiderman, Constitutionalizing Economic Globalization, S. 25 ff.; siehe auch die Übernahme des Regimekonzepts bei Salacuse, Jeswald W.: The Law of International Investment Treaties, Oxford: Oxford University Press 2010, S. 5; für eine Rekonstruktion der Geschichte des Investitionsschutzrechts vgl. Miles, Kate: The Origins of International Investment Law. Empire, Environment and the Safeguarding of Capital, Cambridge: Cambridge University Press 2013. 
Sie haben sowohl soziale Proteste als auch die direkte Intervention der Regierungen in die Preisgestaltung und Eigentumsstrukturen hervorgerufen. ${ }^{33}$ Die Unternehmen klagten vor dem ICSID-Tribunal auf Schadensersatzforderungen und Entschädigungen - und erhielten stets Recht. Das ICSID-Tribunal war regelmäßig der Auffassung, dass Einschränkungen in den Eigentumsrechten der Investoren unzulässig und als Enteignung zu werten seien. Auch an diesem Beispiel wird die marktliberale Selektivität der rechtlich-politischen Formen des transnationalen Raumes deutlich: Die Rechte der Investoren sind stets wichtiger als die sozialen Menschenrechte, etwa die Gewährleistung des Rechts auf Wasser (Art. 11.1 UN-Sozialpakt) oder Ernährung (Art. 11.2 UN-Sozialpakt). ${ }^{34}$

Man könnte die Liste der neuartigen Regelungsarrangements, die zum transnationalen Wirtschaftsregime beitragen, sicherlich noch weiterführen. Das International Accounting Standards Board, das International Chamber of Commerce, das International Institute for Unification of Private Law mit seinen UNIDROIT-Prinzipien - sie tragen zur Verrechtlichung der Weltwirtschaft bei. Genauso hat sich ein teils entstaatlichtes Recht des Welthandels - die lex mercatoria - auf transnationalem Terrain entwickelt, das standardisierte Handelsregeln sowie Streitschlichtungsmechanismen für Unternehmen bereithält. ${ }^{35}$ Vorläufig sollen einige charakteristische Merkmale dieser emergierenden Netzwerkstruktur festgehalten werden:

Erstens ist das Weltwirtschaftsregime nicht zentral gesteuert. Als heterogenes Ensemble reagiert es auf den Bedarf rechtlicher und politischer Regulierungen in der Weltwirtschaft. Dabei ist zu berücksichtigen, dass eine scharfe Trennung zwischen Wirtschaft, Finanzmärkten und Bankenregulierung schwer aufrechtzuerhalten ist.

Zweitens ist deutlich geworden, dass das Weltwirtschaftsregime längst neuartige Akteurs- und Konfliktkonstellationen profiliert, die das internationale Staa-

33 | Vgl. die Fallkonstellationen: ICSID, Aguas del Tunari S.A. v. Republic of Bolivia (ICSID Case No. ARB/02/3); CMS Gas Transmission Company v. Argentine Republic (ICSID Case No. ARB/01/8); Compañía de Aguas del Aconquija S.A. and Vivendi Universal S.A. v. Argentine Republic (ICSID Case No. ARB /97/3); zur Kritik des marktliberalen Bias: Shalakany, Amr A.: "Arbitration and the Third World. A Plea for Reassessing Bias Under the Scepter of Neo-Liberalism ", in: Harvard International Law Journal 41/2 (2000), S. 419-468.

34 | Vgl. zu den Konflikten mit den sozialen Menschenrechten auch Fischer-Lescano, Andreas/Möller, Kolja: Der Kampf um globale soziale Rechte. Zart wäre das Gröbste, Berlin: Wagenbach 2012.

35 | Vgl. Cutler, Claire: Private Power and Global Authority. Transnational Merchant Law in the Global Political Economy, Cambridge: Cambridge University Press 2003, S. 4. 
tensystem übersteigen. Am deutlichsten wird diese Entwicklung in der staatsfernen lex mercatoria. Hier schafft die Weltwirtschaft in relativer Distanz zum Staatensystem sich ihr eigenes Recht und ihre eigenen Institutionen. Es wäre allerdings falsch, von einem einseitigen Bedeutungsverlust des Staates auszugehen. Die Staaten selbst oder aber spezifische Staatsapparate sind in die Institutionen in der Regel eingebettet. Dies gilt natürlich für die WTO, aber auch genauso für die Konfliktkonstellationen im internationalen Investitionsschutzrecht, an denen in der Regel einzelne Nationalstaaten beteiligt sind. Dort sind die Staaten jedoch nicht einfache Gegenspieler der Wirtschaft. Das Verhältnis von Wirtschaft und Politik kann nicht auf ein einfaches Nullsummenspiel reduziert werden, wo mehr ökonomische Liberalisierung und Selbstregulierung in weniger politische Regulierung mündet und umgekehrt; vielmehr sind beide Seiten in der Regel ineinander verstrickt. Auch hilft die Rede von den Nationalstaaten oder der Wirtschaft oft nicht weiter, da jeweils spezifische Apparate der Nationalstaaten (etwa die Zentralbanken im Basler Bankenausschuss) oder spezifische Organisationen (etwa Großunternehmen im internationalen Investitionsschutzrecht) an den inter- und transnationalen Regelungszusammenhängen teilhaben.

Drittens fällt auf, dass nicht nur innere Heterogenität und Ungleichzeitigkeit herrschen, sondern jeweils eine starke substantielle Orientierung auf Freihandel, Finanzialisierung und Marktschaffung stattfindet, die in den Verträgen, Rechtsprechungslinien und Programmen festgehalten ist. Es spricht viel dafür, hier eine Art »marktliberale Grundnorm ${ }^{36}$ auszumachen. Fraglos ist auch diese Entwicklung einigen Gegentendenzen und Blockaden ausgesetzt. Erst recht entsteht die Verallgemeinerung dieser inhaltlichen Orientierungen nicht durch bloße Ableitung oder als ehernes Gesetz. Trotzdem ist festzuhalten, dass ein roter Faden existiert, an dem sich die neoliberale Weltwirtschaft und rechtlichpolitische Strukturbildungen verschränken.

Viertens greift das Weltwirtschaftsregime massiv in die Architektur der Nationalstaaten ein. Mithin bewirkt es eine massive Transformation politischer Steuerung in den nationalstaatlichen Demokratien. Man muss nur auf die Rolle von Ratingagenturen zu sprechen kommen, die mit ihren Bewertungen in der Regel die Bandbreite politischer Entscheidungsmöglichkeiten von vornherein einschränken und über die Zukunft der einzelnen Länder richten. Aber auch in rechtlicher Hinsicht liegen Spannungsverhältnisse vor: etwa dann, wenn die marktliberalen Normen mit eher sozialstaatlichen Regelungsarrangements in den Nationalstaaten (oder auf internationaler Ebene selbst) kollidieren.

36 | Ebenda, S. 29. 
Fünftens bildet das Weltwirtschaftsregime nicht einfach nur Regeln oder Verträge aus. Es zeichnet sich die Tendenz zu reflexiven Strukturbildungen ab, die eingangs als charakteristisches Merkmal des Konstitutionalismus hervorgehoben wurde. In rechtlicher Hinsicht sind entweder durch Verträge und Satzungen oder durch die Eigenaktivität von Gerichten und Spruchkörpern einerseits höherrangige Normen entstanden, von denen Bindungswirkungen ausgehen, die sich sogar gegen die jeweiligen Akteure richten können oder ihre Handlungsspielräume massiv einschränken. ${ }^{37}$ Andererseits sind auch politische Diskurse und die konkrete Institutionalisierung von Kompetenzen zu beobachten, die sich auf eine Grundordnung des jeweiligen Regelungsbereichs beziehen. ${ }^{38}$

Bisher fehlt jedoch ein Erklärungsansatz, der diese charakteristische Kombination aus Ausdifferenzierung und Verallgemeinerung eines marktliberalen Kapitalismusmodells zu erhellen vermag. Der politikwissenschaftliche Institutionalismus geht mit seinen Überlegungen jedenfalls an den Problemlagen vorbei.

\section{Legitimismus}

Eine ganze Reihe von politikwissenschaftlichen Theorien zu inter- und transnationalen Institutionen bearbeiten diese Veränderungen und ihre Folgen für die Idee der demokratischen Verfassung bisher nicht hinreichend. Exemplarisch kann die amerikanische Politikwissenschaftlerin Anne-Marie Slaughter genannt werden. Sie reduziert den am Beispiel der Weltwirtschaft angedeuteten Zusammenhang auf das Entstehen globaler Exekutivnetzwerke, die darauf spezialisiert sind, gemeinsame Probleme effizient zu lösen. ${ }^{39}$ Ausgangspunkt ihrer Überlegungen sind neue Gefährdungslagen wie der internationale Terrorismus, die Stabilität der Weltwirtschaft oder Umweltprobleme, die nur im Rahmen internationaler Kooperation gelöst werden könnten. Die Herkunft dieser Gefährdungen klammert Slaughter aus. Sie stellt nur fest, dass schon jetzt Netzwerke zwischen Staaten zu beobachten sind, die gemeinsame Problemlösungsstrategien entwickeln:

37 | Vgl. M. Renner, "Transnationale Wirtschaftsverfassung“; Tams, Christian J.: "Konstitutionalisierungstendenzen im Recht des internationalen Investitionsschutzes", in: Christian Tietje/Karsten Nowrot (Hg.), Verfassungsrechtliche Dimensionen des Internationalen Wirtschaftsrechts, Stuttgart u. a.: Boorberg, S. 229-251; vgl. auch die politikwissenschaftliche Beobachtung zur Reflexivierung ("Internationalized Governance has reached a reflexive stage") bei M. Zürn/M. Binder/M. Ecker-Ehrhardt, "International Authority and its Politicization ", S. 72.

38 | Vgl. D. Schneiderman, Constitutionalizing Economic Globalization, S. 37.

39 | Vgl. A.-M. Slaughter, A New World Order. 
"Terrorists, arms dealers, money launderers, drug dealers, traffickers in women and children, and the modern pirates of intellectual property all operate through global networks. So, increasingly, do governments. Networks of government officials - police investigators, financial regulators, even judges and regulators - increasingly exchange information and coordinate activity to combat global crime and address common problems on a global scale. " ${ }^{40}$

Die Beamtennetzwerke sind der Indikator für eine »disaggregierte Souveränität « ${ }^{41}$. Aufgrund der neuen Problemlagen können die Staatsfunktionen nicht mehr zentral in einem Einheitsstaat versammelt, »aggregiert« werden. Sie sind zunehmend auf Regierungsnetzwerke im globalen Maßstab verteilt, die von den jeweiligen nationalstaatlichen Regierungen mit Personal bestückt werden.

Dieser Herangehensweise entgeht das Zusammenspiel von Recht, Politik und Ökonomie, das am Weltwirtschaftsregime erkennbar ist. Im Grunde fehlt eine Theorie über den new world order, den Slaughter zum Titel ihres Buches macht. Dass Beamte Informationen institutionalisiert austauschen, ist wahrscheinlich die unspektakulärste und am wenigsten neue Entwicklungstendenz der Weltgesellschaft. Und im nächsten Schritt fällt freilich der wenig problematisierende, auf seine Weise legitimistische Zugang zu den Exekutivnetzwerken auf: Wenn nämlich eine disaggregierte Souveränität zu beobachten, mithin sogar wünschenswert ist, stellt sich die Frage, wie die Verbindung von Demokratie und Souveränität, wie sie für das Verfassungsverständnis einer zunehmend großen Anzahl von Nationalstaaten konstitutiv ist, in Regierungsnetzwerken zu konzipieren wäre. Dies führt direkt zu der Frage, wie das Prinzip der demokratischen Verfassung überhaupt noch aufrechtzuerhalten ist. Der Begriff der disaggregierten Souveränität täuscht darüber hinweg, dass Slaughter im Grunde nur eine disaggregierte Problemlösung beobachtet, die weiterhin auf einer ungebrochenen Souveränität des Nationalstaats aufbaut. Die Staaten sind sowohl der Ort demokratischer Legitimation als auch die zentralen Akteure der Problemlösungsarenen. Fraglich ist, wie aus einer solchen Perspektive die Konturen des Weltwirtschaftsregimes mit seinen eigenen Kreisläufen der Verrechtlichung und Politisierung zu berücksichtigen wären.

In ähnlicher Weise versuchen andere Überlegungen zur sogenannten Outputlegitimation die marktschaffenden Politiken inter- und transnationaler Institutionen zu technischen Entscheidungen zu erklären, die keine demokratischen Herausforderungen produzieren. Giandomenico Majone etwa hat für solche marktschaffenden Institutionen am Beispiel der EU einen eigenen Begriff geprägt. Er schlägt vor, die Kernaufgaben der EU als regulatorische Politik zu bezeichnen. Regulatorische Politik hat keine distributiven Dimensionen.

40 | Ebenda, S. 1.

41 | Ebenda, S. 134. 
Weder verteilt sie finanzielle Mittel um noch ist sie auf eigene finanzielle Ressourcen angewiesen. Sie versucht, die Effizienz von Marktmechanismen zu erhöhen und Monopolbildung, negative Externalitäten, Falschinformationen oder eine unzureichende Bereitstellung öffentlicher Güter zu beheben. ${ }^{42}$ Dabei unterstellt Majone, dass ein spezifischer Ausschnitt im Handlungsbereich von Regierungen vorliegt, der durch objektiv effizient lösbare Probleme bestimmt ist. ${ }^{43}$ Solche efficiency issues lassen sich so lösen, dass alle davon profitieren: »Efficiency issues [...] may be thought of as positive sum games where everybody can gain, provided the right solution is discovered. Hence, such issues could be settled, in principle, by unanimity. ${ }^{44}$

Als Beispiel dient Majone die Geldpolitik. Die Unabhängigkeit der Europäischen Zentralbank, die aktuell durch die faktische Dynamik der Eurokrise sowieso ins Wanken geraten ist, stelle schlicht das »best institutional arrangement « ${ }^{45}$ für die Währungspolitik dar. Daraus erwächst ein eigener Legitimationsmodus. Regierungen erhalten ihre Legitimation nicht nur aus den Wahlen. Sie versichern sich der Loyalität der Bürger auch durch die effiziente Bereitstellung kollektiver Güter. ${ }^{46}$ Ihr Herrschaftsanspruch gründet immer auch auf $»$ regulatorischer Legitimität ${ }^{47}$. Demokratische politische Verfahren, die auf dem Mehrheitsprinzip aufbauen, sind für Majone vollkommen ungeeignet, um regulatorische Legitimität herzustellen. Sie unterliegen schwankenden Mehrheitsverhältnissen, kurzen Zeithorizonten und populistischen Mobilisierungsformen, die einer effizienten Problemlösung entgegenstehen. Die Auflösung dieses Kategorienfehlers entdeckt Majone in einer Politikvariante, die er als »non-majoritarian institutions ${ }^{48}$ bezeichnet. Sie umfassen »public institutions [...] which are not directly accountable either to voters or elected officials « ${ }^{49}$. Wenn die Vermischung der politischen Regulierungstypen dazu führt, dass öffentliche Institutionen bestimmte Probleme offensichtlich nicht effizient lösen, scheint es einzuleuchten, einzelne öffentliche Institutionen von der de-

42 | Vgl. Majone, Giandomenico: Regulating Europe, London/New York: Routledge 1996, S. $28 \mathrm{ff}$.

43 | Vgl. ders.: Dilemmas of European Integration. The Ambiguities and Pitfalls of Integration by Stealth, Oxford: Oxford University Press 2005, S. 38.

44 | Ders., Regulating Europe, S. 294.

45 | Ders., Dilemmas of European Integration, S. 38.

46 | In der BRD vertritt Fritz Scharpf beispielsweise eine Variante der Outputlegitimität, die im Unterschied zu Majone stark sozialdemokratisch geprägt ist, vgl. Scharpf, Fritz W.: Regieren in Europa. Effektiv und demokratisch?, Frankfurt a. M./ New York: Campus 1999.

47 | G. Majone, Regulating Europe, S. 284.

48 | Ebenda, S. 285.

$49 \mid$ Ebenda. 
mokratischen Logik auszuklammern. Im Grunde geht er damit davon aus, dass marktschaffende Institutionen den Modus nationalstaatlicher Demokratie nicht grundlegend verändern. Darüber hinaus sind sie selbst nicht auf eigene demokratische Legitimationsbeschaffung jenseits der Delegation durch die Nationalstaaten angewiesen. Statt demokratische Defizite anzumahnen, sind die regulatorischen Agenturen für Majone gerade Ausdruck eines liberaldemokratischen Checks-and-balances-Prinzips. ${ }^{50}$ Wieder muss die Frage aufgeworfen werden, wie die Figur regulatorischer Legitimation mit dem Umstand umgeht, dass im Weltwirtschaftsregime eigene Kreisläufe der Verrechtlichung und Politisierung beobachtbar sind, die nicht in ein Delegationsverhältnis vom Typ »Prinzipal-Agent« aufzulösen sind. Man versucht hier die Transformationsprozesse einseitig von politischen Institutionen her einzufangen, ohne überhaupt eine Vorstellung zu haben, wie rechtliche, politische und ökonomische, also auch gesellschaftliche Dynamiken zur postnationalen Konstellation beitragen.

Die Schwäche der diskutierten Deutungsmuster besteht maßgeblich in ihrem alleinigen Fokus auf politischer Institutionalisierung und den damit verbundenen Delegationsproblemen. Dagegen hatte die Politik- und Rechtstheoretikerin Ingeborg Maus den Einwand erhoben, dass genau diese Sichtweise an den Problemlagen vorbeisteuert:

„Politologische Institutionenanalysen, die den Zusammenhang zwischen Rechtsstruktur und Legitimitätsproblemen ausblenden, geraten leicht in Gefahr, an der Produktion einer religion civile der rwestlichen Demokratier mitzuwirken, oder sich in kritischer Absicht mit vordergründigen Kompetenzverschiebungen, z. B. zwischen Parlament und Verwaltung, d. h. mit Fragen des 19. Jahrhunderts zu beschäftigen.." ${ }^{51}$

Die Schwäche der genannten Spielarten des politikwissenschaftlichen Institutionalismus besteht in der legitimistischen Auffassung, dass die neuen Strukturbildungen jenseits des Nationalstaats keine Folgen für das Prinzip der demokratischen Verfassung zeitigen. Die Annahme scheint zu sein, dass nationalstaatliche Verfassungsprinzipien weiterhin wirksam sind und nur mit problemlösenden Institutionen im transnationalen Raum garniert werden. Fragen nach demokratischer Legitimation und Gestaltungsspielräumen verschieben sich deshalb gerade nicht.

Demgegenüber versuchen sich andere Ansätze aus den internationalen Beziehungen in neuerer Zeit daran, den Herrschaftsbegriff auf die postnationale

50 | Ders., Dilemmas of European Integration, S. 162 ff.; so auch Keohane, Robert 0./ Macedo, Stephen/Moravscik, Andrew: "Democracy Enhancing Multilateralism", in: International Organization 63/1 (2009), S. 1-31, insbes. S. 9.

51 Maus, Ingeborg: Rechtstheorie und politische Theorie im Industriekapitalismus, München: Wilhelm Fink Verlag 1986, S. 279. 
Konstellation zu übertragen. Demnach ist die Herrschaftsausübung als »eine Struktur institutionalisierter Über- und Unterordnung« zu begreifen, »über die Lebensgüter und Einflusschancen verteilt, Alternativität und Kontingenz minimiert und Erwartungshaltungen stabilisiert werden ${ }^{52}$. Dies ist durchaus als begrifflicher Neuansatz zu werten, da die Herrschaftsausübung traditionell dem Staat zugeschrieben wurde, während die internationalen Beziehungen in der Vergangenheit vor allem Spielarten zwischenstaatlicher Kooperation in den Mittelpunkt ihres Interesses gestellt hatten. Verschiebt sich aber der Fokus von Problemlösungen in den Arenen internationaler Kooperation zu transnationaler Herrschaft, rücken gleichsam die »societal and constitutional effects of international institutions « $^{53}$ ins Blickfeld. Das wiederum erfordert eine Theorie, die nicht nur eine einfache Politisierung dieser Institutionen untersucht, sondern auch die Verrechtlichung und sozialen Dynamiken berücksichtigt und so die Möglichkeitsspielräume und Formen der Politisierung erhellt.

\title{
II. Weltgesellschaft
}

\begin{abstract}
"[D]ass Theorie heute in die Zwangslage versetzt wird, ebenso System wie Nicht-System zu sein, System insofern, als sie die Geschlossenheit der Gesellschaft [...] ausdrücken muss, auf der andern Seite aber auch Nicht-System insofern, als sich gezeigt hat, dass diese Geschlossenheit ihrerseits durch sich selbst die Antagonismen reproduziert, sich also gezeigt hat, dass diese Einheit selber in ihrer Absolutheit die Entzweiung aus sich heraus produziert ${ }^{54}$.
\end{abstract}

Die Defizite des politikwissenschaftlichen Legitimismus weisen nochmals auf den Ersetzungsbedarf hin, der aus der Auseinandersetzung mit dem Verfassungsdenken Marx' und Hegels folgte. Der transnationale Raum besteht nicht aus geschlossenen, nationalen Staaten mit angegliederten Containergesellschaften, die sodann vernetzte Politik- und Verwaltungsinstitutionen hervorbringen. Eher ist von einer Weltgesellschaft auszugehen. Zwischenzeitlich ist

52 | C. Daase/N. Deitelhoff, Zur Rekonstruktion globaler Herrschaft, S. 1.

53 | M. Zürn/M. Binder/M. Ecker-Ehrhardt, "International Authority and its Politicization", S. 72.

54 | Adorno, Theodor W.: Philosophische Elemente einer Theorie der Gesellschaft (1964), Frankfurt a. M.: Suhrkamp 2008, S. 125. 
die Rede von einer postnationalen Konstellation zu einem akademischen Passepartout geworden. ${ }^{55}$ An die Stelle des klassischen internationalen Rechtsdiskurses treten Beobachtungen eines universellen Codes der Legalität, der nicht auf die Staatenwelt begrenzt ist. ${ }^{56}$ Projekte zu den neuartigen Steuerungsarrangements der Global Governance lösen die politikwissenschaftliche Nationalstaatsforschung ab. ${ }^{57}$ An die Stelle von nationalen Sozialstrukturanalysen treten Thesen von einer »Weltkultur«, die über die Grenzen der Nationalstaaten hinweg vergleichbare Muster der Vergesellschaftung aufdecken. ${ }^{58}$ In Zeiten, in denen das Project on International Courts and Tribunals 125 unterschiedliche Gerichte und Streitschlichtungsforen zählt, eine globale Angleichung des Bildungssystems stattfindet und das Kernrecht des nationalstaatlichen Parlamentarismus, nämlich eigenständig über die Haushaltspolitik zu entscheiden, von internationalen Institutionen vereinnahmt wird, zeichnet sich ein Paradigmenwechsel ab: ${ }^{59}$ Gesellschaft ist heute immer Weltgesellschaft. Sie ist nicht nur eine internationale Gemeinschaft von Staaten, sondern auch das Feld, auf dem Individuen ihre Rechte einklagen, transnationale soziale Bewegungen protestieren, multinationale Konzerne investieren und politische Institutionen erfunden oder abgeschafft werden. Die Theorie sozialer Systeme ist schon früh davon ausgegangen, dass gesellschaftliche Kommunikationsverhältnisse nicht dauerhaft auf nationale Grenzen festzulegen sind. Noch vor der akademischen Hochkonjunktur der Globalisierungsdiskussion entdeckte Niklas Luhmann in den 1970er Jahren den Übergang in die Weltgesellschaft. ${ }^{60}$ Demnach überschreitet die Ausdifferenzierung sozialer Systeme die nationalstaatlichen Grenzen. Längst sind eine Vielzahl von Funktionssystemen zu unterscheiden, die von der

55 | Jürgen Habermas hat den Begriff der postnationalen Konstellation geprägt, vgl. ders.: Die postnationale Konstellation. Politische Essays, Frankfurt a. M.: Suhrkamp 1998.

56 | Siehe Günther, Klaus: „Rechtspluralismus und universaler Code der Legalität: Globalisierung als rechtstheoretisches Problem «, in: Lutz Wingert/ Klaus Günther (Hg.), Die Öffentlichkeit der Vernunft und die Vernunft der Öffentlichkeit. Festschrift für Jürgen Habermas, Frankfurt a. M.: Suhrkamp 2001, S. 539-567.

57 | Vgl. Buckel, Sonja/Wissel, Jens: "State Project Europe: The Transformation of the European Border Regime and the Production of Bare Life ", in: International Political Sociology 4/ 1 (2010), S. 33-49.

58 | Meyer, John W.: Weltkultur. Wie die westlichen Prinzipien die Welt durchdringen, Frankfurt a. M.: Suhrkamp 2005.

59 | Siehe http://www.pict-pcti.org (letzter Zugriff: 19.3.2013); die PISA-Studie wird zum Anhaltspunkt für die Ausübung internationaler öffentlicher Gewalt: Goldmann, Matthias: Internationale öffentliche Gewalt. Handlungsformen internationaler Institutionen im Zeitalter der Globalisierung, Heidelberg: Springer 2015, S. $521 \mathrm{ff}$.

60 | Vgl. N. Luhmann, "Die Weltgesellschaft". 
Weltwirtschaft über die Weltwissenschaft bis hin zur Weltpolitik reichen. Die Analyseperspektive wird umgestellt. Statt Einzelentscheidungen der Staatenwelt oder gerichtlicher Foren zum alleinigen Motor der Globalisierung zu erklären, stehen die Dynamiken einer transnationalisierten Selbstreferenz der unterschiedlichen Sozialsysteme im Mittelpunkt der Weltgesellschaftsdiagnose. ${ }^{61}$

So produktiv dieser Paradigmenwechsel sein mag, so führt die Systemtheorie eine offensichtliche Schwäche mit. Indem sie den Prozess funktionaler Differenzierung auf den Weltmaßstab hin verlängert, verliert sie einen Umstand aus dem Blickfeld: dass die Weltgesellschaft auch eine Hegemoniekonstellation ist. Sie bringt nicht einfach evolutionäre Universalien unvermittelt zum Ausdruck. Sie ist genauso das Resultat von umkämpften Prozessen, die dem Übergang des embedded liberalism der Nachkriegszeit zur Weltgesellschaft ihren Stempel aufdrücken. ${ }^{62}$ Die Figur einer horizontalen Ausdifferenzierung der Funktionssysteme droht ideologisch zu werden, da sie keinen Platz für die existierenden Dominanzverhältnisse bereithält. ${ }^{63}$

Zwar erfasst die Systemtheorie die zunehmend dominante Rolle des Weltwirtschaftssystems mit dem Hinweis auf die Führung kognitiver Erwartungsstile in der Weltgesellschaft. ${ }^{64}$ Damit rückt sie aber, wie noch ausführlicher zu zeigen ist, von der Annahme einer horizontalen Ausdifferenzierung ab. Auf einmal scheint eine Konstellation auf, in der einzelne Funktionssysteme ihre sozialen Umwelten beherrschen und ihnen ihre Eigengesetzlichkeiten aufzwingen. Mit der Weltgesellschaft ist somit offenbar ein Strukturwandel verbunden, der über die Ausbreitung funktionaler Differenzierung hinausgeht. Deshalb sind einige Umstellungen erforderlich, die es ermöglichen, die Welt-

61 | Das vom historischen Institutionalismus inspirierte Forschungsprogramm von Zürn et al. etwa weist zwar interessante Zusammenhänge zwischen der inter- und transnationalisierten Institutionenlandschaft der Nachkriegszeit und der Globalisierung nach, es fehlt jedoch ein Erklärungsansatz, wie die Koevolution von Staat und Ökonomie unter Gesichtspunkten systemischer Selbstreferenz zu fassen ist, vgl. Zürn, Michael/Binder, Martin/Ecker-Ehrhardt, Matthias/Radtke, Katrin: "Politische Ordnungsbildung wider Willen «, in: Zeitschrift für internationale Beziehungen 15/ 1 (2008), S. 129-164; siehe dazu mit Kritik in ähnlicher Richtung Brock, Lothar: "Zauberlehrlinge, oder: Die List der (Un-)Vernunft in den internationalen Beziehungen «, in: Zeitschrift für Internationale Beziehungen 14/ 1 (2007), S. 165-174, insbes. S. 168.

62 | Zum embedded liberalism der Nachkriegszeit: Ruggie, John G.: "International Regimes, Transactions and Change: Embedded Liberalism in the Postwar Economic Order", in: International Organization 36/2 (1982), S. 379-415.

63 | Zur Systemtheorie aus herrschaftskritischer Sicht siehe die Beiträge in: Demirovic, Alex (Hg.): Komplexität und Emanzipation. Kritische Gesellschaftstheorie und die Herausforderung der Systemtheorie, Münster: Westfälisches Dampfboot 2001.

64 | Vgl. N. Luhmann, "Die Weltgesellschaft", S. 68 ff. 
gesellschaft unter einem doppelten Gesichtspunkt lesbar zu machen, der insbesondere am Beispiel des Weltwirtschaftsregimes augenfällig bleibt: Die Weltgesellschaft ist sowohl das Terrain einer ausdifferenzierten Selbstreferenz als auch neuartiger Hegemonieverhältnisse. Doch bevor sich die Argumentation einer solchen, postmarxistisch inspirierten Umschrift der systemtheoretischen Diagnose zuwendet, gilt es erst einmal nachzuvollziehen, wo die Leistungen und Grenzen des systemtheoretischen Registers liegen. Im Folgenden soll deshalb gezeigt werden, wie die Systemtheorie den Übergang zur Weltgesellschaft ausleuchtet (1). Die Annahme horizontaler Ausdifferenzierung stößt an Grenzen. Sie macht unausgewiesene Zugeständnisse an neue Dominanzverhältnisse, die auf eine postnationale Hegemoniekonstellation schließen lassen (2). Doch theoretische Erweiterungen, die dazu dienen könnten, den umkämpften Prozessen sozialen Wandels gerecht zu werden, bleiben mit der Absage an herrschaftssoziologische Überlegungen leider verstellt. Die Angst vor der »wissenschaftsimmanent erzeugten Politisierung ${ }{ }^{65}$ der Sozialwissenschaften, die Luhmann zufolge im Herrschaftsbegriff angelegt ist, schmälert hier die analytische Kraft (3). Indem sie an immanente Grenzen stößt, wird es zunehmend notwendig, die systemtheoretische Perspektive zu öffnen und mit Überlegungen kritischer Theorie zu verbinden (4). Der Durchgang stellt das Potential des systemtheoretischen Zugriffs heraus, macht aber genauso auf seine blinden Flecken aufmerksam. Sie sollen in den folgenden Argumentationsschritten eingeholt werden, um schließlich die globale Verfassungsfrage angemessen bearbeiten zu können.

\section{Dominanz kognitiver Erwartungsstile}

Funktionale Differenzierung macht nicht vor den Grenzen der Nationalstaaten oder Regionen halt. Schon längst befinden wir uns am Übergang zur Weltgesellschaft - das ist die provokante Annahme Luhmanns, die er lange vor dem Aufkommen der zeitgenössischen Globalisierungsdebatte platziert: »[A]ls Resultat von Evolution gibt es schließlich nur noch eine Gesellschaft: die Weltgesellschaft, die alle Kommunikationen und nichts anderes in sich einschließt und dadurch völlig eindeutige Grenzen hat ${ }^{66}$. Demzufolge setzt sich die evolutionäre Dominanz der funktionalen Differenzierung zunehmend auch im Weltmaßstab durch. Funktionale Differenzierung bedeutet, dass soziale Systeme entstehen, die ihre Selbstreferenz über funktionsspezifische Codes her-

65 | Ders.: "Systemtheoretische Argumentationen. Eine Entgegnung auf Jürgen Habermas", in: Jürgen Habermas / Niklas Luhmann, Theorie der Gesellschaft oder Sozialtechnologie, Frankfurt a. M.: Suhrkamp 1971, S. 291-405, hier S. 399.

66 | Ders.: Soziale Systeme. Grundriß einer allgemeinen Theorie, Frankfurt a. M.: Suhrkamp 1984, S. 557. 
stellen. ${ }^{67}$ Sie kultivieren je eigene Mechanismen der Selbstreproduktion (Autopoiesis), die sich auf ihre jeweiligen Rationalitäten stützen. ${ }^{68}$ Die moderne Gesellschaft ist nicht mehr nach fest gefügten Segmenten geordnet. Sie dynamisiert die Ausdifferenzierung unterschiedlicher Funktionssysteme wie Wirtschaft, Politik, Wissenschaft und Religion.

Im Gegensatz zu Überlegungen aus den politikwissenschaftlichen internationalen Beziehungen offenbaren so anders gelagerte und teilweise niedrigschwelligere Indizien ihren exemplarischen Charakter für die Weltgesellschaft. In seinem paradigmatischen Aufsatz zur »Weltgesellschaft« beobachtet Luhmann, dass sich »weltweite Interaktion konsolidiert $\ll^{69}$ habe. Darunter versteht er nicht in erster Linie die internationale Politik und Diplomatie. Für seine Weltgesellschaftsannahme ist das internationale Staatensystem gerade nicht das Zentrum der Welt. ${ }^{70}$ Entscheidendes Indiz ist ein im Entstehen begriffener »Welthorizont«, in dessen Licht wir uns beobachten und unsere Erwartungshaltungen bestimmen. ${ }^{71}$ Beispiele dafür sind entgrenzte Sozialkontakte, das »Anwachsen von Wissen ${ }^{72}$ und die emotive Teilnahme an Entwicklungen in anderen Regionen der Welt. All dies führt zum Diktum, dass Gesellschaftstheorie heute nur »Theorie der Weltgesellschaft« sein könne. ${ }^{73}$ Damals waren noch keine virtuellen sozialen Netzwerke en vogue, doch selbst bei Kommunikationen, die auf den Nationalstaat gerichtet sind, gilt demnach, dass immer »Kommunikationsmöglichkeiten vorausgesetzt und immer symbolische Medien verwendet « werden, »die sich nicht auf regionale Grenzen festlegen lassen « ${ }^{74}$.

Dabei ist von Beginn an das Problem präsent, dass die Logik funktionaler Differenzierung nicht zwangsläufig in harmonische Angleichungsprozesse mündet. Es handelt sich ausdrücklich nicht um eine Perspektive, die unterstellt, »dass regionale Unterschiede allmählich verschwinden würden

67 | Vgl. ebenda, S. 31.

68 | Vgl. ebenda, S. 60 ff.

69 | Ders., "Die Weltgesellschaft", S. 66.

70 | Helmut Willke ist aus systemtheoretischer Perspektive skeptischer: Er ist der Auffassung, dass die Weltgesellschaft auf eine noch nicht vorhandene "brauchbare politische Strukturbildung" verwiesen wäre, vgl. Willke, Helmut: Politische Strukturbildung der Weltgesellschaft. Symbolordnung und Eigenlogik lateraler Weltsysteme, in: Mathias Albert/Rudolf Stichweh, Weltstaat und Weltstaatlichkeit. Beobachtungen globaler Strukturbildung, Wiesbaden: VS-Verlag 2007, S. 133-156, hier S. 138, siehe auch ders.: Atopia. Studien zur atopischen Gesellschaft, Frankfurt a. M.: Suhrkamp 2001, S. $107 \mathrm{ff}$.

71 | N. Luhmann, "Die Weltgesellschaft", S. 68.

72 | Ebenda, S. 66.

73 | Ebenda, S. 76.

74 | Ders.: Die Gesellschaft der Gesellschaft I, Frankfurt a. M.: Suhrkamp 1998, S. 150. 
(Konvergenzthese) «5 $^{75}$. Dass globale Ungleichheiten und Fragmentierungen überhaupt beobachtet werden können, ist sogar als Argument für die Weltgesellschaft zu werten. Schließlich ist die Beobachtung von Ungleichheit und Differenz an eine hintergründige Erwartungshaltung über gemeinsame Bezugspunkte gebunden. Erst sie ermöglicht es, Ungleichheiten überhaupt als Ungleichheiten (und beispielsweise nicht als »Völkervielfalt $\aleph^{76}$ ) zu kennzeichnen.

In einem nächsten Schritt erhält die Weltgesellschaftsannahme eine qualitative Wendung. Die evolutionäre Fortsetzung einer schon im nationalstaatlichen Rahmen vorherrschenden Differenzierungsform geht mit neuen Entwicklungslinien einher. Im Mittelpunkt steht die Beobachtung eines Führungswechsels in den Erwartungsstrukturen. Im Übergang zur Weltgesellschaft fällt »ein deutliches Vorherrschen kognitiver, adaptiver, lernbereiter Erwartungen« auf, »während normative, Moral prätendierende und vorschreibende Erwartungen zurücktreten ${ }^{77}$. Kognitive Erwartungshaltungen sind insbesondere in Funktionssystemen der »Wirtschaft, Wissenschaft und Technik « am Werk. ${ }^{78}$ Ihr Gegenmodell, die normativen Erwartungsstile - etwa der Politik, des Rechts oder der Religion -, scheint im Übergang zur Weltgesellschaft ins Hintertreffen zu geraten. Mit den flexiblen, kognitiven Erwartungsstrukturen können sie nicht mithalten. ${ }^{79}$ Dies führt direkt zu Luhmanns dunkler Prognose, die den modernen Verfassungsstaat zu einem rein episodischen Vorgang erklärt, dessen deutlich normativer Erwartungsstil für die ausdifferenzierten globalen Ordnungsmuster eventuell nicht mehr geeignet ist. Er argwöhnt, die Zentralstellung des Rechts im demokratischen Verfassungsstaat sei eventuell »nichts weiter ist als eine europäische Anomalie, die sich in der Evolution der Weltgesellschaft abschwächen wird ${ }^{80}$. War für die historische Entwicklungsphase des Nationalstaats die starke Rolle normativer Erwartungsstrukturen prägend, so ist das »evolutionär vollkommen neuartige Phänomen der Weltgesellschaft« durch eine »Verlagerung des evolutionären und funktionalen Primats auf andere Teilsysteme und Mechanismen der Gesellschaft « bestimmt. ${ }^{81}$

75 | Ebenda, S. 161.

76 | Ebenda, S. 162.

77 | Ders., "Die Weltgesellschaft", S. 68.

78 | Ebenda, S. 72.

79 | Luhmann räumt ein, dass beide Erwartungstypen in "einem eigentümlich komplizierten Verhältnis" (ebenda, S. 69) gegenseitiger Spannung und Abhängigkeit stehen. Das hält inn nicht davon ab, Teilsysteme dahingehend zu unterscheiden, welcher Erwartungstyp dominant ist.

80 | Ders., Das Recht der Gesellschaft, S. 586.

81 | N. Luhmann, "Die Weltgesellschaft", S. $71 \mathrm{f}$. 
Dies ist der Punkt, an dem der Erklärungsansatz einer horizontalen und gleichrangigen Ausdifferenzierung brüchig wird. Im Prozess funktionaler Differenzierung scheinen einzelne Teilsysteme $z u$ »führen «, während andere zurückbleiben. Im Übergang zur Weltgesellschaft erhalten Funktionssysteme eine führende Rolle, die einem kognitiven Erwartungsstil folgen. Sie zeigen sich lernbereiter und funktional gefügiger. In Verbindung mit dem evolutionstheoretischen Herangehen taucht eine massive Schwierigkeit auf. Die Dominanz des Weltwirtschaftssystems wird auf einmal von einer beobachtbaren Realität ins Licht einer evolutionären Notwendigkeit gerückt. ${ }^{82}$ Der Gegensatz von enttäuschungsresistenten Erwartungsstilen und lernbereiten, anpassungsfähigen Stilen ruft mindestens einen triftigen Einwand hervor. Vielleicht hängt das anpassende, lernbereite Erwarten tatsächlich mit der inneren Logik einzelner sozialer Teilsysteme zusammen. Es müsste zumindest gefragt werden, wie sich Erwartungsstile und ihre Dominanz überhaupt herstellen. Dass sich im Wirtschaftssystem anpassungswillige Erwartungshaltungen durchsetzen, hängt mitunter auch davon ab, dass den Teilnehmern am kapitalistischen Markt schlicht keine andere Möglichkeit bleibt, um Pleiten, Arbeitslosigkeit und Ausschluss zu verhindern. Dann sind es nämlich weniger die Segnungen solcher evolutionärer Errungenschaften. Der »stumme Zwang der ökonomischen Verhältnisse « ${ }^{83}$ ist es, den Luhmann mit Lernbereitschaft identifiziert. Der Führungswechsel von Recht und Politik zu Wirtschaft und Wissenschaft wäre nichts anderes als die gewachsene Dominanz eines kapitalistischen Wirtschaftssystems, von Wissenschaft und Technik und einer - um diesen Begriff Max Horkheimers aufzunehmen - instrumentellen (strategisch-kalkulierenden und deshalb stets lernbereiten) Vernunft. ${ }^{84}$ Wie es zu diesem Führungswechsel kommen konnte, welche Kämpfe und Konflikte dazu geführt haben, auf all diese Fragen sozialen Wandels kann die Beobachtung evolutionärer Ausdifferenzierung allein noch keine Antwort geben. Hier stößt die Systemtheorie an ihre Grenzen.

\section{Inklusion/Exklusion als Leitdifferenz}

Mit Luhmanns vereinzelten Einlassungen zum Problem der Exklusion scheint eine weitere, zweite Spur vorzuliegen, die qualitative Veränderungen im Über-

82 Bachur entdeckt eine Reihe von gegenseitigen Anschlüssen bei Marx und Luhmann: Bachur, Joao Paulo: Kapitalismus und funktionale Differenzierung, Baden-Baden: Nomos 2013, S. $26 \mathrm{ff}$.

83 | Marx, Karl: "Das Kapital“ (1864), in: ders. /Engels, Friedrich, Werke. Band 23, Berlin: Dietz 1972, S. 765.

84 | Vgl. Horkheimer, Max: Zur Kritik der instrumentellen Vernunft, Frankfurt a. M.: Fischer-Verlag 1967. 
gang zur Weltgesellschaft beleuchtet. Die jüngere sozialwissenschaftliche Diskussion hat sie dankbar aufgegriffen und weiterentwickelt. ${ }^{85}$ Ist doch eventuell der Ort eines Exklusionsbereichs, der vollständig von den Chancen anschlussfähiger Kommunikation ausgeschlossen ist, mit der Möglichkeit verbunden ein radikales Außen der systemischen Selbstreferenz denkbar zu machen, das wiederum auf ihre Instabilität verweist. ${ }^{86}$ Jedenfalls lässt sich die Unterscheidung Inklusion/Exklusion nicht nonchalant in das Muster einer glatten, evolutionären Ausdifferenzierung einpassen. Insbesondere in seinem Spätwerk ist Luhmann sogar so weit gegangen, der Unterscheidung Inklusion/Exklusion eine strukturbildende Funktion zuzuweisen. ${ }^{87}$ Bei der Beschäftigung mit Transformations- und Entwicklungsländern fällt ihm auf, dass sich der Code Inklusion/Exklusion vielleicht als »Supercode ${ }^{88}$ erweisen könnte, der den Prozess funktionaler Differenzierung als Leitdifferenz überlagert:

"Die Gegenwahrscheinlichkeit ist also ebenfalls groß, und es liegt nicht fern, wie Untersuchungen aus Ländern im Modernisierungsprozess belegen, dass unter diesen Umständen eine kaum noch überbrückbare Kluft zwischen Inklusionsbereich und Exklusionsbereich aufreißt und dazu tendiert, die Funktion einer Primärdifferenzierung des Gesellschaftssystems zu übernehmen." ${ }^{89}$

Diese Überlegungen sind insofern irritierend, als dass hier die sakrosankte Logik funktionaler Differenzierung zur Disposition steht. Die Unterscheidung Inklusion/Exklusion wird zur Primärdifferenzierung erhoben, die alle anderen Codes mediatisiert und sich »vor die Differenzierung in Funktionssystemen schiebt ${ }^{90}$. Ist Luhmann eventuell doch »ein echter Romantiker gewesen, der gelungene Vergesellschaftung unmerklich an erheblich höherstufige In-

85 | Vgl. nur den Sonderband der Zeitschrift "Soziale Systeme": Farzin, Sina/Opitz, Sven/Stäheli, Urs (Hg.): Theorien der Inklusion/Exklusion: Rhetorik - Körper - Macht (= Soziale Systeme 14/2), Stuttgart: Lucius \& Lucius 2008.

86 | Vgl. die dekonstruktive Rekonstruktion im Hinblick auf das Weltrecht bei Opitz, Sven: An der Grenze des Rechts. Inklusion/Exklusion in Zeiten der Sicherheit, Weilerswist: Velbrück 2012, insbes. S. $129 \mathrm{ff}$.

87 | Vgl. Luhmann, Niklas: "Inklusion und Exklusion“ (1995), in: ders., Soziologische Aufklärung 6. Die Soziologie und der Mensch, Wiesbaden: VS-Verlag 2008, S. 226-251.

88 | Ebenda, S. 243; siehe auch ders., Das Recht der Gesellschaft, S. 582; als "Leitdifferenz": ders.: "Jenseits der Barbarei“, in: ders., Gesellschaftsstruktur und Semantik. Studien zur Wissenssoziologie der modernen Gesellschaft, Frankfurt a. M.: Suhrkamp 1999, S. 138-150, hier S. 147.

89 | N. Luhmann, "Inklusion und Exklusion", S. 235.

90 | Stichweh, Rudolf: Die Weltgesellschaft. Soziologische Analysen, Frankfurt a. M.: Suhrkamp 2000, S. 79. 
klusionssicherheiten band « ${ }^{91}$ ? Oder führt der Metacode Inklusion/Exklusion im Gegenteil zu »einem Konzept, das den eigenen theoretischen Vorannahmen widerspricht $\ll^{92}$ ?

Wieder taucht eine Beobachtung auf, die nicht einfach in die funktionale Differenzierung einzupassen ist. Eigentlich regeln die ausdifferenzierten Teilsysteme selbst, wen sie ein- oder ausschließen. Sie sind als »Kommunikationszusammenhänge « darstellbar , die »Menschen bezeichnen ${ }^{93}$ und sie auf diesem Wege inkludieren. Die Folge ist der Abschied von einer Einheitskonzeption des Subjekts. Der Prozess funktionaler Differenzierung zerlegt es in unterschiedliche Kontexte. Die Teilsysteme erkennen immer nur spezifische Personenrollen in ihren Kommunikationskreisläufen an. Individuen sind Marktteilnehmer, Käufer, Verbraucher, Gesunde, Kranke oder Wähler, die jeweils nur hinsichtlich ihrer Inklusion in ein gesellschaftliches Subsystem zu Personen werden. Somit lässt sich das Individuum nur sinnvoll als Knotenpunkt unterschiedlicher Personenrollen in den jeweiligen sozialen Teilsystemen erfassen.

Deshalb ist das Verhältnis von Inklusion und Exklusion nicht weiter problematisch. Tatsächlich arbeitet jedes gesellschaftliche Teilsystem mit Unterscheidungen und schließt Kommunikationsakte (in diesem Fall Menschen) ein oder eben nicht. Die Ausdifferenzierung der Teilsysteme des modernen Wohlfahrtsstaats, den Luhmann vor Augen hat, birgt geradezu exklusionsschonende Dimensionen. Man ist kurzzeitig ausgeschlossen und findet schnell im jeweiligen Teilsystem wieder Anschluss. Oder man ist nur von einzelnen Funktionssystemen exkludiert, von anderen wiederum nicht. Die moderne Gesellschaft macht es möglich. Man kann arbeitslos sein und gleichzeitig Marktteilnehmer, Familienvater und Vorsitzender im Kegelverein. Die Annahme allgegenwärtiger Inklusionschancen bricht allerdings an den Verhältnissen in Slums und Favelas, die für Luhmann als Beispiel für eine Totalexklusion der Individuen aus allen gesellschaftlichen Teilsystemen dienen. Dort verketten sich nämlich Exklusionseffekte der Teilsysteme so, dass der Ausschluss in einem Teilsystem in den Ausschluss aus anderen Teilsystemen mündet: »Wer keine Papiere hat, kann nicht heiraten, kann keine Sozialleistungen beantragen. ${ }^{94}$ Das Resultat ist eine Totalexklusion der Individuen, die einen gesellschaftlichen Ex-

91 | Nassehi, Armin: "Inklusion, Exklusion, Ungleichheit", in: Thomas Schwinn (Hg.), Differenzierung und soziale Ungleichheit. Die zwei Soziologien und ihre Verknüpfung, Frankfurt a. M.: Humanities Online 2004, S. 323-352, hier S. 332. Vgl. dagegen Luhmann kritisch zur Vollinklusion als "Idealisierung": ders.: Die Gesellschaft der Gesellschaft II, Frankfurt a. M.: Suhrkamp 1998, S. 630.

92 | Farzin, Sina: Inklusion und Exklusion. Entwicklungen und Probleme einer systemtheoretischen Unterscheidung, Bielefeld: transcript 2006, S. 111.

93 | N. Luhmann, "Inklusion und Exklusion", S. 229.

94 | Ders., Das Recht der Gesellschaft, S. 584. 
klusionsbereich hervorrufen. Denn »während im Inklusionsbereich Menschen als Personen zählen, scheint es im Exklusionsbereich fast nur auf ihre Körper anzukommen ${ }^{95}$. Die irritierende These lautet: In der Weltgesellschaft liegen Tendenzen dafür vor, dass Individuen systematisch nicht einmal mehr als Personen berücksichtigt werden. Auf ihren Körper reduziert markieren sie einen Exklusionsbereich. Die Drastik dieser Mechanismen hat zur Folge, dass dieser extreme Ausschluss die Rolle einer Primärdifferenzierung erhält, um die ein integrierter Exklusionsbereich gruppiert ist. ${ }^{96}$

Mit dem Metacode Inklusion/Exklusion gebiert die Weltgesellschaft einen Primärcode, der die evolutionäre Logik der funktionalen Differenzierung durchkreuzt. Es ist mitunter durchaus fraglich, inwieweit die Unterscheidung Inklusion/Exklusion auch die Systemtheorie selbst überführt und ihren theoretischen Rahmen sprengt. ${ }^{97}$ Die Diagnose geht davon aus, dass sich in der Weltgesellschaft ein neuer Primärcode seinen Weg bahnt, der Zonen der Totalexklusion produziert und die funktionale Differenzierung überlagert. Die Reduktion von Personengruppen auf den Körper, auf - um einen Begriff des Philosophen Giorgio Agamben zu bemühen - das »nackte Leben« würde so zu einem strukturbildenden Signum weltgesellschaftlicher Ordnungsbildung werden. ${ }^{98} \mathrm{Da}$ für ist jedoch ein Ansatz erforderlich, der zeigen kann, wie sich der neue Pri-

95 | Ders., Die Gesellschaft der Gesellschaft II, S. 632.

96 | Luhmann zeigt, dass Nachbarschafts- und Familiennetzwerke entstehen, die ein Mindestmaß an gesellschaftlicher Teilhabe gewährleisten, dabei aber den Code legal/ illegal des Rechtssystems unterlaufen. Zwar existiere das Recht weiterhin, gleichsam habe für "exkludierte Bevölkerungsgruppen" die Unterscheidung Recht/Unrecht eine "geringe Bedeutung im Vergleich zu dem, was ihre Exklusion innen auferlegt" (ders., Das Recht der Gesellschaft, S. 58).

97 | So argumentiert Ruda, Frank: "Alles verpöbelt sich zusehends! Namenlosigkeit und generische Inklusion «, in: Soziale Systeme 14 / 2 (2008), S. 210-228. Luhmann legt über diesen theoriesubversiven Charakter der Exklusionsthese keine Rechenschaft ab zumal die Exklusionszonen in seinen Überlegungen wechseln. Einmal steht die Situation der Entwicklungsländer im Vordergrund, dann die Netzwerke der Exkludierten oder aber die Großthese einer neuartigen Differenzierungsform der Weltgesellschaft (siehe ders., "Inklusion und Exklusion “, S. 235; ders., Das Recht der Gesellschaft, S. 585; ders., Die Gesellschaft der Gesellschaft II, S. 618 ff.; ders.: "Kausalität im Süden“, in: Soziale Systeme $1 / 1$ (1995), S. 7-28). Handelt es sich bei Inklusion/Exklusion um punktuelle Übergangsphänomene, um Beobachtungen zur Transformation des globalen Südens oder um eine neue Primärdifferenzierung der Weltgesellschaft?

98 | Zum "nackten Leben «: Agamben, Giorgio: Homo Sacer. Die souveräne Macht und das nackte Leben, Frankfurt a. M.: Suhrkamp 2002. Zu den Parallelen von Luhmann und Agamben: Opitz, Sven: "Ausnahme mit System. Giorgio Agamben und Niklas Luhmann an der Grenze zum Anderen des Rechts", in: Kritische Justiz 44 / 4 (2010), S. 436-449. 
märcode verallgemeinert. Wenn er schon als Teil der Weltgesellschaft für das Ganze der Weltgesellschaft steht, dann ist die funktionale Differenzierung ruiniert. Die Rede von einem Metacode legt eine Hierarchisierung der Unterscheidungsmuster nahe, die der Annahme funktionaler Differenzierung eigentlich vollkommen entgegenläuft. In die Heterarchie der Systeme schleicht sich auf diesem Wege eine Semantik ein, die mit oben/unten bzw. Teil/Ganzes-Anordnungen arbeitet: Inklusion/Exklusion als Primärcode (Ganzes) vs. Rechtscode (Teil); Totalexklusion der Individuen (unten) vs. hochdifferenzierte Teilsysteme (oben), Negativverfassung (Körper, Kriminalität, Netzwerke - unten) vs. Positivverfassung (qualifiziertes Leben, nichtmediatisiertes Funktionieren der Codestruktur, funktionale Differenzierung - oben).

Erst recht ruft die Unterscheidung Inklusion/Exklusion einen Revisionsbedarf hervor, wenn sie nicht nur das Wechselspiel ihrer extremen Ausprägungen erfasst. ${ }^{99}$ Hier rücken nicht nur die Extremvarianten ins Blickfeld, sondern gleichsam die Übergänge von Inklusion zu Exklusion. Mit dem Metacode Inklusion/Exklusion ist ein Prozess vorzustellen, der sich zwischen zwei Polen bewegt: einerseits die Inklusion des Individuums in die unterschiedlichen Teilsysteme, andererseits die Reduktion auf den Körper in den Exklusionsbereichen der Weltgesellschaft. Nun wird man auch den Blick darauf richten müssen, was sich zwischen diesen beiden Extrempolen abspielt, um die Kette von Ein- oder Ausschlüssen zu rekonstruieren, die letztlich in Vollinklusion oder Totalexklusion münden. Damit werden partiale Ausschlüsse problematisch, die stets den Ausgangspunkt für eine Kette bilden können, an deren Ende eine Totalexklusion steht. So rücken Fragestellungen ins Blickfeld, die jenseits eines einfachen Innen oder Außen angesiedelt sind: Auf welche Art und Weise finden Auf- und Abqualifizierungsprozesse des Lebens statt? Wie ist die Hierarchie der Teilsysteme untereinander beschaffen? Unter diesem Gesichtspunkt droht für den beobachtenden Stil der Systemtheorie die Gefahr, dass jede Exklusion problematisierungswürdig erscheint und sich Normativitäten einschleichen, die am Maßstab einer Vollinklusion orientiert sind. Luhmann hat sie als ideologische und dysfunktionale Utopie scharf attackiert: »Die Idealisierung des Postulats einer Vollinklusion aller Menschen in die Gesellschaft täuscht über gravierende Probleme hinweg. $\ll^{100}$

In diesem Sinne kann festgehalten werden, dass die Weltgesellschaft nicht allein durch den Verweis auf eine funktionale Ausdifferenzierung lesbar wird. Sowohl bei der Dominanz kognitiver Erwartungsstile als auch bei den Beobachtungen zu Inklusion/Exklusion stößt die Systemtheorie an die Grenzen ihres ei-

99 | Vgl. dazu Castel, Robert: Die Metamorphosen der sozialen Frage. Eine Chronik der Lohnarbeit, Konstanz: UVK 2000. Castel verwendet hier auch konsequent den Begriff der "Entkoppelung" und nicht der Exklusion.

100 | N. Luhmann, Die Gesellschaft der Gesellschaft II, S. 630. 
genen Registers. Probleme der Über- und Unterordnung brechen jeweils in die Systemtheorie der Weltgesellschaft ein. »Einbrechen« ist deshalb eine naheliegende Beschreibung, weil die Systemtheorie keinen originären Platz für die Dominanz der kapitalistischen Wirtschaft oder für die Übercodierung durch Ausschlussmechanismen bereithält. Im Gegenteil versucht sich Luhmann der Herrschaftssemantik mit einer Kritik an der alteuropäischen Soziologie zu entledigen.

\section{Das Herrschaftsproblem}

Es ist deutlich geworden, dass die Systemtheorie der Weltgesellschaft etwas beobachtet, das ihr begriffliches Register massiv herausfordert. Die nötigen Erweiterungsschritte, um diese Phänomenbereiche aussichtsreich auszuleuchten, bleiben versperrt. Luhmann hatte nämlich mit seiner Kritik an der alteuropäischen Soziologie einen Weg eingeschlagen, der Kategorien der Herrschaft, der Dominanz oder der Hegemonie in den Wirkungskreis veralteter Metaphysik verweist. Das zentrale Thema der Soziologie in der Tradition von Karl Marx und Max Weber - die Herausbildung politischer, ökonomischer und kultureller Herrschaft in modernen Gesellschaften - wird zu einer fragwürdigen Prioritätensetzung. ${ }^{101}$ Schon in seiner Kontroverse mit Jürgen Habermas erschien Luhmann die Herrschaftskategorie »für analytische ebenso wie für kritische Zwecke ungeeignet ${ }^{102}$. In der modernen Herrschaftssoziologie entdeckt er die Spuren eines »agrargeschichtlichen Begriffs«, »der mit der Leistungsgesellschaft nicht zusammenpasst ${ }^{103}$. Unversöhnlich positioniert er seinen »neu-europäischen « Beschreibungsmodus gegen »alt-europäisches « Denken. ${ }^{104}$

Das Problem der Herrschaft wird zu einem exemplarischen Fall, an dem eine Art Ideologiekritik vorgeführt wird. Die Annahme ist dabei, dass historisch Selbstbeobachtungen entstanden sind, die von der Ontologie und Metaphysik der Antike und des Mittelalters bis hin zu den Vertragstheorien der bürgerlichen Gesellschaft reichen. Sie sind durch ein doppeltes Merkmal geprägt: Einerseits reflektieren sie die jeweils vorherrschenden gesellschaftlichen Differenzierungsformen ihrer Zeit, ohne eine systemtheoretische Aufklärung ihrer Annahmen vorzunehmen. Ihre Semantiken reichen vom gerechten Gemein-

101 | Vgl. ebenda, S. 919 ff., zu der hier angesprochenen "herrschaftssoziologischen Tradition", die die Herausbildung moderner Herrschaft durch eine verselbstständigte Rationalisierung zum Gegenstand hat, vgl. Habermas, Jürgen: Theorie des kommunikativen HandeIns I, Frankfurt a. M.: Suhrkamp 1984, S. 225.

102 | N. Luhmann, "Systemtheoretische Argumentationen ", S. 399.

103 | Ebenda, S. 400.

104 | Vgl. ders., Die Gesellschaft der Gesellschaft II, S. 893 ff., insbes. S. 912 ff.; ders.: Die Politik der Gesellschaft, Frankfurt a. M.: Suhrkamp 2000, S. 327 ff. 
wesen über die göttliche Ordnung bis hin zur Klassengesellschaft - nur eine Ausdeutung der jeweiligen gesellschaftlichen Verhältnisse als Systemdifferenzierung findet nicht statt. Durch diesen Umstand sinkt ihr Erklärungswert. Die mangelnde systemtheoretische Aufklärung verstellt den klaren Blick auf die gesellschaftlichen Verhältnisse. Andererseits knüpfen die alteuropäischen Deutungsmuster aneinander an. Über Jahrhunderte modulieren sie ähnliche Problemkreise. Sie unterstellen ein vorgängiges Wesen des Menschen und erschließen den Zugang zum Gemeinwesen über die Unterscheidung Teil/Ganzes. ${ }^{105}$ In diesem Zusammenhang tritt die Kategorie der Herrschaft bzw. des Herrschens auf, wenn einzelne Teile über das Ganze erhoben sind:

"Es gibt immer schon obere und untere Teile, Adel und Volk, und in den Hausordnungen unabhängige und abhängige Teile. Die Interpretation dieser Differenz als 'Herrschaft, versteht sich zwar nicht von selbst, aber sie wird im Griechischen durch das Wort arché, árchein erleichtert, das sowohl Ursprung als auch leitendes Prinzip als auch Herrschaft/Herrschen bedeuten kann. "106

Der Herrschaftsbegriff kommt ins Spiel, wenn die »Unterscheidung oben/unten, also durch einen Hinweis auf Hierarchie, ergänzt und interpretiert « ${ }^{107}$ wird. Dann stellt sich die Frage, welche Teile oben stehen oder unten stehen, welche Teile »regieren « und welche »regiert« werden, welche Teile Pars pro Toto stehen und welche nicht. Das »Herrschaftstheorem « ist so zu bestimmen, dass »im Ganzen Teile« dafür »zuständig sind«, immer wieder die »Differenz des Ganzen und seiner Teile « aufrechtzuerhalten. ${ }^{108}$

Damit wird die Selbstbeschreibung der alteuropäischen Gesellschaft, die von einer Unterscheidung des Ganzen und seiner Teile geprägt ist, ${ }^{109} \mathrm{zu}$ einem falschem Bewusstsein. Der divisionale Modus führt dazu, dass die Gesellschaft fälschlicherweise auf ein Einheitsprinzip zurückgeführt wird. Entweder entäußern sich die Teile der Gesellschaft aus einer vorgängigen Einheit oder die Teile der Gesellschaft sollen sich in der Zukunft wieder zu einer Ganzheit zusammenfügen. Mit der Unterscheidung von Teil/Ganzes ist das unterschwellige Movens identifiziert, das es erlaubt, Herrschaftskritik und Herrschaftslegitimation zu einem letztlich ideologischen Filter zu erheben: Aristoteles, Hobbes, Marx, Habermas, Robespierre und Ludwig XIV. gehen hier eine uneingestandene Komplizenschaft ein, indem sie eine entweder politisch oder ökonomisch verwurzelte Einheit der Herrschaftsverhältnisse unterstellen. Luhmann führt

105 | Vgl. ebenda.

106 | Ebenda, S. 327.

107 | Ders., Die Gesellschaft der Gesellschaft II, S. 919.

108 | Ders., Die Politik der Gesellschaft, S. 329.

109 | Vgl. ders., Die Gesellschaft der Gesellschaft II, S. 918. 
eine Ideologiekritik vor, in der politische Philosophie und Theologie gemeinsam eine soziologische Aufklärung der modernen Gesellschaft unterlaufen. Dies gilt insbesondere auch für die moderne Herrschaftssoziologie, die selbst unter Bedingungen funktionaler Differenzierung an diesem »agrargeschichtlichen « Begriff festhält. ${ }^{110}$ Deshalb erscheint eine Perspektive geboten, die auf hintergründige Einheitsannahmen und divisionale Semantiken weitgehend verzichtet. In der funktional ausdifferenzierten Gesellschaft liegen keine Überoder Unterordnungsverhältnisse vor, nur noch rekursive strange loops. ${ }^{111}$

Die Herrschaftsphänomene der Weltgesellschaft lassen sich aber nicht einfach verdrängen. Als Exklusionsbereich oder als Führungswechsel schlagen sie, wie wir gesehen hatten, zurück: »Es ist, als bemerke Luhmann, dass auch die Systemtheorie ein Unbewusstes hat; das, was sie ausschließt, holt sie ein. Der Blick auf die Exklusion gleicht einem Blick in den Abgrund der eigenen Konstitutionsbedingungen. «112 Die Weltgesellschaft wird von Über- und Unterordnungen und neuen Leitdifferenzen heimgesucht, die über die Szenerie einer glatten und in normativer Hinsicht unproblematischen Evolution der Funktionssysteme hineinbrechen. Die Stärke der Systemtheorie besteht wohl darin, dass sie die Probleme überhaupt sieht. Die orthodoxe Variante der Systemtheorie hat jedoch den Herrschaftsbegriff derart aus dem eigenen Entwurf eskamotiert, dass sie Prozesse der Über- und Unterordnung nicht wirklich sinnvoll erklären kann.

Demnach sind die Grenzen der systemtheoretischen Weltgesellschaftsdiagnose auf drei Ebenen angesiedelt. Erstens neigt sie zu einer Reifizierung der sozialen Systeme. Die funktionale Differenzierung avanciert zum »verborgenen Gott« der Weltgesellschaft. ${ }^{113}$ Die sozialen Systeme werden selbst nicht mehr

110 | Siehe z.B. die Kritik an Theorien der Klassenherrschaft bei Luhmann: ebenda, S. 631.

111 | Ders., Die Politik der Gesellschaft, S. 264.

112 | F. Ruda, "Alles verpöbelt sich zusehends", S. 224.

113 | Im Grunde handelt sich die Systemtheorie eine Problemlage ein, die aus dem Marxismus bekannt ist. Marx hatte in seiner politischen Ökonomie die selbstreferentielle Struktur der kapitalistischen Wirtschaftsweise aufgedeckt. Mit der Zentralstellung der ökonomischen Selbstreferenz ist dieses Motiv in der marxistischen Diskussion unter dem Gesichtspunkt einer vorgängigen ökonomischen Basis interpretiert worden, die den politisch-ideologischen Überbau einseitig determiniert. In dieser reifizierenden Lesart der Marx'schen Ökonomiekritik erscheint die ökonomische Selbstreferenz nicht mehr als gesellschaftliches (und damit auch veränderbares) Verhältnis, sondern als "Ding", das den Weltlauf determiniert: Die Kritik an der Verdinglichung der gesellschaftlichen Verhältnisse mündet dann, wenn die Verdinglichung nicht mehr als geronnene soziale Praxis erscheint, selbst in den Bann der Verdinglichung, indem sie die Produktivkraftentwicklung zum "verborgenen Gott" fetischisiert (siehe etwa Gramscis Kritik am 
in soziale Praxis aufgelöst, sondern schon immer als vorgängig konstituiert angenommen. Zweitens ist sie durch eine Herrschaftsvergessenheit geprägt, die Dominanzverhältnisse der Weltgesellschaft beobachtet, ohne sie systematisch ausweisen zu können. Drittens schließlich führt die evolutorische Perspektive dazu, dass soziale Konflikte der funktionalen Differenzierung nachgeordnet werden. Die maßgeblichen Konflikte und Prozesse sozialen Wandels kommen in der orthodoxen Weltgesellschaftsdiagnose nicht hinreichend zur Geltung oder werden evolutionär (normative Erwartungsstile/kognitive Erwartungsstile) eingeebnet.

Es gilt also, den Weg wieder frei zu räumen, der mit der reifizierenden Lesart der Systeme und der Zurückweisung des Herrschaftsbegriffs versperrt geblieben ist. Dazu sollen zuerst solche Überlegungen rekapituliert werden, die auf eine kritische Öffnung der Systemtheorie zielen. Ihnen gelingt es, die Perspektive auf die Weltgesellschaft so zu erweitern, dass ihre Widersprüche und Gefährdungslagen wesentlich deutlicher zu Tage treten, als es bisher der Fall war. Darüber hinaus finden sie wieder Anschluss an den Konstitutionalismus. Wie sich zeigen wird, bleiben sie dem systemtheoretischen Register noch zu sehr verhaftet. Erst eine postmarxistische Umschrift wird es ermöglichen, die Schwächen der Weltgesellschaftsdiagnose einzuholen. Sie verschiebt die globale Verfassungsfrage wiederum erheblich, wie sich zeigen wird.

\section{Hybride Regime}

Die Weltgesellschaftsdiagnose ist in jüngerer Zeit zunehmend weiterentwickelt worden. Neuere systemtheoretische Überlegungen nutzen die Beobachtungen zu transnationalen Funktionssystemen, um sie stärker auf rechtlich-politische Strukturbildungen zu beziehen. ${ }^{114}$ Denn der Übergang in die Weltgesellschaft wirft die Frage auf, welche rechtlich-politischen Formen die Ausdifferenzierung der Funktionssysteme hervorbringt. Waren der Nationalstaat und seine Verfassung die Orte, an denen sich Recht, Politik und andere Sozialbereiche (wie etwa Wirtschaft oder Wissenschaft) strukturell gekoppelt hatten, scheint

Ökonomismus in Gramsci, Antonio: Gefängnishefte [= kritische Gesamtausgabe], hg. v. Klaus Bochmann/Wolfgang Fritz Haug, Hamburg: Argument-Verlag 1991 ff., S. 1241). In Luhmanns Systemtheorie, die das Problem der Selbstreferenz auf andere Sozialsysteme überträgt, tritt ein ähnliches Motiv hervor: Die funktionale Differenzierung wird zu einer vorgängigen invisible hand; die Funktionssysteme erscheinen als "Dinge", die einfach so da und beobachtbar sind. Die funktionale Differenzierung droht zur zweiten Natur der Weltgesellschaft zu werden.

114 | Vgl. die Beiträge in Amstutz, Marc/Fischer-Lescano, Andreas (Hg.): Kritische Systemtheorie. Zur Evolution einer normativen Theorie, Bielefeld: transcript 2013. 
diese zentrale Rolle des Staates im Übergang zur Weltgesellschaft an Bedeutung zu verlieren oder eine grundlegende Veränderung zu erfahren. Neuere systemtheoretische Beobachtungen haben deshalb das Konzept des Regimes eingeführt. ${ }^{115}$ Demnach ist eine teilweise schon dominante Form zu beobachten, die das Terrain für neuartige Koppelungsverhältnisse zwischen Recht, Politik und den Funktionssystemen sondiert. Die Weltgesellschaft geht mit einem Formwandel rechtlich-politischer Ordnungsbildung einher.

Regime sind in vielen sozialwissenschaftlichen Forschungszweigen zwischenzeitlich zu einer wichtigen Analysekategorie geworden. ${ }^{116}$ Insofern liegt es nahe, erst einmal einige Verwendungsweisen genauer zu betrachten. Dabei tritt deutlich hervor, dass die Rede von transnationalen Regimen nicht nur aufschlussreich zu sein scheint, um die neuen Kooperationsmechanismen jenseits des Staates zu erfassen; vielmehr stößt man hier schon auf das oben genannte Herrschaftsproblem - und wird darauf gestoßen, dass es im Hinblick auf die Regime am besten als hegemonietheoretische Frage zu verstehen ist.

(1) Zunächst ist in den internationalen Beziehungen (IB) häufig von Regimetheorie die Rede. Hier dient der Begriff dazu, bestimmte Ordnungsmuster des internationalen Staatensystems auszuleuchten. Folglich wird unter einem Regime das Zusammenspiel aus »Prinzipien, Normen, Regeln und Verfahren zur Entscheidungsfindung [verstanden - d. Verf.], um die herum die Erwartungen in einem gegebenen Sachgebiet konvergieren ${ }^{117}$. War bis in die 1980 or Jahre eine Herangehensweise verbreitet, die das internationale Staatensystem vor allem unter dem Gesichtspunkt eines bloßen einzelstaatlichen Machtstrebens betrachtete, so versuchte die eher »liberal« geprägte Regimetheorie einen anderen Akzent zu setzen. Da die Staaten mit Problemen konfrontiert sind, die sie nur gemeinsam, in Verbünden lösen können, entwickeln sich in einzelnen Themenfeldern issue-spezifische Kooperationsformen. In der Folge setzen solche Regime nicht einfach nur einseitig das Interesse der Einzelstaaten um. Im Gegenteil wirken sie auch auf das Verhalten der Staaten sozialisatorisch zurück. Sie unterfüttern Erwartungshaltungen, indem sie die Einzelstaaten in Rechtfertigungs- und Überwachungsprozeduren einbinden. So können sie durch-

115 | A. Fischer-Lescano/G. Teubner, Regime-Kollisionen.

116 | Zu einer Genealogie des Regimebegriffs in den Sozialwissenschaften und seiner Aktualität siehe Dimitrova, Petja / Egermann, Eva / Holert, Tom / Kastner, Jens / Schaffer, Johanna: Regime. Wie Dominanz organisiert und Ausdruck formalisiert wird, Münster: edition assemblage 2012; Alter, Karen J./ Meunier, Sophie: "The Politics of International Regime Complexity", in: Perspectives on Politics $7 / 1$ (2009), S. 13-24.

117 | Krasner, Stephen D.: "Structural Causes and Regime Consequences: Regimes as Intervening Variables", in: International Organization 36/2 (1982), S. 185-205, hier S. 185. 
aus Verhaltensänderungen herbeiführen. Im Hinblick auf die Weltgesellschaft wirkt eine solche Herangehensweise allerdings zu stark auf das internationale Staatensystem verengt. Denn hier ist die Regimekonzeption einzig auf interstaatliche Kooperation und issue-spezifische Problemstellungen beschränkt, obwohl prägende Tendenzen der Globalisierung weit darüber hinausgehen. Schließlich wird unter dem Stichwort Global Governance zunehmend registriert, dass neue Konstellationen entstehen, die auch nichtstaatliche Akteure einschließen. Eine Reihe von Entwicklungen scheint dabei eine solche Eigendynamik zu erhalten, dass es schwer erscheint, hier einzig Problemlösungsstrategien der Staatenwelt auszumachen.

(2) Interessanterweise hat die vor allem französische Theoriediskussion der $1970 e r$ und 1980er Jahre, die heute unter dem Label »Poststrukturalismus« zusammengefasst wird, schon einen verallgemeinernden Zugriff auf das Konzept des Regimes ausgearbeitet. ${ }^{118}$ In ihrer Studie »Tausend Plateaus« haben Gilles Deleuze und Félix Guattari den Regimebegriff verwendet, um eine diskursive Anordnung von Zeichen zu kennzeichnen. ${ }^{119}$ Sie vertreten die These, dass solche Zeichenregime eine strukturierende Funktion in den gesellschaftlichen Machtverhältnissen übernehmen, indem sie das festschreiben, was sagbar oder unsagbar ist, was repräsentiert wird und was nicht, was sichtbar wird und was nicht. Dabei arbeiten die beiden Autoren einen Doppelcharakter der Regime heraus: Einerseits verweise »das Zeichen [...] bis ins Unendliche auf ein anderes Zeichen « ${ }^{120}$. Innerhalb eines Zeichenregimes findet demnach ein unabschließbarer Verweisungsprozess statt, der bei Deleuze/Guattari als »Deterritorialisierung « gefasst wird. Es ist nicht möglich, den Sinn oder die Bedeutung eines Signifikanten dauerhaft zu fixieren, da er sich selbst in einem Verweisungszusammenhang befindet, der immer wieder neue Bedeutungsüberschüsse hervorruft. Andererseits ist das Zeichenregime um einen »despotischen Signifikanten« gruppiert, um eine Art Gravitationszentrum, das »die Kette« der Verweisungszusammenhänge »konstituiert«. ${ }^{121}$ Auf diese Weise entsteht mit dem Regimekonzept ein umfassenderer Zugriff, der die gesellschaftlichen Machtverhältnisse maßgeblich auf die Rolle diskursiver Zeichenregime zurückführt.

Wenn man sich nun das Zusammenspiel dieser beiden Aspekte - Zerstreuung und Vereinheitlichung - betrachtet, stellt sich unweigerlich die Frage nach

118 | Zur Genese des Labels "Poststrukturalismus" vgl. Angermüller, Johannes: Nach dem Strukturalismus, Bielefeld: transcript 2007.

119 | Vgl. Deleuze, Gilles/Guattari, Félix: Tausend Plateaus. Kapitalismus und Schizophrenie, Berlin: Merve 1997, S. $156 \mathrm{ff}$.

120 | Ebenda, S. 163.

121 | Ebenda, S. 163 u. S. 157. 
der Repräsentation. In gewisser Weise sind nicht alle Momente des Regimes »gleich«. Sie erschöpfen sich nicht in einer unendlichen Vielfalt. Da einzelne Signifikanten eine herausgehobene, strukturierende Stellung einnehmen, ziehen sie Grenzen ein. Sie schaffen Einschluss- und Ausschlussregeln. Und nicht zuletzt setzen sie sich mit ihren partikularen Gehalten an die Stelle der diskursiven Unbestimmtheit. ${ }^{122}$ Insofern liegt es nahe, hier auch Repräsentationsregime $\mathrm{zu}$ verorten, in denen eine spezifische "politics of enunciation « ${ }^{123}$ stattfindet: Partikulare Gehalte - etwa Lebensstile, Natürlichkeitsannahmen, politische Ziele o. Ä. - setzen sich an die vereinheitlichende Stelle und bestimmen auf diese Weise, was artikulierbar wird und was nicht und wie etwas überhaupt, beispielsweise mit welchen Sprachspielen und Codes, artikuliert werden kann. Wie tief die hier aufscheinende Umstrittenheit reicht, darauf haben insbesondere die Studien Michel Foucaults aufmerksam gemacht, wenn sie Wahrheitsregime untersuchen. Die Annahme ist dabei, dass die Umstrittenheit der Regime nicht einseitig im Konflikt kompakter sozialer Gruppen, Klassen oder politischer Fraktionen zu suchen ist, sondern in den Wissensformen, die schließlich maßgeblich darauf Einfluss nehmen, was für wahr oder falsch gehalten wird:

"Jede Gesellschaft hat ihre Wahrheitsordnung (regime de verité - d. Verf.), ihre allgemeine Politik der Wahrheit: das heißt Diskursarten, die sie annimmt und als wahr fungieren lässt; die Mechanismen und Instanzen, die es gestatten, zwischen wahren und falschen Aussagen zu unterscheiden; die Art und Weise, wie man die einen und die anderen sanktioniert, die Techniken und Verfahren, die wegen des Erreichens der Wahrheit aufgewertet werden: die rechtliche Stellung derjenigen, denen es zu sagen obliegt, was als wahr fungiert. "124

Das vielleicht beste Beispiel für diese Politik der Wahrheit ist die zwischenzeitlich ins Wanken geratene heterosexuelle Matrix des »Geschlechterregimes «der wahrheitspolitisch abgesicherten Annahme, dass es einen natürlichen Unterschied zwischen »männlichem« und »weiblichem« Geschlecht in bio-

122 | Die Hegemonietheorie wird genau diesen Aspekt ausführlicher ausarbeiten, dazu siehe unten.

123 | Hall, Stuart: "Cultural Identity and Diaspora", in: Jonathan Rutherford (Hg.): Identity. Community, Culture, Difference, London: Lawrence \& Wishart 1990, S. 222237, hier S. 225.

124 | Foucault, Michel: "Gespräch mit Michel Foucault", in: ders., Dits et Ecrits 3, Frankfurt a. M.: Suhrkamp 2003, S. 186-213, hier S. 210; für eine ausführliche Darstellung des Konzepts bei Foucault vgl. Weir, Lorna: "The Concept of Truth Regime", in: Canadian Journal of Sociology $33 / 2$ (2008), S. 367-390. 
logischer und sozialer Hinsicht gäbe. ${ }^{125}$ Die Pointe dieser Verwendungsweise des Regimekonzepts liegt genau darin, dass sie solche Unterscheidungen als historisch umkämpfte und gewordene Machtverhältnisse entschlüsselt. Folglich sind Regime nicht einzig in der internationalen Politik zu suchen, sondern überall dort, wo sich Machtverhältnisse verdichten.

(3) Es gibt wohl keinen Forschungszweig, in dem der Regimebegriff gerade in jüngster Zeit eine so große Verbreitung gefunden hat, wie in der Diskussion um die Transnationalisierung des Rechts. Zwischenzeitlich liegen eine ganze Vielzahl von Überlegungen zum Verhältnis von Recht und Regimen vor. Sie beobachten insbesondere, wie eigenständige Rechtsregime auf inter- und transnationaler Ebene entstehen. ${ }^{126}$ Dabei können sie sich auf entgegenkommende Tendenzen im Bereich der Rechtsprechung berufen. Als Ausgangspunkt dient häufig das Urteil des Internationalen Gerichtshofs, der in der Auseinandersetzung um den Umgang mit Gefangenen (Teheraner Geiselfall) die Auffassung vertrat, dass dem internationalen Diplomatenrecht der Status eines sogenannten »self-contained regime « zuzusprechen sei. ${ }^{127}$ Die Diskussion setzt hier an und überträgt den Regimebegriff auch auf andere Rechtskreise. Demnach liegen in spezifischen Bereichen, etwa des Diplomatenrechts, aber auch im Umweltrecht, bei den Menschenrechten oder im Recht des Welthandels, teils eigensinnige Arrangements vor. Der Übergang in die Weltgesellschaft, so die Annahme, führt zu einer Vervielfältigung solcher Rechtsregime: »Contemporary international law, [...] resembles a dense web of overlapping and detailed prescriptions in subject areas as diverse a s environmental protection, human rights and international trade « ${ }^{128}$. Besondere Aufmerksamkeit auf die entstehenden Rechtsregime hat der Bericht der International Law Commission zur Fragmentierung des Völkerrechts gelenkt. Er nimmt die Ausdifferenzierung der Regime zum Anlass, um der Fragmentierung des internationalen Rechts nachzugehen:

125 | Judith Butler identifiziert hier ein "epistemisch/ontologisches Regime", Butler, Judith: Das Unbehagen der Geschlechter, Frankfurt a. M.: Suhrkamp 1991, S. 8.

126 | Vgl. nur den Bericht ILC Study Group (Hg.): Fragmentation of International Law: Difficulties Arising from the Diversification and Expansion of International Law, Genf 2006; Simma, Bruno/Pulkowski, Dirk: "Of Planets and the Universe: Self-contained Regimes in International Law", in: European Journal of International Law 17/3 (2006), S. 483-529; Sweet, Alec Stone: "Constitutionalism, Legal Pluralism, and International Regimes", in: Indiana Journal of Global Legal Studies 16/ 2 (2009), S. 621-645.

127 | United States Diplomatic and Consular Staff in Tehran (US vs. Iran), Urteil v. 24.5.1980, ICJ Reports 1980.

128 | B. Simma / D. Pulkowski, "Of Planets and the Universe", S. 484. 
"What once appeared to be governed by 'general international law has become the field of operation for such specialist systems as , trade law', human rights law', ,environmental law', ,law of the sea،, 'European law' and even such exotic and highly specialized knowledges as investment law or international refugee law etc. - each possessing their own principles and institutions. The problem, as lawyers have seen it, is that such specialized law-making and institution-building tends to take place with relative ignorance of legislative and institutional activities in the adjoining fields and of the general principles and practices of international law. The result is conflicts between rules or rule-systems, deviating institutional practices and, possibly, the loss of an overall perspective on the law. ${ }^{129}$

Diese Herangehensweise ist insofern folgenreich, als dass nicht mehr nur ein Zusammenspiel von »general international law« und speziellen Ausnahmeregeln stattfindet, sondern immer wieder Konfliktlagen entstehen, die das Verhältnis von internationalem Recht und Rechtsregimen betreffen. Der Bericht unterscheidet Situationen, in denen unterschiedliche Interpretationen des internationalen Rechts aufeinandertreffen, internationales Recht in einem Spannungsverhältnis zu den speziellen Rechtsregimen steht oder gar unterschiedliche spezielle Rechtsregime aufeinandertreffen. ${ }^{130}$ Hier wird schon ein Bezug zur Verfassungsfrage sichtbar. Im Kern geht es um unterschiedliche Möglichkeiten, eine Konstitutionalisierung auszumachen. Die erste Variante sieht nicht nur Rechtsregime entstehen, sondern gleichsam »Nebenverfassungen« im Zuge einer allgemeinen Konstitutionalisierung des Völkerrechts. ${ }^{131}$ Wird das Völkerrecht zunehmend zu einem höherrangigen Recht, kann sich eine Verfassungsbildung der Regime abzeichnen, indem sie entweder dem internationalen Recht untergeordnet oder wenigstens in ein Verhältnis zu ihm gesetzt werden. Dabei tritt dann das Motiv sekundärer Normierungen wieder auf: Von Verfassungsbildung kann gesprochen werden, wenn Metanormen entstehen, die das Verhältnis der Regime zum allgemeinen Völkerrecht betreffen. Es geht - bildlich gesprochen - um die Konstitutionalisierung eines Netzwerks, das sein Zentrum weiterhin im international public law hat. Koordinationsregeln sollen die unterschiedlichen Konfliktverhältnisse zähmen. ${ }^{132}$ Die andere, zweite Variante im Hinblick auf die Verfassungsfrage besteht in einer internen Verrechtlichungstendenz. Eher ist zu beobachten, dass die Rechtsregime selbst eigene, interne sekundäre Normierungen und Rechtshierarchien ausbilden. Stone

129 | ILC Study Group (Hg.), Fragmentation of International Law, S. 11.

130 | Vgl. ebenda, S. 30.

131 | Kleinlein, Thomas: Konstitutionalisierung im Völkerrecht. Konstruktion und Elemente einer idealistischen Völkerrechtslehre, Berlin: Springer 2012, S. 63 ff.

132 | Vgl. den responsive Rechtspluralismus bei Viellechner, Lars: Transnationalisierung des Rechts, Weilerswist: Velbrück 2013. 
Sweet schlägt beispielsweise vor davon auszugehen, dass Vertragsregime wie die EU, der Europäische Gerichtshof für Menschenrechte und die europäische Menschenrechtskonvention sowie die WTO eine Verfassungsdimension ausgebildet haben, denn »they are constituted, like the systems of virtually all nationstates today, by written meta-norms or codified secondary rules « ${ }^{133}$. In diesem Sinne ist der Konstitutionalismus nicht an die Einzelstaaten und auch nicht an die Staatengemeinschaft gebunden. Er kann in den jeweiligen Regimen in unterschiedlichen Ausprägungen identifiziert werden:

"Simple power-based balance of power arrangements anchored one extreme, the European Union (EU) occupied the opposite extreme, and other regime forms, including the General Agreement on Tariffs and Trade (GATT) and the then-new World Trade Organization (WTO), occupied the middle ground. The continuum captures three dimensions: the extent of hierarchical primacy and entrenchment of the constituting norms; the degree of precision and formality of legal obligation; and the scope of independent, organizational capacity to monitor compliance with, and to enforce, obligations. ${ }^{134}$

So wird eine innere Konstitutionalisierung denkbar, die nicht auf eine Superverfassung »von oben«, sondern auf eine Selbstbeschränkung »von unten« hinausläuft.

Das Problem dieser Überlegungen ist dort zu suchen, wo eine Art EigenKonstitutionalisierung zwar beobachtet, aber nicht näher beleuchtet und in eine Diskussion politischer und gesellschaftlicher Veränderungsprozesse eingebettet wird. Fraglich ist schließlich nicht nur, ob allgemeine Kriterien der Verfassungsbildung im inter- und transnationalen Maßstab Anwendung finden können, sondern die Form des Konstitutionalismus: Wieso ergeben sich die Verfassungsbildungsprozesse? Welche Funktion übernehmen sie und welche neuartigen Machtkonstellationen sichern sie ab oder setzen sie ins Werk? Wie ist ihr Verhältnis zur Weltgesellschaft?

(4) Das ist der Ansatzpunkt der kritischen Systemtheorie des Rechts, die in jüngerer Zeit versucht hat, eine stärker theoretisch informierte Perspektive auf die Rechtsregime einzunehmen. ${ }^{135}$ Auch sie stellt den Befund einer Fragmentierung des Weltrechts in den Mittelpunkt ihrer Überlegungen. Sie bettet ihn jedoch gleichermaßen in eine Theorie der sozialen Evolution ein. Folglich ist die Ausdifferenzierung unterschiedlicher Rechtsregime nur zu begreifen, wenn man davon ausgeht, dass der Übergang in die Weltgesellschaft einen er-

133 | A. S. Sweet, "Constitutionalism, Legal Pluralism and International Regimes", S. 631.

134 | Ebenda, S. 622.

135 | Vgl. A. Fischer-Lescano/G. Teubner, Regime-Kollisionen. 
höhten Normbedarf erzeugt. In transnationalen Funktionssystemen wie Weltwirtschaft oder Weltwissenschaft müssen Erwartungshaltungen stabilisiert werden. Das Umfeld des Nationalstaats, das über Jahrzehnte den primären Ort der Rechtsentwicklung darstellte, ist fraglos noch präsent, aber gleichzeitig bringen die transnationalen Funktionssysteme neue Verrechtlichungstendenzen hervor.

Nimmt man diese Hintergrundannahmen auf, so verändert sich insbesondere die Perspektive auf die Rechtssetzung. Das Rechtssystem wird als Verkettung von Rechtskommunikationen beschrieben. Und damit ist es durchaus möglich, dass auch nichtstaatliche Rechtsphänomene an Bedeutung gewinnen. Im Übergang zur Weltgesellschaft, so die Annahme der systemtheoretischen Regimediagnose, erhöht sich die Bedeutung privater Rechtssetzung in sogenannten Privatregimes:

"Der Schwerpunkt der Rechtsbildung verschiebt sich auf Privatregimes, also auf Verträge zwischen global players, private Marktregulierung durch multinationale Unternehmen, interne Regelsetzungen in internationalen Organisationen, interorganisationale Verhandlungssysteme, weltweite Standardisierungsprozesse. Die dominanten Rechtsquellen befinden sich nun an den Peripherien des Rechts, an den Grenzen zu anderen Sektoren der Weltgesellschaft, die den bisherigen Zentren der Rechtsbildung - nationalen Parlamenten, globalen Legislativinstitutionen und zwischenstaatlichen Vereinbarungen - erfolgreiche Standortkonkurrenz machen. “136

Sie bilden eigene Mechanismen der Entscheidungsfindung, Rechtsbildung und Streitschlichtung aus. Gerade im Weltwirtschaftsregime sind die angedeuteten Tendenzen zu beobachten. Hier sind es die Standardverträge, private Schiedsgerichte und gewohnheitsrechtliche Arrangements, die den Motor einer staatsfernen lex mercatoria ausmachen.

Dies ist die erste Verschiebung, die in der systemtheoretischen Regimediagnose mitschwingt: Die Umstellung auf eine kommunikationstheoretische Perspektive legt die Annahme nahe, dass die Rechtsregime mit einer Pluralisierung der Rechtssetzung einhergehen. Die These vom entstaatlichten Recht hat zwischenzeitlich auch Kritik provoziert. Denn eventuell scheint die Rede von Privatregimen zwar eine wichtige Tendenz anzugeben, die sie jedoch allzu hyperbolisch zuspitzt. ${ }^{137}$ In vielen Bereichsregimen sind Staaten oder Staatenvertreter beteiligt und umgekehrt greifen private Regime oft auf staatliche Ordnungs-

136 | Teubner, Gunther: „Privatregimes: Neo-Spontanes Recht und duale Sozialverfassungen in der Weltgesellschaft", in: Dieter Simon / Manfred Weiss (Hg.), Zur Autonomie des Individuums. Liber Amicorum Spiros Simitis, Baden-Baden: Nomos 2000, S. 437453, hier S. 439.

137 | Vgl. L. Viellechner, Transnationalisierung des Rechts, S. $249 \mathrm{ff}$. 
leistungen zurück. Der Staat ist gewissermaßen Teil der Regimeform. Was der Nationalstaat verliert, ist sein Rechts- und Politikmonopol:

"Das staatliche Recht hat sein Monopol für die Regelung des grenzüberschreitenden Wirtschaftsverkehrs eingebüßt - wenn es jemals ein solches besaß. Mechanismen privater Selbstregulierung gewinnen demgegenüber stetig an Bedeutung. Das staatliche Recht kann die Regeln des grenzüberschreitenden Wirtschaftsverkehrs nur noch punktuell beeinflussen, etwa durch die Aufhebung von Entscheidungen privater Schiedsgerichte oder eine Nichtanerkennung der Regeln privater Standardsetzungsorganisation en. ${ }^{138}$

Seine Apparate werden jedoch in die jeweiligen Regime so miteinbezogen, dass man eher von einer hybriden Ordnungsbildung in den Regimen ausgehen müsste: ${ }^{139}$ In den hybriden Regimen des Transnationalen interagieren nationalstaatliche Apparate mit internationalen Institutionen, multinationalen Unternehmen, NGOs, Lobbygruppen und sozialen Bewegungen. Die Ordnungsmuster sind meist durch gemischte Strukturbildungen bestimmt. ${ }^{140}$ Sie entziehen sich der klassischen Gegenüberstellung von Staat und Gesellschaft und bilden neuartige Eigenstrukturen. ${ }^{141}$

Die zweite Verschiebung besteht in einem stärker soziologischen Beobachtungsstil. Schließlich sind die Rechtsphänomene in gesellschaftliche Veränderungsprozesse eingebettet. Ihr Charakter kann nur sinnvoll ausgeleuchtet werden, wenn man sie auch an die gesellschaftlichen Umbrüche der letzten Jahrzehnte anbindet. Sie sind als Ausdruck einer tieferliegenden Fragmentierung zu verstehen. Wenn man die Herangehensweise konsequent weiterverfolgt, wird deutlich, wie die Systemtheorie aus der rechtsspezifischen Diskussion von innen her ausbricht und deutliche Bezüge zu den machtanalytischen Zugriffen mitführt.

Zunächst bleibt es erst einmal dabei, dass eine Binnendifferenzierung des Rechts diagnostiziert wird. Die Systemtheorie zeigt, wie eine Ausdifferenzierung von Rechtsregimen stattfindet, die nicht mehr vom Vorrang des Staatensystems zu denken ist. In einem nächsten Schritt sprengt sie allerdings die Beschränkung auf eine im engeren Sinne juristische Beobachtung dadurch, dass

138 | M. Renner, "Transnationale Wirtschaftsverfassung", S. 769.

139 | Vgl. L. Viellechner, Transnationalisierung des Rechts, S. 301.

140 | Dies bringt sie in die Nähe von Theorien des Empire, die Michael Hardt und Antonio Negri auch als "gemischte Verfassung" verstehen, siehe ihre Aufnahme der Systemtheorie in: dies.: Commonwealth, Cambridge: Harvard University Press 2009, S. $373 \mathrm{ff}$. 141 | Vgl. Stichweh, Rudolf: "The Eigenstructures of World Society and the Regional Cultures of the World“, in: Ino Rossi (Hg.), Frontiers of Globalization Research. Theoretical and Methodological Approaches, New York: Springer 2007, S. 133-149. 
sie die Regime nicht auf eine Binnendifferenzierung des Rechtssystems beschränkt; vielmehr erscheinen die Rechtsregime als juridische Dimension von transnationalen Sozialbereichen, die in unterschiedlichen Feldern wie Weltpolitik, Weltwirtschaft oder Weltwissenschaft im Entstehen begriffen sind. In ihnen entwickeln sich institutionelle Verdichtungen (etwa Institutionen wie die Weltgesundheitsorganisation (WHO), die WTO, ICSID etc.) und übergreifende Rationalitäten, also Bewertungsstandards, Logiken oder Denkweisen. Die Regime sind also auch als Sozialregime zu betrachten, die gewissermaßen quer zur funktionalen Ausdifferenzierung der Funktionssysteme liegen. ${ }^{142}$ In ihnen - um einen Ausdruck der Soziologin Saskia Sassen zu bemühen - versammeln sich Kommunikationen unterschiedlicher Funktionssysteme unter einer übergreifenden Rationalität des jeweiligen Regimes. ${ }^{143}$ Systemtheoretisch betrachtet ist die Folge eine Art Zweitcodierung: Über die kommunikative Codierung in den Funktionssystemen schiebt sich eine Markierung, die sie den jeweiligen Regimen zuordnet. Rechtliche Kommunikationen können dann danach unterschieden werden, ob sie dem Weltwirtschaftsregime, dem Umweltregime, dem Wissenschaftsregime oder einem anderen Regime zuzurechnen sind. In den Regimen selbst findet eine Koevolution unterschiedlicher Funktionssysteme statt, die durch Mechanismen vom Typ der strukturellen Koppelung (wo ein Funktionssystem dauerhaft auf Kommunikationen aus anderen Funktionssystemen zurückgreift und sie verarbeitet) sichergestellt wird.

Halten wir also fest, dass die Regimediagnose nicht nur spezielle Rechtsregeln beobachtet, sondern umfassendere Sozialregime, die über die rechtliche Grammatik hinausgehen. Sie weisen sogar noch eine weitere, politische Dimension auf, die in den bisherigen Darstellungen oft vernachlässigt bleibt und an die Einsichten der machtanalytischen Zugriffe anknüpft. Die Regime sind nämlich auch als politische Regime zu kennzeichnen, in denen Machtverhältnisse auftauchen. Und zwar ist die politische Dimension der Regime auf zwei Ebenen angesiedelt: Auf einer ersten Ebene kann die Politik dort verortet werden, wo Verhältnisse der Machtüberlegenheit/Machtunterlegenheit dauerhaft eingerichtet werden. In der Regel halten die institutionellen Verdichtungen der jeweiligen Regime Entscheidungsverfahren und Kompetenzverteilungen fest, die als politische Ordnungen darstellbar sind. Freilich erhalten in den hybriden Arrangements nichtstaatliche Akteure eine zunehmend wichtigere Rolle. Dies gilt für multinationale Konzerne wie für soziale Bewegungen, Lobbygruppen und NGOs. Aber selbst wenn man den besonders extremen Fall der sogenannten Privatregime in den Blick nimmt, findet »Politik« statt: Auch hier werden Verhältnisse der Machtüberlegenheit/-unterlegenheit geschaffen und

142 | Vgl. A. Fischer-Lescano/G. Teubner, Regime-Kollisionen, S. 72 ff.

143 | Vgl. Sassen, Saskia: Territory, Authority, Rights. From Medieval to Global Assemblages, Princeton: Princeton University Press 2006, S. 222. 
kommunikativ verarbeitet. Dies geschieht natürlich oft in einem anderen Umfeld als der staatlichen Politik und den etablierten Mechanismen politischer Öffentlichkeit. Eine kritische Betrachtungsweise der Regimeform wird darauf bestehen müssen, dass hier durchaus Politik gemacht wird. Interessen prallen aufeinander, Entscheidungen werden getroffen oder angefochten, dauerhafte Verhältnisse der Über- und Unterordnung entstehen. Die Politik erhält so freilich einen volatileren Ausdruck, als es im nationalstaatlichen Konstitutionalismus der Fall war. ${ }^{144}$

Die $z w e i t e$ Ebene der Politik ist viel grundlegender. Sie entspricht eher dem, was in der neueren Theoriediskussion unter dem Stichwort »das Politische« firmiert. Es sind schließlich nicht nur Fragen einfacher Machtüberlegenheit/-unterlegenheit zu beobachten, sondern genauso dauerhafte Asymmetrien, die recht deutlich dem Muster Teil/Ganzes folgen. Begreifen wir die transnationalen Regime mithin auch als Zeichen-, Repräsentations- und Wahrheitsregime, besteht das grundlegende Verhältnis darin, dass sich ein Teil für das Ganze ausgibt: Die Freihandelslogik der WTO für das Welthandelsregime als Ganzes, die Vereinten Nationen für die internationale Gemeinschaft als Ganze. Jedes Regime kultiviert ein eigenes Esperanto, eine eigene Sprache und damit korrespondierende Bewertungsmaßstäbe. ${ }^{145}$ Die Unschärfe in der Rede vom Weltwirtschaftsregime, also die Frage, ob es sich dabei um ein Ensemble von Institutionen und Verträgen oder um die gesamten vage auf die Wirtschaft bezogenen Kommunikationen der Weltgesellschaft handelt, rührt genau daher. Das Politische der Regime ist dort zu suchen, wo sich Teile für das Ganze ausgeben und so die Rede von Wirtschaft, Politik oder Gesellschaft über ihre jeweiligen Logiken engführen. Hier entstehen genau die schon angesprochenen Politiken: eine Politik der Repräsentation, wenn die jeweilige Institution für sich in Anspruch nimmt, für das Ganze zu sprechen; eine Politik der Veridiktion, da in der Regel bestimmte Wahrheitspolitiken grundlegend für ihr Selbstverständnis sind; schließlich eine Politik der Inklusion/Exklusion, die regelt, was überhaupt gesagt oder getan werden kann. ${ }^{146}$

Nimmt man letztlich den Umstand auf, dass die Regime eine rechtliche, soziale und politische Dimension aufweisen, verändert dies auch die Perspektive auf die Verfassungsbildung. Die bisherigen Ansätze, die von Metakoordinierungsregeln bis hin zu sekundären Normierungen in den Regimen reichen, stellen so nur die eine, rechtliche Seite der Verfassungsbildung dar. Das schon eingeführte Kriterium einer doppelten Reflexivität beschränkt sich nicht auf

144 | G. Teubner, Verfassungsfragmente, S. $182 \mathrm{ff}$.

145 | Zu den Totalisierungstendenzen siehe auch Koskenniemi, Martti: "The Politics of International Law - 20 Years Later", in: European Journal of International Law 20/1 (2009), S. 7-19, insbes. S. 19.

146 | Siehe eingehend dazu den dritten Teil, ab S. 179. 
das Recht allein, sondern buchstabiert die Prozesse zweiter Ordnung auch in sozialer und politischer Hinsicht aus. Der Schritt zur Konstitutionalisierung ist dort zu suchen, wo eine umfassende Reflexivität rechtlich institutionalisiert wird: Wenn also auch der Selbstbezug des Sozialbereichs und seine Machtverhältnisse adressiert werden. In der Regel ist dies ja auch der Fall, wenn etwa Urteile von Gerichten oder Streitschlichtungsmechanismen damit beginnen, höherrangige Ordnungen zu schaffen - die Urteile stehen oft in einem Korrespondenzverhältnis zu allgemeineren Entwicklungen der Sozialregime oder veränderten Machtverhältnissen.

Die Regimediagnose geht mit einem reflexiven Verständnis der Verfassungsbildung jenseits des Staates einher. Vorläufig lässt sich festhalten, dass die Regime als Form der Ordnungsbildung in einer fragmentierten Weltgesellschaft zu begreifen sind. In unterschiedlichen Sozialbereichen entstehen hybride Konstellationen, die sich monistischen oder dualistischen Perspektiven entziehen. Regime sind kein Phänomen der zwischenstaatlichen Politik oder des Rechts allein; vielmehr institutionalisieren sie Verhältnisse der Koevolution von Recht, Politik und Sozialbereichen. Sie können eine verfassungstypische Reflexivität ausbilden und zu Regimeverfassungen gerinnen. Gleichzeitig sollte der scheinbar evolutionäre Charakter dieser Entwicklungen nicht darüber hinwegtäuschen, dass hier eine dauerhafte Institutionalisierung von Machtverhältnissen (beispielsweise in den Achsen Repräsentation, Wissen, Inklusion/Exklusion) stattfindet, die es nahelegen, nicht nur von Fragmentierung, sondern auch von neuartigen Herrschaftsverhältnissen auszugehen, die mit der Regimeform verbunden sind.

\section{EigenRationalitätsmaXimierung}

Die neueren systemtheoretischen Überlegungen reagieren schon auf die angemahnten Defizite. Sie belassen es nicht beim kühlen Beobachten. Wenn sie die Weltgesellschaft thematisieren, sehen sie neue Problem- und Gefährdungslagen auftauchen: »Umweltverschmutzung, eklatante Unterversorgungen [...] Diskrepanzen in Lebens- und Entwicklungschancen ${ }^{147}$. Die Ausdifferenzierung von Sozialregimen wird zum Problem. Es ist nicht nur eine Verallgemeinerung der funktionalen Differenzierung festzustellen, sondern eine übersteigerte »Eigenrationalitätsmaximierung « ${ }^{148}$ der transnationalen Regime. Das Motiv der »Verselbstständigung « ${ }^{149}$ wird bemüht. Die bereichsspezifischen

147 | A. Fischer-Lescano/G. Teubner, Regime-Kollisionen, S. 28.

148 | Ebenda.

149 | Teubner, Gunther: „Die anonyme Matrix: Menschenrechtsverletzungen durch ’private، transnationale Akteure", in: Der Staat 45/2 (2006), S. 161-187, hier S. 168. 
Rationalitäten lösen sich von ihren sozialen Umwelten. Sie setzen ihr Selbstgespräch unendlich fort und schotten sich von äußeren Einflüssen ab. Einerseits setzt die funktionale Differenzierung ein enormes Entwicklungspotential frei, produziert aber andererseits destruktive Potentiale. Die jeweiligen Regime schaffen sich ihre jeweiligen $\gg$ Götter ${ }^{150}$, die sie verehren und mit einer allseitigen Problemlösungskompetenz ausstatten. Das Weltwirtschaftsregime ist um die Expansionslogik finanzialisierter Akkumulation gruppiert, das Staatensystem um den Ausbau von Machtansprüchen in der Sicherheitspolitik und Terrorbekämpfung, das Wissenschaftssystem verallgemeinert einen wahrheitsorientierten Rationalitätstyp, der traditionelle Wissensbestände disqualifiziert. ${ }^{151}$ Die Eigenrationalitätsmaximierung in Weltwirtschaft, Wissenschaft und Technik avanciert zur primären Gefährdungsquelle. Die Regime steigern ihre eigenen Funktionen regelmäßig zu Lasten ihrer sozialen Umwelten. Sie setzen »imperialistische Tendenzen « ${ }^{152}$ frei. Mit dieser Charakterisierung erscheint auf einmal eine Figur, die weniger der Luhmann'schen Systemtheorie als der Marx'schen Kritik der politischen Ökonomie entlehnt ist. Die Produktivkräfte der sozialen Evolution schlagen in Destruktivkräfte um. ${ }^{153}$

Die entscheidende Leistung dieser Beobachtung besteht darin, dass sie das Motiv systemischer Verselbstständigung, wie es eigentlich seit Karl Marx und Max Weber prägend ist, für die postnationale Konstellation fruchtbar macht. Während die zeitgenössische Theorie transnationaler Demokratie illegitime Herrschaftsausübung dort verortet, wo Staaten oder Individuen willkürlich handeln, ${ }^{154}$ bleibt es hier dabei, dass die Weltgesellschaft von verselbstständigten Systemrationalitäten geprägt ist. Die Abwendung von Akteuren hin zu

150 | In Anlehnung an Max Webers Polytheismusthese, vgl. A. Fischer-Lescano/G. Teubner, Regime-Kollisionen, S. 27.

151 | Vgl. Teubner, Gunther: "A Constitutional Moment? The Logics of Hitting the Bottom «, in: Poul F. Kjaer/Gunther Teubner/Alberto Febbrajo (Hg.): The Financial Crisis in Constitutional Perspective. The Dark Side of Functional Differentiation, Oxford: Hart Publishing 2011, S. 9-51; A. Fischer-Lescano/G. Teubner, Regime-Kollisionen, S. 31; dies.: "Cannibalizing Epistemes: Will Modern Law Protect Traditional Cultural Expressions?", in: Christoph Beat Graber/Mira Burri-Nenova (Hg.), Intellectual Property and Traditional Cultural Expressions in a Digital Environment, Cheltenham: Edward Elgar 2008, S. 17-45.

152 | G. Teubner, "Die anonyme Matrix", S. 174.

153 | Vgl. Marx, Karl: „Die Deutsche Ideologie“ (1846), in: ders./Friedrich Engels: Werke. Band 3, Berlin: Dietz 1969, S. 5-530, hier S. 60.

154 | Vgl. Überlegungen, die vor allem auf eine nichtwillkürliche Verrechtlichung des Staatensystems setzen, siehe etwa Niederberger, Andreas: Demokratie unter Bedingungen der Weltgesellschaft, Berlin: De Gruyter 2009, und Pettit, Philip: "A Republican Law of Peoples“, in: European Journal of Political Theory $9 / 1$ (2010), S. 70-94. 
transnationalen Regimen läuft damit zumindest subkutan auf eine Semantik systemischer Hegemonie hinaus, die angeben will, wo die stahlharten Gehäuse der Hörigkeit in der Weltgesellschaft aufzufinden sind. Nicht einzelne Akteure wie Barack Obama oder Angela Merkel lenken die Welt, sondern hegemoniale Regime, die ihren Rationalitätstyp zu verallgemeinern suchen, bestimmen mit ihrem funktionalen Esperanto die Kommunikationslage. Der bereichsspezifischen Selbstreferenz ist ein Drang zur Universalisierung eingeschrieben:

"[T]he point is that regimes such as the international trade system', the iclimate change system ، or the security system ، are all engaged in universalization strategies, trying to make their special knowledge and interest appear as the general knowledge and general interest, a commonplace consciousness. ${ }^{155}$

Diese Eigenrationalitätsmaximierung ist auf unterschiedlichen Ebenen angesiedelt:

(1) Auf einer ersten Ebene findet eine Kolonisierung der sozialen Umwelten statt. Aufgrund der fehlenden Selbstbeschränkungen zwingen die Regime ihnen ihre Eigengesetzlichkeiten auf. Sie zerstören andere Rationalitätstypen. Dies lässt sich gut am Beispiel des Weltwirtschaftsregimes verdeutlichen. Indem das Weltwirtschaftsregime beispielsweise mit seiner Markt- und Verwertungslogik auf das Weltgesundheitsregime übergreift, stehen die Eigentumsrechte der Großunternehmen in der Tendenz immer über der Gesundheit der Menschen. Unterschiedliche Konfliktlagen zwischen der WTO und der WHO haben diesen Widerspruch und die Hegemonieverhältnisse zwischen Marktund Gesundheitslogik sichtbar gemacht. ${ }^{156}$

(2) Nun führt die Eigenrationalitätsmaximierung auf einer weiteren, zweiten Ebene noch zu drastischeren Gefährdungen, die sogar an den Kern der funktionalen Differenzierung heranreichen. Sie bedroht nämlich gleichermaßen die Reproduktion der Regime selbst. Beispielhaft dafür stehen wiederum das Weltwirtschaftsregime und die jüngste Banken- und Finanzkrise. Indem der kognitive Erwartungsstil der Weltwirtschaft auf den normativen Erwartungsstil des Rechtssystems kolonisierend übergegriffen hat, konnte das Recht seine eigene Funktion der Erwartungsstabilisierung nicht mehr hinreichend erfüllen. Da aber das Wirtschaftssystem auf ein Rechtssystem angewiesen bleibt, um zu funktionieren, ist es selbst in seiner Reproduktion gestört worden. »Death by complexity« lautet die Diagnose: ${ }^{157} \mathrm{Zu}$ hohe Komplexitätsstei-

155 | M. Koskenniemi: "Hegemonic Regimes", S. 315.

156 | Vgl. A. Fischer-Lescano/G. Teubner, Regime-Kollisionen, S. 73 ff.

157 | Dies wird vor allem bei Renner, Moritz: "Death by Complexity. The Crisis of Law in World Society", in: Kjaer/Teubner/Febbrajo, The Financial Crisis in Constitutional Perspective (2011), S. 93-112, herausgearbeitet. 
gerung durch kognitive Erwartungen führt zu einer Ent-Differenzierung und gefährdet die Selbstreferenz der Regimes. Die funktionale Differenzierung unterläuft sich selbst.

(3) Auf einer dritten Ebene geht die neuere Systemtheorie davon aus, dass die Eigenrationalitätsmaximierung das psychische System und die körperliche Integrität des Menschen angreift. Sie bemüht eine gewisse Drastik, wenn sie zeigt, wie ein wesentlich größerer Bereich an »lebens- und bewusstseinsbedrohenden Potentialen « ${ }^{158}$ zum Vorschein kommt, als die Luhmann'sche Exklusionsthese nahelegt. Die Verselbstständigung der Kommunikationsnetzwerke mündet in die Abkoppelung von den Eigenrechten der Körper auf Unversehrtheit und Integrität:

"Die spezifische Gefährdung der körperlichen und seelischen Integrität durch eine verselbstständigte kommunikative Matrix geht nicht nur von der Politik aus, sondern im Prinzip von allen autonomisierten Subsystemen, die über eine expansive Dynamik verfügen. «159

Die Eigenrationalitätsmaximierung unterläuft eine gelingende Konstituierung des menschlichen Selbst.

Alle genannten Aspekte zeugen davon, dass sich in den kühlen Beobachtungsstil eine Hegemoniedimension eingenistet hat. Dies geht sogar so weit, dass die funktionale Differenzierung auf ein Zusammenspiel von sozialen Produktivund Destruktivkräften zurückgeführt wird. Die hybriden Regime gehen mit neuen Hegemonieverhältnissen einher, die zwischen Regimen und ihren sozialen Umwelten angesiedelt sind. Bisher hat diese Erweiterung der Weltgesellschaftsthese noch nicht die theoretischen Mittel gewonnen, um die Hegemoniedimension explizit auszuweisen. Erst die postmarxistische Umschrift der Weltgesellschaftsthese wird es ermöglichen, der Eigenrationalitätsmaximierung einen systematischen Status zuzuweisen.

\section{Kollisionen und Paradoxien}

Es hatte sich gezeigt, dass die Überlegungen zu transnationalen Regimen schon dabei sind, die Hegemonieverhältnisse der Weltgesellschaft zu berücksichtigen. So ist freilich auch die Frage aufgeworfen, welche Konfliktverhältnisse entstehen. Wenn die postnationale Konstellation zu einer Regimedifferenzierung führt, liegt es nahe, Konflikte vor allem zwischen diesen neuartigen

158 | G. Teubner, "Die anonyme Matrix“, S. 171.

159 | Ebenda, S. 176. 
Mustern sozialer Ordnungsbildung auszumachen: Prägend für die Weltgesellschaft sind Regimekollisionen. Die auftretenden Konfliktverhältnisse sind ausdrücklich nicht auf die Spannungen zwischen unterschiedlichen Ebenen beschränkt, beispielsweise Konflikte zwischen unterschiedlichen Ebenen des internationalen Staatensystems (nationale Souveränität vs. internationales Recht). Sie sind auch keine Klassenkämpfe zwischen kompakten sozialen Gruppen. Eher ist die tiefere Grammatik der weltgesellschaftlichen Konflikte durch Rationalitätenkollisionen bestimmt, die in den Regimen verankert sind. Es handelt sich nicht um akteurszentrierte, sondern um transsubjektive Konfliktverhältnisse. ${ }^{160}$ Dies gilt beispielsweise in Fällen, wo die dominanten Rationalitäten des Weltwirtschaftsregimes mit dem Weltgesundheitsregime oder den Rechten sozialpolitischer Regime kollidieren.

Aber, so mag man fragen, wo und wie machen diese Kollisionen auf sich aufmerksam? Entsteht nicht eine neue Metabeobachtung, die dramatisierend auf Kollisionslagen zugreift, ohne den Beweis anzutreten, dass sie auch in den Regimen eine Rolle spielen kann? Wird hier der eingeschlagene Weg einer immanenten Betrachtungsweise verlassen? Denn das Wissenschaftssystem kann solche Regimekollisionen relativ folgenlos beobachten und konturieren. Ob sie $\mathrm{zu} »$ Realwidersprüchen ${ }^{161}$ werden, hängt davon nicht ab.

Die Frage nach den Konfliktverhältnissen ist eine Schwelle, an der die neuere Systemtheorie eine Art linksluhmannianische Wende nimmt. ${ }^{162}$ Sie lädt die Unterscheidung von Regimen und ihren sozialen Umwelten normativ auf. Demnach finden in diesen Grenzbereichen nicht ausschließlich Kolonisierungen statt. Hier ist gleichermaßen ein reflexives Potential angesiedelt, das im Wege eines re-entry der Unterscheidung in die Funktionslogik eintreten kann. ${ }^{163}$ Zwar existiert keine Metaperspektive auf die Regimekollisionen, wohl

160 | Vgl. Fischer-Lescano, Andreas: "Kritische Systemtheorie Frankfurter Schule", in: Gralf-Peter Calliess/Andreas Fischer-Lescano/Dan Wielsch/Peer Zumbansen(Hg.), Soziologische Jurisprudenz, Berlin: De Gruyter 2009, S. 49-68, hier S. 52 ff.

161 | Ebenda, S. 56 f.; vgl. auch Amstutz, Marc: "Der zweite Text. Für eine Kritische Systemtheorie des Rechts", in: ders./Andreas Fischer-Lescano (Hg.), Kritische Systemtheorie. Zur Evolution einer normativen Theorie, Bielefeld: transcript 2013, S. 365395, hier S. $369 \mathrm{ff}$.

162 | Vgl. zur linksluhmannianischen Wende Möller, Kolja: "Rechtskritik und Systemtheorie", in: Albert Scherr (Hg.), Systemtheorie und Differenzierungstheorie als Kritik. Perspektiven im Anschluss an Niklas Luhmann, Weinheim/Basel: Beltz Juventa 2015, S. $186-210$.

163 | Vgl. G. Teubner, Verfassungsfragmente, S. 158. Im Kapitel zum gesellschaftlichen Konstitutionalismus wird dieses Moment der Reflexivität ausführlicher diskutiert. Grundlegend zum re-entry: Luhmann, Niklas: "Observing Re-entries", in: Graduate Faculty Philosophy Journal 16/2 (1993), S. 485-498. 
aber erscheint es möglich, die Kollisionen dort zu verorten, wo die Unterscheidung zwischen Regime und Umwelt einen Wiedereintritt ins Regime findet. Dies sind diejenigen Momente der Öffnung, die für neuere systemtheoretische Überlegungen zum Einfallstor möglicher Korrekturen der Selbstreferenz avancieren. Die verselbstständigte Selbstreferenz bricht ab und die Möglichkeit entsteht, innerhalb des Systems auf die Grenzen des Systems zu reflektieren. Der Wiedereintritt der System/Umwelt-Unterscheidung schafft den Platz dafür, dass Umweltrationalitäten systemintern rekonstruiert und berücksichtigt werden können. Die Regimekollisionen tauchen auf, wenn Ansprüche der sozialen Umwelten in die Systemlogik einbrechen. Sie artikulieren sich als Kollisionen zwischen Regimen und ihren sozialen Umwelten. Dies ist beispielsweise der Fall, wenn das Selbstgespräch der transnationalen Regime durch Irritationen, Skandale und colère publique unterbrochen wird. ${ }^{164}$

Die Art, wie die Regimekollisionen ihren Ausdruck finden, verweist auf eine ermöglichende Grundstruktur, die - folgen wir den neueren systemtheoretischen Überlegungen -in der funktionalen Selbstreferenz angelegt ist. Die Möglichkeitsbedingung dieses re-entry der Unterscheidung in das Unterschiedene wird dadurch möglich, dass die Funktionssysteme auf prekärem Terrain ruhen. Die Eigenrationalitätsmaximierung hat keinen festen Grund. Die Funktionssysteme sind von Paradoxien durchzogen, die als Unbestimmtheiten und Unentscheidbarkeiten auf sich aufmerksam machen. ${ }^{165}$ Sie sind kein glatter Raum. Wird die in gewisser Weise gleichursprüngliche Möglichkeit gelingender Selbstreferenz und kommunikativer Prekarität näher beleuchtet, stößt man auf die Form der Paradoxie. Sieistein besonders anspruchsvolles Konfliktverhältnis, das von einfachen Widersprüchen zu unterscheiden ist. Paradoxien haben die Form »A, weil nicht $\mathrm{A} \ll$, während Widersprüche dem Muster »A - Nicht A« folgen. Paradoxien lassen sich also so definieren, dass sie die Möglichkeit und Unmöglichkeit aufeinander beziehen. Sie treten dann auf, wenn Möglichkeitsbedingungen einer Operation gleichzeitig ihre Unmöglichkeitsbedingungen darstellen.

Die Paradoxie schiebt sich vor die Selbstreferenz ${ }^{166}$, und zwar erstens als Fundierungsparadox der System/Umwelt-Unterscheidung. Die Identität des Funktionssystems muss, um seine Identität herzustellen, auf die soziale Um-

164 | Zur Rolle der colère publique für die transnationale Rechtsentwicklung siehe A. Fischer-Lescano, Globalverfassung.

165 | Vgl. N. Luhmann, Soziale Systeme, S. 641, vgl. auch ders.: "Die Paradoxie der Form «, in: Dirk Baecker (Hg.), Kalkül der Form, Frankfurt a. M.: Suhrkamp 1993, S. 197215; für eine Kritik vgl. Bung, Jochen: "Das Bett des Karneades. Zur Metakritik der Paradoxologie", in: Winfried Brugger/Ulfried Neumann/Stephan Kirste (Hg.), Rechtsphilosophie im 21. Jahrhundert, Frankfurt a. M.: Suhrkamp 2008, S. 72-89.

166 | Dies folgt der Unterscheidung bei Stäheli, Urs: „Politik der Entparadoxierung. Zur Artikulation von Hegemonie- und Systemtheorie", in: Oliver Marchart (Hg.), Das Undar- 
welt Bezug nehmen. Damit ist es nicht vollkommen unabhängig und geschlossen, sondern auch umweltabhängig und in gewisser Hinsicht offen. Seine Einheit besteht in der Unterscheidung. Damit ist funktional spezifizierte Selbstreferenz gleichzeitig möglich (weil operativ geschlossen) und doch stets unmöglich (weil umweltabhängig). Und zweitens ist die Paradoxie als Anwendungsparadox sichtbar, da jedes System den eigenen zweiwertigen Code nochmals einer Beobachtung aussetzen kann. Die Unterscheidung Recht/Nichtrecht kann wiederum einer Unterscheidung Recht/Nichtrecht unterzogen werden; Recht kann als Nichtrecht beobachtet werden und umgekehrt. Auch im Wissenschaftssystem kann Wahres als falsch und Falsches als wahr beobachtet werden. Dies sind Beispiele dafür, wie das Anwendungsparadox auf der Codeebene wirksam ist.

Um nicht in einen infiniten Regress der Selbstbefragung zu verfallen, kultivieren die Funktionssysteme eigene Techniken der Ent-Paradoxierung. Sie verdrängen diese Unsicherheiten in ihrem eigenen Operieren und versuchen sie unsichtbar zu machen. Ihnen gelingt dies stets nur vorläufig. Die Paradoxie kann immer wieder aufscheinen und Anlässe für eine Korrektur der Selbstreferenz bieten. ${ }^{167}$

Hatte die orthodoxe Fassung der Systemtheorie schon diese paradoxe Grundstruktur im Blick, lädt die linksluhmannianische Richtung die Paradoxie zu einem Realwiderspruch zwischen Regimen und sozialen Umwelten auf. ${ }^{168}$ Mit der Eigenrationalitätsmaximierung und den Techniken der Ent-Paradoxierung ist gleichursprünglich die Möglichkeit der Re-Paradoxierung gegeben. Skandale und Irritationen können die systemische Selbstreferenz unterbrechen und die Paradoxien sichtbar machen. Der re-entry der System/Umwelt-Unterscheidung öffnet den Raum für die Reflexion über die jeweilige spezifische (Nicht-)Identität des Funktionssystems und ermöglicht es so, Selbstbeschränkungen einzuführen.

Damit erhält die Paradoxie allerdings einen etwas veränderten Status als in der Luhmann'schen Systemtheorie. Dort »benutzt das System die Paradoxie, um sich anhand eines asymmetrischen Differenzierungszwangs zu entparadoxieren und seine Entwicklung als System zu ermöglichen ${ }^{169}$. In der

stellbare der Politik. Zur Hegemonietheorie Ernesto Laclaus, Wien: Turia + Kant 1998, S. 52-66, hier S. $58 \mathrm{ff}$.

167 | Im Hinblick auf die Rechtsparadoxie und die Entparadoxierung durch Rechtssicherheit: Goncalves, Guilherme L.: II Rifugio delle Aspettative. Saggio sulla Certezza del Diritto, Lecce/ Rovato: Pensa Multimedia 2013.

168 | Vgl. A. Fischer-Lescano, Kritische Systemtheorie Frankfurter Schule, S. 56 f.

169 | Blecher, Michael: Zu einer Ethik der Selbstreferenz oder: Theorie als Compassion. Möglichkeiten einer Kritischen Theorie der Selbstreferenz von Gesellschaft und Recht, Berlin: Duncker \& Humblot 1991, S. 55. 
orthodoxen Lesart sichert die Möglichkeit der Reparadoxierung die nötigen Anpassungsleistungen, die Funktionssysteme erfüllen müssen, um ihre Selbstreferenz sicherzustellen. In der linksluhmannianischen Richtung jedoch birgt die Paradoxie dagegen nicht nur die Potentiale kognitiv-anpassenden, sondern auch normativen Lernens: Indem die Selbstreferenz unterbrochen wird, entstehen Reflexionsprozesse und Interpenetrationen zwischen System und Umwelt, die zu einer auch normativ gehaltvollen Selbstkorrektur beitragen. Die Paradoxie ist das Einfallstor für einen funktional spezifizierten »constitutional moment $\ll^{170}$ der transnationalen Regime. Auf diese Weise ist die Eigenrationalitätsmaximierung nicht nur als eine überwältigende oder sogar destruktive Macht zu kennzeichnen. Vielmehr ist in der Grundstruktur der funktionalen Differenzierung der Anknüpfungspunkt für eine Entfaltung regimespezifischer Paradoxien enthalten, die Spielräume für normatives Lernen eröffnet.

\section{Grenzen der Regimediagnose}

Mit den transnationalen Regimes liegt eine Annäherung an den rechtlichen und politischen Formwandel der postnationalen Konstellation vor. Insofern ist der erste, vorbereitende Schritt für eine aussichtsreiche Diskussion der globalen Verfassungsfrage erfolgt - nämlich eine Abmessung des weltgesellschaftlichen Zustands und seine Konsequenzen für Recht und Politik. Dies wird folgenreich für die Koppelung von Recht und Politik in der transnationalen Verfassungsbildung sein, wie sich später zeigen wird. Trotzdem kann die Weltgesellschaftsthese selbst in ihrer linksluhmannianischen Variante nicht vollends überzeugen. Zwischen einem Typ postnationaler Herrschaft in den Regimen und dem systemtheoretischen Register einer Ausdifferenzierung, die eigentlich keinen originären Platz für Hegemonieverhältnisse bereithält, klafft eine eigentümliche Lücke. Offensichtlich gehen die Gefährdungslagen nicht von allen Regimen aus. Die Kollisionen sind asymmetrisch strukturiert und weit von einer gleichrangigen Ausdifferenzierung der Teilsysteme entfernt, wie sie orthodox insinuiert wird. Indem die Systemtheorie semantische Unterscheidungen vom Typ oben/unten und Teil/Ganzes in den Wirkungskreis alteuropäischer Ideologie verwiesen hatte, fehlen ihr die Mittel, um den neuen Dominanzverhältnissen nachzugehen.

Wie symptomatisch dieses Defizit ist, wird bei der Rezeption der Weber'schen Polytheismusthese deutlich. Weber hatte einen Polytheismus in der modernen Gesellschaft herannahen sehen und gezeigt, wie ein formal-instrumenteller Rationalitätstyp in Wirtschaft und staatlicher Bürokratie entsteht, der von

170 | Siehe G. Teubner, A Constitutional Moment?, S. 10; eingehender zu den Verfassungsperspektiven vgl. den dritten Teil, II, ab S. 193. 
dort aus die moderne Gesellschaft als Ganze prägt. ${ }^{171}$ Die These besteht darin, dass bestimmte Sozialsysteme - hier Staat und Wirtschaft - den Modernisierungsprozess überdeterminieren. Dies übersteigt einen heterarchischen Pluralismus. ${ }^{172}$ Damit erhält die Unterscheidung Teil/Ganzes wieder Aktualität. Die transnationalen Regime bilden destruktive Potentiale aus, da sie als Teil der Weltgesellschaft für sich in Anspruch nehmen, das Ganze der Weltgesellschaft zu repräsentieren. Wie passt diese Totalisierungstendenz mit der funktionalen Differenzierung zusammen, die schließlich eine innere Selbstbeschränkung der Systeme schon immanent behauptet? Indem beispielsweise das Wirtschaftssystem seine Kommunikation über den Code Zahlung/Nichtzahlung herstellt, findet eine Begrenzung der Systemlogik statt, da alle anderen Kommunikationen in die soziale Umwelt verwiesen werden. Man könnte systemtheoretisch-orthodox behaupten, dass die Funktionssysteme genetisch auf einen Modus der Selbstbeschränkung hinauslaufen. ${ }^{173}$ Es stellt sich also die Frage, woher der Drang zur Universalisierung herrührt.

Der Erweiterungsbedarf bezieht sich auch auf die korrespondierenden Konflikttypen. Mit Kollisionen und Paradoxien sind zwar einzelne Konfliktdimensionen der Weltgesellschaft näher beleuchtet worden. Aber wie steht es eigentlich um andere Konflikttypen, die nicht auf der Grenze der Funktionssysteme situiert sind, sondern in ihrem Zentrum ${ }^{174}$ Erschöpfen sich die Konfliktlagen der Weltgesellschaft in paradoxen Szenen der Selbstreflexion? Können die Momente des re-entry schon die Gewähr für eine Einhegung der Eigenrationalitätsmaximierung bieten?

Es fällt schwer, Konflikte um die Verteilung von Macht, Reichtum und die Verfügungsgewalt über Eigentum als Kollision bereichsspezifischer Rationalitäten allein darzustellen. Der Soziologe Hauke Brunkhorst insistiert deshalb, dass

"Marx und Adorno, Lukacs und Habermas, Marcuse und Žižek richtig lagen, wenn sie darauf bestanden, dass es keine gesellschaftlich neutrale und unvermittelte funktionale Differenzierung von System und Umwelt gibt und dass Probleme der Umweltverschmut-

171 | Siehe nur die Rekonstruktion der Weber'schen Soziologie in J. Habermas, Theorie des kommunikativen Handelns I, S. $225 \mathrm{ff}$.

172 | Demgegenüber vgl. aber Weber als Pluralist, A. Fischer-Lescano/G. Teubner, Regime-Kollisionen, S. 27.

173 | So Luhmann auch in seiner Kritik an einer normativen Öffnung der Systemtheorie: Luhmann, Niklas: "Einige Probleme mit reflexivem Recht‘", in: Zeitschrift für Rechtssoziologie 6/ 1 (1985), S. 1-18, hier S. 7.

174 | Luhmann hält sie für Tautologien, siehe ders., Soziale Systeme, S. 493. 
zung, Exklusion und Kommodifizierung nicht von sozialen Klassenstrukturen und Klassenkämpfen getrennt werden können «. ${ }^{175}$

Vor diesem Hintergrund bleibt es also bei der Kritik an

1. der Restreifizierung: Die neuere Systemtheorie stößt an die Grenzen der Reifizierung sozialer Systeme;

2. den unausgewiesenen Hegemoniedimensionen: Bisher fehlen die Mittel, um hegemoniale Regime, die sich für das Ganze der Weltgesellschaft ausgeben, auszuleuchten. Woher rührt die Totalisierungstendenz, der Drang zur Fülle in der jeweiligen Eigenrationalitätsmaximierung? Wie wird erklärt, dass das WTO-Regime beispielsweise die Kommunikationslage der Weltwirtschaft eher bestimmt als die International Labour Organization?; sowie

3. mangelnder Konfliktsensibilität: Die kritische Systemtheorie legt die Prekarität der kommunikativen Anschlüsse frei und spielt ihre Sympathien für spontane Sozialbewegungen auf dem weiten Terrain der Zivilgesellschaft aus. Paradoxien bilden aber nur einen Typ des Konflikts, dessen Status zu anderen Typen - etwa Widersprüchen und Antagonismen - noch weitgehend offen ist.

Diese Kritikpunkte sollen nicht über die Leistungen der neueren Systemtheorie hinwegtäuschen. Sowohl der Weltgesellschaftsthese als auch der Beobachtung zu den Regimen ist zu folgen, da so die Gefährdungslagen einer verselbstständigten Selbstreferenz überhaupt sichtbar werden. Die Prozesse sozialen Wandels und sozialer Konfliktivität, die seit den 1990er Jahren zunehmend unter dem Gesichtspunkt einer »Verfassungsbildung jenseits des Staates « untersucht werden, sind jedoch aus systemtheoretischer Sicht allein nur schwer zu erhellen. Deshalb soll im Folgenden das systemtheoretische Register geöffnet werden. Erforderlich ist eine hegemonietheoretische Umschrift.

\section{Hegemonie}

Im Mittelpunkt der bisherigen Überlegungen stand der Befund, dass die systemtheoretische Diagnose bisher noch keine hinreichende Sensibilität für die herrschaftsgesättigten Unterordnungsverhältnisse der Weltgesellschaft gewon-

175 | Brunkhorst, Hauke: "The Return of Crisis", in: P. F. Kjaer/G. Teubner/A. Febbrajo, The Financial Crisis in Constitutional Perspective (2011), S. 133-171, hier S. 148. Brunkhorst erweitert das Modell der funktionalen Differenzierung um staatsorientierte, kapitalorientierte und glaubensorientierte Konflikte, die als Widersprüche darstellbar sind. 
nen hat. Bisher wird ein Expansionsdrang der Regime beobachtet: Sie versuchen ihr Esperanto zu verallgemeinern. Woher rührt aber der Impuls, der auf die Herstellung von Allgemeinheit hinausläuft? Welche Rolle spielen soziale Konflikte in diesem Prozess? Zehren sie nachgängig von der Selbstreferenz der Regime oder spielen sie eine wesentlich wichtigere Rolle als die Differenzierungsthese bisher nahelegt?

Der Vorschlag, der im Folgenden entwickelt werden soll, zielt auf eine hegemonietheoretische Umschrift und damit auf eine Verbindung von Systemund Hegemonietheorie. Erst eine Herangehensweise, die zwischen Äquivalenz und Differenz, zwischen systemischer Rationalität und sozialem Konflikt vermittelt, kann begreiflich machen, worin die Merkmale der Verfassungsbildung jenseits des Staates bestehen. Dabei liefert der postmarxistische Hegemoniebegriff den entscheidenden Ansatzpunkt für eine solche Vermittlung. Die Asymmetrien der Regime werden so auf eine hintergründige, hegemoniale Logik zurückgeführt. Insofern folgt der Übergang zur Weltgesellschaft nicht nur einer allgemeinen Ausdifferenzierung; vielmehr ist er von neuartigen Hegemonieverhältnissen gekennzeichnet (dazu V.1, ab S.83). Dies führt allerdings auch dazu, die Beziehung zwischen Selbstreferenz und Konflikt umzuschreiben. Der paradoxen Grundstruktur moderner Sozialsysteme scheint ein antagonistischer Konflikttyp vorgelagert zu sein. Die Weltgesellschaft ist eine antagonistische Gesellschaft (dazu V.2, ab S. 92). Das Politische ruht nicht mehr nur nachgängig auf der funktionalen Differenzierung. Es ist, so wie es im Hinblick auf die machtanalytische Regimekonzeption schon angeklungen ist, konstitutiv für die Herausbildung der transnationalen Regime. Gerade am Beginn der Regimedifferenzierung stehen auch Konflikt- und Kräfteverhältnisse, die das, was danach kommt, entscheidend prägen (dazu V.3, ab S. 96). Schließlich läuft die hegemonietheoretische Umschrift auch auf eine normative Pointe zu: Das Motiv der »Leere« kann angeben, worin die postdemokratischen Tendenzen der Regime bestehen (dazu V.4, ab S. 98).

\section{Marktliberale Hegemonie}

In den bisherigen Ausführungen ist ein charakteristisches Merkmal deutlich geworden. Die Regime vervielfältigen sich nicht nur, sie bilden ebenso eine hegemoniale Tendenz aus. Gerade die machtanalytischen Zugriffe haben die Rolle von Repräsentations- und Veridiktionsmechanismen betont. Spezifische Zeichenregime bringen Ausschluss- und Einschlussregeln hervor; je spezifische Wissensformen oder Natürlichkeitsannahmen strahlen in die Weltgesellschaft aus. Auf diese Weise schaffen sie dauerhafte Machtverhältnisse. Nun scheint alles darauf hinzudeuten, dass es bei einer bloßen Beschreibung dieser Vorgänge nicht bleiben kann. Es stellt sich die Frage, woher der Drang zur Ausweitung rührt. Bisher sind zwar ausführliche Beispiele bemüht worden, der genannte 
Impuls hat allerdings noch keinen systematischen Platz erhalten. Darum soll eine Umschrift erfolgen, die den Hegemoniebegriff in die Regimediagnose einarbeitet. ${ }^{176}$ Zunächst werden diejenigen theoretischen Ressourcen aufgenommen, die schon immer auf die verallgemeinernden Tendenzen hingewiesen haben. Sicherlich ist der italienische Kommunist Antonio Gramsci mit seinen Thesen zur Hegemonie aus den $1920 e r$ und 1930er Jahren die prominenteste Fundstelle. Gramsci ging davon aus, dass die bürgerliche Klasse ihre Herrschaft in der modernen Gesellschaft nicht nur durch bloßen Zwang herstellt. Im Gegenteil beobachtet er ein komplexes Wechselspiel aus Zwangs- und Integrationsmechanismen. Indem ein weites zivilgesellschaftliches Terrain entsteht, das den kulturellen Raum für die Verallgemeinerung unterschiedlicher Weltanschauungen schafft, wird die kasernierte Herrschaft durch Führungsverhältnisse ergänzt. ${ }^{177}$ Die Analyse von Polizei, Militär oder ökonomischer Ausbeutung allein kann deshalb noch nicht begreiflich machen, wieso die Herrschaftsunterworfenen, die Subalternen, die Dominanz der bürgerlichen Klasse akzeptieren. Hier kommen dann die Öffentlichkeit, die Kirche, das Bildungssystem oder die Kulturindustrie ins Spiel. Sie transportieren oft eigensinnige Weltanschauungen und bringen die Subalternen auf diese Weise dazu, die Perspektive der herrschenden Klasse zu übernehmen. ${ }^{178}$ Dies sollte nicht darüber hinwegtäuschen, dass die Hegemonie auch auf Zwang und Gewalt beruht, aber erst nichtrepressive Führungsmechanismen ermöglichen eine stabile Herrschaftsausübung.

Was offensichtlich in den Ausführungen Gramscis aufscheint, ist ein praktisches Interesse an Veränderung. ${ }^{179}$ Wenn die bürgerliche Gesellschaft eine komplexe Hegemoniekonstellation abgibt, kann sie nicht einfach durch die Übernahme der zentralen Machtpositionen in Staat und Ökonomie umgestaltet werden. Auf die Hegemoniepolitik der bürgerlichen Klasse kann nur ein ähnlich gearteter Zugang der subalternen Klassen antworten, der seinen Platz ebenso in den zivilgesellschaftlichen Sphären einnimmt. Eine wirksame Gegenhegemonie ist nur als gesellschaftliches, mithin kulturelles Projekt denkbar, das eine aktive politische Konstruktionsleistung erforderlich macht: ${ }^{180}$ Weder führt die kapitalistische Produktionsweise notwendig zu einer Anglei-

176 | Vgl. zu dieser Verbindung insbes. Stäheli, Urs: Sinnzusammenbrüche. Eine dekonstruktive Lektüre von Niklas Luhmanns Systemtheorie, Weilerswist: Velbrück 2000.

177 | Vgl. A. Gramsci, Gefängnishefte, S. 1610.

178 | Vgl. ebenda, S. 1267.

179 | Vgl. insbes. ebenda, S. $1353 \mathrm{ff}$.

180 | "Der moderne Fürst, der Fürst-Mythos kann keine wirkliche Person, kein konkretes Individuum sein, er kann nur ein Organismus sein; ein komplexes Gesellschaftselement" (ebenda, S. 1537). Dann braucht es allerdings auch eine Dimension der "Neuschöpfung" (ebenda, S. 1538), die der moderne Fürst einleitet. 
chung der Interessenlagen, wie Karl Marx noch im »Kommunistischen Manifest« spekulierte, noch führt sie zwangsläufig zu Widerstandsbewegungen. Der Fluchtpunkt der Hegemonie besteht darin, Allianzen in sich heterogener sozialer Kräfte unter dem Gesichtspunkt möglicher Verallgemeinerung zu organisieren.

Diesen Faden haben Chantal Mouffe und Ernesto Laclau in den $1980 e r$ Jahren wieder aufgegriffen und zu einer eigenen, postmarxistischen Hegemonietheorie weiterentwickelt. Ihr Zugang ist für unsere Zwecke vor allem deshalb von Bedeutung, da er gegen ein soziologisierendes Systemdenken gerichtet ist, das keinen Platz mehr für den politischen Konflikt bereithält. Laclau und Mouffe sind keine Systemtheoretiker; ja sie schreiben in ihrer ersten gemeinsamen Publikation gegen einen marxistischen Funktionalismus an, der soziale Widersprüche direkt aus der ökonomischen Systemrationalität abzuleiten versucht. ${ }^{181}$ Sie unterziehen marxistische Kategorien wie Hegemonie, Klasse oder Widerspruch einer Lesart, die vom zeitgenössischen Poststrukturalismus und der Dekonstruktionsphilosophie inspiriert ist. Daraus folgt eine grundlegend andere Herangehensweise. Sie siedeln den Hegemoniebegriff nicht mehr auf der Ebene des Klassenkampfes an, sie verlegen ihn auf die Ebene des Diskurses vor. ${ }^{182}$ Hier schließen sie an die schon eingeführte Unbestimmtheit der Bezeichnungsprozesse an, sie ergänzen aber einen Argumentationsschritt, der die Sinnfixierung wieder aufnimmt. Das Spielfeld des Diskurses - das ist die

181 | Laclau, Ernesto/Mouffe, Chantal: Hegemonie und radikale Demokratie. Zur Dekonstruktion des Marxismus, Wien: Passagen-Verlag 1991, insbes. S. $112 \mathrm{ff}$. Der Antiessentialismus sieht bisher nicht hinreichend, dass er wieder in die Ökonomie zurückführt. Nachdem Laclau/Mouffe darauf bestehen, dass auch die jeweiligen Gesellschaftsformationen auf diskursive Artikulationen zurückführen, die sich zu einer dauerhaft "sedimentierten Objektivität" (Laclau, Ernesto: New Reflections on the RevoIution of our Time, London/ New York: Verso 1990, S. 35) verdichten, liegt es nahe, auch aufzuklären, wie hier eine verselbstständigte Systematizität und dauerhafte Interaktionsverhältnisse zwischen Wirtschaft, Recht und Staat entstehen. Bisher neigt die postmarxistische Diskussion oft dazu, mit detektivischem Eifer sogenannte Essentialismen aufzudecken, statt das theoretische Reservoir spezifischer, beispielsweise im Hinblick auf eine postmarxistische Kapitalismustheorie, eine Theorie des Rechts, des Staates etc., zu nutzen.

182 | Vgl. E. Laclau/C. Mouffe, Hegemonie und radikale Demokratie, S. 127 ff.; für die sozialwissenschaftliche Anwendung vgl. Howarth, David R./ Norval, Aletta J./Stavrakakis, Yannis: Discourse Theory and Political Analysis. Identities, Hegemonies and Social Change, Manchester: Manchester University Press 2000; Angermüller, Johannes/Nonhoff, Martin/Herschinger, Eva/Macgilchrist, Felicitas/Reisigl, Martin/Wedl, Juliette/Wrana, Daniel/Ziem, Alexander (Hg.): Diskursforschung. Ein interdisziplinäres Handbuch, Bielefeld: transcript 2014. 
zentrale Weichenstellung - wird nämlich nur durch eine »Konstruktion von Knotenpunkten [eröffnet - d. Verf.], die Bedeutung teilweise fixieren « ${ }^{183}$. Im Hinblick auf die Gesellschaft geht dies mit einer postfundamentalistischen Position einher: Sie bestreitet den historisch unveränderbaren Vorrang einzelner Sphären, sei es die Ökonomie, der Staat, das Recht oder die Kultur, die das Soziale direkt bestimmen. Worauf die Gesellschaft gründet, was zu einer Hegemonie avanciert, ist historisch umstritten und kann unterschiedliche Ausprägungen annehmen. Trotzdem gibt es immer etwas, und das ist mit den Knotenpunkten gemeint, das sich als dominant erweist. ${ }^{184}$

In diesem Sinne gehen Laclau/Mouffe über den differenztheoretischen Ausgangspunkt hinaus. Stets spüren sie einem vereinheitlichenden Vorgang nach. Das Modell lautet wie folgt:

"Im Kontext dieser Diskussion bezeichnen wir als Artikulation jede Praxis, die eine Beziehung zwischen Elementen so etabliert, dass ihre Identität als Resultat einer artikulatorischen Praxis modifiziert wird. Die aus der artikulatorischen Praxis hervorgehende strukturierte Totalität nennen wir Diskurs. ${ }^{185}$

Hier wird schon deutlich, dass erst die Verknüpfungsleistung (oder im Jargon gesprochen: der Übergang von »Elementen« $\mathrm{zu} » M o m e n t e n «)$ eine solche Strukturbildung in Gang zu setzen vermag. So entstehen Diskurse, die zu »sedimentierten Formen der Objektivität« ${ }^{186}$ gerinnen. Dies verunreinigt die differenztheoretischen Annahmen erheblich. Denn die »Gesellschaft« oder das »Soziale« werden erst dadurch möglich, dass ein Drang zur Universalisierung greift, der einen solchen Vorgang einleitet. Vielfalt und »Vereinfachung«, Differenz und Äquivalenz überlagern sich, ohne das eine auf das andere reduzieren zu können. ${ }^{187} \mathrm{Um}$ diesen Zusammenhang zu kennzeichnen, bemühen Laclau und Mouffe den Hegemoniebegriff. Es reicht gewissermaßen nicht, nur die horizontale Dimension zu betrachten, sondern man muss auch die vertikale, auf Einheit abzielende Dimension berücksichtigen, um soziale Ordnungsbildung zu erhellen.

183 | Ebenda, S. 151.

184 | 0. Marchart insistiert deshalb, dass der Postfoundationalismus Laclaus zwar einen "Grund" des Sozialen zurückweist, aber natürlich eine "Dimension der Gründung" beinhaltet, siehe ders.: "Gesellschaft ohne Grund. Laclaus Theorie des Post-Foundationalism", in: Laclau, Ernesto, Emanzipation und Differenz, Wien: Turia + Kant 2002, S. 7-18, hier S. 12.

185 | E. Laclau/C. Mouffe, Hegemonie und radikale Demokratie, S. 141.

186 | E. Laclau, New Reflections on the Revolution of our Time, S. 35.

187 | Ebenda, S. 171. 
Ist der Diskurs so als »primäres Terrain, auf dem Objektivität konstituiert wird ${ }^{188}$, gekennzeichnet, erhält der Hegemoniebegriff einen neuen Status. Insbesondere bezeichnet er nicht einseitig einen spezifischen Typ bürgerlicher Herrschaft; vielmehr ist er als wirksame soziale Logik zu begreifen, die den schon eingeführten Drang zur Verallgemeinerung ausdrücken soll. In der postmarxistischen Herangehensweise beschreibt Hegemonie also denjenigen Mechanismus, aus dem gesellschaftliche Verhältnisse überhaupt erst hervorgehen.

Man stößt hier auf eine geradezu paradoxe Figur, die von der gegenseitigen Überlagerung von Differenz und Äquivalenz herrührt. Die Diskurse folgen einem Impuls zur Ausweitung. Sie treffen jedoch auf eine grundlegende Blockade, da es ihnen immer nur vorläufig gelingen kann, die Verschiebungen zum Stillstand zu bringen. Als Totalitäten müssen sie scheitern. Damit sind die so entstehenden Bedeutungssysteme zugleich möglich und unmöglich. Auf der einen Seite erscheinen sie »essentiell notwendig«, denn »würden die Differenzen sich zu keinem System zusammenschließen, dann wäre überhaupt keine Signifikation möglich « ${ }^{189}$. Damit bedeutet Hegemonie in klassischer Verwendung das Streben nach Vormachtstellung. Auf der anderen Seite scheitern die vereinheitlichenden Vorgänge, da sie das Spiel der Differenzen nie vollständig aussetzen können. Sie müssen immer das Scheitern dieser Vormachtstellung am unerschöpflichen Reservoir der Differenzen in Rechnung stellen. Die Möglichkeitsbedingung - das Ziehen von Grenzen und Schließen in den Bedeutungssystemen - ist zugleich die Unmöglichkeitsbedingung. Man könnte es auch so formulieren: Die Pointe der Hegemonie besteht genau darin, dass sie beschreiben kann, wie Herrschaftsverhältnisse entstehen, die jedoch immer wieder an Konstitutionsvoraussetzungen des Sozialen scheitern und deshalb nicht »total« oder »absolut« sein können.

Diese Lesart führt einen Aspekt wieder ein, der für die Systemtheorie eigentlich zum Problemkreis stratifizierter Gesellschaften gehörte. Die Unterscheidung Teil/Ganzes wird eingeführt, dabei aber in die diskursiven Artikulationen verlegt. Hier beanspruchen Teile (diskursive Einheiten), das Ganze zu repräsentieren, und scheitern daran, Einheit herzustellen. Dabei ist das Verhältnis von Teil und Ganzem jedoch nicht so zu verstehen, dass ein vorausliegendes Ganzes vorliegt, das nur wieder zusammengesetzt wird, sondern als performativer Akt. Indem Teile für sich beanspruchen, das Ganze zu repräsentieren, üben sie eine ökologische Dominanz aus, die jedoch nie »total« werden kann.

188 | Ders.: On Populist Reason, London/ New York: Verso 2005, S. 68.

189 | Ders.: Emanzipation und Differenz, S. 66. 
Die Logik der Hegemonie produziert eine Fülle, die doch unerreichbar bleiben muss. Das Ganze bleibt unverfügbar. ${ }^{190}$

Wird diese Perspektive auf die Regime übertragen, kann sie die bisher ausgemachten Leerstellen schließen. Die Universalisierungstendenz, die dort angelegt ist, erhält einen systematischen Platz. Sie stellt keine rein negative Externalität dar. Und sie repräsentiert keine degenerierte Turboselbstreferenz, die eine »eigentliche« funktionale Differenzierung korrumpierend überlagert. Im Grunde zeugt sie nur von einer Logik der Hegemonie, die in gesellschaftlichen Verhältnissen schon immer am Werk ist.

Auf diese Weise wird der Übergang zur Weltgesellschaft als fragmentierte Hegemoniekonstellation lesbar. Nicht Gleichrangigkeit oder kreative Pluralität bestimmen das Verhältnis der transnationalen Regime zu ihren sozialen Umwelten, sondern Hegemonieverhältnisse, die in systemtheoretischen Termini als Verhältnisse ökologischer Dominanz zu fassen sind. ${ }^{191}$ Es bleibt dabei, dass die Weltgesellschaft nicht nur durch Vielfalt oder neue Unübersichtlichkeit geprägt ist, sondern auch durch dauerhafte Asymmetrien. Sie sind das Resultat von Prozessen der Hegemoniebildung, die stets Gegenkräften und Blockaden ausgesetzt sind.

Dies ist nicht als ein anything goes misszuverstehen. Erst recht sollte es nicht in eine Enthaltsamkeit münden, die letztlich gar nicht mehr in der Lage ist, eine Diagnose zum Zustand der Weltgesellschaft zu formulieren. Denn faktisch schränken bestehende Hegemonieverhältnisse die Spielräume der Kontingenz, also von dem, was »anders möglich« wäre, immer schon ein. Susan Marks hat deshalb darauf aufmerksam gemacht, dass hegemonietheoretische Betrachtungsweisen durchaus Gefahr laufen, einen Analysestil »falscher Kontingenz« zu kultivieren. Sie ruft in Erinnerung, dass »things can be, and quite frequently are, contingent without being random, accidental, or arbitrary « ${ }^{192}$.

190 | Laclau entwickelt dieses Argument auch in einer Art Parallelisierung der Hegemonietheorie mit der psychoanalytischen Subjekttheorie Jacques Lacans, die auch von einem konstitutiven Mangel als Movens der Subjektbildung ausgeht, vgl. ders., On Populist Reason, S. $115 \mathrm{ff}$.

191 | Vgl. das Konzept ökologischer Dominanz bei Jessop, Bob: "Zur Relevanz von Luhmanns Systemtheorie und von Laclau und Mouffes Diskursanalyse für die Weiterentwicklung der materialistischen Staatstheorie", in: Joachim Hirsch/John Kannankulam / Jens Wissel (Hg.), Der Staat der bürgerlichen Gesellschaft. Zum Staatsverständnis von Karl Marx, Baden-Baden: Nomos 2008, S. 157-179; vgl. auch das Verhältnis von funktionaler Differenzierung und kapitalistischer Gesellschaft bei Schimank, Uwe: „Die Moderne: eine funktional differenzierte kapitalistische Gesellschaft", in: Berliner Journal für Soziologie 19/3 (2009), S. 327-351.

192 | Vgl. Marks, Susan: "False Contingency“, in: Current Legal Problems 62 / 1 (2009), S. 1-21, hier S. 2. Die Kontingenz wird dort falsch, wo sie nicht mehr nur die Umstrit- 
Der Analysestil falscher Kontingenz stellt sich dort ein, wo der Annahme eines fast schon unbegrenzten Möglichkeitshorizonts gefolgt wird, der die Offenheit der gesellschaftlichen Entwicklung überstrapaziert. Im Kern wird dann alles in rein zufällige oder willkürliche Konfliktprozesse aufgelöst, die ja aber durchaus - folgen wir der Hegemonietheorie - mit einer Beschränkung der Spielräume einhergehen. Richtig verstanden kann es nicht um Voluntarismus gehen, sondern um den Versuch zu zeigen, welche Logiken in sozialen Konflikten greifen, wie sie die »sedimentierten Formen« in Staat, kapitalistischer Wirtschaft oder dem Recht hervorbringen und rückwirkend von ihnen strukturiert werden.

Im Hinblick auf die Weltgesellschaft liegen eine Reihe von Untersuchungen vor, die dem transnationalen Weltwirtschaftsregime eine solche hegemoniale Rolle zuweisen. ${ }^{193}$ Hier kann die Hegemonietheorie anknüpfen: Die Rolle des Weltwirtschaftsregimes bringt keine historische Universalie und keinen natürlichen Vorrang zum Ausdruck. Sie ist selbst das Resultat umkämpfter Prozesse sozialen Wandels. Wird die systemtheoretische Beobachtung auf eine Weise umgeschrieben, die Ausdifferenzierung und Hegemoniebildung gleichermaßen berücksichtigt, verändert dies die Sichtweise auf den Übergang zur Weltgesellschaft. Zu fragen ist nicht einzig, wie sich die funktionale Differenzierung in den transnationalen Raum verlängert, $\mathrm{zu}$ fragen ist auch, welche Hegemonieverhältnisse in diesem Übergang beobachtbar sind. Dabei wird die Erzählung der Weltgesellschaftsthese um die Annahme einer Veränderung der sozialen Kräfteverhältnisse und der daraus erwachsenden marktliberalen Dominanz ergänzt.

Solche Überlegungen setzen zumeist mit der Krise der fordistischen Gesellschaftsformation in den 1970 er Jahren ein. ${ }^{194}$ Sie zeichnen eine einfache Verlaufsform nach. Der wohlfahrtsstaatlich geprägte Kapitalismus hatte über einige Jahrzehnte hinweg eine halbwegs stabile Gesellschaftsformation abgegeben. Sie stützte sich ökonomisch auf einen nationalstaatlich regulierten Kapitalis-

tenheit der Institutionen freilegt, sondern dort Möglichkeitsspielräume unterstellt, wo faktisch keine sind. So entstehen "abstrakte" Möglichkeiten, die aber keine Rückendeckung in der jeweiligen historischen Situation haben: "The category of possibility - not just abstract possibility, but real, historical possibility - drops out of sight" (ebenda, S. 20).

193 | Vgl. W. Streeck, Gekaufte Zeit; D. Kennedy, "Law and the Political Economy of the World“; Chimni, B. S.: "International Institutions Today: An Imperial Global State in the Making", in: European Journal of International Law 15/ 1 (2004), S. 1-37; C. Cutler/S. Gill (Hg.), New Constitutionalism and World Order; D. Schneiderman, Constitutionalizing Economic Globalization.

194 | Vgl. Cox, Robert W.: Production, Power and World Order. Social Forces in the Making of History, New York: Columbia University Press 1987, S. 274 ff. 
mus, politisch auf sozialstaatlich grundierte Massendemokratien und kulturell auf die Familienstruktur mit einem männlichen Alleinernährer. ${ }^{195}$ Diese Formation gerät in den 1970er Jahren durch unterschiedliche Faktoren massiv unter Druck. Gerade auf internationalem Terrain ist eine neoliberale Wende beobachtbar, die auf die Internationalisierung der Produktionsverhältnisse und den Abbau der Handelsbarrieren hinwirkt. ${ }^{196}$ Schon zu Beginn der 197oer Jahre erlebt die internationale Währungspolitik eine Veränderung. Freie Wechselkurse lösen den Goldstandard der Bretton-Woods-Institutionen ab - eine Entscheidung, die es überhaupt erst ermöglicht, Geschäftsmodelle im Bereich transnationaler Finanzialisierung zu entwickeln. ${ }^{197}$ Doch die Wende ist nicht auf die im engeren Sinne währungs- und handelspolitischen Institutionen beschränkt. Auch kulturell ist ein Wandel zu beobachten, der die Krisentendenzen mit marktliberalen Mitteln beheben will. Freie Märkte verbunden mit einer kulturellen Stilisierung des unternehmerischen Selbst versprechen, eine Alternative zu sein. ${ }^{198}$

Von hier aus lässt sich die marktliberale Dominanz über weitere Etappen verfolgen. Die letzten Versuche keynesianischer Wirtschaftspolitik mit einem Ausbau der Wohlfahrtsstaatlichkeit scheitern Anfang der 1980er Jahre mit der französischen Linksregierung; in den USA und England dominieren Reagonomics und Thatcherismus. In der EU entsteht in den $1980 e r$ Jahren ein liberales Binnenmarktprojekt. Der europäische Binnenmarkt ist zunehmend von einer »wettbewerbsstaatlichen Integrationsweise ${ }^{199}$ geprägt. Sie orientiert sich an der Höherrangigkeit der ökonomischen Grundfreiheiten gegenüber Demokratie und Sozialregulierung. In den $1990 e r$ Jahren entstehen schließlich die maßgeblichen Institutionen des Weltwirtschaftsregimes. Das gilt für den Basler Bankenausschuss und die Programmierung des IWF auf Strukturanpassungsprogramme für Länder des globalen Südens. Die Politiken von Weltbank und IWF transportieren auf diese Weise eine Austeritätspolitik in die Entwicklungs- und Schwellenländer. Mit der WTO ist schließlich 1995 ein umfassen-

195 | Vgl. Jessop, Bob: The Future of the Capitalist State, Cambridge: Polity Press 2002, S. $56 \mathrm{ff}$.

196 | Siehe dazu schon im Jahre 1973: Poulantzas, Nicos: Die Internationalisierung der kapitalistischen Produktionsverhältnisse und der Nationalstaat, Berlin: Merve 1973.

197 | Vgl. D. R. Wood, Governing Global Banking, S. 36; E. B. Kapstein, "Resolving the Regulator's Dilemma", S. 325.

198 | Zum Verhältnis ökonomischer Regulation und Lebensweise siehe Candeias, Mario: Neoliberalismus. Hochtechnologie. Hegemonie. Grundrisse einer transnationalen kapitalistischen Produktions- und Lebensweise, Berlin/Hamburg: Argument-Verlag 2009.

199 | Ziltener, Patrick: Strukturwandel der europäischen Integration, Münster: Westfälisches Dampfboot 1999, S. 138. 
der Rahmen geschaffen, der die Verallgemeinerung des Freihandels und den Abbau von Zöllen und Subventionen zum Prinzip erhebt. Dies ist maßgeblich darauf zurückzuführen, dass es einzelnen Kapitalfraktionen gelungen ist, ihre politischen Präferenzen in die WTO-Verträge zu überführen. ${ }^{200}$

Die Herausbildung der transnationalen Regime war von Beginn an asymmetrisch strukturiert. ${ }^{201}$ Ihre Triebfeder ist nicht nur die allgemeine funktionale Differenzierung oder die kosmopolitische Verbreitung freiheitlicher Normen. In sozialen Konflikten ist es gelungen, ein neoliberales Hegemonieprojekt zu profilieren. Die jetzige Anatomie der Weltgesellschaft, die auf der Führungsrolle kognitiver Erwartungsstile beruht, ist das Resultat politischer Kämpfe um die vielfältigen Krisentendenzen, die in den 1970er und 1980er Jahren einsetzten.

Das Weltwirtschaftsregime ist fraglos ein Regime unter vielen. Der Punkt ist nur, dass es in der historischen Verlaufsform ökologische Dominanz ausübt. ${ }^{202}$ Das umfasst nicht ausschließlich den ökonomischen Austausch. Als Hegemonieprojekt ist die marktliberale Rechtsstaatlichkeit auch auf rechtliche, politische und kulturelle Dimensionen verwiesen, welche die Universalisierungsambition hinreichend unterfüttern. Insofern ist die hier vorgeschlagene Erweiterung ausdrücklich nicht ökonomistisch gemeint. Im Gegenteil: Aus der Logik der Hegemonie folgt auch, dass die Globalisierung nicht auf diese Dominanz reduziert werden kann. Die Weltgesellschaft als Ganze bleibt unverfügbar, auch wenn es Teilen vorläufig gelingt, sich fürs Ganze auszugeben. Einerseits ist die Weltgesellschaft nicht komplett neoliberal heterodeterminiert. Andererseits ist sie nicht das Feld unendlicher Differenz, sondern auch der Ort

200 | Dies zeigt Wissel, Jens: Die Transnationalisierung von Herrschaftsverhältnissen. Zur Aktualität von Nicos Poulantzas' Staatstheorie, Baden-Baden: Nomos 2007.

201 | Zum Begriff des hegemonialen Projekts vgl. die Operationalisierung im Hinblick auf die EU bei Kannankulam, John/Georgi, Fabian: Die europäische Integration als materielle Verdichtung von Kräfteverhältnissen. Hegemonieprojekte im Kampf um das "Staatsprojekt Europa" (= Arbeitspapier der Forschungsgruppe Europäische Integration an der Philipps-Universität 30), Marburg 2012. Damit wird der Hegemoniebegriff auch als hintergründige Logik aufgefasst. Andere Zugriffe beschränken die Verwendung des Hegemoniebegriffs auf eine spezifische Phase des sozialen Kompromisses und betonen, dass er jenseits einer solchen Kompromissstruktur nur schwer Anwendung finden kann. So z. B. Demirovic, Alex: "Neoliberalismus und Hegemonie ", in: Christoph Butterwegge / Bettina Lösch/Ralf Ptak (Hg.), Neoliberalismus. Analysen und Alternativen, Wiesbaden: VS-Verlag 2008, S. 17-33.

202 | Sie ist nicht im Sinne eines "natürlichen" Primats der Ökonomie, sondern als kontingent zu verstehen, vgl. B. Jessop, Zur Relevanz von Luhmanns Systemtheorie und von Laclau und Mouffes Diskursanalyse für die Weiterentwicklung der materialistischen Staatstheorie. 
von Dominanzverhältnissen. Insofern wirft eine solche Umschrift ein anderes Licht auf die postnationale Konstellation. Sie ist ein ausdifferenziertes Terrain und der Ort, an dem es den politökonomischen Regimen zumindest vorläufig gelingt, Dominanz auszuüben.

\section{Antagonismus und das Außen der Regime}

Eine Schwäche der Regimediagnose bestand darin, dass sie soziale Konflikte vor allem als Kollision oder Paradoxie sichtbar macht. Demgegenüber geht die postmarxistische Herangehensweise von einer radikaleren Umstrittenheit aus. Die Regime bestimmen ihre Identität nicht nur funktional (orthodoxe Systemtheorie) oder in paradoxen Momenten der Selbstreflexion (kritische Systemtheorie). Sie gewinnen sie in Abgrenzung von einem antagonistischen »konstitutiven Außen « ${ }^{203}$ : Bad governance, Protektionismus, Terrorismus und Schurkenstaaten sind nur einige derjenigen Gegner, gegen die sie sich richten und sie doch nicht loswerden. Damit verändern sich die Unterscheidungsmuster. Der Unterscheidung Regime/soziale Umwelt wird eine Unterscheidung Regime/konstitutives Außen vorgelagert.

Dieser Argumentationsschritt kann entwickelt werden, indem man der Frage nachgeht, wie die hegemoniale Logik praktisch wirksam wird. Die analytische Ausweitung von Klassenkämpfen hin auf die Möglichkeitsbedingungen von Gesellschaft überhaupt hatte immer wieder die Kontingenz betont. Selbst die hegemonialen Teile, die das Ganze zu repräsentieren versuchen, scheitern oder sind Gegenkräften ausgesetzt. Aber, so muss weiter gefragt werden, was steht am Beginn einer Hegemoniebildung, wie wird sie überhaupt möglich? Und was spielt sich ab, bis sie sich als bedeutsamer »Knotenpunkt« stabilisiert?

Genau an dieser Stelle verorten Laclau und Mouffe einen Konflikttyp, den sie als Antagonismus bezeichnen. In der Regel wird ihr Denken auch genau in diesem Sinne immer wieder als Konflikttheorie betrachtet, die den unversöhnlichen Kampf zur Geltung bringt. Dabei wird oft übersehen, dass sie das Wechselspiel aus Konflikt und Hegemonie äußerst differenziert ausarbeiten. Dies ist im Folgenden an dem zentralen Problem zu verdeutlichen, wie man sich das Wechselspiel aus Hegemonie und Gegenhegemonie überhaupt vorzustellen hat. Wie laufen die Übergänge von einer bestehenden Hegemonie zu einer neuen Spielart der Hegemonie grundsätzlich ab? Betrachtet man diesen Übergang, wird deutlich, dass hier Institution und Destitution, Einrichtung und Zersetzung gleichermaßen greifen: ${ }^{204}$ Bestehende Hegemonien werden porös. Gegen-

203 | E. Laclau, New Reflections on the Revolution of our Time, S. 9.

204 | Vgl. Marchart, Oliver: "Politik ohne Fundament. Das Politische, der Staat und die Unmöglichkeit der Gesellschaft bei Ernesto Laclau und Chantal Mouffe", in: Michael Hirsch/Rüdiger Voigt (Hg.), Der Staat in der Postdemokratie. Staat, Politik, Demokratie 
hegemoniale Projekte und Akteure fordern sie heraus. Ab einem bestimmten Zeitpunkt scheitern sie, werden zersetzt und ein neues Hegemonieverhältnis entsteht. Zum Zwecke der Darstellung können hier unterschiedliche Stadien unterschieden werden. Zunächst muss die Möglichkeit einer grundlegenden Negativität in gesellschaftlichen Verhältnissen gegeben sein, um überhaupt begreiflich zu machen, wie eine hegemoniale Konstellation durch eine neue abgelöst wird. Bisher hat sich die Diskussion stark auf die positiven, ermöglichenden Vorgänge bezogen, die neue Diskurse hervorbringen. Allerdings ist dieser Positivität eine unhintergehbare Negativität vorgelagert. ${ }^{205}$

In einem ersten Schritt ist nochmals zu unterstreichen: Hegemonien können sich erst dadurch herausbilden, dass sie nie vollständig sein können. Damit ist dieser Mangel aber für jede Hegemonie ein geradezu traumatischer Zusammenhang. Stets liegt ein uneinholbares Außen vor, das jeder Vereinnahmung widersteht. Dieses Außen erhält so eine konstitutive Funktion. Jeder Versuch, das Spiel der Signifikanten zum Stillstand zu bringen, trifft auf eine Grenze, eine irreduzible Negativität, die stets das Regime zu zersetzen droht. ${ }^{206}$ Gewissermaßen steht das Wechselspiel aus Hegemonie und Gegenhegemonie im Bann dieser Grenze. Sie ist der Zeuge für die Unmöglichkeit einer vollständigen Vereinnahmung. Sie blockiert die Fülle des Regimes und das Streben nach einer vollständigen Identität. ${ }^{207}$ Daraus resultiert eine Doppelrolle des Antagonismus: Hegemonieverhältnisse grenzen sich gegen ein Außen ab und gewinnen dadurch an Stabilität. Sie gerinnen zu Institutionen. Die Abgrenzung vom Außen ist aber gleichzeitig die Bedingung dafür, dass diese Institutionen nie total sein können. Das Außen kann nämlich in Anspruch genommen werden, um das hegemoniale Verhältnis zu zersetzen, es zu destituieren. Damit zeugt das Außen auch von einer latenten Negativität, ohne die eine Rede von der Hegemonie überhaupt keinen Sinn ergeben würde. Die antagonistische Grenzziehung ist nicht einzig der Garant für die Stabilität der Institution, sondern auch für die Möglichkeit ihrer Destitution.

Laclau und Mouffe unterscheiden dabei zwischen antagonistischen und anderen Konflikttypen: Im Unterschied zum klassischen Widerspruchsdenken

und Recht im neueren französischen Denken, Stuttgart: Steiner-Verlag 2009, S. 133144, hier S. 134.

205 | Vgl. E. Laclau, New Reflections on the Revolution of our Time, S. 26.

206 | Vgl. ebenda, S. 9 u. 18 ff.

207 | Man sollte hier mit Parallelführungen zur Unterscheidung zwischen Freund und Feind im Sinne von Carl Schmitt durchaus vorsichtig sein, denn es geht um ein Argument, dass in Anlehnung an Lacans Psychoanalyse entwickelt wird und versucht, das Ziehen und die Variabilität der Grenzen zu bestimmen, vgl. für die Abgrenzung von Schmitt: Marchart, Oliver: Das unmögliche Objekt. Eine postfundamentalistische Theorie der Gesellschaft, Berlin: Suhrkamp 2013, S. 308. 
(A - Nicht A) handelt es sich bei einer antagonistischen Beziehung um ein besonderes Verhältnis. Hier blockiert die Existenz der einen Seite (B) das Streben nach Fülle der anderen Seite (A). ${ }^{208}$ Daraus resultiert ein Verhältnis der Gegnerschaft zwischen A und B. Eine Aufhebung des Widerspruchs ist nicht möglich. $B$ ist für A geradezu traumatisch, weil es die Unmöglichkeit der eigenen Fülle immer wieder präsent macht. Dies führt eine durchaus normativ zu verstehende Dimension mit. Der Pol radikaler Negativität schafft den Spielraum dafür, dass bestehende Verhältnisse befragbar bleiben. ${ }^{209}$ Die Negativität kommt so einerseits ins Spiel, wenn sich eine Hegemonie stabilisiert (als konstitutives Außen, gegen das sie eingerichtet wird), andererseits aber auch als Möglichkeit der Befragung und Zurückweisung, die insbesondere dann sichtbar wird, wenn bestehende Hegemonieverhältnisse porös werden und Momente entstehen, in denen eine Offenheit und Leere eintritt (dazu später mehr).

Stand also im ersten Stadium die Möglichkeit der Zurückweisung im Mittelpunkt, so läuft im zweiten Schritt jeder zersetzende Impuls doch wieder auf die dauerhafte Einrichtung, die Institution zu. Zwar erlaubt es die schon eingeführte Negativität, auf eine gewisse Distanz zur bestehenden hegemonialen Fixierung zu gehen und sie zu befragen. Letztlich entkommt sie der hegemonialen Logik allerdings nicht. Sie wird schon in ihrem Anspruch, existierende Hegemonien zurückzuweisen, eigene Einrichtungen vornehmen müssen. Das Zurückweisen der bestehenden Verhältnisse ist nicht logisch ableitbar, es muss selbst politisch geschaffen, eben selbstinstituiert werden. Schließlich und das ist das dritte Stadium - wird das Feld der Institution/Destitution mit Bedeutungen überflutet. Dies geht sogar so weit, dass ein Umschlag stattfindet: Während sich der destituierende Impuls noch gegen einen hegemonialen Gegner behaupten musste, kann er selbst erst Hegemonie erlangen, wenn er das Spiel der Differenzen mit eigenen Bedeutungsangeboten überflutet. Die Diskurse treten in eine Verallgemeinerung ein, die nicht spurlos an ihnen vorbeizieht. Da sie neue Positionen aufnehmen und dem Drang zur Ausweitung

208 | Vgl. E. Laclau/C. Mouffe, Hegemonie und radikale Demokratie, S. 162 ff. Urs Stäheli unterscheidet drei Verwendungsweisen des Antagonismuskonzepts bei Laclau/ Mouffe: 1. Kampf antagonistischer Kräfte, 2. Antagonismus als strukturelle Negation einer Subjektposition, 3. Antagonismus als Unmöglichkeit der Gesellschaft, siehe ders.: "Gesellschaftstheorie und die Unmöglichkeit ihres Gegenstandes", in: Schweizerische Zeitschrift für Soziologie 21 / 2 (1995), S. 361-390, hier S. 379 ff.

209 | In der Charakterisierung dieses Bruchs mit bestehenden Fixierungen betont Laclau ihren unableitbaren, kontingenten Status. Hier ist fraglich, ob Laclaus Kontingenzbegriff noch hinreichend präsent hält, dass jede Form der Negativität auch ihr Material beziehen muss. Kontingenz wäre so eher als Anders-möglich-Sein und zugleich Von-etwas-anderem-abhängig-Sein zu verstehen. Vgl. N. Luhmann, Soziale Systeme, S. 152. 
nachkommen müssen, wächst ihre Unbestimmtheit, erleben sie gar ein folgenreiches Ent-Leeren. ${ }^{210}$ Das ist der Preis der Universalisierung.

Nun folgt im Hinblick auf eine Umschrift der Systemtheorie aus diesem Wechselspiel von Institution und Destitution eine weitere Weichenstellung. Vor die Unterscheidung Regime/soziale Umwelten schiebt sich eine andere Unterscheidung vom Typ Regime/konstitutives Außen. Demnach kann jedes Regime seine (unerreichbare) Identität nur im Verhältnis zu einem konstitutiven Außen bilden, von dem es sich abgrenzt. Die sozialen Umwelten haben keinen neutralen und unbestimmten Status; sie sind auch der Gegner, der die Selbstreferenz zu zersetzen droht. Die Ausdifferenzierung der transnationalen Regime bringt auch regimespezifische Antagonisten hervor.

Deshalb ist es kein Wunder, dass nach dem Ende des Ost-West-Konflikts und dem Ende des bisherigen Antagonisten »Ostblock« in der Weltgesellschaft zunehmend neue antagonistische Semantiken zu beobachten sind, die unterschiedliche Varianten des Außen profilieren. Im internationalen Staatensystem beispielsweise florieren die Begriffe des Schurkenstaats und der bad governance, um das Außen eines wohlgeordneten und dem Frieden verpflichteten Staatensystems zu profilieren. ${ }^{211} \mathrm{Im}$ Bereich des Weltwirtschaftsregimes, das wäre ein weiteres Beispiel, beschreibt sich die WTO vor allem dadurch, dass sie sich von protektionistischer Wirtschaftssteuerung abgrenzt und zum »Schutzwall gegen den Totalitarismus « ${ }^{212}$ erhoben wird. Auch in anderen, weniger prominenten Regimen spielt das konstitutive Außen eine zentrale Rolle. Das Regime globaler sozialer Bewegungen im Weltsozialforum grenzt sich antagonistisch von der neoliberalen Globalisierung ab. ${ }^{213}$

Solche Konflikttypen sind nicht nur die Folgen der funktionalen Differenzierung. Sie gehen dem Übergang in die Weltgesellschaft voraus: Die Negativität und die Positivität regimespezifischer Selbstreferenz bedingen einander. Es ist beispielsweise nicht erst die Ausweitung des Welthandels zu beobachten, in die sich sodann eine marktliberale Orientierung einschreibt; vielmehr sind es der fordistische Wohlfahrtsstaat und sein Steuerungsmodell, die das Außen

210 | Vgl. Laclau, Ernesto: "Was haben leere Signifikanten mit Politik zu tun?", in: ders., Emanzipation und Differenz, S. 65-78.

211 | Vgl. Derrida, Jacques: Schurken. Zwei Essays über die Vernunft, Frankfurt a. M.: Suhrkamp 2003, S. 15 ff.

212 Zit. nach S. Joseph, Blame it on the WTO?, S. 84; und das Anliegen wird mit dem Begriff der Menschenrechte überflutet, so: E.-U. Petersmann, "The WTO Constitution and Human rights".

213 | Vgl. Santos, Boaventura de Sousa: The World Social Forum. A User's Manual, Madison 2004 (http://www.ces.uc.pt/bss/documentos/fsm_eng.pdf 2004), und ders.: "The World Social Forum and the Global Left", in: Politics and Society $36 / 2$ (2008), S. 247-270. 
für die Herausbildung des Weltwirtschaftsregimes abgeben. Das bedeutet aber auch, dass die Rede von der antagonistischen Weltgesellschaft nicht einen wesensmäßig gegebenen Zentralkonflikt stilisiert, etwa zwischen Nord und Süd oder Umwelt und Mensch. Im Gegenteil vervielfältigen sich im Zuge der Ausdifferenzierung transnationaler Regime die antagonistischen Konfliktverhältnisse. Sie nehmen regimespezifische Formen an und werden teils in größere Master-Antagonismen eingepasst. ${ }^{214}$

\section{Das Politische}

Im Hinblick auf soziale Protestbewegungen hatte Niklas Luhmann einst das Bild vom »moralischen Voltigieren auf fremden Pferden « ${ }^{215}$ geprägt. Soziale Protestbewegungen zehrten von Ausdifferenzierungsleistungen der modernen Gesellschaft, so Luhmann. Sie satteln als sekundäre Phänomene auf die Systemdifferenzierung auf. Wie wir gesehen hatten, bleiben selbst neuere systemtheoretische Überlegungen diesem sekundären Status verhaftet: Das Politische taucht auf, wenn Unentscheidbarkeiten in der Selbstreferenz auftreten und Fragen der Machtüberlegenheit/Machtunterlegenheit oder der Umweltadäquanz adressiert werden, nicht jedoch am gründenden Ursprungsparadox. Der Code kann und darf nie zur Disposition stehen. Er kann nicht zur Disposition stehen, da der Sündenfall der funktionalen Differenzierung nicht rückgängig zu machen ist. Allerdings darf er auch nicht zur Disposition stehen. Mit der EntDifferenzierung droht immer der Versuch einem Teilsystem die Gesamtsteuerung zu übertragen, was die Freiheits- und Autonomiepotentiale der modernen Gesellschaft zu unterlaufen droht.

Im Vergleich zu dieser Lösung des Politischen vom Staat und der gleichzeitigen Beschränkung seiner Reichweite geht die hegemonietheoretische Umschrift einen anderen Weg. Sie weist dem Politischen einen anderen Status zu und siedelt es in den schon angesprochenen antagonistischen Konfliktverhältnissen an. Ist das Außen der Regime ein entscheidender Faktor in ihrer Entstehung, dann liegt es nahe, das Politische genau hierhin, an die Grenze, zu verlegen. Damit bleibt es dabei, dass das Politische in die Weltgesellschaft disseminiert und seine Form verändert, es wird jedoch aus seinem sekundären Status entrückt und der systemischen Selbstreferenz vorgelagert. Dies führt zu

214 | Vgl. etwa der "Kampf gegen den Terror", der "clash of civilizations", der Kampf für die Menschenrechte oder jüngst in Europa der Kampf fürs Sparen; siehe für den Bereich der Sicherheitslogik im Verhältnis zum Recht S. Opitz, An der Grenze des Rechts, S. $232 \mathrm{ff}$.

215 | Luhmann, Niklas: Protest. Systemtheorie und Soziale Bewegungen, hg. v. Kai Uwe-Hellmann, Frankfurt a. M.: Suhrkamp 1996, S. 188. 
einem »Primat des Politischen ${ }^{216}$ (nicht der Politik!) über das Soziale. Dort, wo Knotenpunkte entstehen, die sich antagonistisch herausbilden, hat das Politische seinen Ort. Das Politische ist allerdings mehr als der Spezialfall einer außerordentlichen Politik der Ent-Paradoxierung.

Stäheli hat mit seiner wechselseitigen Lektüre von System- und Hegemonietheorie den vielversprechenden Vorschlag gemacht, eine Ergänzung vorzunehmen. Demnach ist in der Systemdifferenzierung eine Politik der Ent-Paradoxierung zu beobachten. Als Anknüpfungspunkt dienen ihm unentscheidbare Situationen, wo die Sinnproduktion gestört ist und bestehende Mechanismen der Ent-Paradoxierung versagen. So entsteht der Spielraum für eine spezielle Spielart der Politik, die das System mit ihren Unterscheidungen überflutet. Sie überschreibt den Code und grenzt sich von einem konstitutiven Außen ab. Die System/Umwelt-Unterscheidung geht in ein antagonistisches Verhältnis über. Dabei verändert die soziale Umwelt ihren Aggregatzustand. Sie bleibt das, »was das System nicht ist, aber diese Negation wird nun als Bedrohung des Systems artikuliert « ${ }^{217}$. Stäheli unterstreicht, dass dieser Modus des Politischen auf der Systemdifferenzierung aufgepfropft ist, und schränkt seinen Geltungsbereich erst einmal ein. Gegen die Allgegenwart des Politischen macht er darauf aufmerksam, dass sich Laclau das Problem einer »überpolitisierten Diskurstheorie « ${ }^{218}$ einhandelt. Schließlich sei für Laclau »jeder Diskurs antagonistisch konstituiert, weil nur durch diese Abgrenzung von einem Außen der totalisierende Horizont geschaffen werden kann, der für die Identität des Diskurses notwendig ist « ${ }^{219}$. Deshalb schlägt Stäheli vor, zwischen dislozierten Diskursen und antagonistischen Diskursen zu unterscheiden. Während dislozierte Diskurse in einem unendlichen Feld der Differenzen unproblematisch vagabundieren, tritt der Antagonismus erst auf, »wenn unterschiedliche Versuche unternommen werden, um die dislozierten Systeme wieder zu nähen, das heißt Knotenpunkte einzurichten, an denen Sinn fixiert werden kann « ${ }^{220}$. Das Politische erscheint als ein Spezialfall der Dislokation. Erst wenn die Veränderbarkeit der bestehenden Systeme aufgedeckt wird und ein Raum entsteht, in dem unterschiedliche Alternativen der Entscheidung auf einem unentscheidbaren Terrain auftauchen, tritt das Politische als Politik der Ent-Paradoxierung auf. Zwar kann so erfasst werden, wie unterschiedliche Regime im Falle ge-

216 | E. Laclau, New Reflections on the Revolution of our Time, S. 33.

217 | U. Stäheli, Sinnzusammenbrüche, S. 298; vgl. auch Horst, Johan: „Politiken der Entparadoxierung: Versuch einer Bestimmung des Politischen in der funktional ausdifferenzierten Weltgesellschaft", in: Amstutz/Fischer-Lescano, Kritische Systemtheorie (2013), S. 189-212.

218 | U. Stäheli, Sinnzusammenbrüche, S. 57.

219 | Ebenda, S. 56.

220 | Ebenda, S. 58. 
scheiterter Kommunikation einen im emphatischen Sinne politischen Typ der Ent-Paradoxierung einschlagen und wie sie sogar ihren Code überschreiben. Auf der anderen Seite bleibt das Politische so ein »Voltigieren auf fremden Pferden«. Es ist fraglich, ob der fundierende Antagonismus, den Laclau vor Augen hat, zwangsläufig auf die angemahnte Überpolitisierung hinauslaufen muss. Es bleibt schließlich dabei, dass innerhalb bestehender Differenzierungsmuster immer auch dislozierte Kommunikationen stattfinden, die nicht notwendig antagonistisch sein müssen. Entscheidend ist aber der Umstand, dass die Einrichtung oder Umarbeitung der genannten Knotenpunkten auch dann politischen Charakter trägt, wenn der Code nicht überschrieben wird.

So wird die Herausbildung transnationaler Regime als politischer Vorgang lesbar, der die funktionale Differenzierung nicht nur in die Weltgesellschaft verlängert, um nachträglich ent-paradoxiert zu werden. Die Internationalisierung der Wirtschaft beispielsweise ist schon von Beginn an als Resultat einer spezifischen Kräftekonstellation zu begreifen. Der Konflikt bricht nicht nach der Internationalisierung hinein. So erhält das Politische einen Status jenseits seiner Nachträglichkeit. Hatte Stäheli es der Ausdifferenzierung nachgelagert, würde hier eine konstitutive Rolle des Politischen angenommen. Dies ist wiederum folgenreich für den zu diagnostizierenden Formwandel von Recht und Politik im Übergang zur Weltgesellschaft. Die funktional ausdifferenzierte Weltgesellschaft entsteht nicht einfach nur durch glatte Evolution. Sie ist auch das Produkt revolutionärer Umbrüche, sozialer Kämpfe und der Verallgemeinerung eigensinniger Rationalitätstypen. Mithin produziert sie schon immer ein Außen, das die funktionale Differenzierung zu ruinieren droht: den Totalitarismus, den Protektionismus, die Schurkenstaaten, bad governance und den Exklusionsbereich.

\section{Leere und Kritik}

In einem abschließenden Schritt soll herausgearbeitet werden, welche Spielräume der Kritik sich auf diesem Weg erschließen lassen. Die systemtheoretische Diagnose hatte vor allem die Unterscheidung zwischen Regimen und sozialen Umwelten normativ aufgeladen. Sie hat darauf verwiesen, dass Korrekturen der verselbstständigten Selbstreferenz möglich sind (Responsivität). Die hegemonietheoretische Umschrift stellt bisher vor allem die Dimensionen des Konfliktes und des sozialen Wandels in den Mittelpunkt, um die Leerstellen der Regimediagnose einzuholen. Hier soll es nun darum gehen, genauer zu betrachten, ob nicht auch eine andere Art der Reflexivität auf dem Spiel steht, wenn man die postmarxistische Position aufnimmt.

Im Kern stellt sich die Frage, ob der Hegemonietheorie nicht noch zusätzliche Ressourcen zu entlocken sind. Auf den ersten Blick scheint es erst einmal so, als sei hier ein eher beschreibendes Programm am Werk, das immer- 
zu das strategische Wechselspiel von Hegemonie und Gegenhegemonie betont. Offen bleibt dann, wo und von wo aus noch kritische Anliegen formuliert werden können, die nicht schon rein instrumentell in die Hegemonieverhältnisse einpasst sind. ${ }^{221}$ Bei diesem rein beschreibenden Zugriff, so soll im Folgenden gezeigt werden, handelt es sich jedoch um eine etwas oberflächliche Betrachtungsweise; vielmehr taucht in der Hegemonietheorie eine Figur der Leere auf, die durchaus als Anknüpfungspunkt für Kritik dienen kann - und die im strengen Sinne auch ein nichthegemoniales Moment enthält.

Betrachtet man den schon eingeführten Zyklus, der verdeutlicht, wie sich die Hegemonieverhältnisse verändern, taucht doch ein Spielraum für Kritik auf. An zwei Stellen ist eine Leere im Spiel, die durchaus eine normative Perspektive anleitet. Wie zu zeigen sein wird, spannt sie auch wieder den Bogen zum Problem der Verfassung.

(1) Populare Leere: Die erste Stelle ist mit dem Ent-Leeren der Signifikanten verbunden. Die Idee ist dabei, dass die Ausweitung lediglich partikularer Diskurse nicht einfach folgenlos an ihnen vorbeizieht. Laclau geht von einer Tendenz des Ent-Leerens aus: Sind zu Beginn einer Artikulation die Signifikanten noch enger an ein Signifikat, also an einen zu bezeichnenden Inhalt gebunden, schwächt sich diese Bindung zunehmend ab, wenn es zu einer Verallgemeinerung kommt. Avancieren die Signifikanten zu einem allgemeinen Bezugspunkt, werden sie zu einer Projektionsfläche höchst unterschiedlicher Inhalte. Sie ent-leeren sich und werden zu politisch umkämpften Konzepten: »Die Entleerung eines bestimmten Signifikanten von seinem bestimmten, differentiellen Signifikat ermöglicht, wie wir gesehen haben, das Auftreten eines >leeren < Signifikanten als Signifikat eines Mangels, einer abwesenden Totalität.« ${ }^{222}$

Laclaus Bezugspunkte sind Begriffe wie Gerechtigkeit, Freiheit, Demokratie, Volk oder Recht, die seines Erachtens in westlichen Gesellschaften zu strukturierenden Signifikanten geworden sind. Unterschiedliche gesellschaftliche Kräfte treten in eine Auseinandersetzung um ihre Besetzung. So ist für die Verallgemeinerung ein Preis zu zahlen, der für Laclau durchaus Vorteile birgt: Die Entleerung geht mit einer öffnenden Bewegung einher. Sie erzeugt Unbestimmtheiten und macht die Grenzziehungen zwischen dem Innen und dem Außen zu einer zunehmend variablen Angelegenheit. Die Entleerung der Signifikanten ermöglicht es, dass antagonistische Konfliktverhältnisse zwischen hegemonialen Projekten in agonistische Verhältnisse der Gegnerschaft überführt werden.

221 | Vgl. für eine normative Lesart der Hegemonietheorie im Anschluss an Derrida: Critchley, Simon: "Is there a Normative Deficit in the Theory of Hegemony?", in: ders./ Oliver Machart (Hg.), Laclau - A Critical Reader, New York: Routledge 2004, S. 113-122.

222 | E. Laclau, "Was haben leere Signifikanten mit Politik zu tun?", S. 73. 
Dass Laclau und Mouffe am Ende die »Demokratie« zu ihrem Hauptansatzpunkt machen, hat genau hier seinen Ursprung. Die demokratische Verfassung bewirkt mit ihrer inhaltlichen Unbestimmtheit genau denjenigen Effekt, der mit einer Entleerung der Signifikanten verbunden ist. Sie stellt sie auf Dauer, indem sie vor allem einen Rahmen der Konfliktaustragung bereitstellt, ohne ein spezifisch-inhaltliches Projekt festzuschreiben. Damit bleiben die Grenzen stets im Fluss, Kontestation und Konflikt schaffen eine identitäre Nichtidentität, die mit leeren Begriffen wie Verfassung, Rechtsstaat etc. zusammengehalten wird. Als zentral erweist sich für Laclau insbesondere der Signifikant des »Volkes«, um den die politische Auseinandersetzung in Demokratien letztlich strukturiert ist. ${ }^{223}$ Er kann, darauf macht er immer wieder aufmerksam, von höchst unterschiedlichen politischen Kräften besetzt werden.

Diese Herangehensweise unterscheidet sich vom rechtspositivistischen Verständnis der demokratischen Verfassung dort, wo die Entleerung der Signifikanten vor allem als ein Effekt sozialer Konflikte eintritt. ${ }^{224}$ Die Entleerung hängt mit dem Umstand zusammen, dass der Drang zur Verallgemeinerung auf Widerstände und alternative, inhaltliche Projekte stößt. Erst so kann eine öffnende Bewegung entstehen. Nicht das Recht und der Gesetzgebungsprozess allein sichern die Leere der Verfassung. Dabei wird natürlich schon deutlich, dass Laclau und Mouffe ihre Hegemonietheorie entweder am Beispiel der nationalstaatlichen Ordnungsbildung nach dem Zweiten Weltkrieg oder am Beispiel politischer Herrschaft unter den Bedingungen in Lateinamerika entwerfen: In der Demokratie treffen konkurrierende, antagonistische politische Bewegungen aufeinander und müssen ihr Verhältnis zueinander bestimmen. Ohne ein solches Aufeinandertreffen würde es schließlich gar nicht zum EntLeeren kommen. Im Grunde liegen doch erstaunliche Parallelen zu Theorien »sozialer« Demokratie der Zwischen- und Nachkriegszeit im deutschsprachigen Raum vor. ${ }^{225}$ Auch sie leiteten eine Offenheit der Verfassung dadurch her,

223 | Vgl. E. Laclau, On populist reason, S. 67 ff., kritisch: Žižek, Slavoj: "Against the Populist Temptation", in: Critical Inquiry $32 / 3$ (2006), S. 551-574.

224 | Das unterscheidet Laclaus Lesart etwa vom demokratischen Positivismus, der die Leere der Verfassung vor allem auf die Ergebnisoffenheit verrechtlichter Gesetzgebung zurückführt, vgl. Maus, Ingeborg: Bürgerliche Rechtstheorie und Faschismus. Zur sozialen Funktion und aktuellen Wirkung der Theorie Carl Schmitts, München: Wilhelm Fink Verlag 1980, S. 37; Kelsen, Hans: Vom Wesen und Wert der Demokratie, Tübingen: Mohr Siebeck 1920, S. 21.

225 | Vgl. Bauer, Otto: "Das Gleichgewicht der Klassenkräfte" (1924), in: Hans-Jörg Sandkühler/ Rafael de la Vega (Hg.), Austromarxismus. Texte zu »Ideologie und Klassenkampf“, Frankfurt a. M.: Europäische Verlagsanstalt 1970, S. 79-97; Kirchheimer, Otto: "Zur Staatslehre von Sozialismus und Bolschewismus", in: Wolfgang Luthardt (Hg.), Von der Weimarer Republik zum Faschismus: Die Auflösung der demokratischen Rechts- 
dass unterschiedliche Varianten gesellschaftlicher Ordnungsbildung aufeinanderprallen und sich nicht im Medium der Verfassung verallgemeinern können. Während der Begriff der sozialen Demokratie allerdings dazu diente, eine parteiliche Verfassungspolitik der Arbeiter- und Gewerkschaftsbewegung denkbar zu machen, betont die Hegemonietheorie stärker den emanzipatorischen Gewinn einer solchen, kompromisshaften Blockadesituation: Die demokratische Verfassung stellt das Wechselspiel aus Hegemonie und Gegenhegemonie auf Dauer. So bleiben die gesellschaftlichen Verhältnisse offen, die Grenzen verschiebbar. Im Grunde läuft die Argumentation auf ein Lob des Popular-Werdens, einer popularen Leere hinaus. Die Tendenz zur Verallgemeinerung birgt emanzipatorische Chancen, weil keine Idee der guten Ordnung einfach so $\gg$ in Stein gemeißelt« werden kann. Das Popular-Werden provoziert einen kommunikativen Kontrollverlust, der die antagonistischen Konfliktverhältnisse nicht aufhebt, aber wenigstens zu zivilisieren und zu vervielfältigen vermag.

Es gehört zu den Schwächen dieser Herangehensweise, dass sie die Bedingungen für das Erscheinen einer solchen öffnenden Bewegung kaum diskutiert - nämlich die Verfassungskompromisse der Nachkriegszeit und eine durch starke politische Bewegungen geprägte Gesellschaft. Wie deutlich werden wird, muss man von einer teleologischen Lesart dieses Zugriffs, wonach der Geschichtsprozess genau auf die populare Entleerung der Signifikanten in demokratischen Gemeinwesen zuläuft, Abstand nehmen. Die postdemokratische Verfasstheit des Transnationalen setzt ja genau dort ein, wo wieder inhaltliche Projekte einer guten Ordnung in den Konstitutionalismus eingetragen werden. Die transnationale Konstitutionalisierung kann deshalb nicht das Terrain einer popularen Entleerung bereitstellen.

(2) Plebejische Leere: Nun fällt noch eine zweite Figur der Leere auf, die in einem viel stärkeren Sinne aus dem strategischen Spiel von Hegemonie und Gegenhegemonie ausbricht und es sogar erst in Gang setzt. Halten wir uns nochmals vor Augen, dass das Wechselspiel aus Hegemonie und Gegenhegemonie nur zustande kommt, wenn ein Punkt radikaler Negativität angenommen wird. Erst ein solcher Punkt ermöglicht es, zu einer bestehenden Hegemonie auf Distanz zu gehen und sie schließlich zu zersetzen. Nicht die Partizipation an der Auseinandersetzung um die Deutungshoheit der verbindenden Begriffe (po-

ordnung, Frankfurt a. M.: Suhrkamp 1976, S. 32-52; Neumann, Franz L.: „Die soziale Bedeutung der Grundrechte in der Weimarer Verfassung" (1930), in: ders., Wirtschaft, Staat, Demokratie. Aufsätze 1930-1954, Frankfurt a. M.: Suhrkamp 1978, S. 57-75; Abendroth, Wolfgang: "Zum Begriff des demokratischen und sozialen Rechtsstaates im Grundgesetz der Bundesrepublik Deutschland " (1954), in: Michael Buckmiller/Joachim Perels/Uli Schöler (Hg.), Gesammelte Schriften Band 2, Hannover: Offizin-Verlag 2008, S. 338-357. 
pulare Leere) steht hier im Mittelpunkt, sondern eine destituierende Distanznahme. In Anlehnung an das historische Vorbild einer solchen negativen Bewegung - die plebejischen Sezessionen in der römischen Republik - kann dieses zweite Moment als plebejische Leere beschrieben werden. ${ }^{226}$ Erst der destituierende Impuls setzt das Wechselspiel in Gang. Damit geht Laclau davon aus, dass die Möglichkeit einer »ethischen Erfahrung «227 existiert, in der die bestehende Hegemonie ihre unhinterfragte Natürlichkeit verliert. Sie kann zurückgewiesen werden. Dieses Moment steht noch nicht vollständig im Bann der Politik mit all ihren strategischen Begleiterscheinungen. Laclau bringt es vor allem mit Transzendenzerfahrungen zusammen. ${ }^{228}$

Als exemplarisches Beispiel dient ihm das vieldiskutierte Problem des Generalstreiks. Hier macht sich Laclau die Unterscheidung zwischen einem nur politischen und einem proletarischen Generalstreik zu eigen, wie sie der Syndikalist George Sorel in seiner Studie »Über die Gewalt« vorgeschlagen hatte. Rosa Luxemburgs Massenstreiktheorie und schließlich Walter Benjamins »Kritik der Gewalt« haben diese Unterscheidung wieder aufgegriffen und umgearbeitet. ${ }^{229}$ So unterschiedlich diese sozialistischen, syndikalistischen oder gera-

226 | Laclau selbst bringt den plebs der römischen Republik ins Spiel, um das herrschaftskritische Stadium zu bezeichnen, auf dem ein gelungenes Popular-Werden aufruht, vgl. ders., On Populist Reason, S. 93. Ich werde zu späterem Zeitpunkt ausführlicher auf den Bezug zum plebs eingehen und zeigen, wie sich die Gewichtung von plebs und populus im Hinblick auf die transnationale Konstitutionalisierung verschiebt: Laclaus "Why the Main Task of Radical Politics is Constructing a People " verändert sich zu "Why the Main Task of Constitutional Politics is Constructing the Plebs"; für neuere Bezüge auf plebejische Politik vgl. Lorey, Isabelle: Figuren des Immunen. Elemente einer politischen Theorie, Zürich: diaphanes 2011; McCormick, John P.: Machiavellian Democracy, Cambridge: Cambridge University Press 2011; Breaugh, Martin: The Plebeian Experience. A Discontinuous History of Political Freedom, New York: Columbia University Press 2013.

$227 \mid$ | [E]thical experience is the experience of the unconditioned in a fully conditioned universe, it has to be necessarily empty", Laclau, Ernesto: "Ethics, Normativity and the Heteronomy of Law“, in: ders.: The Rhetorical Foundations of Society, London/New York: Verso 2014, S. 127-138, hier S. 129.

228 | Vgl. ebenda, S. 131, und ders., "The Death and the Resurrection of the Theory of Ideology", in: ders., The Rhetorical Foundations of Society (2014), S. 11-36, hier S. $30 \mathrm{ff}$.

229 | Vgl. Sorel, George: Über die Gewalt (1906), Frankfurt a. M.: Suhrkamp 1981, S. 134 ff.; Luxemburg, Rosa: "Massenstreik, Partei und Gewerkschaften" (1906), in: dies., Politische Schriften I, Frankfurt a. M.: Europäische Verlagsanstalt 1967, S. 135 228; Benjamin, Walter: "Zur Kritik der Gewalt" (1921), in: ders., Gesammelte Schriften II.1., Frankfurt a. M.: Suhrkamp 1991, S. 179-203. 
dezu messianischen Perspektiven auf den Generalstreik sein mögen, so eint sie doch eine Kritik der vermeintlichen Realpolitik: Demnach kann der Generalstreik nicht nur als politisches Instrument verstanden werden, das dazu dient, Forderungen durchzusetzen. Im Streik selbst gehen die Beteiligten auch auf Distanz zur bestehenden gesellschaftlichen Ordnung. Sie erfahren ihre Handlungsmacht und setzen die Ordnung außer Kraft. So entstehen Räume, von denen eine eigene, heute würde man am ehesten sagen: subjektivierende Kraft ausgeht. Im Konflikt entsteht eine Distanz, in der die Einzelnen die Erfahrung machen, dass die bestehenden gesellschaftlichen Verhältnisse instabil und veränderbar sind. Darüber hinaus stellt sich eine Reflexion über das Ganze der jeweiligen Ordnung ein, in der auch die eigenen Handlungsorientierungen von überschießenden Idealen einer neuen Ordnung, einer anderen Welt beeinflusst sind. Für Laclau birgt diese Situation eine Leere: Das, was er Erfahrung nennt, findet in einem Raum statt, der unbestimmt und offen ist. Sofort - und hier gegen Sorel und Benjamin gerichtet - unterstreicht Laclau, dass es natürlich zu einer politischen »Inkarnation« der Streikaktivität kommen muss, um in das Wechselspiel aus Hegemonie und Gegenhegemonie eintreten zu können. ${ }^{230}$ Aber diese Inkarnation kann nicht logisch aus dem Moment der Leere abgeleitet werden, die Erfahrung wird, so Laclau, in die Inkarnation »investiert«, ohne aber schon selbst notwendig in einen bestimmten politischen Inhalt zu münden. ${ }^{231}$ Laclau ergänzt diese Figur der Leere mit dem Hinweis, dass sie wiederum nicht durch die vollständige Abwesenheit von Inhalten bestimmt ist. Im Gegenteil: »The emptiness with which we are dealing is not simply the absence

230 | Vgl. E. Laclau, The Death and Resurrection of the Theory of Ideology, S. 25. Dieses Wechselspiel aus plebejischer Leere und Inkarnation weist etwa Foucault zurück: "Die ,Plebs besitzt zweifelsohne keine soziologische Wirklichkeit. Es gibt jedoch immer etwas im Gesellschaftskörper, in den Klassen, in den Gruppen und in den Individuen selbst, das in gewissem Sinne den Machtverhältnissen entgeht; etwas, das nicht der mehr oder weniger formbare Rohstoff, sondern eine zentrifugale Bewegung, eine gegenläufige befreite Energie ist. Die ,Plebsı existiert zweifellos nicht, aber es gibt retwası Plebejisches", Foucault, Michel: "Mächte und Strategien", in: ders., Dits et Ecrits 3 (2003), S. 538-550, hier S. 542. Laclau teilt sicherlich den Hinweis auf das destituierende Moment, besteht aber auf der Möglichkeit, dass es wenigstens partiell und unvollständig "inkarniert“ werden muss, um überhaupt sichtbar zu werden.

231 | E. Laclau, "Ethics, Normativity and the Heteronomy of Law", S. 132. Laclau nimmt einen Übergang an, wo die ethische Erfahrung durch ein "Investment" in eine politische Inkarnation mündet (erste Verzerrung), die aber noch an ein Signifikat und bestimmte soziale Gruppen gebunden ist. Sie tritt dann in einen Prozess der Entleerung, des Popular-Werdens ein. Hier findet eine zweite Verzerrung statt. Es gehört zu den Schwächen dieser Perspektive, dass sie kein einziges Mal darüber reflektiert, dass mit diesen Verzerrungen nicht nur etwas gewonnen wird, sondern auch etwas verloren geht. 
of content, but is itself a content - it is a fullness that shows itself through its very absence. ${ }^{232}$ Die Beispiele, auf die Laclau anspielt, beschreiben Erfahrungen, in denen gewissermaßen so viel an Leidenschaften und Forderungen zusammenläuft, dass partikulare Inhalte nicht mehr auszumachen sind. Im Extremfall mündet dies in eine rein negative Bestimmung der Fülle. ${ }^{233}$

Stand im ersten Schritt also eine Entleerung im Mittelpunkt, die vom Popular-Werden herrührt, so kann von einem zweiten Moment gesprochen werden, das als plebejische Leere fassbar wird - eine Leere, die daher rührt, dass die Hegemonie nie wirklich »total« sein kann. Erst Spielräume des Entzugs, der Distanznahme und grundlegenden Infragestellung setzen das strategische Spiel in Gang. Während Laclau immer bemüht ist, vor allem zu zeigen, wie unhintergehbar die erste populare Entleerung ist, muss davon ausgegangen werden, dass erst mit der zweiten, plebejischen Leere und ihren destituierenden Funktionen überhaupt angegeben werden kann, wie eine bestehende Hegemonie zersetzt und durch eine neue abgelöst wird.

Von einer zeitlichen Abfolge des Typs: plebejische Leere - erste Verzerrung (politische Forderung/Inkarnation) - zweite Verzerrung (Popular-Werden) Entleerung der Signifikanten, wie sie Laclau nahezulegen scheint, muss allerdings Abstand gewonnen werden. Sie mag aus Gründen der Darstellung sinnvoll erscheinen, praktisch muss man hier jedoch aufpassen, die plebejische Leere nicht unnötig zu verdunkeln. Denn faktisch ist ja immer alles schon gegeben: Hegemonieverhältnisse, so fragil sie sein mögen, politische Inkarnationen und schon konstituierte Organgewalten. Und der Kreislauf der Hegemonie zehrt nicht nur von den Überschüssen der Erfahrungen, sondern auch umgekehrt: Ein Generalstreik etwa, der nicht von Beginn an eine politische Dimension im Sinne von Forderungen und strategischen Koordinationsleistungen hat, ist schwer vorstellbar. Im Gegenteil ermöglicht die »politische Inkarnation« oft erst, dass ein solches Moment eintritt. Einerseits gilt: Ohne »Organisationen und Kassen ${ }^{234}$ und Realpolitik kein Streik. Andererseits: Keine populare Realpolitik ohne das Drohszenario der plebejischen Sezession.

Im Hinblick auf das Problem der Verfassung setzt diese zweite Figur an einer anderen Stelle an. War mit der popularen Entleerung ein Standpunkt gewonnen, der zeigen kann, wie die demokratische Verfassung mit ihren konstituierten Gewalten einen Rahmen für den sozialen Konflikt bereithält, steht hier eine Reflexivität auf dem Spiel, die Verbindungslinien zur Idee der konstituierenden Macht aufweist. Zwar steht die konstituierende Macht schon immer im Bann politischer Inkarnation und auch des Rechts selbst, enthält jedoch auch

232 | Ebenda, S. 130.

233 | Vgl. ders.: "On the Names of God", in: ders., The Rhetorical Foundations of Society (2014), S. 37-52, hier S. $38 \mathrm{ff}$.

234 | R. Luxemburg, Massenstreik, Partei und Gewerkschaften, S. 136. 
ein plebejisches Potential, indem sie eine Reflexion aufs Ganze mitführt (und nicht nur auf spezifische soziale Logiken oder Teilbereiche). Sie enthält eine Negativität und charakteristische Rücknahmedrohung, die eingangs schon im Hinblick auf die Marx'sche Rekonstruktion der demokratischen Verfassung herausgearbeitet wurden. ${ }^{235}$ Insofern kann die demokratische Verfassung mit ihrem Vorrang der konstituierenden Macht auch so verstanden werden, dass sie die zweite Figur der Leere speichert oder wenigstens abrufbar hält. Im Unterschied zu Laclaus Euphorie für die Entleerung im Popularen würden aber die Theoretiker der sozialen Demokratie der Nachkriegszeit Recht behalten: Die Entleerung der Verfassung hängt nicht nur von leeren Signifikanten ab, sondern von der Existenz politischer Bewegungen, die gleichsam eine plebejische Leere präsent halten.

Im Hinblick auf die Verfassungsbildung ist wiederum zu fragen, inwieweit die vorliegenden Ordnungsmuster noch solche Momente aufweisen. Die bisher ausgemachten Anhaltspunkte verdeutlichen, dass die Verfassungsbildung jenseits des Staates im Grunde beider Seiten entbehrt: Weder hält sie Verfahren bereit, die den Rahmen dafür abstecken, antagonistische Konflikte in Verhältnisse der Gegnerschaft zu transformieren, noch enthält sie Anklänge an eine auf das Ganze bezogene Reflexivität, von der aus eine Rücknahme der Differenzierungsprozesse drohen könnte. Das »demokratische« Defizit erweist sich so als Problem mangelnder Leere. Und es scheint eine Spielart des Konstitutionalismus zu entstehen, die eben gerade nicht mehr im Horizont der demokratischen Revolution steht, wie ihn Laclau und Mouffe noch als strukturbildend für die moderne Gesellschaft insgesamt angenommen haben.

\section{Formwandel des Konstitutionalismus}

Insofern ist ein Formwandel des Konstitutionalismus anzunehmen. Unter Formwandel ist dabei zu verstehen, dass die Verfassung weiterhin als höherrangige Form zu verstehen ist, die aber im Übergang zur Weltgesellschaft ihre Gestalt wandelt. Die Verknüpfung von Recht und Politik, ihre strukturelle Koppelung, hatte im nationalen Rahmen die Staatsverfassung gewährleistet. Nun löst sich im Übergang zur Weltgesellschaft die Verfassungsevolution zunehmend von der nationalstaatlichen Ebene. In der fragmentierten Hegemoniekonstellation deuten einige Tendenzen auf eine neue Form des Konstitutionalismus hin. Das erste charakteristische Strukturmerkmal besteht darin, dass in den transnationalen Regimen durchaus eine Verfassungsbildung stattfindet. Dabei übt insbesondere das Weltwirtschaftsregime eine spezifische Dominanz aus (dazu VI.1, ab S.106). Über diese Beobachtung hinaus macht die vorge-

235 | Vgl. den ersten Teil, ab S. 9. 
schlagene Verbindung von Postmarxismus und Systemtheorie begreiflich, dass der Formwandel sich nicht in einer bloßen Vielfalt erschöpft, sondern durch ein weiteres Strukturmerkmal gekennzeichnet ist: Im Zuge einer folgenreichen Substantialisierung werden die Ordnungen mit inhaltlichen Zielbestimmungen aufgefüllt. Substantielle Programme werden in einen höherrangigen Status gehoben. Damit sind sie der Befragbarkeit weitgehend entzogen (dazu VI.2, ab S. 109). So verliert die neue Form des Konstitutionalismus zunehmend ihre Verbindung zur demokratischen Verfassungsidee. Im neuen Konstitutionalismus verhindert die Ausrichtung an einer guten Ordnung, dass antagonistische Konfliktverhältnisse in Verhältnisse der Gegnerschaft umgearbeitet werden können. Und das mit dem Vorrang der konstituierenden Macht verbundene Moment der Distanz- und Rücknahme scheint nicht mehr auf (dazu VI.3, ab S.112). Es sind drei Strukturmerkmale des Formwandels, die aus der postmarxistischen Umschrift der Weltgesellschaftsdiagnose zu gewinnen sind: Regimeverfassungen, Substantialisierung, Rückkehr des Antagonismus.

\section{Regimeverfassungen}

Auf dem Terrain der Regime liegen, so ist schon deutlich geworden, eine Reihe von Indizien für eine bereichsspezifische Verfassungsbildung vor. Sie sind von eigenen Konstitutionalisierungsprozessen gekennzeichnet, die Recht und Politik aufeinander beziehen. An dieser Stelle ist auf die Grundstrukturen der Verfassung zurückzukommen, wie sie einleitend entwickelt wurden. Die drei Strukturmerkmale der modernen Verfassungsevolution - Höherrangigkeit und Reflexivität, Festlegung der Regierungsart und Organisationsverfassung sowie die Grundordnung gesellschaftlicher Kommunikationschancen - müssen nicht zwangsläufig an den Staat gebunden sein, sie können auch in der Regimeform auftreten.

Das entscheidende Merkmal dieser Vorgänge besteht nun darin, dass sie oft aus evolutionären, eher untergründigen Prozessen, insbesondere im Bereich von Gerichten und Streitschlichtungsmechanismen, hervorgehen. Gemeinhin haben weite Teile der Staatsverfassungstheorie immer wieder auf sogenannte constitutional moments hingewiesen, auf verfassungsgebende Momente also, in denen sich die Frage nach dem Selbstbezug eines Kollektivs stellt. ${ }^{236}$ Die höherrangige Verfassung erlaubt es unter anderem, die dort aufscheinende Reflexivität auf Dauer zu stellen, sie gewissermaßen zu speichern und »normale« Kommunikationen des Rechts- und Politiksystems einer Zweitbeobachtung vom Typ verfassungswidrig/verfassungsgemäß auszusetzen. Solche klar ab-

236 | Siehe dazu im Hinblick auf die US-Verfassungsentwicklung: Ackerman, Bruce: "Constitutional Politics/Constitutional Law", in: Yale Law Journal 99 / 3 (1989), S. 453547, hier S. 489. 
lesbaren, öffentlichen Gründungsakte (oder Erzählungen über sie), die etwa in der Folge revolutionär-demokratischer Umwälzungen in die Verfassungsevolution eingeschrieben wurden, sind im Transnationalen nicht recht sichtbar oder nehmen vollkommen anderen Charakter an als das we-the-people der klassischen Gründungsakte.

Eher ist davon auszugehen, dass in Prozessen langer Dauer, durch inkrementelle Rechtsprechung und Politisierung, Verfassungsinstitutionen entstehen. ${ }^{237}$ Darüber hinaus ist zu beobachten, dass Semantiken des Vertrages, der Charta oder gemeinsamer Prinzipien bemüht werden, die zwar nicht explizit von der »Verfassung « handeln, aber die in transformativen Iterationen $\mathrm{zu}$ höherrangigen Ordnungen werden. ${ }^{238}$ Dass die handelnden Akteure nicht zwangsläufig die Verfassungssemantik verwenden, sagt noch nichts darüber aus, ob die Regimeform nicht schon längst einige Funktionen der Verfassung erfüllt. Man muss diesen untergründigen Zug dadurch ergänzen, dass auch diese subkutanen Prozesse durchaus politischen Charakter tragen: Wie der Argumentationsgang nahegelegt hat, werden hier stets Hegemonieverhältnisse hergestellt. Dies gilt natürlich auch, wenn Spielarten des private ordering stattfinden oder eine scheinbar technokratische Verrechtlichung auf den Weltmärkten greift: Wer diese Vorgänge nicht mehr als politische Strukturierung von Hegemonieverhältnissen lesbar machen kann, neigt dazu, die Bedeutung des politischen Systems des Nationalstaats zu überschätzen und die Bedeutung der transnationalen politischen Ökonomie zu unterschätzen. Man bewegt sich dann doch, selbst wenn einer öffentlich-rechtlichen Intuition gefolgt wird, in den Gefilden einer Trennungslehre, wonach ökonomische Austauschprozesse im Bereich der Privatautonomie angesiedelt sind und deshalb auch als unpolitisch betrachtet werden müssen.

Das transnationale Weltwirtschaftsregime war der bisherige Anknüpfungspunkt für die Tendenz einer untergründigen Verfassungsbildung. Am Beispiel der WTO ist zu beobachten, dass mit dem WTO-Gründungsvertrag durchaus eine höherrangige Ordnung vorliegt, die sekundäre Normierungen enthält.

237 | Dazu R. Hirschl, Towards Juristocracy; Teubner, Gunther: "Globale Zivilverfassungen: Alternativen zur staatszentrierten Verfassungstheorie", in: Zeitschrift für ausländisches öffentliches Recht und Völkerrecht 63 (2003), S. 1-28; Ladeur, Karl-Heinz/ Viellechner, Lars: "Die transnationale Expansion staatlicher Grundrechte. Zur Konstitutionalisierung globaler Privatrechtsregimes", in: Archiv des Völkerrechts 46 / 1 (2008), S. 42-73; kritisch: Ladeur, Karl-Heinz: "Die Evolution des Rechts und die Möglichkeit eines 'globalen Rechts، jenseits des Staates - zugleich eine Kritik der 'Selbstkonstitutionalisierungsthese «" in: ancilla iuris (2012), S. 220-255.

238 | Vgl. T. Kleinlein, Konstitutionalisierung im Völkerrecht, S. 28 ff.; zu den fließenden Übergängen von Verfassung und Vertrag vgl. auch L. Viellechner, Transnationalisierung des Rechts, S. 188 f. 
Das Streitschlichtungssystem und der appellate body stellen eine Gerichtsbarkeit bereit, die eine unabhängige Spruchpraxis kultiviert hat und über die Einhaltung der Verträge wacht. In den WTO-Verträgen liegt gleichsam eine Art Organisationsverfassung vor, die Entscheidungsregeln enthält und Kompetenzabgrenzungen vornimmt. Auch die Spruchpraxis des appellate body formt die Organisationsverfassung der WTO, indem sie die Ordnung ansatzweise für Akteure wie Unternehmen, Privatpersonen und NGOs geöffnet hat. ${ }^{239}$ Ferner zeichnet sich auch in der WTO zwar kein klassischer Grundrechtskatalog ab, aber durchaus eine bestimmte, marktliberale Interpretation der Grund- und Menschenrechte. ${ }^{240}$ Insofern liegt es nahe, dass zunehmend von einer Konstitutionalisierung der WTO auszugehen ist. Die Vertragssemantik überdeckt, dass die WTO eine höherrangige Eigenverfassung generiert, die basale Reflexivität, Organisationsverfassung und Abgrenzung von Kommunikationssphären enthält. In gewisser Weise komplizierter und volatiler wird die These von der Eigenverfassung in Fällen, wo keine vertraglichen Grundlagen vorliegen und in Sozialprozessen inkrementelle Verrechtlichungs- und Politisierungskreisläufe evoluieren, die nicht in einem Zentraldokument fixiert sind.

Natürlich kann man diese Tendenz nicht auf das Weltwirtschaftsregime begrenzen. Auch in anderen Arenen, etwa in der Regulierung des Internets durch die ICANN, sind Tendenzen zu einer Verfassungsbildung zu erkennen. ${ }^{241}$ Der Punkt ist nur - und hier hat die hegemonietheoretische Umschrift der pluralistischen Überlegungen eingesetzt - , dass diese Verbreitung des Konstitutionalismus oder wenigstens eines constitutional mindsets nicht einfach auf bloße Heterarchie zuläuft. Da der Übergang zur Weltgesellschaft maßgeblich durch marktliberale Hegemonieprojekte bestimmt war, üben die Konstitutionalisierungsprozesse der Weltwirtschaft eine spezifische Dominanz aus. Dies wiederum bedeutet gerade nicht, dass die Globalisierung einfach nur als »neoliberal « zu etikettieren ist. Trotzdem muss man in Rechnung stellen, dass die Verbindung von politischer Ökonomie, Verrechtlichung und der Einbindung staatlicher Apparate in hybride Regime die Weltgesellschaft durchdringt und die Handlungsspielräume demokratischer Entscheidungsfindung in den Nationalstaaten massiv einschränkt.

239 | Siehe etwa die Möglichkeit der Amicus-curie-Schriftsätze in der Shrimp-TurtleAuseinandersetzung: WTO DSU, DS 58, United States - Import Prohibition of Certain Shrimp and Shrimp Products.

240 | Vgl. E.-U. Petersmann, "The WTO Constitution and Human Rights".

241 | Vgl. V. Karavas, "Governance of Virtual Worlds and the Quest for a Digital Constitution". 


\section{Substantialisierung}

Die Beobachtung dieses ersten Strukturmerkmals ist in einem nächsten Schritt zu ergänzen. In erster Linie verändert sich der Status der Konstitutionalisierung. Sie wird vor allem zu einem Medium, das die Eigenrationalitätsmaximierung, das Streben nach Fülle abstützt. Dabei sind nicht alle Verfassungsprozesse gleich $»$ voll $\ll$. Wie wir gesehen haben, ist es gerade dem Weltwirtschaftsregime gelungen, seine Programme für das Ganze der Weltgesellschaft auszugeben. Weder die WTO noch IWF oder Weltbank haben sich mit höherrangigen Normen und Vertragswerken versorgt, um ihre Rationalitäten in herrschaftsbegrenzender Absicht einzuhegen, sondern um eine marktliberale Wirtschaftsrationalität zu verallgemeinern. ${ }^{242}$ Studien aus der kritischen Internationalen Politischen Ökonomie weisen genau auf diesen Befund hin, wenn sie zeigen, wie ein »neuer Konstitutionalismus « entsteht, der neoliberale Politikansätze höherrangig festschreibt. ${ }^{243}$ So erscheinen die Verfassungsbildungsprozesse nicht als Gegengift einer Ausweitung der jeweiligen Logiken. Im Gegenteil, sie halten bisher ermöglichende Bedingungen für kolonisierende Ambitionen bereit. ${ }^{244}$

Neben ihrer abstützenden Rolle ist sodann noch ein weiterer Befund zu bemühen. Die Regime bilden nicht nur eine Dominanz gegenüber ihren sozialen Umwelten aus, sie füllen sich auch selbst mit substantiellen Projekten und Zwecksetzungen. Auch hier dient das Weltwirtschaftsregime als Untersuchungsgegenstand. Es geht hier schließlich nicht beispielsweise um die allgemeine Rahmung wirtschaftlicher Kommunikation. Rechtsprechungslinien und Verträge der jeweiligen Institutionen erklären regelmäßig Freihandel, finanzialisierte Akkumulation, Schuldenabbau und den Investitionsschutz für

242 S Siehe dazu D. Z. Cass, The Constitutionalization of the WTO, und C. Cutler, Private Power and Global Authority.

243 | Vgl. C. Cutler/S. Gill (Hg.), New Constitutionalism and World Order; S. Gill, "Constitutionalizing Inequality and the Clash of Globalizations", S. 47 ff.; Bieling, HansJürgen: "Die Konstitutionalisierung der Weltwirtschaft als Prozess hegemonialer Verstaatlichung", in: Sonja Buckel/Andreas Fischer-Lescano (Hg.), Hegemonie gepanzert mit Zwang. Zivilgesellschaft und Politik im Staatsverständnis Antonio Gramscis, BadenBaden: Nomos 2007, S. 143-160, hier S. 144; Hirschl, Ran: „The Political Origins of the New Constitutionalism «, in: Indiana Journal of Global Legal Studies 11 / 1 (2004), S. 71108; Hayek, Friedrich A.: The Constitution of Liberty, Chicago: Chicago University Press 1978, S. $220 \mathrm{ff}$.

244 | Das schließt nicht aus, dass es gegenwärtig auch gegen- und nichthegemoniale Eigenverfassungen gibt, siehe etwa Möller, Kolja: "Subalterne Konstitutionalisierung. Zur Verfassung von Revolution und Evolution in der Weltgesellschaft«, in: Amstutz/ Fischer-Lescano, Kritische Systemtheorie (2013), S. 169-188. 
Unternehmen zu quasiverfassungsmäßigen Grundlagen. Sie avancieren zum Kern der Verfassungsbildung. Als höherrangige Bestimmungen schränken sie die Bandbreite möglicher politischer Optionen ein. Besonders deutlich wird dieser Befund, wenn man ihn in systemtheoretischen Kategorien reformuliert. Die gewandelte Form des Konstitutionalismus führt zwei Ebenen zusammen, die eigentlich an unterschiedlichen Stellen angesiedelt sind: In die Codierung verfassungswidrig/verfassungsgemäß werden substantielle Programme eingepflanzt. Die Unterscheidung zwischen Codes und Programmen, hier konkret: Weltwirtschaft und Neoliberalismus, verschwimmt. Die Programme sind eben nicht mehr die Ebene, wo eine Öffnung gegenüber den sozialen Umwelten stattfindet (wie es die Systemtheorie eigentlich angenommen hat). ${ }^{245}$ Jetzt sind sie der Ort, an dem sich die Bereichsrationalitäten abdichten und gegenüber möglichen Alternativen immunisieren. Der Konstitutionalismus ist so kein Ort der Öffnung, sondern der Schließung. Der Verfassungsdiskurs erlebt dabei eine eigentümliche Transformation: Die rechtlich-politische Reflexivität, also der Selbstbezug des Teilbereichs, ist durch die Engführung entlang substantieller Programme so begrenzt, dass er sie der Befragbarkeit entzieht. Damit führen grundlegende Fragen - nach dem Zweck des Wirtschaftens, nach der besten Geld- und Haushaltspolitik, nach der Höhe der Investitionsquote etc. notwendig dazu, dass sie »außerhalb« der Eigenverfassung stehen: Mit Freihandelsorientierung, Austeritätspolitik und Schuldenabbau stehen nämlich schon auf Verfassungsebene diejenigen Projekte fest, die als konsensual vorausgesetzt werden. Man fühlt sich hier an Adornos Kritik am Hegel'schen Verfassungsmodell erinnert: »Die >Verfassungく, Name der geschichtlichen Welt, die alle Unmittelbarkeit von Natur vermittelt, bestimmt umgekehrt die Sphäre der Vermittlung, eben die geschichtliche, als Natur. «246

Die letzte Rettung besteht darin, dass mögliche Alternativen sich im Jargon der jeweiligen Verfassungsessenzen artikulieren müssen. Ein gutes Beispiel dafür ist die Auseinandersetzung um Agrarsubventionen im Rahmen der WTO. Es ist offensichtlich, dass die Agrarsubventionen reicher Länder des globalen Nordens für massive Probleme für die Lebensbedingungen im globa-

245 | Systemtheoretisch formuliert: "Ausgehend von der Veränderbarkeit der Codes, kann die Programmebene verstanden werden als Ort, wo alternative Lösungen ausprobiert und unterschiedliche Artikulationen des Codes angeboten werden. Programme dienen als Supplement des Codes, indem sie dessen Anwendung spezifizieren " (U. Stäheli, Sinnzusammenbrüche, S. 283). Zu dieser Öffnungsfunktion der Programme vgl. auch S. Opitz, An der Grenze des Rechts, S. 50 ff.; zum Verschwimmen von Codes und Programmen vgl. Luhmann, Niklas: Die Kunst der Gesellschaft, Frankfurt a. M.: Suhrkamp 1997, S. 309.

246 | Adorno, Theodor W.: Negative Dialektik (= Gesammelte Schriften. Band 6), Frankfurt a. M.: Suhrkamp 2003, S. 350. 
len Süden verantwortlich sind. Auf der anderen Seite sind gerade die ärmeren Länder auf marktschützende Maßnahmen wie Zölle und Eigensubventionen angewiesen, um Hungerkatastrophen zu bekämpfen und einigermaßen stabile Versorgungsstrukturen aufzubauen. Das Agreement on Agriculture kommt scheinbar einem Kampf gegen die Subventionen entgegen. Es betrachtet jegliche Art von Subventionen als »Marktverzerrungen«, die sofort abgeschafft gehören. ${ }^{247}$ Dort, wo es nicht möglich ist, greifen Übergangs- oder Ausnahmeregeln.

In dieser Ausgangslage haben Länder des globalen Südens gegen die Subventionen des Nordens, hier die EU-Zuckersubventionen, geklagt. ${ }^{248}$ Das Problem ist, dass sie selbst auf Sprachspiele verpflichtet sind, mit denen sie ihre eigenen Entwicklungsperspektiven kaum noch artikulieren können. Sie müssen selbst eine radikale Variante der Freihandelsverfassung unterschreiben, um sie gegen die Profiteure des Freihandels zu wenden. Das höherrangig dignisierte Freihandelsprojekt erhält damit eine solche Stärke, dass Freihandelskritik in der Freihandelsverfassung eigentlich nicht mehr erscheinen kann und selbst auf die Sprache des Freihandelsverfassung zurückgeworfen ist. Dies ist eine Leerstelle neuerer Hoffnungen auf eine »Politisierung« der WTO. Hier wird argumentiert, dass etwa unter Artikel IX im Zuge sogenannter waiver Ausnahmeregelungen möglich sind. ${ }^{249}$ Sie sollen als Einfallstor für eine Politisierung dienen, um andere Prioritäten ins Gespräch zu bringen und Abweichungen zu legalisieren. Darüber hinaus hat der appellate body der WTO in einer Reihe von Berichten zunehmend Fragen behandelt, die negative Effekte des Welthandels auf andere Rechtsregime, etwa das Umweltregime oder das Menschenrechtsregime, betreffen. ${ }^{250}$

Nun mögen alle diese Überlegungen als rechtspolitische Handlungsstrategien einleuchten. Das Problem ist bloß regelmäßig, dass es um Ausnahmen von der Priorität des Freihandels geht. Es müsste dann gezeigt werden, wieso solche Ausnahmen auch tatsächlich eine subversive Kraft entwickeln, welche als Ausnahme nicht die Regel einfach nur bestätigen. ${ }^{251}$ Darüber hinaus

247 | Vgl. http://www.wto.org/english/docs_e/legal_e/14-ag_01_e.htm (letzter Zugriff 21.2.2015).

248 | Dazu etwa die Klagen Brasiliens, Thailands und Australiens gegen die EU-Zuckersubventionen bei der WTO: WTO DSU, DS 265, 266 u. 283 European Communities - Export Subsidies on Sugar.

249 | VgI. I. Feichtner, The Law and Politics of WTO Waivers.

250 | Vgl. A. Lang, World Trade after Neoliberalism.

251 | Deshalb wird zunehmend auf die Stärkung anderer Regime gesetzt wie die Food and Agricultural Organization, vgl. Margulis, Matias E.: "The Regime Complex for Food Security: Implications for the Global Hunger Challenge", in: Global Governance: A Review of Multilateralism and International Organizations 19/1 (2013), S. 53-67. 
ist auch fraglich, ob die Bezugnahme auf andere Rechtsregime nicht auch eine Gefahr enthält. Die WTO erweist sich als besonders responsive Institution, indem sie Umwelt- und Sozialbelange in ihren Kompetenzbereich eingliedert, sie dabei aber marktliberal rekonstruiert. ${ }^{252}$ Die Reflexivität ist so von der Freihandelsverfassung durchdrungen, dass die Hoffnungen auf eine Selbstkorrektur durch Konstitutionalisierung zurücktreten. Die eingetragenen Projekte und Programme erschweren eine immanente Befragung. Sie schränken die Bandbreite möglicher politischer Gestaltung ein.

\section{Antagonistische Verfassungen}

Das letzte, dritte Strukturmerkmal des Formwandels zielt auf die Weise, wie soziale Konfliktlinien umgearbeitet werden. Es ist gerade deshalb von Interesse, da es sowohl einen Bezug zum Formwandel aufweist als auch die Frage nach der demokratischen Verfassung wieder in den Horizont der Diskussion einführt. Die postmarxistische Umschrift ging davon aus, dass die Regimeverfassungen sich in Abgrenzung zu einem konstitutiven Außen herausbilden. Sie sind von antagonistischen Konfliktverhältnissen gekennzeichnet. Die eingangs eingeführte Variante der demokratischen Verfassung ruht zwar auf antagonistischen Konfliktverhältnissen auf, das Demokratieprinzip in Verbindung mit Grund- und Menschenrechten eröffnet jedoch die Möglichkeit, die Formen der Herrschaftsausübung zu befragen, zu revidieren oder zu verändern. Die Leere war dabei auf unterschiedlichen Ebenen angesiedelt: Einerseits führt das Prinzip der konstituierenden Macht des Volkes einen Moment der Reflexivität über das Ganze mit, die eine Befragung der bestehenden Hegemonieverhältnisse in Gang setzen kann. Andererseits ist die demokratische Verfassung dadurch ge-

252 | Vgl. auch die Kritik bei Niesen, Peter: Von verfassungsgebender Gewalt zu konstituierender Autorität: ein Grundbegriff für die Internationale Politische Theorie, Antrittsvorlesung Universität Hamburg (2014), Manuskript, S. 6: "Um ein Beispiel zu nennen: auch wenn die Streitbeilegung innerhalb der Welthandelsorganisation WTO sich zunehmend an den Menschenrechten und allgemeinen Fairnessgrundsätzen orientiert und dies allgemein als fundamentale Änderung ihrer Spruchpraxis angesehen wird, ist damit die Frage, ob der Prozess inrer Konstitutionalisierung sich auf verfassungsfortbildende Autorität berufen kann, noch nicht vom Tisch. Kommen wir zur Ansicht, dass die Rechtsentwicklung innerhalb der WTO sich nicht von konstituierender Autorität ableiten lässt, da sie ausschließlich über die richterliche Dogmatik im appellate body, im Berufungsschiedsgericht verläuft, sind wir in der Lage, den Prozess prinzipienorientiert zu kritisieren, als Usurpation konstituierender Gewalt. Diese Verfassungsusurpation im Dienste der Menschenrechte muss aus deren Perspektive nicht falsch sein, verschafft aber der Welthandelsorganisation eine eigenständige Legitimation und wertet sie als vorgeblich unparteiliche globale Verfassungsordnung auf." 
kennzeichnet, dass sie ein positives Verhältnis zum Wechselspiel aus Hegemonie und Gegenhegemonie hat. Historisch ist sie aus Konflikten politischer Bewegungen hervorgegangen, in deren Folge die Verfassung, auch auf der Ebene der schon konstituierten Gewalt, zunehmend zu einer inhaltlich leeren und politischer Gestaltung zugänglichen Ordnung geworden ist. Durch diese inhaltliche Leere der demokratischen Verfassung kann das konstitutive Außen noch einmal in der Verfassung erscheinen. Selbst Demokratiekritik kann in der demokratischen Verfassung legal abgesichert geübt werden. Chantal Mouffe beschreibt diesen Entwicklungsprozess als »agonistische« Transformation der antagonistischen Sozialkonflikte:

"Obwohl sie [die Gegner - d. Verf.] sich also im Konflikt befinden, erkennen sie sich als derselben politischen Gemeinschaft zugehörig; sie teilen einen gemeinsamen symbolischen Raum, in dem der Konflikt stattfindet. Als Hauptaufgabe der Demokratie könnte man die Umwandlung des Antagonismus in Agonismus ansehen. “253

Das löscht den Antagonismus nicht aus. Es formt ihn aber um und führt schließlich - so argumentieren Laclau/Mouffe - zu einer Pluralisierung der Konfliktverhältnisse. Sie treiben die demokratische Verfassung über das politische System hinaus und setzen andere gesellschaftliche Ordnungsmuster der Legitimationsfrage aus. ${ }^{254}$

Deutlich tritt hervor, dass der transnationale Konstitutionalismus im Hinblick auf diese Leere eine Veränderung durchläuft. Beide Aspekte der Leere, plebejische und populare, fehlen. Die mit der konstituierenden Macht verbundene Rücknahmedrohung und Distanznahme findet kein Äquivalent. Gleichermaßen tritt keine idealtypische Entleerung der Ordnungen ein, da ja substantielle Programme festgeschrieben sind. Dies ist folgenreich im Hinblick auf soziale Konflikte. Das konstitutive Außen kann nicht mehr in der Verfassung erscheinen. Die Konfliktverhältnisse werden nicht in Gegnerschaft überführt. Die Systemkritik kann kaum noch einen legalen re-entry ins System finden. Oder aber sie wird - wie im Falle der Freihandelskritik - so von den Verfassungsessenzen imprägniert, dass sie kein agonistisches Verhältnis der Gegnerschaft mehr begründet, wie es für demokratische Politik typisch ist. Die Folge dieses Formwandels der Verfassung ist das Wechselspiel aus Antagonismus und Assimilation. ${ }^{255} \mathrm{Da}$ antagonistische Konflikte zunehmend nicht mehr in

253 | Mouffe, Chantal: Über das Politische, Frankfurt a. M.: Suhrkamp 2007, S. 30.

254 | Vgl. E. Laclau/C. Mouffe, Hegemonie und radikale Demokratie, S. 189 ff.

255 | So auch die Beobachtung (hier hinsichtlich eines im Entstehen begriffenen globalen Verwaltungsrechts) bei Chimni, B. S.: "Between Co-option and Resistance: Two Faces of Global Administrative Law", in: NYU Journal of International Law and Politics 37 / 4 (2005), S. 799-827. 
der Verfassung die Bühne der Geschichte betreten können, sind sie auf eine Position des Außen oder aber der Anpassung zurückgeworfen. Auf der einen Seite stehen Phänomene wie Vorortrevolten, Aufstände und moralische Entrüstung über den Zustand der Welt. Auf der anderen Seite findet eine Assimilation an den Jargon der hegemonialen Regimeverfassungen statt: Hochprofessionalisierte NGOs beteiligen sich an der transnationalen Governance. Es gibt keinen transnationalen Politikbereich mehr, der ohne »runde Tische«, Stakeholder-Partizipation oder Bürgervorschläge auskommt. ${ }^{256}$ Die gewandelte Form des Konstitutionalismus korrumpiert die Konfliktverhältnisse. Er hält kaum Ansatzpunkte bereit, um den Realwidersprüchen der Weltgesellschaft eine Bühne zu bieten. Das erinnert an eine postmoderne Spielart der herrschaftlichen Verfassung, wie Hegel sie entworfen hatte. Auch in Prozessen der Global Governance hält - so könnte man mit der Marx'schen Kritik an der Ständeverfassung argumentieren - das »ständische Element [...] die illusorische Existenz der Staatsangelegenheiten als einer Volkssache « ${ }^{257}$ bereit.

256 | Im Vorfeld der Finanzkrise wurde beispielsweise die Erarbeitung der Basel-IIRichtlinien im Bereich der Bankenregulierung für Kommentare aus der Zivilgesellschaft geöffnet, vgl. M. S. Barr/G. P. Miller, "Global Administrative Law". Die EU hat sich in inrer blairistisch-marktliberalen Hochphase am Leitbild eines umfassenden Bürgerdialogs orientiert und dies in einzelnen Politikfeldern erprobt, vgl. European Comission: European Governance - A White Paper, COM(2001) 428, Brussels 2001.

Auch in der WTO sind Beteiligungsmöglichkeiten für zivilgesellschaftliche Akteure entstanden, vgl. A. Lang, World Trade after Neoliberalism, S. $88 \mathrm{ff}$.

257 | K. Marx, "Kritik des Hegelschen Staatsrechts", S. 265. 


\section{Dritter Teil - Kritik zeitgenössischer Verfassungstheorie}

Im Folgenden sollen zeitgenössische Suchbewegungen der Verfassungstheorie dahingehend untersucht werden, ob sie der neuartigen Konstellation gerecht werden. Es ist fraglich, ob sie mit ihren Ansatzpunkten diejenigen Entwicklungen berücksichtigen, die charakteristische Merkmale eines gewandelten Konstitutionalismus sind. Insbesondere stellt sich die Frage nach dem Verhältnis von Verfassung und Demokratie. Berücksichtigen die aktuellen Zugänge zur Verfassungsfrage die veränderten Modalitäten von Recht und Politik? Haben sie das Potential, dem »Widerspruch der Verfassung mit sich selbst « ${ }^{1}$ nachzugehen? Der Argumentationsgang soll dabei nicht darauf begrenzt sein, die vorliegende Diagnose schematisch auf andere theoretische Anstrengungen anzuwenden. Er will zeigen, wo und wie die vorliegenden Entwürfe in Widersprüche geraten.

Zunächst steht die Konstitutionalisierung des Völkerrechts im Mittelpunkt der Überlegungen, um in einem nächsten Schritt zum transnationalen gesellschaftlichen Konstitutionalismus überzugehen. Jede der aufgemachten theoretischen Anstrengungen wird an einer Teilfrage scheitern. Zwar transportieren die kosmopolitischen Aspirationen im Völkerrecht starke Annahmen zur Verbindung von Demokratie, Menschenrechten und Verfassung (I, ab S.116). Da sie den Formwandel der Verfassungsevolution nicht angemessen berücksichtigen, steuern sie jedoch an der fragmentierten Hegemoniekonstellation vorbei. Demgegenüber arbeitet der gesellschaftliche Konstitutionalismus den Formwandel umfassend aus (II, ab S.153), ohne den »Widerspruch der Verfassung mit sich selbst« zwischen herrschaftlicher und demokratischer Konstitutionalisierung noch präsent halten zu können.

1 | K. Marx, "Kritik des Hegelschen Staatsrechts", S. 260. 


\section{Die Konstitutionalisierung des Völkerrechts}

Immanuel Kant hatte in seiner berühmten Friedensschrift die Perspektive eines internationalen Rechts entworfen, das auf eine »weltbürgerliche Verfassung ${ }^{2}{ }^{2}$ hinausläuft. Demnach sollen alle Menschen über die nationalstaatlichen Grenzen hinweg grundlegende Rechtsgarantien erhalten. Auch jenseits des Staates, so argumentieren die Kant-Rezipienten der Gegenwart, ist es Aufgabe eines Weltbürgerrechts, die Individuen vor willkürlicher Machtausübung zu schützen. ${ }^{3}$ Diesen Impuls hat der gegenwärtige Konstitutionalisierungsdiskurs dankbar aufgegriffen. Er sieht in der Menschenrechts- und Völkerrechtsentwicklung ein internationales öffentliches Recht angelegt, das hegemoniales Machtstreben begrenzt und die Individuen weltweit mit grundlegenden Rechtsgarantien ausstattet. Tendenziell verlieren innere staatliche Angelegenheiten zunehmend den Status einer domaine réservé. Das Völkerrecht beschränkt sich nicht nur auf Souveränitätsschutz, sondern bringt geteilte Werte der internationalen Gemeinschaft zum Ausdruck. Damit verliert es mehr und mehr seinen rein zwischenstaatlichen Status. Es bildet eine Schicht höherrangigen Rechts aus, das auf eine Verfassungsbildung hindeutet. Die Konstitutionalisierungsthese stützt sich zumeist auf entgegenkommende Entwicklungen der letzten Jahrzehnte. So beinhalten die Pflichten der Einzelstaaten (jus cogens und erga omnes) grundlegende Aggressionsverbote und den Schutz der Menschenrechte. ${ }^{4}$ Auch die Ausweitung auf immer neue Kompetenzbereiche - von den weltwirtschaftlichen Institutionen bis zur Umwelt- und Sozialregulierung - deuten auf die gewachsene Bedeutung der internationalen Gemeinschaft hin.

2 | Kant, Immanuel: Zum Ewigen Frieden (1796), in: ders., Werke. Band 9, Darmstadt: Wissenschaftliche Buchgesellschaft 1964, BA 41, S. 214. Oliver Eberl zeigt in seiner Rekonstruktion der Friedensschrift, wie der Kant'sche Text seit dem Ende der Blockkonfrontation als Projektionsfläche für westliche Hegemonialprojekte dient. Dadurch wird das Kernstück der Friedensschrift, nämlich ein kategorischer Ausschluss des Krieges als Auseinandersetzungsform, zunehmend entstellt, siehe ders., Demokratie und Frieden, S. $87 \mathrm{ff}$.

3 | Vgl. etwa Archibugi, Daniele: "Immanuel Kant, Cosmopolitan Law and Peace", in: European Journal of International Relations 1/ 4 (1995), S. 429-456.

4 | Vgl., wenn auch mit unterschiedlicher Akzentsetzung: Frowein, Jochen A.: "Konstitutionalisierung des Völkerrechts", in: Berichte der Deutschen Gesellschaft für Völkerrecht Band 39 (2000), S. 427-448, hier S. 427 ff.; T. Kleinlein, Konstitutionalisierung im Völkerrecht; ferner die Aufarbeitung bei C. J. Schwöbel, "Situating the Debate on Global Constitutionalism", und Kratochwil, Friedrich: The Status of Law in World Society. Meditations on the Role and the Rule of Law, Cambridge: Cambridge University Press 2014. 
Zwischenzeitlich liegen höchst unterschiedliche Varianten der Konstitutionalisierungsthese vor. Sie reichen von der weltbürgerlichen Orientierung in der politischen Philosophie über den Vorschlag, die UN-Charta als Verfassung der internationalen Gemeinschaft zu verstehen, bis hin zu zurückhaltenden Vorschlägen, die auf eine Stärkung des internationalen Rechts setzen. ${ }^{5}$ Trotzdem bleibt es überall beim Fluchtpunkt einer Konstitutionalisierung des Völkerrechts, so dass eine gemeinsame (und keine vergleichende) Thematisierung sinnvoll erscheint.

Gemeinsam ist den Überlegungen, dass sie im internationalen Recht eine liberale, herrschaftsbegrenzende Verfassungsbildung angelegt sehen. Der historische Einschnitt, der die Grundlage für die Konsolidierung des Völkerrechts legt, ist nach dem Zweiten Weltkrieg angesiedelt. ${ }^{6}$ Hier beginnt mit der Gründung der Vereinten Nationen und der weltwirtschaftlichen Institutionen sowie den Menschenrechtserklärungen die eingangs skizzierte Verselbstständigung des internationalen Rechts gegenüber den Einzelstaaten. Daraus wird eine veränderte »Komposition des Rechtsmediums ${ }^{7}$ abgelesen. War bis dahin eine dualistische Einteilung in »hartes« nationalstaatliches Recht und »weiches« internationales Recht durchaus plausibel, so scheint sich die Weltgesellschaft zunehmend dem Kelsen'schen Modell eines monistisch konzipierten Völkerrechts anzunähern.

Im Zusammenspiel von Menschenrechten und internationalem Staatensystem, so die geteilte Annahme, ist eine normativ gehaltvolle Verfassungsbildung ablesbar. Die legitimatorische Dimension der Verfassungsbildung bleibt an die demokratische Verfasstheit der Nationalstaaten angebunden. Ergänzt wird sie durch neuartige Mitbestimmungsmechanismen jenseits des Staates, etwa durch supranationale Demokratiemodelle (EU) oder die Beteiligung von NGOs.

Bisher versucht sich der Kosmopolitismus daran, das demokratische Projekt in Teilen vom Nationalstaat zu lösen. Sind internationale Organisationen

5 | Vgl. Held, David/Archibugi, Daniele (Hg.): Cosmopolitan Democracy. An Agenda for a New World Order, Cambridge: Polity Press 1995; B. Fassbender, The United Nations Charter as Constitution of the International Community; A. Niederberger, Demokratie unter Bedingungen der Weltgesellschaft; Hitzel-Cassagnes, Tanja: Die Verfassung des Transnationalen, Baden-Baden: Nomos 2012.

6 | Vgl. nur die Überlegungen bei Kumm, Mattias: "The Cosmopolitan Turn in Constitutionalism. An Integrated Conception of Public Law", in: Indiana Journal of Global Legal Studies 20/2 (2013), S. 605-628; J. Habermas, "Hat die Konstitutionalisierung des Völkerrechts noch eine Chance?«; B. Fassbender, The United Nations Charter as the Constitution of the International Community.

7 | Habermas, Jürgen: Stichworte zu einer Diskurstheorie des Rechts und des demokratischen Rechtsstaats, in: ders. (Hg.), Im Sog der Technokratie, Berlin: Suhrkamp 2013, S. 67-81, hier S. 73. 
und Verhandlungssysteme erst einmal als eigenständige Träger internationaler öffentlicher Gewalt charakterisiert, ${ }^{8}$ liegt es nahe, dass sie eigenständige Legitimationsressourcen benötigen. In der Regel läuft alles auf den Vorschlag hinaus, das Demokratieprinzip von der territorial eingegrenzten Selbstbestimmung eines geschlossenen Kollektivs zu lösen und es mit einem individualrechtlichen Verständnis von Demokratie anzureichern. Demokratie verwirklicht sich hier nicht einzig in politischen Selbstbestimmungsprozeduren der Staatsbürger; vielmehr verweist das Demokratieprinzip selbst vor allem auf individuelle Rechtsansprüche.

Von dort aus ist es möglich, die konstituierende Macht, die in der demokratischen Verfassungstheorie dem Volk zukam, sozusagen auf unterschiedliche Ebenen und Personenrollen zu verteilen. Dies schlägt sogar auf die gründende, konstituierende Macht des Volkes durch. Das territorial gebundene pouvoir constituant wird durch ein »pouvoir constituant mixte « ${ }^{9}$ abgelöst. Die für weiterhin intakt angesehenen Legitimationsflüsse der Nationalstaaten, in denen sich die Menschen als Staatsbürger verstehen können, werden mit komplementären Legitimationsmechanismen ergänzt. Demnach ist die Menschenrechtsentwicklung der Vereinten Nationen so zu verstehen, dass die Staatsbürger gleichermaßen zu Weltbürgern werden, die auch auf einklagbare Rechte bestehen können - etwa wenn sie von ihren jeweiligen Nationalstaaten oder anderen internationalen Institutionen verletzt werden. In der EU zeichnet sich darüber hinaus eine Transnationalisierung der Demokratie dergestalt ab, dass die Menschen als Bürger der EU an der politischen Willensbildung, insbesondere im Rahmen des europäischen Parlamentarismus, teilnehmen. Auch NGOs und transnationale Öffentlichkeiten finden in der Aufspaltung des Demokratieprinzips ihren Platz: Da kein globaler demos vorstellbar sei, müssen Öffentlichkeiten und issue-spezifische Gruppen versuchen, Druck auf die Träger der öffentlichen Gewalt im Hinblick auf Allgemeinwohlbelange auszuüben. Sie kompensieren für die ausbleibenden demokratischen Verfahren auf transnationaler Ebene. ${ }^{10}$

Meine These ist nun, dass die Konstitutionalisierungsthese an denjenigen Anatomien vorbeisteuert, die sich als prägend für den Formwandel der Verfassung erwiesen haben. Sie hält keine befriedigenden Antworten auf die Konfliktlagen bereit, die bisher herausgearbeitet wurden. Im Folgenden soll ers-

8 | So der allerdings nicht konstitutionalistische, sondern öffentlich-rechtliche Ansatz bei A. v. Bogdandy/P. Dann/M. Goldmann, "Völkerrecht als öffentliches Recht".

9 | J. Habermas, Zur Verfassung Europas, S. $67 \mathrm{ff}$.

10 | Vgl. Peters, Anne: "Dual Democracy", in: Jan Klabbers/Anne Peters/Geir Ulfstein (Hg.), The Constitutionalization of International Law, Oxford: Oxford University Press 2009, S. 263-341, hier S. 318 ff.; grundlegend zum Problem demokratischer Öffentlichkeiten: Gregorrato, Federica: Il doppio volto della comunicazione. Normatività, dominio e critica nell'opera di Jürgen Habermas, Mailand/Udine: Mimesis 2013. 
tens verdeutlicht werden, dass die Konstitutionalisierungsthese schon in der Beschreibung die transnationalen Regime einer kosmopolitischen Tendenz im Völkerrecht nachordnet (I.1, ab S.120). Nicht nur, dass dadurch die Problemlagen, die insbesondere vom Weltwirtschaftsregime ausgehen, in ihrer Tragweite kaum Berücksichtigung finden; vielmehr sind grundlegende Fragen im Hinblick auf das Projekt einer Internationalisierung der Demokratie aufgeworfen. Sind die Entscheidungsspielräume internationaler Organisationen und der Nationalstaaten im Zuge einer neuen Form des Konstitutionalismus stark begrenzt, führt dies zu einem grundsätzlichen Legitimationsproblem. Hier ist fraglich, ob vor allem neue Verfahrenswege oder individuelle Rechtsansprüche überhaupt dazu geeignet sind, ein Gegengewicht aufzubauen. In einem zweiten Schritt wird an den herrschaftsformenden Charakter der Verfassungsbildung erinnert (I.2, ab S. 128). Sie begrenzt Herrschaft in der Regel nicht einseitig, sondern formt sie. ${ }^{11}$ So können allerdings hoch unterschiedliche Spielarten des Konstitutionalismus entstehen, die nicht notwendig auf eine demokratische Verfassungsbildung hinauslaufen. Demgegenüber zehrt die Konstitutionalisierungsthese von der Annahme, dass sich selbst in höchst hegemonialen Spielarten der Verrechtlichung doch noch ein Anknüpfungspunkt finden lässt, der auf universalistisch-emanzipative Bewusstseinsstrukturen hindeutet. Indem das Recht auch immer mit Rechtfertigungspflichten und Begründungsdiskursen einhergeht, kann es befragt und in gewisser Weise ent-hegemonisiert werden: Wer sich auf die Sprache des Rechts einlässt, kann nicht puren Dezisionismus walten lassen. Die Aufarbeitung neuerer Überlegungen zur Politisierung des internationalen Rechts sowie ein kurzer Exkurs in die Rechtsphänomene der Frühen Neuzeit (Policey) sollen verdeutlichen, dass auch ein anderer, »dunkler« Anteil im Konstitutionalismus vorliegt, der stabilisierende Funktionen für die bestehenden Hegemonieverhältnisse erbringt. Zwar erbringt der rechtliche Formalismus als mindset durchaus normative Leistungen. ${ }^{12}$ Aber es ist fraglich, ob das Recht allein der Garant dafür sein kann, dass der hegemoniale Mr. Jekyll wieder eine Rückverwandlung in den kantianischen Dr. Hyde erfahren kann. Recht und Verfassung sind stark überfordert damit, für die Hegemonie, die Gegenhegemonie und die Möglichkeit der Verwandlung zuständig zu sein.

Schließlich wendet sich die Kritik drittens der Rolle von Grund- und Menschenrechten zu. Die jüngeren kosmopolitischen Überlegungen unterstreichen zumeist den Übergang von Menschenrechten zu kosmopolitischen Weltbürgerrechten. Sie werden als Grundrechtsteil der Globalverfassung betrachtet, abgesichert vom Gewaltmonopol der Vereinten Nationen. Die Menschenrechte gelten als Möglichkeit, um normative Potentiale, die einst mit der nationalstaatlichen Verfassung verknüpft waren, in die Weltgesellschaft zu tragen. Aber

11 | Vgl. C. Möllers, "Verfassunggebende Gewalt", S. 235 f.

12 | Vgl. M. Koskenniemi, "Constitutionalism as Mindset". 
die Hoffnungen verkennen oft, dass die Sprache der Menschenrechte auch einen Formwandel durchläuft. Sie kann ebenso einer repressiven Toleranz der Weltgesellschaft zum Ausdruck verhelfen. Dies gilt insbesondere, wenn sie zu einem herrschaftlichen »Dispositiv für weltpolitische Vorgänge ${ }^{13}$ degeneriert. Zwar erscheint es durchaus attraktiv, die Menschenrechte für eine Kritik der hegemonialen Regime zu nutzen, doch dies ist keine zwingende Folge von Weltbürgerrechten allein, sondern stets auf kollektive, aneignende Politiken verwiesen (I.3, ab S. 143).

\section{Nachordnung der hegemonialen Regime}

Die Konstitutionalisierungsthese stützt sich auf eine spezifische Betrachtung der Völkerrechtsentwicklung nach dem Zweiten Weltkrieg. Aus dem Zeitalter der Extreme, wie der englische Historiker Eric Hobsbawm das 20. Jahrhundert nannte, sind demzufolge nicht nur Kriege und Katastrophen hervorgegangen, sondern ebenso normative Lernprozesse. Beginnend mit der Menschenrechtserklärung, den Bretton-Woods-Institutionen und dem schrittweisen Ausbau der Vereinten Nationen hat der kosmopolitische Horizont ein institutionelles und vor allem rechtliches Pendant gefunden. Betrachtet man die Konstitutionalisierungsthese genauer, so fällt immer wieder auf, dass ein grundsätzlicher Vorrang dieser historischen Tendenz angenommen wird. Zwar sieht sie eigenwillige »technokratische Regimes « entstehen, die aber - so scheint es - einzig im Schatten einer Konstitutionalisierung der internationalen Staatengemeinschaft als Nebeneffekt auf sich aufmerksam machen. ${ }^{14}$ Diese Nachordnungsannahme ist von äußerst großer Bedeutung, wenn es zur Frage kommt, wie die transnationalen Funktionssysteme wieder an demokratische Legitimationsmechanismen angebunden werden können. Die Hoffnung besteht darin, dass eine solche Anbindung zu einhegenden Effekten führt.

Zunächst legt die Konstitutionalisierungsthese einen veränderten, rekonstruktiven Zugriff auf das internationale Recht nahe. Es erscheint als »Protoverfassung «, da sich Staaten zu einer Rechtsgemeinschaft zusammenschließen und dadurch ihre Souveränität massiv einschränken. ${ }^{15}$ Im Zuge der Globalisierung findet ein weiterer Konstitutionalisierungsschub statt, der über die Souveränitätsbeschränkung hinausgeht. Das internationale Recht wird zu einem Weltbürgerrecht transformiert: »Der innovative Kern dieser Idee liegt in der

13 | Vismann, Cornelia: "Das Recht erklären. Zur gegenwärtigen Verfassung der Menschenrechte", in: Kritische Justiz 29/3 (1996), S. 321-335, hier S. 335.

14 | Vgl. J. Habermas, "Stichworte zu einer Diskurstheorie des Rechts und des demokratischen Rechtsstaats", S. 79.

15 | Vgl. ders., "Hat die Konstitutionalisierung des Völkerrechts noch eine Chance?", S. 131. 
Konsequenz der Umformung des internationalen Rechts als eines Rechts der Staaten in ein Weltbürgerrecht als ein Recht von Individuen. $\ll^{16}$ So kommt es zu einer Verteilungsbewegung. Man kann die Entwicklung des internationalen Rechts dann als eine dezentrierte Verfassungsbildung verstehen, in der die unterschiedlichen Dimensionen des Konstitutionalismus auf unterschiedliche Ebenen verteilt sind, als ein »Mehrebenensystem, dem im Ganzen der staatliche Charakter aus guten Gründen fehlt« ${ }^{17}$.

Die herrschaftsbegrenzende, liberale Dimension des Konstitutionalismus soll vor allem im Rahmen der Vereinten Nationen verwirklicht werden. Sie soll eine effektive Sicherung von Frieden und Menschenrechten gewährleisten. Dies wird durch den Kompetenzgewinn internationaler Organisationen und Verhandlungssysteme ergänzt. In einem solchen Zusammenspiel entsteht eine herrschaftsbegrenzende Verfassung der Weltgesellschaft, die das Machtstreben der Einzelstaaten einhegt. ${ }^{18}$ Die daraus erwachsenden Vorschläge zielen auf eine stärkere gerichtliche Überwachung der Menschenrechtsgeltung. Inter- und transnationale Institutionen sind an ein öffentliches Recht der Globalisierung zu binden, ihre Gerichtsbarkeiten zu stärken. Eine so verstandene Verfassungsbildung beinhaltet auch ein globales Gewaltmonopol. Im Fall völkerrechtlich sanktionierter Menschenrechtsverletzungen gilt es, eventuell militärisch zu intervenieren.

Dieser liberale Zug wird sogleich durch die herrschaftskonstituierende Dimension ergänzt. Nachdem die Herrschaftsbegrenzung auf überstaatlicher Ebene abgesichert ist, wird für die Erhaltung demokratischer Legitimation wieder ein Schritt zurückgetreten. Die herrschaftskonstituierende Dimension sichern die »Legitimationsflüsse der Verfassungsstaaten $\aleph^{19} \mathrm{ab}$. Sie bleiben weiterhin der Ort, an dem die demokratische Willensbildung stattfindet. Die liberale Verfassung der Weltgesellschaft speist ihren Legitimationshaushalt aus »mittelbarer Rückendeckung ${ }^{20}$ der Nationalstaaten, nicht aus direkter Legitimation der Weltbürger.

Eine Transnationalisierung der Demokratie kann vor allem an kontinentalen Integrationsprozessen, wie demjenigen in der EU, anknüpfen. Dabei setzt sich die Dispersion der Verfassungsfunktionen auf unterschiedliche Ebenen fort. Sie schlägt schließlich auf die konstituierende Macht des Volkes durch. Im Zuge einer supranationalen Integration, wie sie beispielhaft in Europa stattfindet, scheint nämlich ein legitimatorischer Dualismus angelegt zu sein. Einerseits haben Bürger einen Rechtsstatus innerhalb der jeweiligen Nationalstaa-

16 | Ebenda, S. 123.

17 | Ebenda, S. 134.

18 | Vgl. ebenda, S. 130.

19| Ebenda, S. 139.

20 | Ebenda, S. 140. 
ten, andererseits sind sie Bürger der EU mit verbrieften Grundrechten. Damit wird das Legitimationssubjekt in zwei komplementäre Rollen aufgespalten: zum einen die Rolle als Bürger der EU, zum anderen als Bürger der Einzelstaaten. Als Bürger des Nationalstaats werden sie - so die Annahme - durch ihre jeweilige Regierung vertreten. Als Bürger der EU nehmen sie vor allem am europäischen Parlamentarismus teil. Und sie sind Träger der europäischen Grundrechte. So entsteht die Figur eines »pouvoir constituant mixte ${ }^{21}$, das die herrschaftskonstituierende Funktion der Verfassung teilt. In der Weltgesellschaft zerfällt der Zusammenhang zwischen einem unitarisch gedachten Legitimationssubjekt (Volk) und einem einzigen, einheitlich gedachten Legitimationsobjekt. Dies führt zum schon eingeführten Mehrebenenmodell. Folglich liegt eine Spaltung zwischen dem liberalen Prinzip der Herrschaftsbegrenzung und dem republikanischen Demokratieverständnis vor, das auf dem Prinzip der Volkssouveränität beruht. Wurden im Wohlfahrtsstaat diese beiden Dimensionen als »gleichursprüngliche« Dimensionen vermittelt, ${ }^{22}$ hält sie jetzt nur noch die Theorie zusammen. Herrschaftsbegrenzung und Herrschaftskonstitution treten auseinander.

Die Anliegen der Konstitutionalisierungsthese können in drei Schritten nachvollzogen werden. Das erste Anliegen richtet sich auf eine rationale Rekonstruktion des internationalen Rechts. ${ }^{23}$ Sie kann zeigen, dass die internationale Verrechtlichung schon immanent ein Verfassungsprojekt und damit zusammenhängende normative Überschüsse enthält. Das zweite, prospektive Anliegen besteht dann darin, Reformen durchzuführen, die diesen mitschwingenden Sockel der internationalen Verrechtlichung explizit machen. Sie reichen von einer Stärkung der Vereinten Nationen bis zur Demokratisierung der EU. Hier werden verfassungsgebende Verfahren oder die Stärkung des Europäischen Parlaments angeregt. Stets sollen die Vorschläge jeweils das sichtbar machen oder verstärken, was ohnehin schon in der internationalen Verrechtlichung mitschwingt. Das dritte Anliegen ist wohl eher eine Hoffnung. Sie besteht darin, dass eine Konstitutionalisierung der Weltgesellschaft dazu führt, die Funktionssysteme, insbesondere die kapitalistische Weltwirtschaft, leichter einhegen zu können. Es rücken also wenigstens indirekt die »sozialen Ent-

21 | Vgl. ders., Zur Verfassung Europas, S. $67 \mathrm{ff}$.

22 | Siehe etwa Jürgen Habermas' Argumentation in "Faktizität und Geltung", die auf eine auf "Gleichursprünglichkeit privater und öffentlicher Autonomie" hinausläuft, ders.: Faktizität und Geltung, Frankfurt a. M.: Suhrkamp 1992, S. 135.

23 | Vgl. Patberg, Markus: "Supranational Constitutional Politics and the Method of Rational Reconstruction", in: Philosophy \& Social Criticism 40/6 (2014), S. 501-521; Gaus, Daniel: "Rational Reconstruction as a Method of Political Theory between Social Critique and Empirical Political Science", in: Constellations 20/ 4 (2013), S. 553-570. 
stehungsbedingungen privater und öffentlicher Autonomie ${ }^{24}$ ins Blickfeld, die nicht in liberalen Abwehrrechten oder politischen Teilnahmerechten aufgehen. Erst eine solche Verrechtlichung der Weltgesellschaft, so die Annahme, schafft die Grundlage für eine soziale Demokratie.

(1) Das Problem der Konstitutionalisierungsthese ist vor allem in einer positiven Dialektik der internationalen Verrechtlichung zu suchen. Was, wenn die technokratischen Regime nicht nur eine nachgeordnete Rolle einnehmen, sondern sogar die Vorboten einer gewandelten Form des Konstitutionalismus abgeben? Von woher gewinnt das internationale Recht die Kraft, tatsächlich regulierend auf die transnationalen Funktionssysteme einzuwirken? Wie wird in diesem Umfeld eine gehaltvolle politische Partizipation der Bürger möglich?

Diese Fragen gewinnen insbesondere im Lichte der eingangs erläuterten Hybridität transnationaler Ordnungsbildung an Bedeutung. Die Regime verstärken eine Tendenz, die sich schon im Nationalstaat abzeichnete. Hier hatten kritische Rechts- und Verfassungstheorien darauf hingewiesen, dass die Trennung von öffentlichem Recht und Privatrecht »unanwendbar « ${ }^{25}$ wird. Im Zuge der kapitalistischen Modernisierung »verschränkt sich« die öffentliche Sphäre zunehmend mit dem privaten Bereich, so hatte der junge Habermas noch im »Strukturwandel der Öffentlichkeit« im Anschluss an die kritische Rechtsstaatslehre von Franz L. Neumann und Otto Kirchheimer argumentiert. ${ }^{26} \mathrm{Um}$ den »Verkehr der Privatleute« nachhaltig zu regulieren, zeichne sich eine »Verstaatlichung der Gesellschaft ${ }^{27} \mathrm{ab}$, in der staatliche Interventionsbefugnisse in die Privatautonomie eingreifen. Demgegenüber ist eine »Vergesellschaftung des Staates $\ll^{28}$ zu beobachten, die öffentliche Aufgaben auf private Körperschaften überträgt. Diese Entwicklung setzt jeweils eine »Veröffentlichung des Privatrechts « und eine »Privatisierung des öffentlichen Rechts « in Gang..$^{29}$ Bleiben diese Einsichten der kritischen Rechtsstaatslehre noch dem Verhältnis von Staat und Gesellschaft verhaftet, muss in der postnationalen Konstellation grundlegender an den jeweiligen Regimen angesetzt werden. Hier ist die Unterscheidung Staat/Gesellschaft und öffentliches Recht/Privatrecht erst recht nicht mehr schematisch anwendbar. An die Stelle der Unterscheidung zwischen Staat und Gesellschaft treten multiple Grenzverhältnisse zu den sozialen Umwelten. Das macht den freiheitsverbürgenden Gehalt der Unterscheidung

24 | J. Habermas, Faktizität und Geltung, S. 101.

25 | Siehe ders.: Strukturwandel der Öffentlichkeit, Frankfurt a. M.: Suhrkamp 1962, S. 268.

26 | Vgl. ebenda, S. 226 f.

27 | Ebenda.

28 | Ebenda.

29 | Vgl. ebenda, S. 234 ff. 
privat/öffentlich nicht komplett obsolet, ruft aber die Notwendigkeit auf, sie auf die neuartigen Grenzbeziehungen hin zu respezifizieren. ${ }^{30}$

Eine einfache Gegenüberstellung zwischen Privatrechtsgesellschaft und demokratischer Politik, zwischen »den Imperativen der Märkte und der Regulationskraft der Politik « greift zu kurz. ${ }^{31}$ Aus welcher Kraft sollte sich die Regulation speisen, wenn die politischen Institutionen stark vom Welthandel und den internationalen Finanzmärkten abhängig sind? Nicht zuletzt sind die Marktimperative oft das Ergebnis politischer Entscheidungsprozesse. Sie kommen in der Regel nicht ohne Regulierung und politische Einbettung aus. Die schematische Gegenüberstellung von politischer Regulierung und ökonomischer Liberalisierung läuft Gefahr, mit einer Null-Summen-Hypothese zu operieren. Sie geht davon aus, dass eine Ausweitung ökonomischer Liberalisierung zu weniger politisch-rechtlicher Regulierung führt. Was die Null-Summen-Hypothese nicht abzubilden vermag, ist der Umstand, dass die ökonomische Liberalisierung zumeist mit neuen Regulierungen oder einer Veränderung der Regulierung, nicht ihrem absoluten Abbau einhergeht. ${ }^{32}$ Demgegenüber erscheint es aussichtsreicher zu berücksichtigen, dass die transnationale Verrechtlichung in die Weltwirtschaft verstrickt ist. Diese Wiederaufnahme des Themas aus Habermas' Theorie des kommunikativen Handelns - nämlich ein verselbstständigter Rechtsmechanismus als Organisationsmedium der Subsysteme ${ }^{33}$ würde die Ambitionen einer liberalen Konstitutionalisierung mit einem Ideologievorwurf konfrontieren, der in den letzten Jahren von unterschiedlichen Seiten erhoben wurde: Handelt es sich bei der Konstitutionalisierungsthese eventuell um eine Ideologie, die den Expansionstendenzen globaler Funktionssysteme ein menschliches Antlitz verleiht? ${ }^{34}$

(2) Dieses Defizit in der kapitalismustheoretischen Anbindung zeitigt Folgen für das Demokratieprinzip. Kommt es zu einem Zusammenspiel von Staatsap-

30 | Insbes. im Hinblick auf Gemeingüter (commons) und ihre Konstitutionalisierung: Negri, Antonio: "The Law of the Common «, in: Finnish Yearbook of International Law 21 (2010), S. 16-25.

31 | J. Habermas, Zur Verfassung Europas, S. 42.

32 | So die Einsichten der Regulationsschule, vgl. Boyer, Robert/Saillard, Yves (Hg.): Regulation Theory. The State of the Art, London/ New York: Routledge 2001.

33 | Vgl. Habermas, Jürgen: Theorie des kommunikativen Handelns II (1981), Frankfurt a. M.: Suhrkamp 1995, S. 534 ff.; wenigstens müsste spezifiziert werden, wie eine öffentlich-rechtliche Regulierung der Weltwirtschaft überhaupt funktionieren kann, wenn der Zugriff vom internationalen Staatensystem her auf die verrechtlichten Subsysteme verstellt ist.

34 | Vgl. Marks, Susan: The Riddle of all Constitutions. International Law, Democracy, and the Critique of Ideology, New York: Oxford University Press 2000, inbes. S. $101 \mathrm{ff}$. 
paraten und marktliberaler Weltwirtschaft in hegemonialen Regimen, die auf eine inhaltlich bestimmte, freihandelsorientierte Weltwirtschaftsverfassung hindeuten, ${ }^{35}$ führt dies auch zu rückwirkenden Effekten in den nationalstaatlichen Demokratien. Der Nationalstaat ist selbst Teil eines konstitutionellen Formwandels. War der alte Konstitutionalismus des demokratischen Rechtsstaats zumindest in der westlichen Welt durch Sozialstaatsgebote, Offenheit der Wirtschaftsform und der Möglichkeit einer Ausweitung der Demokratie auf die gesamte Gesellschaft gekennzeichnet, findet im transnationalen Konstitutionalismus ein Übergang zum »nationalen Wettbewerbsstaat ${ }^{36}$ statt.

Dies geht auch mit einer Entparlamentarisierung einher. Werden Entscheidungen der Haushalts-, Wirtschafts- und Sozialpolitik zunehmend auf europäischer und/oder internationaler Ebene getroffen, sind die parlamentarischen Spielräume eingeschränkt. ${ }^{37}$ Dabei ist der Formwandel nicht auf die Eingrenzung von Entscheidungsspielräumen beschränkt; vielmehr ergreift er das Terrain der Verfassung. Deutlichster Ausdruck ist die Einführung von Schuldenbremsen als Verfassungsinstitutionen, die das Budgetrecht der Parlamente einschränken und eine antizyklische Konjunktursteuerung erschweren. Hier findet genau jene Substantialisierung statt, die schon im Hinblick auf die Regime ausgedeutet wurde. Dies ist natürlich von besonderer Brisanz, da gerade

35 | Vgl. S. Gill, "Constitutionalizing Inequality and the Clash of Globalizations", und die spiegelbildliche Position des deutschen Ordoliberalismus in Bezug auf die EU: Mestmäcker, Ernst-Joachim: Wirtschaft und Verfassung in der Europäischen Union, Baden-Baden: Nomos 2003; ferner: Brand, Ulrich/Görg, Christoph/Wissen, Markus: "Verdichtungen zweiter Ordnung. Die Internationalisierung des Staates aus einer neopoulantzianischen Perspektive", in: Prokla - Zeitschrift für kritische Sozialwissenschaften 147 / 2 (2007), S. 217-234. Die dort ausgearbeitete These von der "Internationalisierung des Staates" geht davon aus, dass der kapitalistische Akkumulationsprozess immer auf eine politische Form angewiesen ist, die eigene Funktionen in den ökonomischen Produktionsverhältnissen erfüllt (beispielsweise Rechtssicherheit schafft) und soziale Kräfteverhältnisse zwischen Klassen prozessiert. Im Übergang zur Weltgesellschaft wird die Kohärenz des Nationalstaates zu Gunsten eines regulativen Netzes abgelöst, das sich durch eine Pluralität von Staatsapparaten auf unterschiedlichen Ebenen auszeichnet. Das Konzept einer Internationalisierung des Staates geht auf Nicos Poulantzas, Die Internationalisierung der kapitalistischen Produktionsverhältnisse und der Nationalstaat, zurück.

36 | Vgl. B. Jessop, The Future of the Capitalist State, S. 95 ff.; siehe für den alten Konstitutionalismus in der BRD etwa die klassische Position von Wolfgang Abendroth, "Zum Begriff des demokratischen und sozialen Rechtsstaates im Grundgesetz der Bundesrepublik Deutschland".

37 | I. Ley identifiziert eine größere Änderungsresistenz des nationalen Rechts durch Internationalisierung, vgl. dies., Opposition im Völkerrecht, S. 67. 
die Haushaltspolitik kein Politikbereich wie alle anderen ist. Das Haushaltsrecht gilt klassisch als »Königsrecht des Parlaments«. Aber die unterschiedlichen politischen Gestaltungsalternativen können nur dann erscheinen, wenn auch Gelder verteilt und ausgeben oder unterschiedliche Varianten der Konjunktursteuerung eingeschlagen werden können. Sonst bleibt es bei bloß deklarativen Politiken, die nicht gering zu schätzen sind, aber an bestimmte Kernbereiche politischer Gestaltung nicht heranreichen können. ${ }^{38}$ In der Haushaltsdebatte findet folglich auch kein gesellschaftspolitischer Schlagabtausch mehr statt. Sie verkehrt sich in einen Ideenwettbewerb für die besten Sparvorschläge. Längst übernimmt der demokratische Rechtsstaat die Rolle eines nationalen Wettbewerbsstaats, der mit anderen Standorten der Welt konkurriert. Er steht vor dem permanenten Tribunal privatwirtschaftlicher Ratingagenturen. Sie grenzen mit ihren Bewertungen maßgeblich diejenigen fiskalpolitischen Strategien ein, die einzelne Nationalstaaten überhaupt noch aussichtsreich verfolgen können. ${ }^{39}$

Die Konstitutionalisierungsthese muss aber die Persistenz des demokratischen Rechtsstaats alter Prägung unterstellen. Nur so kann die demokratische Legitimation weiterhin ihren Ort finden. Nur so können die gewählten Regierungen im internationalen Staatensystem als Ausdruck von Legitimationskreisläufen jenseits funktionaler Integration in die Weltwirtschaft begriffen werden. Die Staaten sind so sehr in die Regime verstrickt, dass sie nicht aussteigen können, ohne grundlegend andere ökonomische Entwicklungspfade einzuschlagen. ${ }^{40}$ Der neue Konstitutionalismus schlägt auf die Verfassung des Nationalstaats durch. Er hält nicht mehr zwingend Ressourcen für eine gestaltende Weltinnenpolitik bereit. Dass regionale Kooperationsarenen regulierend auf die neoliberale Privatrechtsgesellschaft zugreifen können, unterstellt die Möglichkeit, dass die Staaten als demokratische Rechtsstaaten durch poli-

38 Im kommunalpolitischen Bereich der BRD kann politische Gestaltung etwa kaum noch stattfinden, weil finanzielle Mittel fehlen. Es bleibt bei Mängelverwaltung oder Symbolpolitik. Kommunen beschließen das Verteilen von Organspendeausweisen, erstellen aufwändige Internetportale zur Bürgerbeteiligung, beteiligen sich an allerlei bundesweiten Kampagnen zur Hebung der Lebensqualität oder zur gesunden Ernährung, können allerdings nicht darüber entscheiden, ob nun Geld in eine neue Kita oder in den Ausbau der Hauptverkehrsstraße investiert werden soll.

39 | Gerade an der jüngsten Entwicklung in der EU ist diese Entwicklung ablesbar. Dass spätestens mit den Maastrichter Verträgen ein liberaler Binnenmarkt seine "Konstitutionalisierung" erfuhr, die der EuGH mit seiner Rechtsprechung inkrementell abgesichert hat, geht in der positiven Dialektik der Rechtsevolution oft unter, vgl. dazu nur Höpner, Martin/Schäfer, Armin: Die Politische Ökonomie der europäischen Integration, Frankfurt a. M./ New York: Campus 2008.

40 | Vgl. die Diskussion um "Postdemokratie»: C. Crouch, Post-democracy. 
tische Entscheidung voluntaristisch in der Lage sind, aus der ökonomischen Staatenkonkurrenz auszubrechen und kooperative Lösungen zu verwirklichen. Ist dieser Weg durch die geschilderten Entwicklungen verstellt, hat der Entwurf einer einhegenden Weltinnenpolitik fast »unartikulierte sozial-revolutionäre Voraussetzungen « ${ }^{41}$. Erforderlich wäre nämlich ein Ausstieg aus dem Zusammenspiel von Weltwirtschaft und Wettbewerbsstaatlichkeit. Gegen solche Gefährdungslagen erscheint es problematisch, den nationalstaatlichen Konstitutionalismus mit normativen Potentialen auszustatten, die er gegenwärtig nicht einlöst oder nur um den Preis sozialrevolutionärer Voraussetzungen erlangt. Man kann also nicht so tun, als ob der demokratische Rechtsstaat, wie er idealtypisch in den Nachkriegsgesellschaften institutionalisiert wurde, in die Weltgesellschaft ungebrochen verlängert werden kann (und sei es in dezentrierter Fassung).

Diese skeptische Diagnose zu den Spielräumen einer Weltinnenpolitik muss nicht zwangsläufig zur Resignation führen. Eventuell würde sich vielleicht doch noch eine Hintertür für die Kritik an der neoliberalen Privatrechtsgesellschaft öffnen. Wenn politische und ökonomische Verfassung nicht gegeneinander ausgespielt werden können, sondern als politökonomischer Konstitutionalismus zusammenhängen, wird deutlich, dass eine aussichtsreiche Transformation an beiden Seiten ansetzen muss. Ohne eine postneoliberale Koppelung von Wirtschaft und Weltgesellschaft bleibt es bei einer ausufernden Wettbewerbsstaatlichkeit, die demokratische Verfahren umarbeitet.

Insofern ist das demokratische Defizit der Weltgesellschaft nicht ausschließlich ein prozedurales Problem der wachsenden Verflechtung, die dazu führt, dass die Identität von Rechtsautoren und Rechtsadressaten auseinandertritt. Auch die sozialen Voraussetzungen des Demokratieprinzips, soziale Sicherungsmechanismen etwa, Koalitionsfreiheit und Streikrechte, finden bisher kaum funktionale Äquivalente in der Weltgesellschaft. Reformvorschläge zur Transnationalisierung der Demokratie oder zur Stärkung der Vereinten Nationen sind keineswegs gering zu schätzen. Sie müssen sich aber der Frage aussetzen, inwieweit sie auch effektiv in der Lage sind, die politischen Entscheidungsspielräume zu öffnen oder tatsächlich zur gewünschten Herrschaftsbegrenzung beizutragen.

41 | So lesen konsequenterweise Oliver Eberl und Florian Rödl das Verhältnis von Internationaler Politischer Ökonomie und radikaler Demokratietheorie bei Habermas, siehe dies.: "Kritische Politische Ökonomie und radikale Demokratietheorie. Eine Begegnung auf der Suche nach der postneoliberalen Weltrechtsordnung ", in: Kritische Justiz 43 / 4 (2010), S. 416-430, hier S. 426. 


\section{Verfassung der Form der Herrschaftsausübung}

An dieser Stelle soll nochmal in Erinnerung gerufen werden, dass der moderne Konstitutionalismus einen Doppelcharakter trägt: Einerseits ermöglicht und formt er die Herrschaftsausübung, andererseits ist er in seiner Verbindung mit dem Demokratieprinzip auch der Anknüpfungspunkt für eine Herrschaftskritik. Sie enthält, folgen wir dem jungen Marx, das Motiv einer drohenden Rücknahme. Das muss aber nicht dazu führen, dass jede Variante des modernen Konstitutionalismus kategorisch mit normativen Überschüssen überflutet werden muss. Die Verfassungsbildung folgt in vielen Fällen einem »managerial mindset ${ }^{42}$. Sie bezieht Recht und Politik aufeinander. Sie muss nicht notwendig an ein herrschaftskritisches Motiv angebunden sein. Das heißt nicht, dass bestehende Verfassungsinstitutionen nicht im Sinne eines solchen Motivs uminterpretiert werden können. Man sollte aber vorsichtig damit sein, diese Möglichkeit zum Übergang von der einen zur anderen Seite genetisch angelegt zu sehen oder gar zum einzigen Weg der Kritik zu erheben.$^{43}$ Deshalb soll im Folgenden gezeigt werden, dass in der völkerrechtlichen Konstitutionalisierungsthese diese politischen Spannungen verschwimmen. Sie neigt dazu, die positive Dialektik der Verfassung gegen ein dezisionistisches Außen abzugrenzen (I.2.a, ab S. 128). Damit bleibt jede Spielart der Verfassungsbildung zunächst verteidigenswert. Am Beispiel der frühneuzeitlichen Policey soll sodann verdeutlicht werden, dass die Wurzeln des Konstitutionalismus nicht einseitig in die bürgerliche Revolutionsepoche zurückreichen, sondern ebenso aus der Verrechtlichung des modernen Verwaltungsstaates erwachsen (I.2.b, ab S.131). Im Lichte einer umkämpften Verfassungsevolution mit ihren unterschiedlichen Bezugspunkten erscheint es dann aussichtsreicher, den Blick auf die politischen Kämpfe innerhalb des internationalen Rechts zu richten, die sich an den aufgemachten Spannungen entzünden (I.2.c, ab S.138).

\section{a. Kelsen oder Schmitt?}

Die Konstitutionalisierungsthese ruft stets eine Gefahr herbei. Sie lauert im ungebundenen Dezisionismus, sei es der Staaten oder inter- und transnationaler Institutionen. Die Einhegung staatlicher Willkür steht im Mittelpunkt.

42 | Vgl. M. Koskenniemi, "Constitutionalism as Mindset", S. 13.

43 | Eine Vielzahl von Übergängen erscheint möglich, die trotzdem im Horizont des Konstitutionalismus bleiben (vgl. H. Brunkhorst, Critical Theory of Legal Revolutions): Die Konfrontation einer bestehenden Verfassung mit einer anderen Verfassung (Französische Revolution); die Aneignung von Verfassungsinstitutionen durch soziale Bewegungen (Roosevelts New-Deal-Wende in den 1930er Jahren); die kantianisch inspirierte (reformerische) Möglichkeit einer Neubeschreibung von Recht und Verfassung. Letztere ist eine Möglichkeit. 
Individuelle Selbstbestimmung soll vor dem einseitigen Machthandeln politischer Institutionen geschützt werden. »Die Selbstbestimmung des Menschen ist das Grundprinzip des öffentlichen Rechts, jedenfalls in seiner freiheitlichdemokratischen Tradition, das genau dieses Spannungsverhältnis zwischen einseitigen Akten und Selbstbestimmung regelt.« ${ }^{44}$ Dies läuft seinerseits auf eine Entscheidungssituation zu. Man muss sich zwischen Immanuel Kant und Carl Schmitt, zwischen Rechtsbindung und Geopolitik entscheiden: ${ }^{45}$ Entweder Rechtsherrschaft oder Dezisionismus der Einzelstaaten.

Das Irritierende an dieser Alternative ist, dass die Trennschärfe zwischen Recht und Politik, öffentlicher Gewalt und (privater?) Willkür eigentümlich verwischt erscheint. ${ }^{46}$ Fraglich ist genauso, ob die Politisierungsprozesse des transnationalen Rechts mit dieser Gegenüberstellung erfasst werden können. Was ist, wenn eine auctoritatis interpositio im Zwischenraum zwischen Recht und Rechtsanwendung auffindbar ist, wenn die liberale Verfassung letztlich doch mit politischen Substanzen und Interessenlagen gefüllt ist, so dass die Gegenüberstellung von Dezisionismus und Rechtsherrschaft an Plausibilität verliert ${ }^{47}$, wenn die »Gewalt des Rechts nicht das Andere seiner Form ist, sondern die Gewalt des Rechts seiner Form entspringt « ${ }^{48}$ ? Wo hat in der Euphorie für die Rechtsherrschaft die grundlegende Paradoxie des Rechts ihren Platz: Das internationale Recht tritt als Garant für internationale Gerechtigkeit auf, ruft aber gleichzeitig selbst neue Ausschlüsse und Herrschaftsverhältnisse hervor. ${ }^{49}$ Wo wird der Umstand ernsthaft bearbeitet, dass die »Verrechtlichung, Konstituti-

44 | A. v. Bogdandy/P. Dann/M. Goldmann, "Völkerrecht als öffentliches Recht", S. 24, auch wenn die Autoren keine konstitutionalistische Agenda verfolgen.

45 | Vgl. J. Habermas, "Hat die Konstitutionalisierung des Völkerrechts noch eine Chance?", S. 187.

46 | Vgl. Prien, Thore: "Kosmopolitismus und Gewalt. Fragen an die Weltinnenpolitik mit Blick auf Vertreibung, Landgrabbing und die Kämpfe der Subalternen«, in: Franziska Martinsen / Oliver Flüger (Hg.), Gewaltbefragungen. Beiträge zur Theorie von Politik und Gewalt, Bielefeld: transcript 2013, S. 165-183.

47 | Zur auctoritatis interpositio, der "dazwischentretenden“ Gewalt im Rechtsvollzug: Fischer-Lescano, Andreas/Christensen, Ralph: "Auctoritatis Interpositio. Die Dekonstruktion des Dezisionismus durch die Systemtheorie", in: Der Staat 44/2 (2005), S. $213-241$.

48 | C. Menke, Recht und Gewalt, S. 34.

49 | Vgl. die Beobachtung bei Gayatari Spivak, dass die "subalternen Epistemen" sich häufig einer Artikulation in der Rechtsform vollkommen entziehen, dies.: Righting Wrongs - Unrecht richten, Zürich/Berlin: diaphanes 2008, S. 54 ff., und vgl. auch das Zusammenspiel von Rechtscode und Enteignungspraktiken in der Weltgesellschaft bei Mattei, Ugo/Nader, Laura: Plunder. When the Rule of Law is Illegal, Oxford: Blackwell Publishing 2008. 
onalisierung und Herrschaft des Rechts [...] nicht per se zur Demokratie [führen], sondern sie immer die jeweils bestehende und sich herausbildende Herrschaftsform [stärken]?« ${ }^{50}$

Damit rückt ein weiterer Kritikpunkt an der Konstitutionalisierungsthese ins Blickfeld. Zwischen den Erwartungen an eine Zivilisierung der Welt durch die Konstitutionalisierung des internationalen politischen Systems und dem Charakter der Regimeverfassungen klafft eine allzu große Lücke. Wenn das internationale Recht direkt in die Regime verstrickt ist, fällt es schwer, das Staatensystem zum herrschaftsbegrenzenden Hoffnungsträger zu erklären. ${ }^{51}$ Der liberale Konstitutionalisierungsdiskurs unterschlägt gewissermaßen die herrschaftlichen Wurzeln des modernen Konstitutionalismus; jene »andere Seite « der Verfassungsevolution, die weniger eine Verbindung zu den bürgerlichen Revolutionen hat als zur frühneuzeitlichen Policey, die einst die Grundlage für den modernen Gesetzgebungsstaat gelegt hatte. ${ }^{52}$ In den Verfassungsordnungen der Weltgesellschaft erhalten Dispositive zunehmend Dominanz, die eben nicht nur herrschaftsbegrenzend wirksam sind. Sie stützen die Hegemonieverhältnisse $\mathrm{ab}$ und sind eher dieser anderen Seite zuzuordnen (I.2.b, ab S. 131). Ist der moderne Konstitutionalismus erst einmal als widersprüchliches Phänomen entziffert, das keine eindeutige Zuordnung zu Herrschaftsausübung oder Herrschaftskritik erlaubt, verschiebt sich die Problemlage. Dezision und Rechtsherrschaft werden nicht mehr idealtypisch kontrastiert. Sie werden auf ihre gegenseitige Verstrickung in den politischen Verfassungskämpfen befragt (I.2.C, ab S. 138).

50 | Brunkhorst, Hauke: "There will be Blood", in: ders. (Hg.), Demokratie in der Weltgesellschaft, Baden-Baden: Nomos 2009, S. 99-123, hier S. 113.

$\mathbf{5 1}$ | Vgl. für den Bereich der globalen Sicherheitslogik und der zentralen Rolle des Staatensystems: Maus, Ingeborg: "Menschenrechte als Ermächtigungsnormen internationaler Politik oder der zerstörte Zusammenhang von Menschenrechten und Demokratie", in: Hauke Brunkhorst/Wolfgang R. Köhler/Matthias Lutz-Bachmann (Hg.), Recht auf Menschenrechte. Menschenrechte, Demokratie und internationale Politik, Frankfurt a. M.: Suhrkamp 1999, S. 276-292.

52 | Vgl. dazu Stolleis, Michael: "Öffentliches Recht und Privatrecht im Prozeß der Entstehung des modernen Staates", in: Wolfgang Hoffmann-Riem/Eberhard SchmidtAßmann (Hg.), Öffentliches Recht und Privatrecht als wechselseitige Auffangordnungen, Baden-Baden: Nomos 1996, S. 41-61, hier S. 52 ff.; der Bezug zum modernen "Gesetzgebungsstaat" wird auch hier hergestellt: Süßmann, Johannes: "Die Wurzeln des Wohlfahrtsstaats - Souveränität oder Gute Policey?", in: Historische Zeitschrift 285 (2007), S. 19-47, hier S. 28. 


\section{b. Policey und Verfassung}

"Die Sicherheit ist der höchste soziale Begriff der bürgerlichen Gesellschaft, der Begriff der Polizei, daß die ganze Gesellschaft nur da ist, um jedem ihrer Glieder die Erhaltung seiner Person, seiner Rechte und seines Eigentums zu garantieren. “53

Die moderne Verfassungsbildung wird zumeist auf eine rechtsoptimistische Fortschrittserzählung zurückgeführt. Die bürgerlichen Revolutionen hätten einem Typ politischer Herrschaft zum Durchbruch verholfen, der eine Selbstbegrenzung beinhaltet. Seine Ausübung sei an ein höherrangiges Recht gebunden, das soziale Autonomiesphären vor willkürlicher Machtausübung schützt. Bürgerliche Revolutionen, moderne Verfassungen und öffentliches Recht bildeten einen unauflösbaren Nexus. ${ }^{54}$ Die Verfassung bindet den Odysseus der politischen Willkür an den Mast. Sie hegt den politischen Dezisionismus ein und formalisiert die Politik. Die moderne Verfassung stellt sich als herrschaftsbegrenzende Reaktion auf die Entstehung der Staatssouveränität dar. Dieses Argumentationsmuster bezieht seine Orientierungspunkte maßgeblich aus der bürgerlichen Revolutionsepoche, in deren Nachgang der Rechtsstaat seine prägenden Züge angenommen hat. Es unterschlägt dabei einen Teil der Verfassungsevolution, der viel früher datiert und doch in sie eingeht. Diese andere Seite gewinnt im Übergang zur Weltgesellschaft ein stärkeres Gewicht, als die Konstitutionalisierungsthese annimmt.

Um dieser anderen Seite nachzugehen, muss man nicht zwangsläufig auf den restaurativen Konstitutionalismus des frühen 19. Jahrhunderts zurückkommen oder auf die rechtsbindenden Mechanismen im aufgeklärten Absolutismus. ${ }^{55}$ Man kann die Verbindung von Verfassung und moderner Staatlichkeit bis in die Frühe Neuzeit zurückverfolgen. Dort stößt man auf den Begriff der Policey. Zwischenzeitlich haben verschiedene Studien versucht ihn genauer zu beleuchten und für staats-, rechts- oder gesellschaftstheoretische Zwecke

53 | K. Marx, "Zur Judenfrage", S. 365 f.

54 | Vgl. H. Vorländer, Die Verfassung, S. 7 ff. Diese Erzählung sieht sich einigen Einwänden ausgesetzt. Denn die moderne Verfassung und ihr öffentliches Recht haben nicht nur Herrschaft begrenzt, sondern gleichermaßen die moderne Staatssouveränität konstituiert und entfesselt: Preuss, Ulrich K.: "Disconnecting Constitutions from Statehood. Is Global Constitutionalism a Viable Concept?", in: Dobner/Loughlin, The Twilight of Constitutionalism? (2010), S. 23-46, hier S. $33 \mathrm{ff}$.

55 | Vgl. zu den Keimformen des Rechtsprinzips im aufgeklärten Absolutismus am französischen Beispiel B. Kriegel, The State and the Rule of Law, S. 51. 
fruchtbar zu machen. ${ }^{56} \mathrm{Im} 16$. und 17. Jahrhundert sind in den Herrschaftsverbänden, insbesondere im Deutschland und Frankreich der damaligen Zeit, eine ganze Vielzahl von Regulierungen aufzufinden, die eine "gute Ordnung « ${ }^{57}$ des Gemeinwesens herbeiführen sollen. Ihr Gegenstand ist das gesellschaftliche Leben. Sie reichen von Alltäglichem (Kleiderordnungen, Religion, Ehe etc.) über den Umgang mit Armen bis zu Gesundheitsschutz und wirtschaftlicher Zirkulation. So entstehen Policeyordnungen, die jeweils spezifische Gegenstandsbereiche haben, etwa Religionspolicey, Armenpolicey, Gesundheitspolicey oder Getreidepolicey. ${ }^{58}$ Den Hintergrund dafür, dass in Europa diese minutiösen Regulierungen entstehen, ist die Konsolidierung von Herrschaftsverbänden. Sie entmachten die Kirchen, die freien Städte und die mittelalterlichen Loyalitätsverhältnisse. An ihre Stelle tritt zunehmend der »ständisch gestufte, aber tendenziell vereinheitlichte Untertanenverband « ${ }^{59}$. Die embryonale Form des modernen Staates entsteht auf der Schwelle der Policey. Die Policeyverordnungen zeugen von einem Entwicklungsprozess, der »persönliche Herrschaft in die des Staatsapparats « $^{60}$ verwandelt. So entsteht »eine Form der Gemeinschaft oder eines Vereins, der durch öffentliche Autorität geleitet wird, eine Art von menschlichem Verband, sobald so etwas wie eine politische Macht oder eine öffentliche Autorität ausgeübt wird « ${ }^{61}$. Der gesamte Diskurs um die Policey erhält neue Anwendungsbereiche, beispielsweise im Wissenschaftsbetrieb als Disziplin (Policeywissenschaft) oder schließlich in der modernen Polizei des Staates. Die Policey entfaltet eine eigene Dynamik und weitet ihren Geltungsbereich aus. Sie löst sich

"von den Sammlungen lokaler, städtischer und landesherrlicher Verordnungen über Kleidung und Luxus, Zünfte und Sitten, Feuergefahren und Bettler [und erstreckt sich]

56 | Vgl. Stolleis, Michael (Hg.): Policey im Europa der frühen Neuzeit, Frankfurt a. M.: Vittorio Klostermann 1996; Foucault, Michel: Sicherheit, Territorium, Bevölkerung (= Geschichte der Gouvernementalität 1), Frankfurt a. M.: Suhrkamp 2004, S. 449 ff.; Bohlender, Matthias: Metamorphosen des liberalen Regierungsdenkens. Politische Ökonomie, Polizei und Pauperismus, Weilerswist: Velbrück 2007.

57 | Iseli, Andrea: Gute Policey. Öffentliche Ordnung in der frühen Neuzeit, Stuttgart: UTB 2009, S. 8.

58 | Siehe die Beispiele bei Iseli, ebenda, S. $32 \mathrm{ff}$.

59 | M. Stolleis, "Öffentliches Recht und Privatrecht im Prozeß der Entstehung des modernen Staates", S. 52.

60 | Ders.: Geschichte des öffentlichen Rechts in Deutschland. 1. Band: Reichspublizistik und Policeywissenschaft, München: C. H. Beck 1988, S. 70.

$61 \mid$ M. Foucault, Sicherheit, Territorium, Bevölkerung, S. 450. 
auf die Lebensbedingungen des Volkes, auf die Formen des Zusammenlebens insgesamt und auf alle Gebiete des politischen Wesens“62.

Entscheidend ist, dass der policeyliche Diskurs mit seiner Orientierung an der »guten Ordnung« eine produktive, ausdrücklich nichtsouveränistische Wendung nimmt. Die Policey regiert. Als »prinzipielle Lebensbetätigung des modernen Staates « hat sie »die herrschaftliche Wahrung der Ordnung im bürgerlichen Leben durch verwaltende staatliche Tätigkeit « ${ }^{63}$ zum Zweck. Noch in einer Abhandlung aus der Mitte des 18. Jahrhunderts wird die Policey im Hinblick auf eine produktive Machtausübung definiert, die nicht einseitig verbietet, sondern Kräfte und Vermögen des empirischen Gesellschaftskörpers mehrt:

"Im weitläufigen Verstande begreift man unter der Policey alle innerlichen Landesangelegenheiten, wodurch das allgemeine Vermögen des Staates dauerhaftiger gegründet und vermehret, die Kräfte des Staates besser gebraucht und überhaupt die Glückseligkeit des gemeinen Wesens befördert werden kann. ${ }^{64}$

Die Policey unterbindet nicht einseitig. Sie setzt Anreize. Sie bezieht wirkende Kräfte aufeinander. Sie erfasst das Leben der Bevölkerung auf dem Territorium. Sie ist um die Gesundheit des Gesellschaftskörpers bemüht. Sie legt Statistiken über das gesellschaftliche Leben an. Beamte und Funktionäre sorgen für das Allgemeinwohl.

Im Grunde laufen in der Herausbildung moderner Staatlichkeit seit dem 17. Jahrhundert zwei Entwicklungslinien aufeinander zu, die als »zwei Körper des Staates « ${ }^{65}$ verständlich werden. Der eine, symbolische Körper des Staates »beerbt die mittelalterliche Königsmacht« und kreist um die »Konfiguration eines gemeinsamen Willens « ${ }^{66}$. Der andere, physische Körper »umfasst den Zusammenhang von Bevölkerung, Individuen und Gütern«, das »Spiel von Leidenschaften und Interessen « sowie »einen Komplex aus veränderlichen Kräften und Vermögen «. ${ }^{67}$ Zugespitzt formuliert und auf die moderne Verfassungsevo-

62 | Vogl, Joseph: "Staatsbegehren. Zur Epoche der Policey“, in: Deutsche Vierteljahrsschrift 74/ 4 (2000), S. 600-626, hier S. 606.

63 | Wolzendorff, Kurt: Der Polizeigedanke des modernen Staates (1918), Aalen: Scientia Verlag 1964, S. 5.

64 | Justi, Johann Heinrich Gottlob von: Grundsätze der Policeywissenschaft, Göttingen: W. Vandenhoek 1782, §2.

65 | In Anlehnung an Ernst H. Kantorowitz' These von den beiden Körpern des Königs im Mittelalter, siehe ders.: The King's Two Bodies. A Study in Mediaeval Political Theology, Princeton: Princeton University Press 1957.

66 | J. Vogl, Staatsbegehren, S. 604.

67 | Ebenda. 
lution bezogen: Die eine Seite ist das Problem der Souveränität und des Gesellschaftsvertrags; die andere Seite ist das der Policey, der Biomacht und der politischen Ökonomie. Es ist jener zweite, physisch-soziale Körper der Bevölkerung, auf den sich die Policey richtet. Die Policey verweist nicht auf ein transzendentes Prinzip. Sie sucht immanente Wege zur Regulierung des corps social. ${ }^{68}$

Das Recht ist an beiden dieser Linien beteiligt. Es wäre falsch, das Recht einseitig dem ersten Körper des Staates zuzuordnen, der auf die Transzendenz des corps politique verweist. Die policeyliche Linie ist nicht einfach eine wilde, ursprüngliche Akkumulation des Dezisionismus, die dann im Nachgang durchs Recht gezähmt wird. Sie spielt sich wenigstens auf drei Ebenen ab: Sie umfasst die angestrebte »gute Ordnung « des Gemeinwesens, sie bezeichnet die »herrschaftliche Tätigkeit, sie einzurichten «, und weist schließlich auch - und das wird im Folgenden wichtig sein - ihre juridische Dimension als Verordnungswesen auf. ${ }^{69}$ Das Recht tritt gewissermaßen nicht nach der policeylichen Intervention ein. Die Policey ist von Beginn an in hohem Maße verrechtlicht. Sie »fand somit ihren Ausdruck in Verordnungen, die in Gerichtsverfahren geformt, gewandelt und als Richterspruch festgelegt wurden « ${ }^{70}$. Dadurch gewinnt sie zunehmend »gesetzgebenden Charakter « ${ }^{71}$. Ergänzt und komplettiert werden diese Rechtsordnungen durch institutionelle Innovationen. Dazu gehören

68 | Gerade die Studien von Michel Foucault zeigen, wie die policeylichen Apparate das gesellschaftliche Leben zunehmend durchdringen. Aus der frühneuzeitlichen Policey erwächst schließlich im Übergang vom 17. zum 18. Jahrhundert ein Machttyp, den Foucault als Biomacht bezeichnet. Die Biomacht diszipliniert die individuellen Körper der Untertanen und erfasst den sozialen Körper: "Fortpflanzung, die Geburten- und Sterblichkeitsraten, das Gesundheitsniveau, die Lebensdauer, die Langlebigkeit [...] wurden zum Gegenstand regulierender Kontrollen: Bio-Politik der Bevölkerung", ders.: Der Wille zum Wissen (= Sexualität und Wahrheit I), Frankfurt a. M.: Suhrkamp 1987, S. 166. Für Foucault legt die Biomacht die Grundlage für den Siegeszug einer spezifischen Verknüpfung von kapitalistischer Wirtschaftsweise und modernem Rechtsstaat. Denn "ohne kontrollierte Einschaltung der Körper in die Produktionsapparate und ohne Anpassung der Bevölkerungsphänomene an die ökonomischen Prozesse (ebenda, S. 168) wäre die Entstehung des Kapitalismus nicht möglich gewesen.

69 | Vgl. J. Süßmann, "Die Wurzeln des Wohlfahrtsstaats", S. 27; Simon, Thomas: "Gute Polizei«. Ordnungsleitbilder und Zielvorstellungen des politischen Handelns in der Frühen Neuzeit, Frankfurt a. M.: Vittorio Klostermann 2004, S. 111; vom "Recht der Polizey" geht auch Luhmann aus, vgl. ders., Die Kunst der Gesellschaft, S. 325.

70 | Iseli, Andrea: "Bonne Police«. Frühneuzeitliches Verständnis von der guten Ordnung eines Staates in Frankreich, Epfendorf: bibliotheca academica Verlag 2003, S. 28.

71 | Süßmann, "Die Wurzeln des Wohlfahrtsstaats", S. 28. 
sowohl örtliche »Policeybeauftragte«, die über die Einhaltung der Regeln wachen, als auch Gerichtsbarkeiten, die das Recht der Policey judizieren. ${ }^{72}$

Die Rechtsstruktur der Policey deutet an, dass die Geschichte eines herrschaftsbegrenzenden Rechts, das im Fahrwasser der Aufklärung und der bürgerlichen Revolutionen entsteht, ergänzungsbedürftig ist. Der Rechtshistoriker Michael Stolleis geht sogar davon aus, dass die Trennung zwischen öffentlichem Recht und Privatrecht keine Errungenschaft des 18. Jahrhunderts darstellt, sondern bis auf die Policey der Frühen Neuzeit zurückzuverfolgen ist. ${ }^{73}$ Mit der policeylichen Regulierung geht die verstärkte Rede vom ius publicum einher. Dem entspricht die zunehmende Verwendung von Formeln wie »publicus, publicare, publicum, bona publica, potestas publica im rechtlichen Diskurs dieser Zeit. ${ }^{74}$ Juristische Kommentare behandeln einerseits zunehmend das öffentliche Leben, Erziehung, Ehe, Gesundheit und Schutz der Gemeinschaft, andererseits evozieren die internen Kompetenzfragen des Staatsaufbaus schon inkrementell ein »komplexes Verfassungsrecht « ${ }^{75}$. Dies lässt darauf schließen, dass die Keimformen des modernen Rechts, das »hoheitliche Element des ius publicum « ${ }^{76}$, einen Teil seiner Wurzeln in der Polizei der Frühen Neuzeit hat und nicht nur vom 18. und 19. Jahrhundert her erklärbar ist. Das inkrementelle Anwachsen von policeylichen Regulierungen markiert den Übergang zur modernen Gesellschaft, nicht die Epoche der bürgerlichen Revolutionen. Damit tritt ein zumeist unterschlagener, policeylicher Anteil zu Tage. Gerade das öffentliche Recht ist auch als »law relating to the activity of governing « $\mathrm{zu}$ begreifen, das sich aus einer »assemblage of rules, principles, canons, maxims, customs, usages, and manners that condition and sustain the

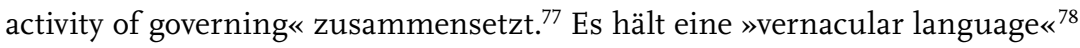
bereit, um die Regierbarkeit der Bevölkerung zu sichern. Dies schließt insbesondere eine Ausweitung der Herrschaftsordnung auf neue Gegenstandsbereiche, etwa Schule und Erziehung, familiäres Zusammenleben und Gesundheit, auf die good governance des physischen Gesellschaftskörpers ein. Insbesondere in der deutschen Verfassungsgeschichte hat die Policey eine überaus bedeu-

72 | Vgl. A. Iseli, Gute Policey, S. $96 \mathrm{ff}$.

73 | Vgl. M. Stolleis, "Geschichte des öffentlichen Rechts", S. 58.

74 | Vgl. ders., "Öffentliches Recht und Privatrecht im Prozeß der Entstehung des modernen Staates", S. 54, und die Datierung der Anfänge des öffentlichen Rechts im Zeitraum von 1555 und 1648 bei ders., "Geschichte des öffentlichen Rechts", S. 70.

75 | Ders., "Öffentliches Recht und Privatrecht im Prozeß der Entstehung des modernen Staates", S. 54.

76 | Ebenda, S. 52.

77 | Loughlin, Martin: The Idea of Public Law, Oxford: Oxford University Press 2004, S. 30.

78 | Ebenda. 
tende Rolle gespielt. »Der Antagonismus von Polizeistaat und Rechtsstaat«, so Stolleis, »wie er später in populärer Verkürzung behauptet wurde, hat deshalb in Deutschland in dieser Form nie bestanden «" ${ }^{79}$. Wenn der Konstitutionalismus einen policeylichen Anteil hat, begrenzt er nicht einfach die Herrschaftsausübung. Er ermöglicht und formalisiert sie in einem produktiven Sinne. Deshalb ist die übliche Gegenüberstellung von herrschaftsbegrenzender und herrschaftskonstituierender Verfassung korrekturbedürftig. Die herrschaftsbegrenzende Verfassung wäre eher als »herrschaftsformende« Verfassung zu verstehen, ${ }^{80}$ die einerseits die Herrschaftsausübung über den corps politique formt (das Problem der Souveränität) als auch regulierend-inkrementell auf den corps social (das Problem der Policey und der Biomacht) zugreift. ${ }^{81}$ Die rule of law führt nicht zwangsläufig zu einem absoluten Abbau an Herrschaft. Im Zuge einer folgenreichen Umformung der Herrschaftsausübung überschneiden sich die beiden Linien - Verfassung des corps politique und des corps social. ${ }^{82}$

Die Schwäche der neueren Verfassungstheorie im Völkerrecht besteht darin, dass sie nur eine Theorie über den corps politique (in diesem Falle das Völkerrecht) bereithält und die Verfassungslehre des corps social (also der Weltgesellschaft und beispielsweise der Weltwirtschaft) verdrängt. Das Recht des corps politique steht gewissermaßen empirisch und normativ über dem Recht des corps social. Wird jedoch, wie eingangs in Anlehnung an den jungen Marx erläutert, nicht von einer einheitlichen, sondern spannungsreichen Verfassungsevolution ausgegangen, ist fraglich, ob eine stets abrufbare Verbindung zu den emanzipatorischen Idealen, der Demokratie und der Aufklärung aufrechtzuerhalten ist. Wenn man davon ausgeht, dass selbst »hegemoniales Recht noch Recht ist ${ }^{83}$, setzt man auf eine positive Dialektik des modernen Rechts. Die hintergründige Logik der Rechts- und Moralentwicklung erlaubt es, in jedes policeyliche Recht doch noch eine Verbindung zu den Idealen der Aufklärung und zum transzendenten corps politique hineinzulegen. Mag das vorliegende internationale Recht noch so hegemonial überformt sein, die Rechtsevolution hält die emanzipatorischen Potentiale präsent. Ist dieser Optimismus aufrechtzu-

79 | M. Stolleis, "Geschichte des Öffentlichen Rechts «, S. 392.

$\mathbf{8 0}$ | Vgl. C. Möllers, "Verfassunggebende Gewalt", S. 235 f.

81 | Eingehender zu dieser Verschränkung von Herrschaft und Regierung siehe Möller, Kolja: "Herrschen und Regieren. Zur Doppelstruktur der konstituierenden Macht", in: Thore Prien (Hg.), Das Staatsverständnis des Postoperaismus, Baden-Baden: Nomos 2015, S. 95-117.

82 | Der Ausgangspunkt der Studie, nämlich das Verfassungsdenken des jungen Marx, ist auch deshalb so gewählt, weil hier beide Linien, Souveränitätsproblem und bürgerliche Gesellschaft, noch nicht hierarchisiert vermittelt werden.

83 | J. Habermas, "Hat die Konstitutionalisierung des Völkerrechts noch eine Chance?", S. 181. 
erhalten, wenn die Verfassungsevolution nicht als teleologisches Fortschreiten der Vernunft gelten kann, wenn sie den Schauplatz für beide Entwicklungslinien bereitstellt, wenn die Konstitutionalisierung der Weltgesellschaft den Polizeianteil im Recht verstärkt? ${ }^{84}$

Der Formwandel der Verfassungsevolution im Übergang zur Weltgesellschaft legt jedenfalls nahe, dass diese Anteile eher dominanter werden, als dass sie weichen. Der Völkerrechtler Martti Koskenniemi hat dies mit dem Begriff des »managerial mindsets « beschrieben, das mit der Ausbreitung funktional spezialisierter Regime einhergeht. ${ }^{85}$ Rechtlich-politische Formen dienen, wie gezeigt wurde, immer stärker der Durchsetzung von substantiellen Programmen einer »guten Ordnung «. Dies wurde im zweiten Teil im Hinblick auf die Weltwirtschaftsverfassung ausgeführt (I.1, ab S. 34). Im Mittelpunkt steht die Verallgemeinerung eines substantiell bestimmten Freihandelsprojekts, einer »guten Ordnung« der internationalen politischen Ökonomie. Diese Entwicklung wird wiederum - ganz ähnlich der frühneuzeitlichen Policey - getrieben von regulativen Zugriffen auf das ökonomische Geschehen, die ihre kleinteiligen Orientierungspunkte zuerst in lokalen Abkommen, Verhaltenskodizes, expertisegetriebenen Regulierungen und weniger in übergreifenden, allgemeinen Gesetzen finden. Und die "gute Ordnung « ist nicht auf die hybriden Arrangements der Weltwirtschaft beschränkt. Sie taucht prominent im Kernbereich der Konstitutionalisierung des Völkerrechts auf. Mit Blick etwa auf die Figur der »humanitären Intervention« lässt sich zeigen, dass das internationale Recht zwischenzeitlich nicht nur der Friedenssicherung dient. Es soll auch "gute Ordnungen«, good governance in die Welt transportieren. ${ }^{86}$ Was hier zu Tage tritt, ist eventuell eine postmoderne Spielart der frühneuzeitlichen Policey: »Globalizations gute Policey « ${ }^{87}$. Die Policey ordnet das Gemeinwesen auf eine "gute Ordnung « hin. Dieses übergreifende Ziel macht eine »rechtserhaltende Gewalt« erforderlich, die nicht nur Recht durchsetzt, sondern auch erhält, wenn sie Lücken füllt und Anpassungsbedarfe feststellt. Dabei wird die

84 | Diese Tendenz der Policey als "beherrschender Teil" (Naucke, Wolfgang: "Vordringen des Polizeigedankens im Recht, d. i.: Vom Ende der Metaphysik im Recht", in: Gerhard Dilcher/Bernhard Diestelkamp (Hg.), Recht, Gericht, Genossenschaft und Policey. Studien zu Grundbegriffen der germanistischen Rechtshistorie, Berlin: Erich Schmidt Verlag 1986, S. 177-187, hier S. 184) wird schon für die Industriegesellschaft diagnostiziert bei ebenda, insbes. S. 179.

85 | Vgl. M. Koskenniemi, "Constitutionalism as Mindset", S. 13.

86 | Zur Kritik: I. Maus, "Menschenrechte als Ermächtigungsnormen internationaler Politik oder der zerstörte Zusammenhang von Menschenrechten und Demokratie".

87 | So Somek, Alexander: "Administration without Sovereignty", in: Dobner/Loughlin, The Twilight of Constitutionalism? (2010), S. 267-287, hier S. 273. 
»rechtserhaltende Gewalt« selbst »rechtssetzend ${ }^{88}{ }^{8}$ Die Trennung von Rechtssetzung und Rechtsanwendung verschwimmt.

Damit ist ein weiteres Mal auf den Formwandel der Verfassungsevolution zurückzukommen. Wenn die policeyliche Linie privilegiert ist, verändert sich die Perspektive auf eine Konstitutionalisierung des Völkerrechts. Es ist in dieser Konstellation offen, ob das internationale Recht noch aus sich heraus die gespeicherten emanzipativen Potentiale aufweist, die der Weltgesellschaft abrufbereit zur Verfügung stehen sollen. Die Folge dieser Herangehensweise ist weniger, dass die Konstitutionalisierungsthese einfach nur unkritisch der faktischen Verrechtlichung folgt, sondern dass die erste, relevante Konfliktlinie zunächst immer eine ums Recht ist. Da das Recht diejenigen historischen Lernprozesse »speichert«, die der Marxismus einst in der Entwicklung der ökonomischen Produktionsverhältnisse angesiedelt hatte, hält jede Verrechtlichung doch noch normative Überschüsse abrufbereit, die auch in kritischer Absicht genutzt werden können. ${ }^{89}$ Am Ende kann hegemoniales Recht durch rechtsimmanente Neubeschreibung ent-hegemonisiert werden. Die Rechtsevolution wird aus sich heraus allerdings kaum in der Lage sein, die policeyliche Dominanz in eine normativ gehaltvolle Verfassungsbildung zu überführen. Sie ist damit überfordert, für die Hegemonie, die Kritik und die Transformation die alleinige Zuständigkeit zu erhalten.

\section{c. Die Politik des internationalen Rechts}

Fraglich ist also nicht nur, wie mit der herrschaftlichen Seite der Verrechtlichung umzugehen ist. Fraglich ist auch, wie die Kämpfe ums Recht, um die Anteile der jeweiligen Entwicklungslinien eine Berücksichtigung erfahren können. Der Fluchtpunkt besteht zunächst in der Annahme, dass selbst hegemoniales Recht noch Recht sei. Mag das internationale Recht noch so politisch überformt, in Ausbeutung und Herrschaft verstrickt sein, es ist Recht. Und als Recht bietet es die Möglichkeit, am eigenen rechtlichen Maßstab gemessen zu werden, der - folgen wir den Annahmen der Konstitutionalisierungsthese - starke normative Überschüsse im Hinblick auf Demokratie und Werte wie Freiheit, Menschenwürde und Gleichheit enthält. Dann stellt sich aber die Frage, wie das hegemoniale Recht aussichtsreich ent-hegemonisiert werden kann. Schließlich wird es jeden Versuch der Befragung zunächst in das nichtrechtliche Außen verweisen oder eingemeinden. Dies lenkt den Blick auf

88 | Siehe dafür auch die Rekonstruktion von Walter Benjamins Text zur "Kritik der Gewalt" bei Loick, Daniel: Kritik der Souveränität, Frankfurt a. M./New York: Campus 2012, S. 181 ff., insbes. S. 184.

89 | Das Recht wird unter dem Gesichtspunkt einer Evolution normativer Bewusstseinsstrukturen begriffen, die zunehmend "universalistisch" werden, siehe J. Habermas, Zur Rekonstruktion des historischen Materialismus, S. 260. 
das Problem, wie sich eine bestimmte Anschauung und Funktion des Rechts überhaupt als »hegemonial« etabliert und wie seine Befragung möglich wird. Auf dem Spiel steht die politische Dimension des internationalen Rechts, und zwar in einem spezifischen, nichtinstrumentellen Sinne. Unter einer Politik des internationalen Rechts soll nicht nur die bloße, externe Instrumentalisierung des Rechts für politische oder ökonomische Zwecke verstanden werden, sondern auch die rechtsinternen Politisierungsbedingungen, die schließlich dazu führen, dass überhaupt von einem dauerhaften hegemonialen Recht die Rede sein kann.

Die Überlegungen der neueren Critical-legal-studies-Bewegung und kritischer Theorien des internationalen Rechts halten hier eine Reihe von weiterführenden Einsichten bereit. ${ }^{90}$ Sie nehmen ihren Ausgangspunkt in der Unbestimmtheit des Rechts. Seine Konkretisierungsbedürftigkeit und »opportunistische« Anpassungsfähigkeit trägt stets ein politisches, teils auch dezisionistisches Moment. ${ }^{91}$ Das Recht gewährleistet nicht die ihm zugeschriebene »Neutralität, Objektivität und Rationalität « ${ }^{92}$. Es führt Unentscheidbarkeiten mit. Sie ziehen sich vom interpretationsbedürftigen Text des Rechts, der sprachliche Differenzen enthält, über den normativen Anspruch des modernen Rechts, sowohl Individuum als auch die Gesellschaft als Ganze zu schützen, bis hin zur Konstruktionsleistung von Fällen und Relevanzen, die das Rechtssystem aktiv herstellt. Regelmäßig sind hier Politiken des Rechts im Recht am Werk. Sie versuchen die Paradoxien des Rechts in Bestimmtheit zu überführen. Den Politiken der juridischen Intellektuellen muss es gelingen, ihre Positionen als unausweichlich darzustellen. Sie verbergen die Rechtsparadoxien. ${ }^{93}$

90 | Zu den critical legal studies: Kennedy, Duncan: A Critique of Adjudication, Cambridge/London: Harvard University Press 1997, und Frankenberg, Günter: "Partisanen der Rechtskritik. Critical Legal Studies etc.", in: Sonja Buckel/Andreas Fischer-Lescano/Ralph Christensen (Hg.), Neuere Theorien des Rechts, Stuttgart: Lucius \& Lucius 2006, S. 97-116; vgl. auch den Überblicksband zum Verhältnis der crits und der deutschen Rechtskritik: Joerges, Christian/Trubek, David M. (Hg.): Critical Legal Thought. An American-German Debate, Baden-Baden: Nomos 1989.

91 | Vgl. Koskenniemi, Martti: "Hierarchy in International Law. A Sketch", in: European Journal of International Law 8/ 4 (1997), S. 566-582, hier S. 571.

92 | Vgl. Kennedy, Duncan: "Comment on Rudolf Wiethölter's 'Materialization and Proceduralization in Modern Law', and 'Proceduralization of the Category of Law' (1989), in: German Law Journal 12/ 1 (2011), S. 474-487, hier S. 483.

93 | Teubner kritisiert die Unbestimmtheitsthese dafür, zu oberflächlich im Überbau der dogmatischen Rechtsarbeit anzusetzen, vielmehr müsse von einer "Realparadoxie" in der Grundstruktur des Rechts ausgegangen werden, siehe ders.: "'And God laughed ...' Indeterminacy, Self-Reference and the Paradox in Law" (1989), in: German Law Journal 12/ 1 (2011), S. 376-406, hier S. 386. 
Das Ziel dieser kritischen Rechtsbetrachtung besteht also ausdrücklich nicht in einem anything goes; vielmehr soll gezeigt werden, wie die Systematizität des Rechts auf einem prekären Terrain entsteht, das von unterschiedlichen Rechtspolitiken durchdrungen ist. ${ }^{94}$

Dies führt ausdrücklich nicht zu der Annahme, dass das moderne Recht nichts anderes darstellt als willfährigen Dezisionismus des Richterstandes. ${ }^{95}$ Die Politik des Rechts im Recht muss im Umfeld des juridischen Formalismus operieren. Damit formt das Recht die Dezision und bürdet ihr auf, Anschluss an bestehende Systematizität zu gewinnen oder neue Begründungszusammenhänge zu etablieren. ${ }^{96} \mathrm{Um}$ es nochmals zu betonen: Das Recht ist nicht nur Instrument der Herrschaftsausübung, sondern formt die Herrschaftsausübung. Dies führt dazu, dass in diesem Prozess der »Formung« selbst (rechts-)politisch gerungen wird.

Damit wird aber eine Betrachtung möglich, die danach fragt, welche Verfassungspolitiken hier wirksam sind, wie juridische Hegemonieverhältnisse entstehen und wie man sie befragen kann. Die Diskursgeschichte des Völkerrechts, die Martti Koskenniemi vorgelegt hat, kann erste Anhaltspunkte für eine solche Betrachtung bieten. ${ }^{97}$ Seine Kernthese geht von einer widersprüchlichen Grundstruktur des Völkerrechts aus. Demnach weist der internationale Rechtsdiskurs eine interne Struktur auf, die zwischen apologetischem Realismus und utopischen Idealvorstellungen oszilliert. ${ }^{98}$ Koskenniemi macht im Völkerrecht ein strukturbildendes Motiv aus, das seine Wurzeln in den liberalen Vertragstheorien hat: Sie wollen die Herrschaft von den subjektiven Rechten des Individuums her legitimieren, schlagen aber in der Regel ebenso eine Theorie vor, die es ermöglicht, subjektive Rechte einzuschränken oder aufzuheben. ${ }^{99}$ Einerseits stehen subjektive Rechte im Zentrum moderner Herrschaftslegitimation. Das Recht soll die Individuen schützen, damit sie ihre Freiheit ausüben können. Andererseits entdeckt Koskenniemi in den klassischen Ver-

94 | So lautet die eindeutige Zurückweisung der Anything-goes-Kritik an den crits bei Kennedy, Duncan: "A Left Phenomenological Critique of the Hart/Kelsen Theory of Legal Interpretation “, in: Kritische Justiz 40/3 (2007), S. 296-305, inbes. S. 300 ff.

95 | Die "Struktur des Rechts sichert die Möglichkeit der Dekonstruktion «, Derrida, Jacques: Gesetzeskraft. Der mystische Grund der Autorität, Frankfurt a. M.: Suhrkamp 1991, S. 30.

96 | Vgl. Buckel, Sonja: Subjektivierung und Kohäsion. Zur Rekonstruktion einer materialistischen Theorie des Rechts, Weilerswist: Velbrück 2007, S. 126 ff.

97 | Koskenniemi, Martti: "The Politics of International Law", in: European Journal of International Law $1 / 1$ (1990), S. 4-32, und ders.: From Apology to Utopia. The Structure of International Legal Argument, Cambridge: Cambridge University Press 2005.

98 | Vgl. ebenda, S. $67 \mathrm{ff}$.

99 | Vgl. ebenda, S. 84. 
tragstheorien immer wieder Mechanismen für den Fall, dass subjektive Rechte im Hinblick auf das Allgemeinwohl auszusetzen sind. ${ }^{100}$ Er zeigt, dass diese paradoxe Zielvorstellung wie ein Alp auf dem internationalen Rechtsdiskurs lastet. Schlagen die liberalen Lehren vom Gesellschaftsvertrag vor, subjektive Rechte gleichzeitig zu gewährleisten und auszusetzen, so soll das internationale Recht sowohl die Souveränität der Staaten als auch die internationale Gemeinschaft als Ganze, mithin normative Güter wie Freiheit, Gerechtigkeit und Frieden schützen. Der internationale Rechtsdiskurs vollzieht die paradoxen Grundannahmen der liberalen Vertragslehren nach: Er gleitet zwischen Apologie und Utopie.

Als über den Wandel gesellschaftlicher Umstände erhaben erweisen sich zwei typische Argumentationsmuster. Sie verfolgen jeweils einen stark universalisierenden Anspruch, den sie von unterschiedlichen Seiten zu erhärten suchen. Das erste typische Argumentationsmuster ist idealistisch bestimmt. Die Idealisten plädieren für den internationalen Schutz normativer Güter. Aus diesem verhältnismäßig abstrakten Anspruch nehmen sie eine absteigende politische Konkretisierung vor. Sie müssen auf die Frage antworten, was es bedeutet, den Frieden zu sichern oder die Menschenrechte durchzusetzen. Demgegenüber argumentieren die Realisten von einer anderen Seite her. Sie beziehen sich nicht auf höchste normative Güter. Eher wählen sie die empirischen Realitäten der Staatenwelt und die Souveränität der Einzelstaaten zum Ausgangspunkt ihrer Rechtsauffassung. ${ }^{101}$

Die Pointe der Diskursgeschichte des internationalen Rechts, die Koskenniemi vorschlägt, ist im Zusammenspiel der paradoxen Strukturmerkmale des internationalen Rechts und den jeweiligen Reflexionstheorien angelegt. Da das Völkerrecht nicht auf festem Grund ruht, erscheint das Wechselspiel zwischen Idealisten und Realisten als schlichter Ausdruck der widersprüchlichen Prämissen des internationalen Rechts. Die Politisierung des internationalen Rechts ist kein Privileg der Realisten. Beide typischen Argumentationsmuster politisieren das internationale Recht auf ihre Weise und beide werden den Dezisionismus nicht vollständig los. Dies ist bei der idealistischen Seite der Fall, wenn es um die höchsten Güter geht: Soll etwa im Hinblick auf den Erhalt der Menschenrechte bestehendes Friedensvölkerrecht außer Kraft gesetzt werden? Demgegenüber argumentieren die Realisten aufsteigend. Sie wollen die Akzeptanz des internationalen Rechts als Souveränitätsschutz dadurch erhalten, dass es ausgesetzt oder bestehenden politischen Problemlagen angepasst wird. Man muss den rechtlichen Formalismus nicht gering schätzen, um zu zeigen, dass die Rechtsbindung allein noch kein befriedigendes Programm zur Zivilisierung der Welt abgibt. Das Plädoyer für eine »formale Rechtsherr-

100 | Vgl. ebenda, S. $71 \mathrm{ff}$.

101 | Vgl. ebenda, S. 59. 
schaft« wird zunehmend »unbefriedigend «: »Arguments from legal principles are countered with arguments from equally legal counter-principles. Rules are countered with exceptions, sovereignty with sovereignty.«102

Es gilt, den rechtlichen Formalismus dahingehend ernst zu nehmen, dass er die Herrschaftsausübung formt und nicht nur einseitig begrenzt. Aus dieser Perspektive, die von der kritischen Diskursgeschichte des internationalen Rechts geprägt ist, kann die Diskussion um die Verfassungsbildung jenseits des Staates gerade nicht einfach in die Gegenüberstellung von Recht und Nichtrecht eingeebnet werden. Die jüngeren Versuche, so etwas wie eine Globalverfassung auszuweisen, reproduzieren nur eine transnationale Verfassungsparadoxie, wenn sie zwischen Rechtsbindung und politischem Dezisionismus hin- und herlavieren. ${ }^{103}$

Das Programm einer herrschaftsbegrenzenden Konstitutionalisierung hält bisher keine Antwort für den Umstand bereit, dass das paradoxe Verhältnis von Politisierung und Rechtszustand in die limitativen Ambitionen liberaler Verfassungsbildung eingeschrieben ist. Die Bindung an ein höherrangiges Recht allein wird der Herausforderung nicht gerecht. Sie ist nur eine Seite der Paradoxie und damit Teil eines iterativen Spiels, das Rechtsbindung gegen Dezision ausspielt und umgekehrt. Der liberale Konstitutionalismus wird den Dezisionismus nicht los, auch wenn er ihn in eine neue Form überführt, die vollkommen ungebundenes Entscheiden erschwert. Diese Einsichten führen zu einer wesentlich defensiveren oder wenigstens anderen Einschätzung der normativen Potentiale einer Konstitutionalisierung des Völkerrechts. ${ }^{104}$

In Koskenniemis neueren Überlegungen wird das politische Moment des internationalen Rechts leicht verschoben. Es taucht vor allem dort auf, wo unterschiedliche, funktional spezifizierte Rechtsregime dabei sind, auf bestehende Herausforderungen zu reagieren oder selbst neue Problemlagen ins Spiel zu bringen. Die Folge ist eine umstrittene »Politik der Definition«, die im Umfeld eines fragmentierten Völkerrechts zum zentralen Auseinandersetzungsfeld avanciert. ${ }^{105}$ Der Zugriff auf die Normativität des Rechts ist hier allerdings ein schwacher. Die Rechtsform übernimmt die Rolle eines gentle civilizer, der unterschiedlichen Interessenlagen und politischen Projekten ein Terrain zur

102 | Ebenda, S. 543.

103 | Für die Kreuzung von Kant und Schmitt vgl. das Plädoyer, den Afghanistaneinsatz dafür zu nutzen, eine freiheitliche Globalverfassung zu definieren, bei Slaughter, AnneMarie/Burke-White, William: "An International Constitutional Moment", in: Harvard International Law Journal 43/1 (2002), S. 1-22.

104 | Siehe Koskenniemis Plädoyer für die Spielräume einer praktischen Urteilskraft der international lawyers im rechtlichen Formalismus, ders., "Constitutionalism as Mindset".

105 | Vgl. ders., "The Politics of International Law - 20 years later", S. 11. 
Verfügung stellt. ${ }^{106}$ Das internationale Recht selbst ist allerdings im Hinblick auf seine Befragung auf ein Supplement verwiesen, etwas Drittes, das hinzustößt, um die hegemoniale Konkretisierung des Rechts zurückzudrängen. Erforderlich erscheint eine alternative Politisierung des Rechts zu sein, die sich nicht im Verweis auf die Allgemeinheit des internationalen Rechts und eine immanente List der Rechtsvernunft erschöpft.

\section{Menschenrechte}

Bisher hat sich der Argumentationsgang auf die beiden ersten Strukturmerkmale der Verfassung, auf die höherrangige Verknüpfung von Recht und Politik sowie auf die Regierungsart, bezogen. In einem letzten Schritt soll das dritte Strukturmerkmal näher beleuchtet werden, nämlich die Rolle von Menschenrechten. Hier profiliert die Konstitutionalisierungsthese eine kosmopolitische Rekonstruktion der Menschenrechte. Sie geht davon aus, dass die Menschenrechte nicht nur die Lücken füllen sollen, die entstehen, wenn sich Menschen nicht mehr auf dem Territorium ihres Staates befinden und der staatsbürgerlichen Rechte entbehren. Ihr Bedeutungsgewinn nach dem Zweiten Weltkrieg und ihre Ausweitung auf immer neue Gegenstandsbereiche werden so interpretiert, dass sie zu individuellen Weltbürgerrechten werden. ${ }^{107}$ Sie sind als eine Art Grundrechtsteil der Globalverfassung wirksam. Die internationale Gemeinschaft soll sie gewährleisten und im Zweifel durch militärische Intervention durchsetzen. Tatsächlich stellt sich die Frage, inwieweit die Menschenrechte nicht doch einen allgemeinen Bezugspunkt darstellen, der über die Fragmentierung des internationalen Rechts erhaben ist. So könnten sich wenigstens Spielräume für eine Ächtung der gröbsten Rechtsverletzungen ergeben.

Auch an dieser Stelle ist die Frage nach dem Formwandel aufgeworfen. Fraglos durchzieht die Verbreitung der Menschenrechte nach dem Zweiten Weltkrieg eine kosmopolitische Ambition. Sie reicht von den Menschenrechtserklärungen und der Kritik an den Exzessen staatlicher Gewalt bis hin zur Stärkung sozialer Rechte. Aber spätestens mit dem Zusammenbruch des realexistierenden Sozialismus tritt eine Komponente globaler Menschenrechtspolitik hinzu. Die Menschenrechte avancieren zu einer verbreiteten und damit kosmopolitischen Sprache, die in einer Vielzahl von politischen Projekten der Weltgesellschaft ihren Niederschlag findet. Der Ausbau des Menschenrechts-

106 | Vgl. ders., The Gentle Civilizer of Nations, Cambridge: Cambridge University Press 2002.

107 | Vgl. Benhabib, Seyla: Another Cosmopolitanism, New York: Oxford University Press 2006, S. 27 ff.; vgl. für eine Diskussion internationaler Bürgerschaft ColliotThélène, Catherine: La Démocratie sans "demos", Paris: Presses Universitaires de France 2011, S. $163 \mathrm{ff}$. 
schutzes in den Vereinten Nationen, der Versuch westlicher Staaten, ihre militärischen Interventionen mit dem Kampf für die Menschenrechte zu begründen, und der Menschenrechtsaktivismus neuer sozialer Bewegungen sind nur einige Beispiele für ihre allgegenwärtige Rolle. Einerseits ist eine Ausweitung der Menschenrechte auf immer neue Sphären zu beobachten. Sie übersteigt schon längst die klassischen Zugriff, wonach Menschenrechte vor allem negative Abwehrrechte gegen staatliche Willkür bereithalten. Inzwischen gewinnen soziale Rechte, Umweltrechte oder die Rechte indigener Völker zunehmend an Bedeutung. ${ }^{108}$ Um diese neuen Felder entsteht sogar ein starker politischer Aktivismus. ${ }^{109}$ Auf der anderen Seite hat im Zuge einer liberalen Revolution im Völkerrecht seit den $1990 e r$ Jahren eine ausufernde Instrumentalisierung stattgefunden, um Hegemonialprojekte des Westens zu rechtfertigen. ${ }^{110}$ Die herrschaftsbegrenzenden Dimensionen der Menschenrechte und ihr kritischer Fluchtpunkt schwinden zu Gunsten einer Legitimationsideologie für die weltweite Durchsetzung des westlichen Entwicklungsmodells. ${ }^{111}$ Sie sind nicht einfach der »Rahmen des Widersprechens «, mit dem die Entrechteten der Welt ihre Unrechtserfahrungen sichtbar machen, sondern ein »Dispositiv für weltpolitische Vorgänge «. ${ }^{112}$ Längst hat sich die Gute Policey der Globalisierung der Menschenrechte bemächtigt, um ihre Ordnungsvorstellungen zu verallgemeinern. Hier wird das Verhältnis von Menschenrechten und kollektiver Selbstbestimmung durchtrennt. Sie schlagen in repressive Toleranz um (I.3.a, ab S. 144). Die Menschenrechte bleiben allerdings auch ein Mittel der Kritik: Sie können durchaus als Anknüpfungspunkt dienen, um die bestehenden Mechanismen der Konstitutionalisierung zu befragen. Dann übernehmen sie die Rolle eines vorläufigen Platzhalters für die Frage, wer welchen Anteil, wer überhaupt ein Recht auf Rechte in der Weltgesellschaft hat. Dies ist jedoch eine Folge ihrer politischen Aneignung, nicht der Menschenrechte selbst (I.3.b, ab S. 147).

\section{a. Repressive Toleranz}

Dass Menschen- und Grundrechte in eine repressive Toleranz übergehen können, ist keine neue Beobachtung. Schon die klassische Menschenrechtskritik

108 | Vgl. zu den Menschenrechten der "dritten Generation “ etwa Riedel, Eibe: "Menschenrechte der dritten Generation «, in: Europäische Grundrechte-Zeitschrift 16 (1989), S. 9-21.

109 | Vgl. Rajagopal, Balakrishnan: International Law from Below. Development, Social Movements and Third World Resistance, Cambridge: Cambridge University Press 2003. 110 | Eine Genealogie dieser liberalen Revolution zeichnet S. Marks, The Riddle of all Constitutions, S. $30 \mathrm{ff}$, nach.

111 | Vgl. Douzinas, Costas: The End of Human Rights, Oxford: Hart Publishing 2000, S. 380 .

112 | Siehe C. Vismann, "Das Recht erklären“, S. 325 u. S. 335. 
setzt hier an: Werden die Grund- und Menschenrechte nur in einem liberal-naturrechtlichen Sinne verstanden, der zentrale gesellschaftliche Institutionen, wie das Privateigentum, die Erziehung oder die Geschlechterverhältnisse, vor staatlichem Eingriff schützen soll, geht dies in der Regel mit einer Reifizierung einher. Die gesellschaftlichen Institutionen erhalten einen vorpolitischen, unbefragbaren Charakter. Sie sind der gesellschaftlichen Neuverhandlung entzogen. Dieser Zug bringt einen verkehrenden Nebeneffekt hervor: Wenn die Menschenrechte als vorpolitische Rechte verstanden werden, die schon bestehende gesellschaftliche Institutionen schützen sollen, entsteht so eine Programmformel für das Handeln der staatlichen Exekutive. Da letztere sowohl an den Gesetzgebungsprozess als auch an den Schutz der Menschenrechte gebunden ist, eröffnen sich Spielräume dafür, das eigenmächtige Handeln mit einer Legitimationsgrundlage zu versehen. Die Exekutive kann stets in Anschlag bringen, die Menschenrechte zu verteidigen, wenn es darum geht, staatliche Politik mit zwingend durchzusetzenden Werten in Verbindung zu bringen. Dadurch verkehrt sich das auf den ersten Blick staatskritische Anliegen der naturrechtlichliberalen Konzeption in eine Vorlage für die Verselbstständigung staatlicher Exekutivorgane, für eine Verstaatlichung der Menschenrechte.

Dies führte schon im Bereich der Rechtskataloge auf nationalstaatlicher Ebene zur Beobachtung, dass Grundrechte zu »repressiven gesellschaftlichen Formen ${ }^{113}$ werden können. Hier tritt die verkehrende Bewegung ein weiteres Mal auf. Demnach schützt die Judikative nicht demokratieermöglichende Autonomien, wenn sie die Grundrechte konkretisiert; vielmehr stützt sie die Ordnungssubstanz der kapitalistischen Gesellschaft, indem sie einen Wertekatalog definiert, den der politische Prozess nicht antasten darf. ${ }^{114}$ Sie zurrt die gesellschaftlichen Verkehrsverhältnisse rechtlich fest. Dabei erleben die Grundrechte eine Transformation. Durch den Verlust an Unbestimmtheit, durch ihre Füllung mit der Ordnungssubstanz der jeweiligen Gesellschaftsordnung wird »Freiheit als Repression «115 institutionalisiert. Diese repressive Toleranz führt ihren freiheitsverbürgenden Gehalt ad absurdum: ${ }^{16}$

113 | Preuss, Ulrich K.: "Zum Strukturwandel politischer Herrschaft im bürgerlichen Verfassungsstaat", in: Claudio Pozzoli (Hg.), Rahmenbedingungen und Schranken staatlichen Handelns. Zehn Thesen, Frankfurt a. M.: Suhrkamp 1976, S. 71-88, hier S. 82.

114 | Siehe ders.: Legalität und Pluralismus. Beiträge zum Verfassungsrecht der BRD, Frankfurt a. M.: Suhrkamp 1973, S. $17 \mathrm{ff}$.

115 | Ders., "Zum Strukturwandel politischer Herrschaft im bürgerlichen Verfassungsstaat", S. 80.

116 | Zur repressiven Toleranz: Marcuse, Herbert: "Repressive Toleranz", in: Robert Paul Wolff/Barrington Moore/ders., Kritik der reinen Toleranz, Frankfurt a. M.: Suhrkamp 1966, S. 91-128. 
"An die Stelle des Verhältnisses von grundrechtlich gesicherter staatsbürgerlicher Freiheit zur legalitär gebundenen staatlichen Herrschaft und deren demokratische Verfügbarmachung durch demokratische Teilnahmerechte tritt das synallagmatische Verhältnis von Schutz und Gehorsam, von Fürsorge und Treue. ${ }^{117}$

In diesem Phänomenbereich steht in der BRD die Idee der freiheitlich-demokratischen Grundordnung als »Superlegalität «118 im Mittelpunkt des Interesses. Hier hat die Rechtsprechung des Bundesverfassungsgerichts Kerne der Gesellschaftsverfassung festgesetzt, die dem demokratischen Prozess vor- und übergeordnet sind.

Die Kritik an der Euphorie für die Menschenrechtsdurchsetzung in der Weltgesellschaft verläuft ähnlich. Die hegemonialen Apparate der Weltgesellschaft schließen die Menschenrechte mit dem westlichen Entwicklungsmodell kurz. Damit - so lauten skeptische Befunde - sei ein »Ende der Menschenrechte«, zumindest ihres kritischen Gehalts, eingeläutet. ${ }^{119}$ Sie dienen nicht mehr zur Kritik oder gar zum Widerstand, sondern sind längst in die hegemonialen Sprachspiele eingemeindet. Eine ganze Reihe von Analysen zeigt beispielsweise, wie stark die Rede von den Menschenrechten auf die Rahmung von sozialen Konflikten einwirkt. ${ }^{120}$ So werden etwa Bürgerkriegs- und Gewaltszenarien zunehmend als humanitäre Katastrophen thematisiert, die tieferliegenden Ursachen sowie der Umstand, dass sich selbst solche Bürgerkriegsszenarien oft nicht mit humanitärer Hilfe beheben lassen, bleiben jedoch im blinden Fleck. Die Folge ist also nicht nur eine stärkere moralische Sensibilisierung für Vorgänge in anderen Teilen der Welt, sondern auch eine folgenreiche Viktimisierung. Der Völkerrechtler Makau Mutua entdeckt einen paradigmatischen Zirkel, in dem immer wieder Einzelpersonen oder soziale Gruppen als »Opfer« dargestellt werden, deren Leben dann durch die externe Intervention meist westlicher Befreier gerettet werden müsse. Er nennt diesen Zirkel »Savages Victims - Saviors«, den er als Narrativ in den neueren humanitären Interventionen entdeckt: »Wilde« begehen Menschenrechtsverletzungen an Opfern, die

117 | U. K. Preuss, "Zum Strukturwandel politischer Herrschaft im bürgerlichen Verfassungsstaat", S. 81.

118 | Ders., Legalität und Pluralismus, S. $17 \mathrm{ff}$.

119 | Vgl. C. Douzinas, The End of Human Rights; siehe auch Vismanns Problembeschreibung, dass es "zu einer Verrechtlichung der Menschenrechte gekommen ist, die von der [...] Anlage der Menschenrechte nicht viel übrig lässt", dies., "Das Recht erklären ", S. 331. Für die Autorin steht der Schließungseffekt einer Institutionalisierung gegenüber der widerständigen Redeform der Menschenrechte im Mittelpunkt.

120 | Zur Übersicht: Kennedy, David: "The International Human Rights Movement: Part of the Problem?", in: Harvard Human Rights Journal 15 (2002), S. 101-125. 
sodann von westlichen Befreiern gerettet werden sollen. ${ }^{121}$ Hier, so lautet die Kritik, übernehmen die Menschenrechte eine geradezu passivierende Funktion, indem sie die handelnden Akteure immer nur in die Rolle eines hilfebedürftigen Opfers drängen (und gerade nicht als Weltbürger betrachten). Damit mystifizieren sie die Konfliktlagen und ihnen entgehen die analytischen Ressourcen, um tatsächlich Hilfe leisten zu können. Alles läuft auf die tragische Tendenz zu einer »wertzerstörenden Wertverwirklichung « hinaus. ${ }^{122}$

\section{b. Platzhalterfunktion}

Dies führt zu der Einsicht, »dass das Wort Menschenrechte mit einem immensen symbolischen Kapital, von einer Vielzahl relativ unabhängiger Diskurse, Praktiken, Institutionen und Kampagnen kooptiert wurde ${ }^{123}$. Die aufscheinende Offenheit der Menschenrechte als populäre Form, die das Rechtssystem »über seine Grenzen hinaus popularisiert ${ }^{124}$, eröffnet vielleicht doch noch Spielräume, die nicht zwangsläufig auf die repressive Toleranz festgelegt sind. Der Haupteinwand richtete sich bisher vor allem gegen Erklärungsansätze, die das widersprüchliche Schwanken der transnationalen Menschenrechte zwischen Emanzipation und Policey nicht hinreichend berücksichtigen. In der Unterscheidung Menschenrechtsgewährleistung/Menschenrechtsverletzung verschwindet der Umstand, dass beide Seiten umkämpfte Begriffe sind, die von unterschiedlichen, teils gegenläufigen Politisierungskreisläufen umspielt werden. Die Hoffnung auf eine Zivilisierung der Konfliktlagen, die sich aus der Durchsetzung menschenrechtlicher Standards speist, kann ebenso in eine Intensivierung des Konfliktgeschehens übergehen. Das Geschehen wird moralisiert und gegen ein »böses « Außen abgegrenzt, das die zivilisatorischen Standards unterläuft. Schon in diesem Sinne sind die Menschenrechte ein hochpolitischer Begriff.

Was ist nun aber mit der revolutionären Dimension der Menschenrechte, mit ihrer Verbindung zur Idee gleicher Freiheit oder zur Demokratie? Hängt am Ende nicht doch viel davon ab, ob man die Menschenrechte als naturrechtlich-liberale Kategorie betrachtet oder ob man sie im Sinne eines demokratischen Republikanismus als revolutionäre Errungenschaft deutet? Schließlich stand am Beginn der bürgerlichen Revolutionsepoche die Gleichursprünglich-

121 | Vgl. Mutua, Makua: "Savages, Victims, and Saviors: The Metaphor of Human Rights", in: Harvard International Law Journal 41/1 (2001), S. 201-245, insbes. S. $227 \mathrm{ff}$.

122 | Um diese Formulierung gegen die sogenannte Wert-Philosophie aufzugreifen, vgl. Schmitt, Carl: Die Tyrannei der Werte (1967), Berlin: Duncker \& Humblot 2011, S. 45.

123 | Douzinas, Costas: "The Paradoxes of Human Rights", in: Constellations 20/1 (2013), S. 51-67, hier S. 52 - Übers. d. Verf.

124 | S. Opitz, An der Grenze des Rechts, S. 186. 
keit von Demokratie und Menschenrechten. Schon in der Französischen Revolution zeichnete sich ein alternatives Modell der Menschenrechte ab, das in einem Widerspruch zum naturrechtlich-liberalen Erbe steht. Hier standen Demokratie und Menschenrechte in einem zwingenden Zusammenhang. Erst wenn demokratische Verfahren existieren, in denen die Menschen als Bürger kollektive Selbstbestimmung ausüben, wird die Rechtskonkretisierung der Exekutive und Judikative entrissen. Sie wird dem demokratischen Prozess übereignet. Demnach kann

"die Funktion der Menschenrechte nicht mehr so verstanden werden, dass sie in einer moralischen Begrenzung des politischen Prozesses von außen besteht. Vielmehr ist ebenso die menschenrechtliche Verfassung selbst demokratisch (und nicht moralisch oder naturrechtlich) wie der revolutionäre Begriff der Demokratie selbst menschenrechtlich (und nicht Herrschaft eines unterdrückenden Ganzen). ${ }^{125}$

Für eine solche radikaldemokratische Interpretation der Menschenrechte stellt sich im Hinblick auf die Weltgesellschaft die Frage nach denjenigen politischen Räumen, in denen die Anbindung an demokratische Verfahren stattfinden könnte. Bisher sind die demokratischen Formen jenseits des Nationalstaates schwach ausgeprägt. Die einzige Möglichkeit besteht darin, die halbierte Menschenrechtsentwicklung doch als einen unvollständigen Platzhalter zu verstehen, als einen Vorgriff, der so mit demokratischen Ansprüchen und Projekten zu überfluten wäre, dass er als Beginn für weitergehende Demokratisierungsschritte gelten kann. Im Schatten der Menschenrechte könnte sich ein politischer Aktivismus entfalten, der schließlich auch auf die erforderlichen politischen Strukturbildungen drängt oder sie selbst ausbildet. Als »Platzhalter demokratischer Autonomie « hielten die so politisierten Menschenrechte »den kategorischen Imperativ der Volkssouveränität: Es soll keine Herrschaft sein! « ${ }^{126}$, präsent. So entsteht eine Aufladung der Menschenrechte, die sich von den mäßigend-zivilisierenden Aspirationen abhebt. Schließlich soll hier der Verkehr von Staaten und Privatleuten in der Weltgesellschaft nicht nur einzelnen moralischen Erfordernissen unterworfen werden, die zu berücksichtigen sind;:127 vielmehr ist ein revolutionäres Verständnis der Menschenrechte angesprochen. Demnach adressieren die Menschenrechte grundlegende Fragen der

125 | Menke, Christoph: "Einleitung", in: ders. / Francesca Raimondi (Hg.), Die Revolution der Menschenrechte. Grundlegende Texte zu einem neuen Begriff des Politischen, Berlin: Suhrkamp 2011, S. 247-252, hier S. 249.

126 | Brunkhorst, Hauke: Solidarität. Von der Bürgerfreundschaft zur globalen Rechtsgenossenschaft, Frankfurt a. M.: Suhrkamp 2002, S. 107.

127 | Das wäre etwa vergleichbar mit dem Vorbild der Horizontalwirkung der Grundrechte im Nationalstaat. 
Machtverteilung und übersteigen dabei gleichzeitig jede Form politischer Institutionalisierung. Sie setzen eine dauernde Befragung in Gang.

Eine solche revolutionäre Politik der Menschenrechte ist als eine Politik zweiter Ordnung, eine Politik der Politik zu verstehen: Indem sie die Rechte des Menschen einklagt, definiert sie, wer und wie rechtmäßige Anteile an der Weltgesellschaft hat. ${ }^{128}$ Dann adressiert sie indirekt die demokratische Frage: Wie sind die Anteile in einem politischen Gemeinwesen verteilt, wenn eigentlich niemand wirklich herrschen darf, weil alle über alle unter Bedingungen gleicher Freiheit das Gleiche beschließen sollen? In diesen Ausführungen scheint schon auf, dass eine Zusatzinnovation erforderlich ist. Denn alles hängt davon $\mathrm{ab}$, inwieweit es gelingt, die Menschenrechte auch entsprechend aufzuladen und so gegen die naturrechtlich-liberale Traditionslinie in Stellung zu bringen. Erst aneignende Politiken sind in der Lage, die Verteilung der bisherigen Anteile zu erschüttern. Nicht die Menschenrechte sind das »Subjekt« der Menschenrechte, sondern diejenigen, die sie sich aneignen, sie einklagen und politisieren und paradoxerweise $»$ noch gar nicht haben ${ }^{129}$. Für die Platzhalterthese verschiebt sich das Problem auf die Menschenrechtspolitik. Das ruft eine Problemlage auf. Sie steht in direktem Zusammenhang mit der Politik zweiter Ordnung. So revolutionär diese Interpretation auf den ersten Blick scheinen mag, es ist fraglich, wie sie zu einer praktischen, materiellen Gewalt werden kann. In der Regel sattelt eine solche Politik zweiter Ordnung auf einer Politik erster Ordnung auf: Spezifische politische Ziele transportieren eine Dimension zweiter Ordnung mit (oder hegemonietheoretisch formuliert: Teilen gelingt es, das Ganze zu thematisieren): Der Unmut über globale Armut und Ungleichheiten führt dazu, die Legitimation der G7 oder G20 in Frage zu stellen; der Protest gegen die aktuellen Praktiken des land grabbing führt zur Kritik des transnationalen Eigentumsrechts; die Angst vor gentechnisch manipulierten Lebensmitteln im Supermarkt mündet in die Kritik des Welthandelsrechts. So kleinteilig die genannten Beispiele erscheinen, so sehr wird bei einer Betrachtung der transnationalen Konfliktlagen deutlich, dass eine Politik zweiter Ordnung nur als Bestandteil eines umfassenderen Politisierungskreislaufs verstanden werden kann. Insofern kann die Politik zweiter Ordnung grundlegenden Paradoxien des Politischen nicht vollständig entkommen. Ab einem bestimmten Zeitpunkt stellt sich die Frage nach institutionellen Bezügen oder spezifischen Engführungen des jeweils in Rede stehenden Menschen der Menschenrechte. Dies spricht nicht gegen ein revolutionäres Potential der Menschenrechte, wohl aber dafür, dass sie es nur im Kontext einer Politik ausspielen können.

128 | Vgl. Balibar, Etienne: "On the Politics of Human Rights", in: Constellations 20/1 (2013), S. 18-26, hier S. 20.

129 | Rancière, Jacques: "Who is the Subject of the Rights of Man?", in: South Atlantic Quarterly 103/2, 3 (2004), S. 297-310, hier S. 298 - Übers. d. Verf. 
Jacques Rancière gibt eine mögliche Antwort, wenn er unterstreicht, dass die Menschenrechte als »Gleichheitseinschreibungen« nur wirksam werden, wenn sie vom Standpunkt der Anteillosen angeeignet und in politischen Konflikten »verifiziert« werden. ${ }^{130}$ Dies ruft nicht zuerst die Frage nach den individuellen Rechten der Weltbürgermonaden vor den Gerichtsbarkeiten der Welt auf. Es verweist auf eine Politik, die vom Standpunkt der Anteillosen ausgeht. ${ }^{131}$ In dem Moment, wo sich die Anteillosen die Gleichheitseinschreibungen der Weltgesellschaft aneignen, verbinden sie die Menschenrechte mit dem universellen Standpunkt der Anteillosigkeit, der immer wieder eingenommen werden kann, um die Zuweisung der Anteile zu befragen. ${ }^{132}$ Erst wenn die Menschenrechte die Bühne des Dissenses zwischen Anteiligen und Anteillosen betreten, entfalten sie ihr emanzipatorisches Potential. Dann verweisen sie auf den Standpunkt der Anteillosigkeit, der vom demos eingenommen wird: »The Rights of Man are the rights of the demos, conceived as the generic name of the political subjects who enact - in specific scenes of dissensus - the paradoxical qualification of this supplement. ${ }^{133}$ In der Verknüpfung mit sozialen Selbstorganisierungen und politischen Handlungsformen können die Menschenrechte eine provisorische Funktion übernehmen. Dafür braucht es nicht nur die Menschenrechte. Hinzutreten muss ein von ihnen unterscheidbares Supplement, um eine demokratische Politisierung zu bewirken: eine Politik der Menschenrechte, die den Standpunkt des demos vorläufig einnimmt. ${ }^{134}$ Diese Betrachtungsweise führt zu einem Zugriff, der die Menschenrechte nicht nur als strategisches Instrument betrachtet. Sie sind revolutionär und auch normativ bedeutsam. Sie sind jedoch von sich aus nicht dagegen immunisiert, in mora-

130 | Ebenda, S. 303 f.

131 | Zu diesem Verständnis des Politischen, das die Anordnung der Anteile eines Gemeinwesens vom Standpunkt der Anteillosigkeit her durchkreuzt, vgl. ders.: Das Unvernehmen. Politik und Philosophie, Frankfurt a. M.: Suhrkamp 2002, S. 24.

132 | Rancière identifiziert diesen Anteil der Anteillosigkeit schließlich mit der Demokratie. Der demos ist weder die umfangslogische Mehrheit noch sind das einfach die "Armen", sondern der Standpunkt derjenigen, die "keine Qualifikation zur Herrschaftsausübung" haben, die Anteillosen, siehe ders., "Who is the Subject of the Rights of Men?", S. 304; zur Doppelbedeutung des Volks als umfangslogische Menge aller Staatsbürger und der Herrschaftsunterworfenen vgl. den vierten Teil, ab S. 179.

133 | Ebenda, S. 305.

134 | Rancière kümmert sich leider zu wenig um den Umstand, dass der Standpunkt des demos auch aktualisiert werden muss, um überhaupt die Bühne der Geschichte zu betreten. Das Lob des "spontanen Aufstands" (so hinsichtlich des Rancière'schen Paradigmas Žižek, Slavoj: Die Tücke des Subjekts, Frankfurt a. M.: Suhrkamp 2001, S. 234) interessiert sich leider zu wenig für die Frage, wie der Anteil der Anteillosen überhaupt dauerhaft erscheint und nicht sofort niedergeschlagen wird. 
lische »gute Policey« überzugehen und sich in repressive Toleranz zu verkehren. ${ }^{135}$

Insofern läuft alles darauf zu, dass die Menschenrechte als Teil des transnationalen Konstitutionalismus zu begreifen sind. Sie durchlaufen jedoch ebenso einen Formwandel und arbeiten die Konfliktverhältnisse der Weltgesellschaft um. Ihr genuin demokratisches Potential ist dabei begrenzt: Sie erscheinen als Medium der mäßigenden Zivilisierung, können jedoch ebenso in eine massive Re-Antagonisierung umschlagen, indem sie bestehende Institutionen menschenrechtlich aufladen und gegen ein (absolut) böses Außen positionieren. Sie können eine provisorische Funktion für demokratische Ansprüche übernehmen, wenn sie als Teil eines entsprechenden Politisierungskreislaufs auftreten.

\section{Dr. Jekyll and Mr. Hyde}

Die Konstitutionalisierung des Völkerrechts ist eine nicht mehr abzuweisende Realität. Im Staatensystem entsteht ein höherrangiges Recht mit konstitutionellen Dynamiken. Transnationale Legitimationsfragen sind aufgeworfen und die Menschenrechtsentwicklung schreitet in immer neuen Gegenstandsbereichen voran. Die Schwäche der Konstitutionalisierungsthese ist vor allem dort anzusiedeln, wo die vorgeschlagene Diagnose zu den Regimen ihren Einsatz hatte: Dass nämlich ein Formwandel des Konstitutionalismus stattfindet, der durch hybride Arrangements, policeyliche Dominanz und rückwirkende Effekte im Nationalstaat gekennzeichnet ist. Die Hoffnungen auf eine Verfassungsbildung im Völkerrecht halten keine Antwort dafür bereit, wie mit den policeylichen Anteilen sowie der Unbestimmtheit des internationalen Rechts und dem Gleiten zwischen Formalismus und Politisierung umzugehen ist.

Erstens gehen ja gerade von denjenigen Regimen effektive Gefährdungen für die Weltgesellschaft aus, die schon in hohem Maße konstitutionalisiert sind. Sie weisen in der Regel einen hohen Grad der Verrechtlichung auf und sind oft an das Staatensystem angebunden. Zweitens verliert die Konstitutionalisierungsthese die zentralen politökonomischen Verfassungsfragen der Weltgesellschaft aus dem Blickfeld. Im Zuge einer marktliberalen Substantialisierung erfährt der demokratische Rechtsstaat eine rückwirkende Transformation. Man kann nicht mehr vom nationalstaatlichen Konstitutionalismus der Nachkriegszeit mit seinen demokratiekonstitutiven Autonomiesphären und sozialen Rechten ausgehen.

135 | Dies gilt auch für die revolutionäre Menschenrechtstradition. Ein gutes Beispiel ist die haitianische Revolution $1791 \mathrm{ff}$.: Die Sklaven Haitis mussten die französischen Truppen an den universalistischen Gehalt der französischen Revolution erinnern, indem sie innen die Marseillaise vorsangen, vgl. Buck-Morss, Susan: Hegel und Haiti. Für eine neue Universalgeschichte, Berlin: Suhrkamp 2011, S. 58 ff. 
Drittens muss das Projekt einer globalen Menschenrechtsgeltung auf seine Teilung zwischen Policey und politischem Aktivismus hin befragt werden. Die kosmopolitische Wendung zu Weltbürgerrechten ist janusköpfig. »Gute Policey« und soziale Bewegungen nutzen teilweise die Sprache der Menschenrechte, um ihre Anliegen zu artikulieren. Die Menschenrechte können freilich als Signifikant mit demokratischen Verweisungszusammenhängen überflutet werden und so die Idee der demokratischen Verfassung in ihrem Fahrwasser mitführen. Dies ist alles andere als voraussetzungslos und embryonal im »Recht« an und für sich enthalten. Die demokratische Politisierung der Menschenrechte ist auf ein hinzutretendes Supplement verwiesen, das den Zusammenhang von Menschenrechten und dem universellen Standpunkt der Anteillosen politisch herstellt. ${ }^{136}$

Man sollte mit der These einer offenen Konvertierbarkeit rechtlicher Institutionen gerade dann vorsichtig sein, wenn sie - wie es jenseits des Staates der Fall ist - auf policeyliche Ordnungsmuster festgelegt sind. Das Gleiten des internationalen Rechts zwischen »managerial« und »kantian mindset« ist kein vollkommen symmetrischer Prozess, in dem immerzu beide Optionen vorliegen, weil es sich um Verrechtlichung handelt. Die Analogie zur Robert Louis Stevensons Novelle über Dr. Jekyll und Mr. Hyde liegt auf der Hand. ${ }^{137}$ Sie endet tragisch. Nach einem langen Wechselspiel der Verwandlungen gelingt es Mr. Hyde nicht mehr, sich in Dr. Jekyll zurückzuversetzen:

"Ich fing an Gefahr zu wittern - die Gefahr, dass, wenn dies länger fortgesetzt würde, das Gleichgewicht meines Wesens für die Dauer verlorengehen, die Macht freiwilliger Verwandlung verwirkt und der Charakter von Edward Hyde unwiderruflich der meinige werden könnte. «138

In der fragmentierten Hegemoniekonstellation singen die Sirenen nicht ausschließlich aus dem Arkanum politischer Willkür. Dies macht es erforderlich alle drei Ebenen der Verfassungsfrage (Höherrangigkeit, Regierungsart, Grundrechte) vom Staatensystem auf die Weltgesellschaft zu entgrenzen. Es würde nicht nur um die Verfassung der internationalen Staatengemeinschaft gehen. Die Legitimationsfrage würde vom Staatensystem gelöst und auf die

136 | Vgl. Chantal Mouffes Position, dass die Verbindung von Rechtsstaat und Volkssouveränität nicht notwendig, sondern als politisch hergestellte Paradoxie der bürgerlichen Revolutionsepoche zu verstehen ist, dies.: The Democratic Paradox, London/ New York: Verso 2000, S. 20.

137 | Vgl. Brunkhorst, Hauke: Das doppelte Gesicht Europas. Zwischen Kapitalismus und Demokratie. Berlin: Suhrkamp 2014.

138 | Stevenson, Robert Louis: Dr. Jekyll \& Mr. Hyde, Frankfurt a. M./Leipzig: InselVerlag, S. 117. 
fragmentierte Hegemoniekonstellation bezogen, um funktionale Äquivalente zur Tradition des Konstitutionalismus auszumachen. Dies ist der Leitfaden, dem der gesellschaftliche Konstitutionalismus folgt. Wie wir sehen werden, berücksichtigt er den Formwandel der Verfassung, scheitert aber daran, den Widerspruch zwischen demokratischer und herrschaftlicher Verfassung präsent zu halten.

\section{ZWISChEN VERSELBSTSTÄNdIGUNG UNd EMANZIPATION: TRANSNATIONALER GESELLSCHAFTLICHER KONSTITUTIONALISMUS}

Nachdem sich gezeigt hatte, dass die Konstitutionalisierungsthese den Formwandel nicht hinreichend berücksichtigt, wendet sich der Argumentationsgang der Theorie des transnationalen gesellschaftlichen Konstitutionalismus zu. Schon einleitend sind im Hinblick auf die Regime einige Überlegungen dieses Entwurfs eingeflossen. Die These vom Formwandel der Verfassung hat maßgebliche Inspirationen aus denjenigen Vorschlägen erhalten, die mit postmodernem Register versuchen, eine neuartige Perspektive auf die rechtlichpolitischen Strukturbildungen der Weltgesellschaft zu gewinnen. Um nochmals den Ausgangspunkt zu rekapitulieren: Es wird davon ausgegangen, dass die transnationalen Sozialregime neuartige Mechanismen der Koppelung von Recht und Politik hervorbringen. Demnach sind in den spontanen Rechtsbildungsprozessen des transnationalen Wirtschaftsrechts, der Finanzmärkte oder des Cyberspace sogar schon transnationale Verfassungsinstitutionen (»Zivilverfassungen«) auszumachen:

"Die These heißt: Emergenz einer Vielzahl von Zivilverfassungen. Die Verfassung der Weltgesellschaft verwirklicht sich nicht exklusiv in den Stellvertreter-Institutionen der internationalen Politik, sie kann aber auch nicht in einer alle gesellschaftlichen Bereiche übergreifenden Globalverfassung stattfinden, sondern sie entsteht inkrementell in der Konstitutionalisierung einer Vielheit von autonomen weltgesellschaftlichen Teilsystemen. Die im Internet tobenden Kämpfe um cyberanarchy, staatliche Regulierung und Kommerzialisierung sind verfassungspolitische Konflikte ersten Ranges, in deren chaotischem Verlauf nichts anderes als das Organisationsrecht einer Digitalverfassung allmählich Konturen gewinnt. ${ }^{139}$

Zunächst wird der Verfassungsbegriff von seinem staatlich-holistischen Anspruch distanziert. Die Regime selbst bringen höherrangige und reflexive Normierungen hervor, die es plausibel machen, hier Verfassungsinstitutionen

139 | G. Teubner, "Globale Zivilverfassungen«, S. 6. 
zu verorten. Diese Umstellung setzt sodann in doppelter Hinsicht an: Einerseits ist mit dem zivilen Verfassungsbegriff eine viel weiter gehende Diagnose zu den Gefährdungslagen der Weltgesellschaft verbunden. Sie bestehen nicht ausschließlich in der Willkür staatlicher Machtausübung. Da jedes Regime zu einer problematischen Eigenrationalitätsmaximierung neigt, bildet es eigene, regimespezifische Dominanzverhältnisse aus, die sich zerstörerisch auf die sozialen Umwelten auswirken können. ${ }^{140}$ An die Stelle zentralisierter Verfassungsbildung tritt eine pluralistische Normproduktion, die jedoch in die Eigenrationalitätsmaximierung verstrickt ist. Andererseits wird so die Normativität der Verfassung rehabilitiert. Die Zivilverfassungen erscheinen als Hoffnungsträger, um dem Expansionsdrang zähmend zu begegnen: Die herrschaftsbegrenzende Leistung der Staatsverfassung ist auf die Sozialregime im transnationalen Raum zu erweitern. ${ }^{141}$

Genau an dieser Überschneidung von Beschreibung und normativem Programm lauern Fallstricke. Im Hinblick auf die erste, leitende Fragestellung nach dem Formwandel wird zwar deutlich, dass die Theorie ziviler Konstitutionalisierung starke Potentiale bereithält. Das Problem besteht jedoch darin, dass sie bisher an der zweiten Fragestellung scheitert: Es gelingt nur unzureichend, den Widerspruch zwischen herrschaftlicher und demokratischer Konstitutionalisierung, den Konflikt der Verfassung mit sich selbst, der eingangs in Anlehnung an die Marx'sche »Kritik des Hegelschen Staatsrechts« eingeführt wurde, angemessen zu artikulieren. Die Potentiale der beobachtbaren zivilen Verfassungsinstitutionen erscheinen in einem eigentümlichen Zwielicht. Ununterscheidbar wird, wo sie den Expansionsdrang der Sozialregime abstützen und wo sie ihren normativen Funktionen nachkommen.

Dies ist zunächst in der Verfassungskonzeption nachzuzeichnen (II.1, ab S. 155). Die fehlende Konfliktdimension, wie sie im ersten Teil als Logik der Antagonisierung entwickelt wurde, führt dazu, dass das demokratische Defizit der Zivilverfassungen unterschätzt bleibt. Folglich bleibt das Desiderat einer zivilgesellschaftlichen Demokratisierung, die direkt an den transnationalen Regimen ansetzt, allzu beschränkt (II.2, ab S.166). Indem sie in umweltbezogene Responsivität, Reflexion oder Politisierung überführt wird, ist offen, wie eine effektive Herrschaftsbegrenzung möglich sein soll. Ein ähnlicher Zusammenhang wird anhand von Grund- und Menschenrechten deutlich. Zwar versucht ihre transsubjektive Reformulierung die systemischen Gefährdungslagen zu berücksichtigen, sie changiert aber zwischen einer eher defensiv-liberalen und einer radikaldemokratischen Variante (II.3, ab S.174). Im

140 | Vgl. A. Fischer-Lescano/G. Teubner, Regime-Kollisionen, S. 28 ff.; zu einer Verbindung dieser systemtheoretischen Diagnose mit hegemonietheoretischen Überlegungen vgl. den zweiten Teil, ab S. 33.

141 | Vgl. G. Teubner, Verfassungsfragmente, S. 89. 
Durchgang durch die drei Ebenen wird gezeigt, dass der Formwandel des Konstitutionalismus aussichtsreich aufgenommen wird, ohne die radikalen Gehalte des Demokratieprinzips zu aktualisieren.

\section{Zivile Verfassungstheorie}

Am Anfang steht ein Pluralisierungs- und Entstaatlichungsbefund. Der Übergang zur Weltgesellschaft bringt eine Ausdifferenzierung unterschiedlicher Sozialregime hervor, die je eigene Formen der Normproduktion ausbilden. Dies führt zu einem Paradigmenwechsel. An die Stelle des internationalen Rechts tritt ein plurales Weltrecht. Als Beispiele für diesen Pluralisierungsbefund dienen beispielsweise das staatsferne Recht der Weltwirtschaft, die lex mercatoria oder die emergierende lex digitalis des Cyberspace. ${ }^{142}$ Das Recht wird vom Staat gelöst, aber die Rechtskommunikation setzt sich fort. In gewisser Weise wird sie sogar intensiviert. In der Vielzahl von internationalen Gerichten, Spezialnormen (lex specialis), Rechtsquellen und Streitschlichtungsinstitutionen kann abgelesen werden, dass der Code legal/illegal längst in die Weltgesellschaft disseminiert. Die »globale Bukowina « - so hat Gunther Teubner die Konstellation bezeichnet ${ }^{143}$ - unterläuft eine zentralisierte Rechtshierarchie genauso wie die Hoffnungen auf ein Superrecht der Weltgesellschaft.

Nun reicht diese globale Bukowina allerdings über einen bloßen Rechtspluralismus hinaus. Die These lautet, dass sogar schon anspruchsvoll strukturierte Verfassungsinstitutionen beobachtbar sind. Eine systemtheoretische Generalisierung und Respezifizierung des Verfassungsbegriffs soll das Blickfeld dafür öffnen, dass der Konstitutionalismus weder zwingend an staatliche Institutionen noch an das politische System im engeren Sinne gebunden ist.

Zunächst hatte Niklas Luhmann die moderne Verfassungsevolution von ihren revolutionären Gründungsmythen und normativen Überschüssen distanziert. Der »politische Eifer « ${ }^{144}$ der bürgerlichen Revolutionsperiode ist für Luhmann nur die eine, letztlich ideologische Seite des Verfassungswesens; vielmehr reagiere die moderne Verfassung »auf die Ausdifferenzierung von Recht und Politik und deren Verknüpfungsbedarf « ${ }^{145}$, indem sie eine strukturelle Koppelung von Rechts- und Politiksystem gewährleistet. Gunther Teubner knüpft mit seiner Verfassungssoziologie an diesen Befund an, distanziert sie jedoch wesentlich stärker als Luhmann vom Zusammenspiel von Recht und Poli-

142 | Siehe u. a. die Beispiele bei A. Fischer-Lescano/G. Teubner, Regime-Kollisionen, S. $66 \mathrm{ff}$.

143 | Teubner, Gunther: "Globale Bukowina: Zur Emergenz eines transnationalen Rechtspluralismus", in: Rechtshistorisches Journal 15 (1996), S. 253-255.

144 | N. Luhmann, "Verfassung als evolutionäre Errungenschaft", S. 183.

145 | Ebenda, S. 180. 
tik. Der Vorschlag besteht darin, den Begriff der Verfassung nochmals wesentlich komplexer anzusetzen. Er unterscheidet zwischen Verfassungsfunktionen, Verfassungsbereichen, Verfassungsprozessen und Verfassungsstrukturen. ${ }^{146}$

Unter Verfassungsfunktionen versteht Teubner die Selbstkonstitution der sozialen Teilbereiche. Verfassungen stützen die unterschiedlichen Teilbereiche $\mathrm{ab}$, indem sie die »Abstraktion eines einheitlichen kommunikativen Mediums - Macht, Geld, Recht, Wissen - als ein autonomes soziales Konstrukt innerhalb eines weltweit konstituierten Funktionssystems ${ }^{147}$ regulieren. Dabei werden »Organisationsregeln, Verfahren, Kompetenzen und subjektive Rechte ${ }^{148}$ voneinander abgegrenzt. Verfassungen haben konstitutive Funktionen. Sie schaffen die institutionellen Voraussetzungen für die kommunikativen Anschlüsse in den sozialen Teilbereichen. Diese konstitutiven Funktionen werden um limitative Funktionen ergänzt. Verfassungsnormen sollen die Steigerungszwänge einhegen.

$\mathrm{Zu}$ den Verfassungsfunktionen tritt ein spezifisches Verhältnis von Verfassungsbereichen hinzu. Teubner geht davon aus, dass stets ein Zusammenspiel zwischen einem formalisierten Organisationsbereich und einem Spontanbereich stattfindet. Dies ist in den jeweiligen Funktionssystemen unterschiedlich angeordnet: in der Wirtschaft etwa im Verhältnis der Unternehmen zu den Verbrauchern, im politischen System von Institutionen zur öffentlichen Meinung. Der Spontanbereich sichert die nötigen Irritationen des Organisationsbereichs ab. Während der Organisationsbereich entscheidet, ist mit den Spontanbereichen die Möglichkeit eröffnet, dass Entscheidungen ex post angefochten werden können. Von diesem Ex-post-Mechanismus hängt unter anderem die »demokratische Qualität des jeweiligen Gesellschaftssektors ab « ${ }^{149}$.

Verfassungsprozesse identifiziert Teubner in Phänomenen doppelter Reflexivität. Hier werden sowohl die Rechtsprozesse als auch die Sozialprozesse in den jeweiligen Regimen in dem Sinne verdoppelt, dass sich über »normale« Rechts- und Sozialprozesse nochmals höherrangige, sekundäre Prozesse errichten. Im Rechtssystem sind dies sekundäre Normierungen, die als reflexive Rechtsprozesse die Normierungen der Normierungen regeln. Sind diese sekundären Normierungen dauerhaft mit reflexiven Sozialprozessen verkoppelt, kann von einer Verfassungsbildung gesprochen werden.

In einem letzten Schritt kommen mit den Verfassungsstrukturen klassische Vorstellungen eines höherrangigen Rechts ins Spiel. Verfassungsstrukturen bilden sich, wenn ein dauerhafter Metacode vom Typ verfassungsgemäß/verfassungswidrig beobachtbar ist, der sowohl dem Rechtscode (Recht/Nicht-

146 | Vgl. G. Teubner, Verfassungsfragmente, S. $120 \mathrm{ff}$.

147 | Ebenda, S. 121.

148 | Ebenda, S. $121 \mathrm{f}$.

149 | Ebenda, S. 141. 
recht) als auch der teilbereichsspezifischen Reflexion der Sozialregime übergeordnet ist. ${ }^{150}$

Dieser Durchgang durch Bereiche, Funktionen, Prozesse und Strukturen versucht, den Verfassungsbegriff so auszubauen, dass er auch jenseits des Staates seine Anwendung finden kann. Dabei wird die Verfassungsfrage nicht auf den Vorrang des internationalen Rechts reduziert. Sie ist als gesellschaftliches Problem zu reformulieren. Das Recht ist hier immer nur die eine Seite. Auf der anderen Seite stehen die Rationalitäten der jeweiligen Sozialbereiche. Nicht nur das Recht wird reflexiv, auch die Sozialbereiche müssen ein bestimmtes Maß an Reflexivität gewährleisten, um eine strukturelle Koppelung mit den Rechtsprozessen einzugehen. Ferner richtet dieser theoretische Entwurf sein Augenmerk auch auf den Umstand, dass Verfassungsbildungsprozesse nicht notwendig am Modell der politischen Konstitution orientiert sein müssen. Da die Sozialbereiche von unterschiedlichen Rationalitäten durchzogen sind, können unterschiedliche Spielarten der strukturellen Koppelung auftauchen. ${ }^{151}$ Dabei wechselt die Darstellung zwischen einem skeptischen Blick einerseits, der die destruktiven Tendenzen in der Weltgesellschaft herausstellt (und der deutlich macht, dass auch die Zivilverfassungen in die Steigerungszwänge verstrickt sind), und der normativen Hoffnung auf eine Konstitutionalisierung andererseits, die den Gefährdungslagen begegnet. ${ }^{152}$ Die Verfassung erscheint in einem eigentümlichen Zwielicht zwischen Verselbstständigung und Emanzipation. Der Unterschied zwischen einer bloß abstützenden und einer demokratischen Verfassungsbildung verschwimmt. Dies folgt, wie im Folgenden ausgearbeitet werden soll, aus der mangelnden hegemonietheoretischen Perspektive. Die Verbindung mit der postmarxistischen Hegemonietheorie, die im ersten Teil der Arbeit entwickelt wurde, führt auch in normativer Hinsicht zu einer Revision.

\section{a. Gesellschaftsverfassung im Nationalstaat}

Zunächst ist auf die Erzählung zurückzukommen, aus der sich die Theorie des gesellschaftlichen Konstitutionalismus speist. Sie schlägt vor, die Entwicklung im Nationalstaat so zu lesen, dass hier eine gesellschaftliche Verfassungsbildung wirksam war. Dies gilt vor allem im Hinblick auf den Ausbau des Wohlfahrtsstaats, der spätestens seit den 1920er Jahren das Terrain der Verfassung

150 | Vgl. ebenda, S. 171.

151 | Vgl. Teubner, Gunther: "Exogene Selbstbindung: Die Konstitutionalisierung von Gründungsparadoxien gesellschaftlicher Teilsysteme", in: Zeitschrift für Rechtssoziologie 35 (2015), S. 1-21.

152 | Siehe nur den Kontrast zwischen der scharfen Kritik an der Weltwirtschaftsverfassung bei: ders., A Constitutional Moment?, und der Hoffnung auf eine zivilgesellschaftliche Konstitutionalisierung bei: ders., "Privatregimes“, S. 450. 
betreten hatte. ${ }^{153}$ Nicht nur, dass in dieser Zeit bereits von einer gesellschaftlichen Gesamtverfassung die Rede war; vielmehr sind schon dort Verfassungsbildungsprozesse, insbesondere im Bereich der Arbeits- und Wirtschaftsverfassung, zu beobachten. Durch die Einführung von Mechanismen betrieblicher Mitbestimmung, Tarifautonomie und einer institutionalisierten Koalitionsfreiheit soll die Arbeitswelt der Weimarer Republik eine Konstitutionalisierung erfahren. ${ }^{154}$ Zentrale Entscheidungen sind den Tarifpartnern übereignet und nicht in der staatlichen Politik monopolisiert.

Die Staatszentrierung der Verfassungsdiskussion, so die Annahme, reicht deshalb direkt in den Erkenntnisprozess hinein. Sie führt zu einer Verengung, indem sie diese bedeutsamen Muster der Verfassungsbildung nicht angemessen präsent hält. Da sie eine Identität von Staat und Konstitution unterstellt, überdeckt sie die historisch gewachsene Vielfalt des Verfassungsphänomens. Zwar ist der konstitutiv-limitative Doppelcharakter der Verfassung idealtypisch im Bereich politischer Machtausübung ablesbar, aber schon in der funktional ausdifferenzierten Gesellschaft des Wohlfahrtsstaats hat sich die Verfassungsfrage ebenso in den gesellschaftlichen Teilbereichen gestellt. Der Wohlfahrtsstaat habe

"viele Funktionsregime in Eigenregie: Bildung, Wissenschaft, Gesundheitswesen, Rundfunk und Fernsehen verfasst, denen der Staat begrenzte Autonomie einräumt. Zum anderen belässt der Wohlfahrtsstaat andere Subsysteme, besonders die Wirtschaft, in inrer gesellschaftlichen Autonomie, übernimmt dann aber selbst die Aufgabe gesamtgesellschaftlicher Koordination. «155 $^{15}$

Der gesellschaftliche Konstitutionalismus ist also kein vollkommen neues Phänomen. Als unterschwelliger Movens spielt er schon immer in die soziale Evolution hinein, auch wenn er häufig eine verdrängte Rolle einnimmt. Die Annahme besteht hier darin, dass die funktionale Differenzierung eigenständige Dynamiken hervorbringt, die einer Verstaatlichung entzogen bleiben. Aus dieser Perspektive neigt die Verfassung des Wohlfahrtsstaats freilich immer wieder dazu, sie dem staatlichen Steuerungsanspruch unterzuordnen. Grosso modo ist es jedoch exemplarisch gelungen, gesellschaftlichen Autonomieräumen eine halbwegs kontextsensible Eigenverfassung zu ermöglichen.

In dieser Erzählung schwingen durchaus normative Überschüsse mit. Die funktionale Differenzierung erscheint nicht nur als unhintergehbarer Sündenfall, sondern genauso als Bedingung einer freiheitlichen Gesamtverfassung der Gesellschaft. Eine Gesellschaft ohne Spitze und Zentrum bringt Autonomie-

153 | Ders., Verfassungsfragmente, S. $45 \mathrm{ff}$.

154 | Vgl. Sinzheimer, Hugo: Grundzüge des Arbeitsrechts, Jena: Gustav Fischer 1927.

155 | G. Teubner, Verfassungsfragmente, S. 45. 
sphären und Mechanismen sozialer Selbstorganisation hervor. Die normative Pointe ist dort zu suchen, wo erst einmal jede dieser Autonomiesphären, auf das richtige Maß begrenzt, als evolutionäre Errungenschaft zu begreifen und mit vernünftigen Entwicklungspotentialen ausgestattet ist. Die Verfassung schützt die Ausdifferenzierung vor Rückschlägen, Entdifferenzierung und totalitärer Selbstanmaßung politischer Macht. So scheint ein hegelianisierender Modus durch, der in den Autonomiesphären der ausdifferenzierten Gesellschaft neben funktionaler Selbstreferenz auch Freiheitspotentiale identifiziert. ${ }^{156}$

Ist damit ein normativer Standpunkt gewonnen, so ruft die Erzählung im nächsten Schritt gefährdende Bedrohungsszenarien herbei, die das Verfassungsprojekt untergraben. Die erste Bedrohung für die Freiheitspotentiale besteht im imperialen Übergriff der funktionalen Selbstreferenz auf andere soziale Teilbereiche. Dies ist der Fall, wenn Kommunikationsmedien entfesselt, aber unzureichend begrenzt werden. Beispielhaft entwickelt der gesellschaftliche Konstitutionalismus diesen Befund an der Wirtschaftsverfassung. Er übernimmt von Theorien der Wirtschaftsverfassung die Notwendigkeit, den Verfassungsbegriff auf die wirtschaftliche Sphäre auszudehnen. Scharf kritisiert er sodann eine Eindimensionalität, die jede gesellschaftliche Frage in ein Problem der Wirtschaft verwandelt. Die Wirtschaftsverfassung gebärde sich »imperialistisch ${ }^{157}$. Daraus resultiert die Forderung nach einer Begrenzung der Verfassungsreichweite: Die funktionale Differenzierung muss vor dem zerstörerischen Alleinvertretungsanspruch eines Teilbereichs über die anderen geschützt werden.

So ist ein Hinweis auf die andere, zweite Bedrohung gegeben. Die Staatsverfassung verfolgt den Anspruch, das gesellschaftliche Leben als Ganzes normativ zu durchdringen. Die Logik des politischen Konstitutionalismus läuft Gefahr, die Orientierung am Machtcode blind auf andere soziale Teilbereiche anzuwenden, ohne deren Eigenrationalität zu berücksichtigen. Die »Entscheidungsmuster der Politik werden ungeprüft auf gesellschaftliche Teilbereiche übertragen « ${ }^{158}$. Als Beispiel dafür dient die Verfassung der Wissenschaft. Sie muss anderen Kriterien folgen (Wahrheit) als einer aus der Staatsverfassung entliehenen Parlamentarisierung. ${ }^{159}$ Ansonsten kolonisiert der Machtcode andere soziale Teilbereiche. Es droht eine autoritäre Zentralsteuerung, die bestehende Mechanismen sozialer Selbstorganisation ignoriert oder gar unterbindet. Die Errungenschaften der funktionalen Differenzierung sind schützenswert.

156 | Kritisch gegen den gesellschaftlichen Konstitutionalismus gewendet bei Hirsch, Michael: Die zwei Seiten der Ent-Politisierung. Zur politischen Theorie der Gegenwart, Stuttgart: Steiner-Verlag 2007, S. $128 \mathrm{ff}$.

157 | G. Teubner, Verfassungsfragmente, S. 60.

158 | Ebenda, S. 53.

159 | Emphatisch: ders., "Privatregimes, S. 450. 
Sie können nur um den Preis massiver Freiheitseinschränkungen voluntaristisch zurückgebaut werden.

Man mag fragen, ob die Erzählung einer Ausdifferenzierung der Teilbereiche, die nur richtig verstanden und von zentralen Steuerungsambitionen frei $\mathrm{zu}$ halten ist, nicht wichtige Aspekte der modernen Verfassungsevolution ignoriert. Was ins Hintertreffen gerät, sind im Grunde zwei Aspekte: Der erste bezieht sich auf den Prozess der Ausdifferenzierung. Die Konstitution der Sozialregime auf transnationalem Terrain folgt (wie die moderne Verfassungsevolution insgesamt) einem antagonistischen Modus. Am Beginn steht ein konstitutives Außen, gegen das sich die jeweilige Verfassung überhaupt erstmal behaupten muss (II.1.b, ab S.160). ${ }^{160}$ Der zweite Aspekt bezieht sich auf die Rechtsgeschichte. Eine Geschichte des Konstitutionalismus muss die revolutionär-voluntaristische Komponente in der sozialen Evolution berücksichtigen (II.1.c, ab S. 165).

\section{b. Antagonismus}

In seinem frühen Aufsatz »Naturrecht und Revolution « hatte Jürgen Habermas eine folgenreiche Unterscheidung zwischen den Revolutionen in Frankreich und Nordamerika eingeführt. ${ }^{161}$ Während die amerikanische Verfassungsrevolution bestehende gesellschaftliche Verkehrsverhältnisse konstitutionalisiert, ist mit der Umwälzung in Frankreich und Europa eine andere Ausgangslage verbunden. Im Mittelpunkt der Französischen Revolution steht nicht nur der Steuerungsanspruch, das gesamte gesellschaftliche Leben von der demokratischen Selbstbestimmung der Nation her auszugestalten, sondern erst einmal die negative Seite der Volkssouveränität. Sie muss sich gegen die bestehende Souveränität des Ancien Régime in sozialen Auseinandersetzungen behaupten. Während die amerikanische Bill of Rights versucht, »der überlieferten Rechtsmaterie eine andere Legitimationsgrundlage zu verschaffen «, bringt die französische Menschenrechtsdeklaration »prinzipiell neues Recht positiv erst zur Geltung «. ${ }^{162}$ Demnach sei, so folgert Habermas, »der revolutionäre Sinn der Deklaration [...] die Begründung einer neuen Verfassung, in Amerika aber die der Unabhängigkeit, in deren Folge allerdings eine neue Verfassung nötig wird ${ }^{163}$.

160 | Es geht also um darum, dass sich die Unterscheidung Regime/konstitutives Außen vor die Regime/Umwelt-Unterscheidung drängt, vgl. den zweiten Teil, ab S. 33.

161 | Habermas, Jürgen: "Naturrecht und Revolution “ (1963), in ders., Theorie und Praxis. Sozialphilosophische Studien, Frankfurt a. M.: Suhrkamp 1972, S. 89-127.

162 | Ebenda, S. 94.

163 | Ebenda. 
Deshalb geht die revolutionäre Verfassungsdiskussion in Frankreich andere Wege. ${ }^{164}$ Die Volkssouveränität bezieht sich nicht nur auf die radikaldemokratische Gestaltung einer möglichen Zukunft der Nation; sie ist auch das Mittel, um den antagonistischen Sozialkonflikt mit dem Ancien Régime zu symbolisieren. Das Volk ist alles, der König ist nichts. Die radikaldemokratische Besetzung des Verfassungsbegriffs, die in dieser Zeit stattfindet, wird so lesbar. Mit Artikel 16 der Menschen- und Bürgerrechtserklärung aus dem Revolutionsjahr 1789 (»Eine Gesellschaft, in der die Gewährleistung der Rechte nicht gesichert und die Gewaltenteilung nicht festgelegt ist, hat keine Verfassung «) wird es dem Ancien Régime schlicht abgesprochen, die Gesellschaft legitim zu verfassen. Die Nation eignet sich die verfassungsgebende Gewalt an. ${ }^{165}$

Erst jüngst hat Hauke Brunkhorst in einer ausführlichen Studie zur »kritischen Theorie von Rechtsrevolutionen « diesen Konflikttyp verallgemeinert. ${ }^{166}$ Demzufolge erwächst der moderne Konstitutionalismus aus revolutionären Umbrüchen, die als Teil der sozialen Evolution (und nicht als schematischer Gegenpart) zu verstehen sind. Was bei Habermas angeklungen ist, verfolgt die Studie bis zum Investiturstreit des Mittelalters im 11. und 12. Jahrhundert zurück: Dort hat eine tiefgreifende Revolution stattgefunden, die ein neues Rechtsverständnis in die Welt brachte, aus dessen Schatten keiner der revolutionären Umbrüche der letzten Jahrhunderte vollständig getreten ist. Dieses Rechtsverständnis wurde freilich vollkommen unversöhnlich gegen die bestehenden Zustände positioniert. Die Kirche verbündete sich mit den Armen, den pauperes, und der Spitzname des Papstes Gregor VII. (Höllenbrand) deutet freilich auf eine totalisierende Dynamik des Umbruchs hin, der dann im Nachgang in die Entstehung eines funktional ausdifferenzierten Rechtssystems mündete. ${ }^{167}$ Besonders prägnant wird diese revolutionäre Konstellation, in der Verfassung gegen Verfassung steht, mit der protestantischen Reformationsbewegung. Brunkhorst identifiziert hier eine $»$ De-Konstitutionalisierung ${ }^{168}$. Die Orientierung des Protestantismus an Text und individuellem Glauben wird als politische Strategie lesbar. Sie kommt zur Anwendung, um die Verfassung der katholischen Kirche zu attackieren, sie zu de-konstitutionalisieren. Gerade vor dem Hintergrund der hegemonietheoretischen Erweiterung erscheint es na-

164 | Vgl. ebenda, S. 110 f.

165 | Daraus erwächst ein vertikaler Modus der Gewaltenteilung, der nicht als Souveränitätsteilung zu verstehen ist, vgl. Eberl, Oliver: "Die Gewaltentrennung. Sieyes' Begründung eines 'französischen Modellsı der vertikalen Gewaltenteilung", in: Ulrich Thiele (Hg.), Volkssouveränität und Freiheitsrechte. Emmanuel Joseph Sieyes' Staatsverständnis, Baden-Baden: Nomos 2009, S. 191-210.

$166 \mid$ H. Brunkhorst, Critical Theory of Legal Revolutions.

167 | Vgl. ebenda, S. 126.

168 | Ebenda, S. 149. 
heliegend, diesen Gedankengang weiterzuverfolgen. Die Dynamiken sozialer Selbstorganisation und funktionaler Differenzierung bilden sich zuallererst in Abgrenzung zu einem konstitutiven Außen heraus.

Was sich für die modernen politischen Verfassungen explizieren lässt, kehrt auch in den sozialen Teilbereichen wieder. Als paradigmatisches Beispiel kann die Arbeits- und Sozialverfassung der 1920er Jahre in der Weimarer Republik herangezogen werden. Sie sollte einen dritten Weg gegen die sozialistische Räteverfassung sowie gegen den Konkurrenzkapitalismus bereithalten. Ihre Durchsetzung verdankt sie dieser doppelten Frontstellung:

"Gelang es der Arbeiterschaft nicht, durch den Vorstoß der Revolution die bestehende Wirtschafts- und Gesellschaftsverfassung grundlegend zu verändern, so war sie doch in der Lage, gewisse Ansätze zu einer Umbildung der Staats- und Gesellschaftsordnung, die die Revolution zuwege gebracht hatte, in das sozialpolitisch-arbeitsrechtliche Fahrwasser abzulenken und hier festzuhalten. Charakteristisch ist die Entwicklung der Räteverfassung, die von dem politischen auf das wirtschaftlich-soziale Gebiet umgeschaltet wurde, wirtschaftspolitisch scheiterte, sich jedoch sozialpolitisch in Gestalt der Betriebsräte wenigstens teilweise erhielt. $1^{169}$

Die Teilbereichsverfassung, die progressive Juristen und Staatsrechtler »im Bereich der Wirtschafts- und Arbeitsverfassung als einheitliche politische Entscheidung des zweiten Teils der Weimarer Verfassung ${ }^{170}$ konturiert haben, erhält ihre Konstitutionsbedingungen aus antagonistischen Konfliktverhältnissen, nicht aus der funktionalen Differenzierung allein. Eine ähnliche, negative Seite ist für die ordoliberale Wirtschaftsverfassung und die soziale Marktwirtschaft in der jungen BRD festzuhalten. Sie gewinnt ihr Selbstverständnis aus der Abgrenzung von planwirtschaftlichen und wirtschaftsdemokratischen Bestrebungen. So konnte sie zum Gründungsmythos und zum politischen Mastersignifikanten der BRD werden. ${ }^{171}$

Am Beginn jeder Verfassungsbildung steht der Konflikt. Staats- und Sozialverfassungen bilden ihre prägenden Strukturmerkmale gegen eine bestehende oder drohende Verfassung eines konstitutiven Außen heraus. Damit sind Teilbereichsverfassungen gerade nicht Ausdruck von tendenziell unschuldigen Eigennormativitäten. Im Gegenteil haben sie immer schon bestehende Ord-

169 | Fraenkel, Ernst: „Die politische Bedeutung des Arbeitsrechts" (1932), in: ders.: Reformismus und Pluralismus, Hamburg: Hoffmann und Campe 1973, S. 60-72, hier S. $65 \mathrm{f}$.

$\mathbf{1 7 0}$ | F. L. Neumann, "Die soziale Bedeutung der Grundrechte in der Weimarer Verfassung", S. 60.

171 | Vgl. Nonhoff, Martin: Politischer Diskurs und Hegemonie. Das Projekt "Soziale Marktwirtschaft», Bielefeld: transcript 2006, S. 127 ff. 
nungsmuster verdrängt. Die Autonomieräume mussten sich in Konflikten gegen bestehende Mechanismen sozialer Selbstorganisation durchsetzen. Diese Einsicht unterläuft die schematische Gegenüberstellung zwischen einer freiheitlichen Ausdifferenzierung und einer politisch-voluntaristischen Entdifferenzierung. Am Beginn steht stets ein Moment der Entdifferenzierung mit all seinen politisierten Begleiterscheinungen, messianischen Heilserwartungen und anderen alteuropäischen Versatzstücken. Die funktional ausdifferenzierte Gesellschaft ist nicht von konstituierenden Selbstanmaßungen - sei es der Staatsverfassung oder der jeweiligen Teilbereichsverfassungen - zu trennen, die darauf zielen, einen bestehenden Zustand zu überwinden, und sich dabei die allseitige Problemlösungskompetenz zuweisen. Dass Theorien der sozialen Teilbereichsverfassung oft nur ihre originäre Spezialsicht, etwa der Wirtschaft, der Arbeit, der Wissenschaft etc., auf die Gesellschaft übertragen wollen, hängt deshalb nicht nur mit Differenzierungsvergessenheit zusammen, sondern schlicht mit einer konfliktiven Logik.

Dann kann der Formwandel nicht auf Entstaatlichung und Pluralismus beschränkt werden. Ihm entspricht gleichsam die Verdrängung der wohlfahrtsstaatlichen Verfassung im atlantischen Raum und den damit zusammenhängenden Systemen internationaler Kooperation. Wie im Laufe des Argumentationsgangs hervorgetreten ist, sind soziale Konflikte maßgeblicher Teil der Konstellation, in der die transnationalen Regimeverfassungen ihre Charakteristika annehmen. Sie haben sich gegen die fordistische Wirtschaftsverfassung des Nachkriegskapitalismus durchgesetzt und eine neoliberale Doktrin (nicht einfach: Wirtschaftsrationalität) verallgemeinert. Die Regimeverfassungen haben nicht schlicht das Kommunikationsmedium Geld entfesselt. Sie haben spezifische Programme zum Kern der Sozialregime erhoben. Sie entziehen sie durch höherrangige Konstitutionalisierung weitgehend der Kritik (Substantialisierung). Hier wird die Unterscheidung von limitativer und konstitutiver Funktion der Verfassung problematisch. Begrenzende Spielräume entstehen erst dann, wenn man den Kern der Verfassung - ihre konstituierende Dimension - überhaupt befragbar macht.

Die hier vorgenommene Umschrift der Regime/Umwelt-Unterscheidung auf eine Regime/konstitutives-Außen-Unterscheidung legt eine veränderte Diagnose nahe. Die Verfassungsevolution der westlichen Industriegesellschaften hat im 20. Jahrhundert soziale Teilbereichsverfassungen ermöglicht, indem sie das Demokratieprinzip in Form des allgemeinen Wahlrechts realisiert und die Ausweitung der Demokratie auf andere soziale Teilbereiche zumindest in Ansätzen verwirklicht hat. In diesem Rahmen hat sie antagonistische Sozialkonflikte zunehmend bearbeitbar gemacht. ${ }^{172}$ Die verhältnismäßige Stabilität des wohlfahrtsstaatlichen Konstitutionalismus liegt in der Institutionalisierung des

172 | Vgl. C. Mouffe, Über das Politische, S. 30. 
sozialen Konflikts begründet. Dass insbesondere die Arbeiterbewegung ihre Interessen vertreten konnte und zumindest formal die Möglichkeit aufschien, »die Wirtschafts- und Gesellschaftsordnung zur Disposition demokratischer Willensbildung ${ }^{173} \mathrm{zu}$ stellen, hat auch über die Staatsverfassung hinaus eine Tendenz befördert, antagonistische Sozialkonflikte in agonistische Verhältnisse der Gegnerschaft zu überführen.

Der Übergang zur Weltgesellschaft kann nicht auf einen postmodernen Pluralismus begrenzt werden; vielmehr ist davon auszugehen, dass gleichermaßen eine folgenreiche Re-Antagonisierung stattfindet. Die agonistische Leistung des wohlfahrtsstaatlichen Konstitutionalismus wird gerade nicht in die Weltgesellschaft verlängert. Im Gegenteil scheinen die Regimeverfassungen nicht in der Lage zu sein, antagonistische Sozialkonflikte zu bearbeiten. Unter weitgehender Abwesenheit solcher Kompromisse schaffen sich die Regime und die dort dominanten Eliten einen Konstitutionalismus nach ihrem Bild. ${ }^{174}$ Die innerste Substanz der jeweiligen Regime, also: um was es dort eigentlich geht, wird der Diskussion durch höherrangige Konstitutionalisierung weitgehend entzogen und letztlich - an dieser Stelle ist das sozialwissenschaftliche Modewort tatsächlich angebracht - als Verfassungsnorm essentialisiert.

Die Konstitutionalisierung verweist die Konfliktlagen ins Außen der Regime, indem sie das, um was es in den Regimes »eigentlich « geht, als konstituierende Programme höherrangig zum Kern der Verfassung erhebt. Vor diesem Hintergrund wird die Unterscheidung in limitative und konstitutive Verfassungsfunktionen zunehmend porös. Jede Begrenzung wird schnell dazu führen, die Frage nach den konstituierenden Programmen aufzuwerfen. Denn Öffnungen der jeweiligen Bereichsrationalität sind im Grunde nur möglich, wenn man die zentralen Verfassungsessenzen umgeht. Wer die Expansionstendenzen der Weltwirtschaft begrenzen will, gelangt schnell zur Erkenntnis, dass die konstitutive Entbindung einer Freihandelsrationalität erst einmal in Frage stehen können muss. Um das Demokratieprinzip überhaupt noch präsent zu halten, müsste ein normativ gehaltvolles Verfassungsprojekt vor allem destituierend ansetzen: Indem es die konstituierenden Programme aus ihrem höherrangigen Status verdrängt, werden limitative Dynamiken erst denkbar. ${ }^{175}$

173 | W. Abendroth, "Zum Begriff des demokratischen und sozialen Rechtsstaates im Grundgesetz der Bundesrepublik Deutschland“, S. 346.

174 | Vgl. Maus, Ingeborg: "Verfassung und Verfassungsgebung. Zur Kritik des Theorems einer ,Emergenz supranationaler und transnationaler Verfassungen ", in: Regina Kreide/Andreas Niederberger (Hg.), Staatliche Souveränität und transnationales Recht, München: Mering: Hampp 2010, S. 27-70, hier S. 49.

175 | Vgl. auch die Schlussfolgerung bei Christodoulidis, Emilios: "Of Boundaries and Tipping Points: A Response to Gunther Teubner", in: Social \& Legal Studies 20/2 (2011), S. 238-243. 


\section{c. Evolution und Revolution}

Daraus folgt eine weitere Korrektur. Sie betrifft das Verhältnis von Evolution und Revolution. Am Beginn der funktional ausdifferenzierten Gesellschaft stehen revolutionäre Umwälzungen in Kultur, Religion, Politik und Ökonomie:

"[G]roße verfassungsrechtliche Innovationen der modernen Gesellschaft [sind] nicht die Folge allmählicher Anpassungen, sondern plötzlicher Umwälzungen [...] Vor allem in den großen Rechtsrevolutionen haben sich normative Lernprozesse, die durch strukturelle Klassenkonflikte [...] ausgelöst worden [sind,] zu umfassenden Gesellschaftsreformen verdichtet. ${ }^{1176}$

Jedenfalls kann die Erzählung nicht auf die evolutorische Ausdifferenzierung, auf die »untergründigen evolutionären Prozessen von langer Dauer, [...] in denen sich im Zuge der Verrechtlichung von Gesellschaftssektoren auch konstitutionelle Normen inkrementell entwickeln «, reduziert werden. ${ }^{177}$ Nicht zuletzt Harold J. Berman hat in seiner berühmten Studie zur Herausbildung der westlichen Rechtstradition auf die bedeutende Rolle von Revolutionen hingewiesen. Demnach ist der moderne Konstitutionalismus auf die päpstliche Revolution des 11. und 12. Jahrhunderts zurückzuverfolgen: eine »transnationale Revolution«, die »in ganz Europa für die Geistlichkeit, unter dem Papst gegen kaiserliche, königliche und feudale Beherrschung « eintrat. ${ }^{178}$ Erst die Kämpfe zwischen Papst und weltlicher Herrschaft, die sich gewaltsam über mehrere Jahrzehnte erstreckten, verhalfen dem kanonischen Kirchenrecht zum Durchbruch, das die Grundlagen des modernen Rechtsverständnisses embryonal in der Kirchenverfassung enthält..$^{179}$ Berman zeigt, dass mit der protestantischen Reformation, der englischen, französischen, amerikanischen und der russischen Revolution Umwälzungen einhergehen, die der sozialen Evolution eine andere Richtung geben, dabei aber nach dem revolutionären Furor stets wieder auf die westliche Rechtstradition zurückkommen. ${ }^{180}$ Die Revolution ist nicht

176 | Brunkhorst, Hauke: "Legitimationsverhältnisse. Replik auf Ingeborg Maus", in: Oliver Eberl (Hg.): Transnationalisierung der Volkssouveränität. Radikale Demokratie diesseits und jenseits des Staates, Stuttgart: Steiner-Verlag 2011, S. 317-348, hier S. $322 \mathrm{f}$.; siehe auch für einen systemtheoretischen Versuch, die Revolution wieder in den Horizont der Bemühungen einzuordnen, Opitz, Sven: "Gibt es einen normativen Eigensinn der (R)Evolution? Über Streit und Ästhetik in der Soziologie des Politischen ", in: Soziale Welt 63/3 (2012), S. 283-292, insbes. S. 284 ff.

177 | G. Teubner, "Globale Zivilverfassungen «, S. 15.

178 | Berman, Harold J.: Recht und Revolution. Die Bildung der westlichen Rechtstradition. Frankfurt am a. M.: Suhrkamp 1991, S. 50.

179 | Vgl. ebenda, S. 341.

180 | Vgl. ebenda, S. 43. 
der Gegenbegriff zur Evolution. Revolutionäre Umwälzungen sind ein integraler Bestandteil der sozialen Evolution selbst: »Alles ist Evolution, aber die Evolution ist nicht alles. ${ }^{181}$

Wiederum wird dieser Zusammenhang am Beispiel des wohlfahrtsstaatlichen Konstitutionalismus besonders deutlich. Wenn dort wenigstens Keimformen einer Verfassung gesellschaftlicher Teilbereiche entstanden sind, kann dies nicht einseitig auf die evolutionäre Ausdifferenzierung zurückgeführt werden. Nicht nur die hintergründige List der funktionalen Differenzierung hat sich im Wohlfahrtsstaat niedergeschlagen. Der sozial-demokratische Konstitutionalismus ist aus einer Epoche der Bürgerkriege und Revolutionen hervorgegangen. Entscheidende Fortschritte in den Teilbereichsverfassungen sind unter dem Eindruck drohender sozialer Umwälzungen mit all ihren entdifferenzierend-voluntaristischen, nichtkomplexitätsadäquaten und oft politikzentrierten Begleiterscheinungen entstanden. Paradoxerweise hat die funktional ausdifferenzierte Industriegesellschaft ihre identitäre Nichtidentität aus der drohenden Umwälzung gewonnen, die seit dem Ende des Ersten Weltkriegs zu einer realen Option wurde. Die Verfassung als Klassenkompromiss, industrielle Demokratie, Sozial- und Arbeitsverfassung - diese evolutionären Errungenschaften sind nicht von der Furcht vor der Revolution zu trennen. Wer die Position vertritt, dass die transnationale Verfassungsevolution korrekturbedürftig ist, wird Wege suchen müssen, um die Dialektik von evolutionärer und revolutionärer Konstitutionalisierung in der Weltgesellschaft zu erneuern.

\section{Soziale Demokratie}

Hatte der bisherige Argumentationsgang versucht aufzuklären, welche Folgen es hat, wenn die Zentralstellung der Regime/Umwelt-Unterscheidung durch eine Unterscheidung Regime/konstitutives Außen ersetzt wird, wendet er sich nun der Frage nach der Regierungsart zu. Gelingt es dem gesellschaftlichen Konstitutionalismus, die zwei Seiten der Verfassungsevolution, die konkurrierenden Momente der Herrschaftsausübung und der Herrschaftskritik, präsent zu halten? Die Forderung nach demokratischer Legitimation folgt hier einem vollkommen anderen Impuls, als er üblicherweise die Diskussion um die Legitimation der transnationalen Governance beherrscht. Im Mittelpunkt steht nicht das klassische Legitimationsverfahren durch Zustimmung eines umfangslogisch gedachten Volks. Nicht mehr Staaten, Bürger und internationale Organisationen sind die privilegierten Orte der Demokratie. Die verselbstständigten Logiken der Teilbereiche sollen eine Anbindung an Allgemeinwohlforde-

181 | Brunkhorst, Hauke: "Machbarkeitsillusionen, feierliche Erklärungen und Gesänge - Zum Verhältnis von Evolution und Revolution im Recht", in: Calliess et al., Soziologische Jurisprudenz (2009), S. 447-464, hier S. 450. 
rungen erfahren. Dabei ist das Verhältnis der Regime zu ihren sozialen Umwelten entscheidend. Es rückt ins Zentrum der demokratischen Herausforderung.

Folglich gehen staatszentrierte Demokratiemodelle schlicht an den neuartigen Gefährdungslagen vorbei. Sie halten weder die normativen noch die praktischen Ressourcen bereit, um den Bereichslogiken des Transnationalen adäquat zu begegnen. Solche Modelle handeln noch von Staaten, Bürgern und Völkern, wo doch die Hauptgefährdungslagen vom Esperanto der Sozialregime ausgehen. Das alteuropäische Demokratieverständnis kann vor diesem Hintergrund kaum noch auf die neuartige Konstellation reagieren. Indem es die Selbstbestimmung eines souveränen und territorial gebundenen Staatsvolks zum Ausgangspunkt nimmt, fällt es hinter den Stand der sozialen Evolution zurück. Deshalb beginnt die Suche nach funktionalen Äquivalenten, nach Formen der Mitbestimmung, Allgemeinwohlorientierung und Responsivität, die auch in der Weltgesellschaft diejenigen Effekte erzielen, die das Demokratieprinzip im Nationalstaat mehr oder weniger erfolgreich erreicht hatte. ${ }^{182}$ Da sich gesellschaftliche Teilbereiche verselbstständigen, erscheint eine zivilgesellschaftliche Demokratisierung als die passende Antwort, um die Normbildung für die sozialen Umwelten zu öffnen. Responsivitätspflichten, Reflexionspotentiale und Politisierungschancen sollen einen Gegenkreislauf in Gang setzen. Man setzt auf Verbraucher, die nach der Herkunft und Herstellung der Produkte fragen; auf Berufsverbände, die ihre Aktivitäten dahingehend prüfen, wie sie sich auf die soziale Umwelt ihres Sozialbereichs auswirken; auf den Schutz von gegenhegemonialen Kommunikationsstrukturen durch Grund- und Menschenrechte. Die zivilgesellschaftliche Demokratisierung zielt weder auf die Weltgesellschaft als Ganze noch setzt sie auf umfassende Steuerungsprogramme. Sie setzt inkrementell in den Regimen an. Es geht darum,

"ob solche nicht-staatlichen Institutionen tragfähige Analogien zum nationalstaatlichen pouvoir constituant, zur Selbstkonstituierung eines Kollektivs, zur demokratischen Entscheidungsfindung und zum Organisationsteil einer im engeren Sinne politischen Verfassung aufweisen « ${ }^{183}$.

In einem Durchgang durch unterschiedliche funktionale Äquivalente zum Demokratieprinzip (Responsivität, Reflexivität und das Politische) ist der Befund absehbar, der eingangs angedeutet wurde: Die Vorschläge erfüllen den Anspruch einer zivilgesellschaftlichen Mitbestimmung, scheitern jedoch am

182 | Siehe zu den funktionalen Äquivalenten auch Kjaer, Poul F.: "The Metamorphosis of the Functional Synthesis: A Continental European Perspective on Governance, Law and the Political in the Transnational Space", in: Wisconsin Law Review 2010 / 2 (2010), S. 489-534, hier S. $522 \mathrm{ff}$.

183 | G. Teubner, Verfassungsfragmente, S. 23. 
Maßstab einer demokratischen Konstitutionalisierung. Jedes der vorgeschlagenen Äquivalente stellt die Regime und ihre Rationalitäten nie vollständig zur Disposition. Systemkritik kann nur domestiziert erscheinen.

\section{a. Responsivität}

Die Forderung nach Responsivität bringt die Forderung nach demokratischer Legitimation in eine neue Form. Weil die Ausdifferenzierung nicht zurückzunehmen ist, erscheint eine nachträgliche Ex-post-Responsivierung der Regime als aussichtsreich, um der Verselbstständigung entgegenzuwirken. Man kann auf die Differenz der Regime und der sozialen Umwelten »nicht mit Inklusion, sondern allenfalls mit Responsivität ${ }^{184}$ reagieren.

Die Forderung nach Responsivität lässt das vertikale Verhältnis Staat/Bürger hinter sich und überschreibt es mit der horizontalen Unterscheidung Regime/soziale Umwelt. Hier werden die Überwältigungen thematisierbar, hier können Gegenmachtakteure doch noch Eingang ins System finden. Man mag fragen, wie es dazu kommt. Eigentlich hat der gesellschaftliche Konstitutionalismus gezeigt, dass sich die Regime abschotten. Mit ihrer Ausdifferenzierung ist aber genauso - gewissermaßen gleichursprünglich - die Möglichkeit eines re-entry gegeben. ${ }^{185}$ Das Unterschiedene (System/Umwelt) wird nochmal im System als Wiedereintritt der Unterscheidung sichtbar. Dann reflektiert das Regime auf seine eigene Leitdifferenz und die Ent-Paradoxierung misslingt kurzweilig. So ist der Spielraum dafür, dass Umweltrationalitäten im System repräsentiert werden, auf einmal da.

Die Möglichkeit des re-entry führt zur Forderung nach einer »hybriden Konstitutionalisierung « ${ }^{186}$. Die funktional ausdifferenzierten Ordnungen werden nicht der Gestaltungsmacht der Politik unterworfen. Sie werden von innen her konstitutionalisiert, indem zivilgesellschaftliche Gegenmachtakteure dauerhaft einziehen. Die allgemeine Unterscheidung Regime/Umwelt tritt als Koppelung des Teilbereichs mit einem spezifischen Gegenmachtkreislauf auf:

"Eine 'hybride Konstitutionalisierung، ist in dem Sinne gefragt, dass externe gesellschaftliche Kräfte, also neben staatlichen Machtmitteln, rechtliche Normierungen und zivilgesellschaftlicher Gegenmacht aus anderen Kontexten - Protestbewegungen, NGOs, Gewerkschaften - in der Weise so massiven Druck auf die expansionistischen

184 | Hier im Hinblick auf die Differenz Mensch/Institution: G. Teubner, "Die anonyme Matrix", S. 169.

185 | Dies ist auch das Einfallstor für die kritische Systemtheorie, vgl. den zweiten Teil, III, ab S. 62.

186 | Ders., A Constitutional Moment?, S. 13. 
Funktionssysteme ausüben, dass es innere Selbstbeschränkungen aufbaut, die tatsächlich greifen. “187

Demnach ist unter hybrider Konstitutionalisierung eine Koppelung zwischen dem jeweiligen Teilbereich und zivilgesellschaftlicher Gegenmacht zu verstehen. Die Gegenkreisläufe weisen das entscheidende Potential auf, um den Expansionsdrang der Teilsysteme von innen her zu bändigen. Damit erhalten Irritationen aus der Peripherie der sozialen Teilbereiche direkte Bedeutung für die Konstitutionalisierungsprozesse. Nicht in den verfestigten Organisationsbereichen ist nach funktionalen Äquivalenten zu suchen, sondern in den irritationsanfälligen Spontanbereichen.

Diese Sympathie für die Irritation leuchtet aus systemtheoretischer Sicht direkt ein. Handelt es sich um verselbstständigte Selbstreferenzen, die sich abschotten, sind Irritationen notwendig, um den Steigerungszwang überhaupt zu unterbrechen. Das Leitbild besteht in einer »dualen Verfassung zivilgesellschaftlicher Freiheit« als »interne Differenzierung in einen Spontanbereich und einen Organisationsbereich ${ }^{188}$. Während der Organisationsbereich entscheidet, hat der Spontanbereich die Aufgabe, die nötige Responsivität herzustellen, Irritationen zu produzieren, Legitimationsfragen $\mathrm{zu}$ stellen und mit Protesten die Allgemeinwohlanforderungen $\mathrm{zu}$ thematisieren. Beispiele dafür sind zivilgesellschaftliche Protestbewegungen genauso wie NGOs und kritische Berufsverbände, die in ihren jeweiligen Bereichen aktiv sind. Überall dort - so die sehr optimistische Sicht des gesellschaftlichen Konstitutionalismus - zeichnen sich Gegenmachtkreisläufe ab, die schließlich auf ein funktionales Äquivalent zum Demokratieprinzip hinauslaufen können. Sie schaffen den Spielraum dafür, den systemischen Imperialismus einzuhegen und »eine Dissipation der Macht und damit eine Demokratisierung der Gesellschaft « ${ }^{189}$ $\mathrm{zu}$ befördern.

Diese Vorschläge stehen wieder in einem eigentümlichen Zwielicht. Sie versuchen, eine demokratische Konstitutionalisierung denkbar zu machen, die an den weltgesellschaftlichen Realitäten ansetzt. Es wird allerdings nicht recht deutlich, ob dieses Modell die Anforderungen an eine gelingende Konstitutionalisierung absenkt oder im Gegenteil sehr hoch ansetzt. Genügen reflexive Sozialprozesse und Governancemechanismen, die eine schwache Responsivität sicherstellen? Oder läuft alles auf starke Mechanismen der Gegenmacht hinaus? Bleibt es bei der Berücksichtigungspflicht, wie sie das Bundesverfas-

187 | Ebenda.

188 | Ders., "Privatregimes", S. 448.

189 | A. Fischer-Lescano/G. Teubner, Regime-Kollisionen, S. 64. 
sungsgericht schon heute in seinen Urteilen entwirft? ${ }^{190}$ Oder sind NGOs und Öffentlichkeiten in den Gegenmachtkreisläufen mit starken Vetomöglichkeiten ausgestattet?

Genau genommen werden zwei unterschiedliche Problemkreise miteinander kurzgeschlossen. Die gewünschte Öffnung soll negative Externalitäten der funktionalen Selbstreferenz abfedern. Sie soll die destruktiven Potentiale der funktionalen Differenzierung einhegen, um ihren Produktivkräften zur Geltung zu verhelfen. Demgegenüber reicht die anklingende Gegenmachtfrage freilich weiter. Sie besteht darin, inwieweit das konstitutive Außen eine Chance hat, im System zu erscheinen, und ob die Verfassung es ermöglicht, antagonistische Konflikte in agonistische Verhältnisse der Gegnerschaft umzuarbeiten. Die Zentralfrage ist, ob das konstitutive Außen im System repräsentiert werden kann, ob Systemkritik ein re-entry im System findet und ob das System seine demokratische Ab- und Ent-Setzung institutionalisiert? Damit übersteigt die Forderung nach einer demokratischen Konstitutionalisierung eine korrigierende Ex-post-Responsivität. Erst wenn auch der Kern der Regime zumindest zeitweise zur Disposition stehen kann, findet eine hybride Verfassungsbildung überhaupt ihre Haltepunkte. ${ }^{191}$

\section{b. Reflexivität}

Das so aufgemachte Problem wiederholt sich auf einer weiteren Ebene, die dazu geeignet scheint, funktionale Äquivalente zum Demokratieprinzip bereitzuhalten. Für die Verfassungsbildung ist die Koppelung von reflexiven Mechanismen im Recht und im jeweiligen Sozialbereich ein entscheidendes Kriterium. Dauerhafte Institutionen müssen absichern, dass eine höherrangige, reflexive Strukturbildung greift, welche die Anwendung des Rechtscodes einer Zweitbeobachtung vom Typ verfassungsgemäß/verfassungswidrig aussetzt. ${ }^{192}$ Auf diese Weise arbeitet der gesellschaftliche Konstitutionalismus einen demokratischen Selbstbezug systemtheoretisch um. Das, was rückwirkend konstitutionellen Gründungsakten zugeschrieben wird, erlebt einen Wiedereintritt. Während die demokratische Verfassungstheorie im Gründungsakt den konsti-

190 | Zuletzt ausführlich Viellechner, Lars: „Berücksichtigungspflicht als Kollisionsregel. Zu den innerstaatlichen Wirkungen von völkerrechtlichen Verträgen und Entscheidungen internationaler Gerichte, insbesondere bei der Auslegung und Anwendung von Grundrechten“, in: Nele Matz-Lück/Mathias Hong (Hg.), Grundrechte und Grundfreiheiten im Mehrebenensystem - Konkurrenzen und Interferenzen, Berlin u. a.: Springer 2012, S. 109-160.

191 | Vgl. den Versuch bei Pasquale Femia, eine "infrasystemische Subversion" denkbar zu machen, ders.: "Infrasystemische Subversion", in: Amstutz/Fischer-Lescano, Kritische Systemtheorie (2013), S. 305-326, hier S. $310 \mathrm{ff}$.

192 | Vgl. G. Teubner, Verfassungsfragmente, S. 159. 
tuierenden Selbstbezug eines Kollektivs ausmacht, durchläuft er hier eine kommunikationstheoretische Wende. ${ }^{193}$ Der Selbstbezug wird von Akten der politischen Gründung gelöst. In den Regimen findet keine emphatische Gründung statt, sondern nur eine Ex-post-Reflexion. Sie bezieht sich auf die Regime/Umwelt-Unterscheidung sowie auf die Dissipation des jeweiligen Kommunikationsmediums. Es handelt sich also um zwei Umstellungen. Erstens tritt der konstitutionelle Moment nur nachträglich als reflexiver Selbstbezug der Regime auf. Zu dieser Nachträglichkeit tritt zweitens eine diskursive Einschränkung solcher Reflexionen hinzu, die sich auf die Eigenverfassung des jeweiligen Regimes beziehen. Die Reflexion kann sich nur auf die spezifische Koppelung zwischen dem sozialen Teilbereich und dem Recht beziehen. Dies wiederum unterscheidet sich je nach Sozialregime bzw. Funktionssystem: Wissenschaftliche Reflexion bezieht sich auf das Kommunikationsmedium »Wahrheit«, politische Reflexion über das Kommunikationsmedium »Mach»«, wirtschaftliche Reflexion über das Kommunikationsmedium »Geld «. ${ }^{194}$ Das funktionale Äquivalent der konstituierenden Verfassungsgebung besteht in regimespezifischen Reflexionskreisläufen, in denen Selbst- und Fremdbegegnungen der jeweiligen Rationalitäten beobachtbar sind. Hier "geschieht die sinnhafte Begegnung von verschiedenartigen Reflexionsprozessen [...] - der Identitätsreflexion des Individuums und der Identitätsreflexion von sozialen Systemen ${ }^{195}$. Dies sichert Anschlüsse an alteritätsorientierte Verständnisse von Demokratie, Recht und Gerechtigkeit. ${ }^{196}$ Über den Begriff der Reflexivität werden Momente der demokratischen Verfassungsbildung in die kommunikativen strange loops der Weltgesellschaft überführt. Gründungsmythen, feierliche Erklärungen und voluntaristische Selbststeuerungsillusionen spielen dabei keine Rolle mehr.

Damit geht eine Beschränkung der Reflexionsprozesse einher. Die Regimerationalität und ihr Kommunikationsmedium dürfen und können nie fundamental zur Disposition stehen. Sie können nicht zur Disposition stehen, da der Sündenfall der funktionalen Differenzierung nicht zurückzunehmen ist. Und sie dürfen nicht zur Disposition stehen. Schließlich droht so eine totalisierende Bewegung, die das Leitbild zivilgesellschaftlicher Freiheit unterläuft.

Besonders deutlich wird diese Perspektive im Hinblick auf die Weltwirtschaftsverfassung. Hier wird argumentiert, dass sowohl eine Entdifferenzierung durch die Unterordnung der Wirtschaft unter die staatliche Politik problematisch erscheint als auch eine vollständige Unterbindung des Steige-

193 | Vgl. ebenda, S. 102.

194 | Vgl. ebenda, S. 159.

195 | Ebenda, S. 103.

196 | Etwa Parallelen zur Dekonstruktionsphilosophie: ders.: "Selbstsubversive Gerechtigkeit: Kontingenz- oder Transzendenzformel des Rechts?", in: Zeitschrift für Rechtssoziologie 29/1 (2008), S. 9-36. 
rungszwangs. Kritisch werden einzig »selbstdestruktive Wachstumsexzesse« betrachtet, da »eine funktionierende Geldwirtschaft auf Wachstumszwang angewiesen ${ }^{197}$ sei. Dies führt zu einer Begrenzung solcher Befragungen, die möglich und normativ überhaupt wünschenswert sind. Nicht nur, dass auf diese Weise die radikalen Dimensionen der demokratischen Verfassung aus der gesellschaftlichen Verfassungsfrage verschwinden. Es war schließlich ein Impuls der konstituierenden Macht des Volkes, jede Form der Herrschaftsausübung unter den Vorbehalt zu stellen, dass eine Rücknahme in herrschaftskritische Gegenkreisläufe droht.

Insgesamt ist fraglich, ob eine solche Selbstbeschränkung überhaupt greifen kann, wenn sie auf innere Reflexion beschränkt bleibt. In der Weltgesellschaft machen gerade die Regime enormen Gebrauch von Reflexionsprozessen und internen Öffnungen für Umweltrationalitäten. Nicht zuletzt die sozialwissenschaftliche Diskussion hat mit dem Konzept der Governancesteuerung und Stakeholderpartizipation versucht, diese Prozesse auszuleuchten. ${ }^{198}$ Oft entfalten diese Mechanismen keine begrenzenden, sondern legitimationsbeschaffende Funktionen. Bei der Unterscheidung zwischen einem alteuropäischen Selbstbezug der demokratischen Verfassung und einer postmodernen Reflexivität der transnationalen Regime geht der Unterschied zwischen einer demokratischen und einer legitimistischen Variante verloren, die Mechanismen der Öffnung inszeniert, um die Expansion abzusichern. Zu unterscheiden wären korrupte Mechanismen einer selbstversorgenden Autolegitimation von demokratischer Reflexivität in den einzelnen Sozialregimen, die jeweils auch auf die Codeebene durchschlagen kann. Sie muss sich nicht konstruktiv auf die ausdifferenzierten Ordnungen und ihre Kommunikationsmedien beziehen. Sie kann negativ bleiben.

\section{c. Das Politische}

Das dritte Moment, das funktionale Äquivalenzen zum Demokratieprinzip absichern soll, ist die innere Politisierung gesellschaftlicher Teilsysteme. ${ }^{199}$ Hier erlebt der Politikbegriff eine Aufspaltung. Es wird zwischen der staatlichen Politik, der Politik des politischen Systems (die Politik) auf der einen und dem Politischen in jeder sozialen Ordnungsbildung auf der anderen Seite unterschieden. ${ }^{200}$ Da die Systemdifferenzierung auf Unentscheidbarkeiten und Paradoxien aufruht, taucht das Politische schon auf, wenn diese Kontingenzen

197 | Ders., Verfassungsfragmente, S. 153.

198 | Zum Überblick: M. Behrens, "Global Governance".

199 | Vgl. G. Teubner, Verfassungsfragmente, S. 182.

200 | Zu den neueren Diskussionen um diese Unterscheidung siehe Bröckling, Ulrich / Feustel, Robert (Hg.): Das Politische denken. Zeitgenössische Positionen, Bielefeld: transcript 2010. 
sichtbar werden und die Umstrittenheit der jeweiligen Ordnungsbildung zu Tage tritt. Wurde die Unterordnung der sozialen Teilbereiche unter das politische System zurückgewiesen, ist so doch noch eine politische Möglichkeit gewonnen. Der Fluchtpunkt besteht in einer inkrementellen Politisierung, in der nach »der Sozialverantwortung von dezentralen Kollektivakteuren ${ }^{201}$ gefragt wird. Aufgabe der Teilbereichsverfassungen ist es, solche Mechanismen der Politisierung auf Dauer zu stellen. Die Ent-Paradoxierungsmechanismen der Regime sollen durch Re-Paradoxierungschancen politisiert werden. Als Träger treten wiederum Berufsverbände, Verbraucherorganisationen und NGOs auf, die eine Reflexionspolitik in Gang setzen sollen. ${ }^{202}$ Das Politische versucht, Momente der Unentscheidbarkeit zu nutzen oder aktiv hervorzurufen.

Im gleichen Atemzug findet hier eine Eingrenzung statt. In der Unterscheidung Regime/Umwelt bleibt es mit einem ökologischen Allgemeinwohl kurzgeschlossen. Parasitär sattelt das Politische auf und soll rückwirkend korrigieren. Die fundamentale Rücknahme darf seine Sache nicht sein. Was so unbearbeitet bleibt, ist freilich die gründende Ursprungsparadoxie der Funktionssysteme. An dieser Stellen kann man die Unterscheidung zwischen Gründungs- und Anwendungsparadoxie nochmals fruchtbar machen: Das Politische wird aufs Entscheiden bezogen und nicht auf die Paradoxie der Form selbst. ${ }^{203}$ Zur Disposition steht, ob eine rechtliche Entscheidung gerecht ist, eine politische Entscheidung dem Allgemeinwohl entspricht, ein ökonomisches Programm auch das Knappheitspostulat berücksichtigt. Die jeweiligen Kontingenzformeln sind das Einfallstor des Politischen. Ist dieses Nadelöhr genommen, stehen die Form und der Code selbst nicht mehr zur Disposition. Die Form kann nicht unterbrochen oder zumindest kurzzeitig in die Gesellschaft zurückgenommen werden. Der Begriff des Politischen ist auf der Programmebene und der Anwendungsparadoxie angesiedelt, nicht auf der Ebene des Codes und der Gründungsparadoxie. Dieser Umstand führt dazu, dass über den Begriff des Politischen die Systemkritik im System nur sehr begrenzt zu erscheinen vermag. Von dieser Kritik bleibt der emanzipatorische Impuls des gesellschaftlichen Konstitutionalismus, nämlich eine Vergesellschaftung des Politischen denkbar zu machen und dem politischen System das Politikmonopol zu rauben, freilich unberührt; er bleibt allerdings durch seine Engführung über die Entscheidungsparadoxie allzu beschränkt.

201 | G. Teubner, Verfassungsfragmente, S. 186.

202 | Vgl. ders.: "Societal Constitutionalism without Politics? A Rejoinder", in: Social \& Legal Studies 20/2 (2011), S. 248-252, insbes. S. 250.

203 | Vgl. J. Horst, "Politiken der Entparadoxierung". 


\section{Grund- und Menschenrechte}

Schließlich wird eine eigene, systemtheoretische Rekonstruktion der Grundund Menschenrechte vorgeschlagen. Hier ist der Umschlagplatz der Menschenrechtsentwicklung nicht das monadisch zu begreifende Individuum, das willkürlicher Herrschaft des Staates gegenübersteht. Die Entwicklung der Grund- und Menschenrechte entsteht vielmehr an der Schnittstelle systemischer Kommunikation zu ihren sozialen Umwelten. Niklas Luhmann hatte für die Grundrechte des Nationalstaats gezeigt, wie sie

"als eine unter vielen funktional äquivalenten Institutionen der industriell-bürokratischen Sozialordnung dazu [dienen], das Kommunikationswesen so zu ordnen, dass es im großen und ganzen für Differenzierung offen bleibt. Die Garantie von Freiheit ist nichts anderes als eine Garantie von Kommunikationschancen. "204 $^{20}$

Die Grundrechte schaffen diejenigen Autonomieräume, die solche Kommunikationschancen überhaupt erst ermöglichen. Jedem Grundrecht entsprechen folglich auch kollektive Institutionalisierungen. Beispielsweise besteht die Meinungs- und Pressefreiheit nicht nur in der Freiheit, Flugblätter zu drucken. Sie ist auch als Institution zu verstehen, die im öffentlich-rechtlichen Rundfunk ihren Ausdruck findet. Die Religionsfreiheit ist nicht nur eine Frage des individuellen Glaubens, sie ist auch mit institutionell abgesicherter Kommunikation verbunden. Die Grundrechte haben so einerseits eine negative Dimension, da sie diese Autonomieräume gegenüber staatlichen Eingriffen schützen. Andererseits haben sie eine positive, ermöglichende Funktion, da sie die angesprochenen Institutionalisierungen bewirken oder schützen.

Aber wie steht es um den Übergang in die Weltgesellschaft? Wie kann diese Herangehensweise auf den transnationalen Raum übertragen werden? Hier erhalten die Grund- und Menschenrechte nun einen bedeutenden, im Vergleich zum Nationalstaat gewachsenen Status:

"Grundrechte, wie sie hier vorgeschlagen werden, unterscheiden sich von den subjektiven Rechten، des Privatrechts dadurch, dass sie gerade nicht die wechselseitige Gefährdung von Individuen durch Individuen, also intersubjektive Beziehungen betreffen, sondern die Gefährdung durch anonyme kommunikative Matrices (Institutionen, Diskursen, Systemen) für die Integrität von Institutionen, Personen und Individuen. «205

204 | N. Luhmann, Grundrechte als Institution, S. 23.

205 | G. Teubner, Verfassungsfragmente, S. 215. 
Demnach sind Grundrechte als »Gegeninstitutionen zu den Expansionstendenzen der Sozialsysteme ${ }^{206} \mathrm{zu}$ begreifen.

Die Weichenstellung besteht also in einer Ökologisierung. Die Annahme ist, dass sich die Kommunikationsnetzwerke verselbstständigen und gegenüber ihren sozialen Umwelten destruktive Effekte erzielen. Dies ist auch deshalb folgenreich, da Gesellschaft und Bewusstsein/Körper kommunikativ nicht für einander erreichbar sind. Insofern haben die Grund- und Menschenrechte eine wichtige Funktion. Sie sind das Medium, mit dem die sozialen Umwelten und die psychischen Systeme ihre Blessuren skandalisieren und den anonymen Matrices Kommunikationschancen abtrotzen können. Die Menschenrechte weisen eine Dimension »jenseits der positivierten Menschenrechte und jenseits des Naturrechts ${ }^{207}$ auf. Sie sollen vor den »negativen Externalitäten der Kommunikation, [...] ihrem lebens- und bewusstseinsbedrohenden Potential « ${ }^{208}$ schützen. Deshalb greift die Forderung nach einem globalen Grundrechtskatalog zu kurz. ${ }^{209}$ Erforderlich ist die Respezifizierung der Rechte auf die Sozialregime. Sie werden nicht von internationalen Zentralagenturen gewährleistet. Als gesellschaftliche Gegenrechte zu den verselbstständigten Kommunikationsnetzwerken nisten sie sich in die unterschiedlichen Kontexte ein. Ihr Movens ist keine übergeordnete Werteordnung der internationalen Gemeinschaft. Proteste und Skandalisierungen von bestehendem Unrecht sind vielmehr der Anknüpfungspunkt. Sie können sich in die Rechtsevolution einschreiben und Rechten der Individuen gegen die Eigenrationalitätsmaximierer zur Geltung verhelfen. ${ }^{210}$ Dort adressieren sie nicht ausschließlich politische Institutionen; sie binden auch private Akteure, etwa Unternehmen und hybride Akteurskonstellationen.

$\mathrm{Zu}$ dieser Sozialisierungskomponente der Grund- und Menschenrechte, die der juristische Diskurs als sogenannte Horizontalwirkung thematisiert, kommt ein Umbau negativer Abwehrrechte hinzu. Sie schützen das Individuum in dem Sinne, dass sie ihm als psychisches System Chancen einer gelingenden Selbstkonstituierung einräumen. Nimmt man diesen Gedankengang auf, enthalten die negativen Abwehrrechte mit dem Schwerpunkt auf psychische und körperliche Integrität eine zutiefst soziale, in Teilen auch materielle Dimension. Die Selbstkonstitution als psychisches System zu ermöglichen

206 | Ebenda.

207 | So Prien, Thore: Fragmentierte Volkssouveränität. Recht, Gerechtigkeit und der demokratische Einspruch in der Weltgesellschaft, Baden-Baden: Nomos 2010, S. 100, in seiner Rekonstruktion.

208 | G. Teubner, "Die anonyme Matrix", S. 171.

209 | Vgl. etwa B. Fassbender, The United Nations Charta as the Constitution of the International community.

210 | Vgl. A. Fischer-Lescano, Globalverfassung, S. 277. 
fordert zwangsläufig auch Teilhaberechte und materielle Sicherungsmechanismen. Nur sie gewährleisten eine gelingende Selbstkonstitution des psychischen Systems.

Diese Umarbeitung der Menschenrechtsentwicklung erfährt sodann eine transsubjektive Ausweitung. ${ }^{211}$ Die Menschenrechte werden vom konkreten Menschen gelöst. Der Mensch der Menschenrechte erscheint als Form, die eine gelingende individuelle und kollektive Selbstkonstitution eröffnen soll. Ökologisierung wäre so auch im alltagssprachlichen Sinne wörtlich zu nehmen. Die sozialen Umwelten, die der Schauplatz der Selbstkonstituierung sind, haben eine natürliche Komponente. Die Selbstkonstitution sozialer Systeme entscheidet sich unter anderem daran, ob ökologische Systeme überhaupt funktionieren oder von den Expansionstendenzen wirtschaftlicher Regime zerstört werden. Umweltfragen erhalten in diesem Sinne hohe Bedeutung für die Menschenrechtsentwicklung und können auch begründen, wieso schon heute eine Ausweitung der Menschenrechtsentwicklung auf den Umweltbereich beobachtbar ist. ${ }^{212}$

Über diese Schritte wird ein Zugang ausgearbeitet, der direkt an den expansionsaffinen Sozialregimen ansetzt. Dabei gehen allerdings die demokratischen Verweisungszusammenhänge der Menschenrechtsentwicklung zunehmend verloren. Was stattfindet, ist eine systemtheoretische Übersetzung der liberalen Grund- und Menschenrechtstheorie. ${ }^{213}$ In vielerlei Hinsicht bleibt man so dem negativen Verständnis der Grund- und Menschenrechte treu. »Partizipationsromantik« darf die ökologische Grundrechtstheorie auch nicht nähren. ${ }^{214}$ Mechanismen der psychischen Selbstkonstitution, körperliche Integrität und introspektive Potentiale stehen im Mittelpunkt.

Weitergehende Überlegungen bauen diese Perspektive auf die Möglichkeit demokratischer Partizipation und auf die abgesicherte Entfaltung gesellschaftlicher Kräfte hin aus. ${ }^{215}$ Hier erfahren die Rechte doch noch eine Anbindung ans Demokratieprinzip. Sie übersteigen die individuelle Selbstkonstitution als Integrität und ermöglichen kollektive Selbstbestimmung. Diese Anbindung ist insofern folgenreich, als dass ihre Ausübung nicht darauf reduziert werden kann, die Kommunikationsnetzwerke zu begrenzen und mit Alteritätsanforde-

211 | Zur Transsubjektivierung: ders., Kritische Systemtheorie Frankfurter Schule, S. $52 \mathrm{ff}$.

212 | Siehe etwa Kreck, Lena: "Möglichkeiten und Grenzen des rechtlichen Schutzes für Umweltflüchtlinge", in: Kritische Justiz 44 / 2 (2011), S. 178-184.

213 | Die analytische Pointe dieses Zugriffs besteht bei Chris Thornhill, A Sociology of Constitutions, allerdings vor allem darin, wie die Verbreitung subjektiver Rechte die Konsolidierung politischer Macht durch Begrenzung ermöglicht.

214 | G. Teubner, "Die anonyme Matrix", S. 186.

215 | Vgl. Fischer-Lescano, Andreas: Rechtskraft, Berlin: August-Verlag 2013. 
rungen zu konfrontieren. Die Menschenrechte beinhalten auch die Möglichkeit, die Kommunikationsnetzwerke effektiv zu unterbrechen und zumindest zeitweise zurückzunehmen. ${ }^{216}$

\section{Systemkritik im System}

Über alle drei Ebenen - Verfassung, Demokratie und Menschenrechte - löst sich das systemtheoretisch inspirierte Modell von der Staatsverfassung. Es versucht, die Errungenschaften der Verfassungsevolution in einer funktional ausdifferenzierten Weltgesellschaft nochmals fruchtbar zu machen. Die überaus leistungsfähige Reflexionstheorie berücksichtigt allerdings diejenigen antagonistischen Sozialkonflikte zu wenig, die im ersten Teil des Buches als prägend für die fragmentierte Hegemoniekonstellation hervorgehoben wurden. Der demokratisch-subversive Moment der Verfassungsevolution gerät aus dem Blickfeld und bleibt nur noch domestiziert, als Ex-post-Responsivierung präsent. Es bleibt bei einer»Konstruktion der Rücksicht« ${ }^{217}$

Hatte der demokratische Konstitutionalismus des Nationalstaats es als Ergebnis sozialer Kämpfe zumindest ansatzweise ermöglicht, Systemkritik im System zu repräsentieren und antagonistische Sozialkonflikte in Verhältnisse agonistischer Gegnerschaft umzuformen, erbringen die hegemonialen Regime diese Leistung nicht mehr. Hier verschwimmen Codierungen und Programme zu einem substantiellen Amalgam, das es nicht mehr zulässt, das Regime als Ganzes zu befragen. Diesen Zug berücksichtigt der gesellschaftliche Konstitutionalismus nicht hinreichend. Er entwirft normative Vorstellungen davon, wie mögliche Abmilderungen der verselbstständigten Selbstreferenz greifen können. So sinnvoll dies im Einzelnen sein mag, die Frage bleibt, was eine im starken Sinne demokratische Konstitutionalisierung der Sozialregime bedeuten könnte, wenn die Diagnose lautet: nation-state paradigm lost. Zwar wird hier das Demokratieprinzip in eine Ex-post-Responsivierung sowie in Formen gesellschaftlicher Mitbestimmung überführt. Aber, so hat die Argumentation zu zeigen versucht, damit wird das Demokratieprinzip seiner konstituierenden Macht beraubt. Dies ist kein antitotalitärer Fortschritt. Schließlich führt die Unmöglichkeit, Systemkritik im System zu repräsentieren, unter anderem

216 | Siehe dazu Fischer-Lescano, Andreas/Buckel, Sonja: "Democrazia operaiar? Hegemonietheoretische Überlegungen für ein aktualisiertes Recht auf politischen Streik", in: Jochen Bung/Brian Valerius/Sascha Ziemann (Hg.): Normativität und Rechtskritik (=Archiv für Rechts- und Sozialphilosophie Beiheft 114), Stuttgart: Steiner-Verlag 2007, S. 238-256.

217 | So sah sie Marx in der Hegel'schen Ständeverfassung angelegt, mitsamt ihrer "sehr diplomatischen" Konstruktion der gesetzgebenden Gewalt, siehe ders., "Kritik des Hegelschen Staatsrechts", S. 288. 
dazu, dass die Kommunikationsnetzwerke selbst ihre Totalisierungsansprüche ungehemmt verfolgen können.

Ob die Regime nicht nur verfasst sind, ob sie auch eine demokratische Verfassung aufweisen, hängt davon ab, ob ihre Ausdifferenzierung unter dem Vorbehalt steht, zumindest kurzweilig in die Weltgesellschaft zurückgenommen zu werden. Es geht somit nicht nur um rückwirkende Korrekturmechanismen. Die Systemkritik in das System einzuschreiben, ein re-entry der Systemkritik ins System - das wäre die radikaldemokratische Variante des gesellschaftlichen Konstitutionalismus. Bisher ist die Weltgesellschaft weit von einer Verfasstheit entfernt, die dies ermöglicht. Insofern wird das Projekt einer demokratischen Verfassungsbildung in der Weltgesellschaft negativ und destituierend, das heißt ab- und ent-setzend orientiert sein müssen, um die Sozialregime von ihrer hegemonialen Füllung zu befreien und eine mögliche Leere der Verfassung als Form wieder denkbar zu machen. Im Folgenden wird diese Überlegung weiterverfolgt und mit den Überlegungen Claude Leforts verknüpft, dessen Theorie radikaler Demokratie in den gesellschaftlichen Konstitutionalismus hineinkopiert werden soll, um eine gleichermaßen postwestfälische wie radikaldemokratische Perspektive auf die Konstitutionalisierung der Weltgesellschaft zu gewinnen. 


\section{Vierter Teil - Von der konstituierenden Macht zur destituierenden Macht}

Die bisherige Diskussion ist ernüchternd, wenn das Verhältnis von Verfassung und Demokratie näher beleuchtet wird. Der Formwandel der Verfassung im Übergang zur Weltgesellschaft ist durch weitgehende demokratische Defizite geprägt. Funktionale Äquivalente zum Prinzip der demokratischen Verfassung sind nur schwer auszumachen. Die konstituierende Macht des Volkes, in die noch Karl Marx große Hoffnungen investierte, ist nur schemenhaft erkennbar. Verfassung ohne Demokratie lautet die Diagnose. Weder haben sich bisher die großen Geschichtszeichen gezeigt, die selbst noch begrenzte Mechanismen der Mitbestimmung mit ihren demokratischen Verweisungszusammenhängen überfluten, noch evozieren die Regime aus sich heraus die demokratische Frage. Die Beobachtung mündet in eine skeptische Einschätzung. In der Folge der bürgerlichen Revolutionen ist die nationalstaatliche Verfassung zumindest ansatzweise Schauplatz des Kampfes zwischen beiden in der Einleitung benannten »Subverfassungen«, zwischen demokratischer und herrschaftlicher Verfassung geworden. Das Projekt demokratischer Konstitutionalisierung, das exemplarisch in der Idee der Volkssouveränität zum Ausdruck kommt, erscheint inzwischen ortlos. Es kann genauso wenig in den schwachen Mitbestimmungsmechanismen der Regime seinen Haltepunkt finden wie in einem Nationalstaat, der in die hybriden Arrangements der Weltgesellschaft verstrickt ist. Vor diesem Hintergrund stellt sich die Frage: Wie kann der Konflikt, der »Widerspruch der Verfassung mit sich selbst « ${ }^{1}$ einen re-entry in die Verfassungsevolution finden?

Dafür muss - so die Hypothese, die im Folgenden erläutert werden soll auch das Demokratieprinzip einen Formwandel durchlaufen, um dem Übergang in die Weltgesellschaft gerecht zu werden. Der Formwandel betrifft nicht nur die Seite des Konstitutionalismus als Herrschaftsform. Auch die andere, demokratische Seite muss den Formwandel anerkennen. Dabei erweist sich jedoch das Prinzip der Volkssouveränität und einer daraus folgenden Rück-

1 | K. Marx, "Kritik des Hegelschen Staatsrechts", S. 260. 
besinnung auf den »alten Konstitutionalismus « des Nationalstaats zunehmend als unfähig, eine herrschaftskritische Normativität einzulösen (dazu I, ab S.181). In der postnationalen Konstellation geht es darum, die Regime zu entleeren, sie von substantiellen Projekten und Zwecksetzungen zu befreien: Erst durch ihre Destitution in transnationalen Verfassungskämpfen entstehen möglicherweise Spielräume für eine demokratische Konstitutionalisierung. Die konstituierende Macht des Volkes geht in eine destituierende Macht über, die auf eine Entleerung der Regime zielt. Sie artikuliert sich nicht zentralisiert in einem einheitlichen demos, sondern in Organen der Negativität (dazu II, ab S. 193).

Daraus erwächst der Vorschlag, das Nachdenken über eine mögliche transnationale Demokratie umzustellen: Bei Annäherungen hilft die Urszene der bürgerlichen Revolutionen, in der ein gründendes Volk in souveräner Selbstbestimmung die Bühne der Geschichte betreten hat, nicht weiter. Als Urszene des weltgesellschaftlichen Konstitutionalismus dienen eher Perioden von Verfassungskämpfen langer Dauer (dazu III, ab S. 201). Exemplarisch steht dafür der Konflikt zwischen Patriziern und Plebejern in der römischen Republik. Am Beispiel des plebejischen Tribunats wird ein interner Zusammenhang zur Verfassungsfrage deutlich: Die Ordnungskämpfe sind Verfassungskämpfe in einem eminenten Sinne. Sie artikulieren den Konflikt von herrschaftskritischer und herrschaftlicher Verfassung, ohne einen starken Bezug in einer übergreifenden und allgemein konsentierten Ordnung zu haben. Sie halten trotzdem den »Widerspruch der Verfassung mit sich selbst« präsent. Dies wird dadurch möglich, dass die plebejische Bewegung selbst eine Eigenverfassung ausbildet. Sie bringt eine verfasste potestas, eine konsolidierte und im Medium einer höherrangigen Ordnung stabilisierte Gegenmacht hervor. Für die Weltgesellschaft ist die demokratische Verfassungsfrage deshalb vorläufig als Frage nach der Konstitutionalisierung gegenhegemonialer Kommunikationsstrukturen zu stellen. 


\section{VolKSSOUVERÄNITÄT}

"Positives Recht, von Menschenhand gesetztes Gesetzesrecht, so hatte man im Lauf des 19. Jahrhunderts erfahren, ist ebenso leer wie omnipotent. “²

Bisher war im Zusammenhang mit der demokratischen Verfassung immer von der Volkssouveränität die Rede. Es war schließlich ein Ausgangspunkt der Überlegungen, dass der Konstitutionalismus seit den bürgerlichen Revolutionen von einer irreduziblen Spannung zwischen zwei Verständnissen geprägt ist, die beide als Subverfassungen der einen Verfassung persistieren. Die eine Seite gründet die Verfassung auf den Staat und seine Herrschaftsausübung; die andere Seite gründet sie aufs Volk und damit auf das pouvoir constituant, sich eine Verfassung zu geben und in ihrem Rahmen selbst zu regieren. Aus dieser Perspektive kann nur demokratisch gesetztes Recht legitim sein. ${ }^{3}$ Nur das »souveräne Volk (direkt oder repräsentiert) « ${ }^{4}$ hat die Gesetzgebungskompetenz und verfügt über die demokratische Steuerung des gesamten Entscheidungsprozesses. Erst demokratische Verfahren, in denen freie und gleiche Bürger kollektive Selbstbestimmung ausüben, bringen legitimes Recht hervor. Die verselbstständigte Verregelung in transnationalen Institutionen, die ihre Anbindung an die konstituierende Macht keineswegs mehr darstellen können, muss daher in hohem Maße suspekt erscheinen. Jeder Versuch, diesen spezifisch modernen Rechtsbegriff auf die Weltgesellschaft anzuwenden, droht ideologisch zu werden. Da ein globaler demos weder vorstellbar noch wünschenswert erscheint, argumentiert der radikaldemokratische Republikanismus, dass die transnationale Verrechtlichung es schlicht nicht verdient, als »Recht« oder »Konstitutionalisierung « zu gelten. Deshalb liegt die Schlussfolgerung nahe, doch wieder auf die Verfassung des Nationalstaats zurückzukommen, wie es etwa die radikaldemokratische Rechtstheoretikerin Ingeborg Maus einfordert: Das Erbe der Französischen Revolution soll dort verteidigt werden, wo noch basale Elemente demokratischer Verfahren identifizierbar sind. ${ }^{5}$ Für den Volkssouverä-

2 | Fögen, Marie Theres: Das Lied vom Gesetz, München: Carl Friedrich von Siemens Stiftung 2007, S. 18.

3 | Vgl. Maus, Ingeborg: Zur Aufklärung der Demokratietheorie. Rechts- und demokratietheoretische Überlegungen im Anschluss an Kant, Frankfurt a. M.: Suhrkamp 1992, S. 37.

4 | Dies., Über Volkssouveränität, S. 8.

5 | Vgl. dies.: "Verfassung oder Vertrag. Zur Verrechtlichung globaler Politik", in: Peter Niesen / Benjamin Herborth (Hg.), Anarchie der kommunikativen Freiheit. Jürgen Ha- 
nitätsrepublikanismus ist dies weiterhin die nationalstaatliche Verfassung. Das Problem ist allerdings, dass der Formwandel nicht nur auf die Seite der herrschaftlichen Verfassungsdimension übergreift. Er wird auch auf der demokratischen Seite wirksam. Die Bindung des Demokratieprinzips an eine volkssouveräne Staatsverfassung geht an den transnationalen Entwicklungslinien vorbei und versteigt sich so in eine nur externe Kritik.

\section{Vertrag statt Verfassung}

Am Anfang steht eine Unterscheidung. In der Vormoderne bezeichneten Verfassungen im allgemeinen Wortsinn bestehende Zustände, beispielsweise den »Zustand eines Landes « ${ }^{6}$. Nachdem dieser nichtnormative, weitgehend neutrale Begriff über Jahrhunderte verwendet wurde, findet im Umfeld der Französischen Revolution und der Vertragstheorien Rousseaus und Kants ein folgenreicher Einschnitt statt, der die Idee der demokratischen Verfassung in die Welt bringt. Der demokratische Verfassungsbegriff der bürgerlichen Revolutionsepoche vollzieht die soziale Evolution nicht begrifflich nach. Er bezeichnet eine politische Verfassung, die gleichzeitig ein normatives Ideal beinhaltet, an dem gesellschaftliche Zustände gemessen werden: das Demokratieprinzip, das auf der strengen Identität von Rechtsautoren und Rechtsadressaten beruht. In gewisser Weise geht die demokratische Verfassung in der sozialen Evolution auf Distanz zur Evolution und maßt sich an, das gesellschaftliche Leben demokratisch zu steuern. Maus bringt diesen Zusammenhang in einer dichten Passage wie folgt auf den Punkt:

"Diese Entgegensetzung einer Verfassung, die man bereits hat, und einer Verfassung, die man erst machen muss, bezeichnet eine Differenz ums Ganze. Die Verfassung, die man immer schon hat, ist die Verfassung der Vormoderne und also auch diejenige des Ancien Régime. Sie bezeichnet nichts anderes als den faktischen Gesamtzustand aller politischen und gesellschaftlichen Institutionen und umfasst situativ entstande-

bermas und die Theorie der internationalen Politik, Frankfurt a. M.: Suhrkamp 2007, S. 350-382; Böckenförde, Ernst-W.: "Die Zukunft politischer Autonomie. Demokratie und Staatlichkeit im Zeichen von Globalisierung, Europäisierung und Individualisierung", in: ders., Staat, Nation, Europa, Frankfurt a. M.: Suhrkamp 1999, S. 103-126; Grimm, Dieter: Die Zukunft der Verfassung II, Berlin: Suhrkamp 2012, S. 315 ff.; Dobner, Petra: "More Law, Less Democracy? Democracy and Transnational Constitutionalism", in: dies./Loughlin, The Twilight of Constitutionalism? (2010), S. 141-161.

6 | Grimm, Dieter: Die Zukunft der Verfassung, Frankfurt a. M. Suhrkamp 1991, S. 11; siehe auch die Erörterung zur Herkunft des Verfassungsbegriffs bei Koselleck, Reinhart: Begriffsgeschichten. Studien zur Semantik und Pragmatik der politischen und sozialen Sprache, Frankfurt a. M.: Suhrkamp 2006, S. 365 ff. 
ne Rechtsmaterien und nicht verrechtlichte, aber eingeübte und tradierte Praktiken gleichermaßen. Dagegen verweist der Begriff der Verfassung, die man 'machen muss und über deren zentrale Prinzipien man sentscheidet،, notwendig auf den bewussten Willensakt ihrer positiv-rechtlichen Setzung und damit zugleich auf den legitimen und legitimierenden Träger dieser Verfassungsrechtsetzung, hier: die verfassungsgebende Gewalt des Volkes [...] Die gemachte Verfassung ist wesentlich normativ. “7

Demnach ruft die moderne Verfassung immer ein normatives Projekt auf. Erst die verfassungsgebende Gewalt des Volkes schafft die Verfassung in einem demokratischen Willensakt, nicht umgekehrt. Die Volkssouveränität in der Tradition Kants und Rousseaus erhält eine monistische Zentralstellung. Aus dem Prinzip der Volkssouveränität werden alle anderen Elemente der modernen demokratischen Verfassung abgeleitet. Um die Staatsapparate an die demokratische Selbstorganisation der gesellschaftlichen Basis zu binden, bietet sich ein streng formal gehaltenes und inhaltlich bestimmtes, ein »souveränitätsloses Recht ${ }^{8}{ }^{2}$ an. Es soll sicherstellen, dass die Staatsapparate sich nicht selbst ermächtigen, um eine (inkrementelle) Rechtserzeugung zu betreiben, die eigentlich dem demokratischen Souverän vorbehalten ist. Der Allgemeinheitsanspruch des Gesetzes soll garantieren, dass es in seiner Begründung auf den gemeinsamen Willen freier und gleicher Staatsbürger zurückzuführen ist und nicht dem einseitigen, nutzenmaximierenden »Selbstgespräch der Interessenten « ${ }^{9}$ entspringt. Zwischen der Volkssouveränität und dem Gesetz ist somit ein Zwischenraum auffindbar, der die Beteiligten entlang demokratischer Verfahren in ein Universalisierungsrelais einbindet. Nicht hintergründige Moral oder Konsensvermutungen, es ist das demokratische Verfahren selbst, das dem Demokratieprinzip zu Stabilität verhilft. Die »demokratische Organisationsform des Rechtssetzungsverfahrens und die semantische Allgemeinheit des demokratischen Gesetzes« befördern eine »prozedurale Rationalität, die willkürliche Entscheidungen gerade verhindert ${ }^{10}$.

Grund- und Menschenrechte haben in diesem Zusammenhang keine herrschaftsbegrenzende Funktion. Sie ermöglichen die Ausübung demokratischer Volkssouveränität. Freiheitsrechte sollen zuallererst die Partizipation am demokratischen Gesetzgebungsprozess sichern. Sie stehen in einem komplementären Verhältnis zum Demokratieprinzip oder, wie Ingeborg Maus es pointiert, in einer

7 | I. Maus, "Verfassung oder Vertrag", S. 352.

8 | Dies., Zur Aufklärung der Demokratietheorie, S. 42.

9 | Dies., "Verfassung und Verfassungsgebung", S. 49.

10 | Dies., Über Volkssouveränität, S. 110. 
"Konzeption der wechselseitigen Optimierung [...] die noch impliziert, dass Menschenrechte nicht etwa von ihren potentiellen Verletzern, den politischen Machtapparaten, garantiert werden können, sondern nur im Wege volkssouveräner Gesetzgebung und öffentlicher Deliberation zu konkretisieren sind «"11.

Zerfällt der Zusammenhang von Freiheitsrechten und Demokratie, besteht die große Gefahr, dass die Ausgestaltung menschenrechtlicher Garantien von Exekutivapparaten übernommen wird, die sie als Legitimationsgrundlage für ihr eigenes Machthandeln missbrauchen. In diesem Sinne liefert der herrschaftsbegrenzende Konstitutionalismus, der unter weltgesellschaftlichen Bedingungen wieder populär wird, eine Legitimationsideologie dafür, den Gehalt der Menschenrechte umzuarbeiten. In einer ähnlichen Argumentationslinie, die schon unter dem Gesichtspunkt repressiver Freiheitsinstitutionalisierung vorgestellt wurde, sieht Maus genau einen solchen Vorgang im Übergang zur Weltgesellschaft angelegt. Da der Zusammenhang von Freiheitsrechten und demokratischen Verfahren nicht mehr darstellbar ist, werden die Menschenrechte zu einem Katalog an Eingriffsnormen, der eine Legitimationsideologie für das Machthandeln für Exekutivapparate bereithält. Die Menschenrechte verkehren sich von »individuellen Rechtsansprüchen « zu »objektiven Systemzwecken « ${ }^{12}$. Sie sichern den Expansionsdrang funktional ausdifferenzierter Sozialsysteme ab, statt ihre kritische Befragung zu befördern.

Gegen optimistischere Einschätzungen einer zivilgesellschaftlichen Menschenrechtspolitik insistiert Maus auf der Unhintergehbarkeit demokratischer Verfahren, die weder durch transnationale Öffentlichkeit noch schwache Varianten der expertokratischen »Deliberation « zu ersetzen sind. ${ }^{13}$ Die Forderung nach einem Mehrebenensystem, in dem Recht und Politik auf unterschiedlichen Ebenen interagieren und Souveränitätsansprüche aufteilen, muss aus der volkssouveränistischen Perspektive suspekt erscheinen.

Auch die Gewaltenteilung wird so entfaltet, dass sie das Demokratieprinzip nicht einhegt. Im Gegenteil verhilft es ihm erst zur Geltung. Die Volkssouveränität geht mit dem französischen Modell einer vertikalen Gewaltenteilung

11 | Dies., "Verfassung oder Vertrag", S. 355.

12 | Dies., Über Volkssouveränität, S. 361.

13 | Siehe dazu auch Niesen, Peter: "Deliberation oder Demokratie? Zur Konstruktion von Legitimität jenseits des Nationalstaats", in: Regina Kreide/Andreas Niederberger (Hg.), Transnationale Verrechtlichung. Nationale Demokratien im Kontext globaler Politik, Frankfurt a. M.: Campus 2008, S. 240-259; Somek, Alexander: „Demokratie als Verwaltung. Wider die deliberativ halbierte Demokratie", in: Brunkhorst, Demokratie in der Weltgesellschaft (2009), S. 323-348. 
einher. ${ }^{14}$ Demnach muss sehr wohl eine Trennung zwischen Rechtssetzung und Rechtsanwendung, also eine Gewaltenteilung zwischen Legislative und Exekutive stattfinden, nicht aber die horizontale Teilung der Souveränität. Die Souveränität der Verfassungs- und Gesetzgebung liegt einzig beim Volk. Die liberale Verfassungsdoktrin einer horizontalen Teilung der Souveränität Montesquieu'scher Prägung sorgt letztlich dafür, dass Entscheidungskompetenzen auf Exekutive und Judikative verlagert werden, die eigentlich dem demokratischen Prozess vorbehalten sind. Dadurch ist die Bindung der Exekutivapparate ans Recht prekär. Die Wahrscheinlichkeit ist hoch, dass die Staatsapparate den demokratischen Formalismus in seinem Vollzug einfach situativ anpassen oder aussetzen. Macht kann unter diesen Bedingungen nicht effektiv kontrolliert werden, da die Gesetzesbindung der Exekutive zur Farce wird. Insofern buchstabiert Maus ihr Konzept der radikalen Demokratie im Sinne Kants als Verbindung einer demokratischen Herrschaftsform mit einer republikanischen Regierungsart aus, in der die gesetzgebende und exekutive Gewalt voneinander getrennt sind. ${ }^{15}$ Dies impliziert allerdings eine vertikale Gewaltenteilung in der Tradition Lockes, Rousseaus und Kants und gerade keine horizontale Souveränitätsteilung.

Im Lichte einer solchen radikalen Demokratie erscheint die Konstitutionalisierung der Weltgesellschaft als ideologisches Blendwerk: »Ancien Régime«, »[g]egenrevolutionärer Widerstand $\aleph^{16}$ - eine Refeudalisierung des Verfassungsbegriffs ist feststellbar. Die »Basis« der gesellschaftlichen Verhältnisse tritt im zeitgenössischen Konstitutionalisierungsdiskurs nochmals als »Überbau« in Erscheinung. ${ }^{17}$ Hatte die Aufklärungsphilosophie wenigstens eine demokratische Prozeduralisierung des Allgemeinen ${ }^{18}$ entworfen, schwört die neuere Rechts- und politische Theorie dem Demokratieprinzip ab. Verselbstständigte Exekutivapparate erklärt sie zu Governanceinstitutionen, Regeln für Spezialmaterien des gesellschaftlichen Lebens erscheinen schon einfach so als »Recht«, und der Verfassungsbegriff fällt in seiner Verwendung wieder auf das mittelalterliche Niveau zurück. Er kennzeichnet bestehende Zustände und ist durch Beliebigkeit geprägt. Während Teile der Völkerrechtstheorie ja gera-

14 | Vgl. I. Maus, Über Volkssouveränität, S. 11 u. S. 111, siehe dazu ausführlicher: 0. Eberl, "Die Gewaltentrennung".

15 | Vgl. I. Maus, Zur Aufklärung der Demokratietheorie, S. $191 \mathrm{ff}$.

16 | Dies., "Verfassung und Verfassungsgebung", S. 29 f.

17 | Dies.: "Die Basis als Überbau oder 'Realistische، Rechtstheorie", in: dies., Rechtstheorie und politische Theorie im Industriekapitalismus (1986), S. 247-276, hier S. 255, zur Verrechtlichungsdiskussion in 1970er und 1980er Jahren.

18 | Buckel, Sonja: "Von der Selbstorganisation zur Gerechtigkeitsexpertokratie. Zum Wandel der Prozeduralisierung des Allgemeinen ", in: Eberl, Transnationalisierung der Volkssouveränität (2011), S. 33-56, hier S. 40 ff. 
de Hoffnungen hegen, dass mit dem Konstitutionalisierungsbegriff normative Vokabulare eine Revitalisierung erfahren, sieht Maus sie in die voraufklärerischen Entwicklungstendenzen verstrickt. Sie sind das Problem und nicht die Lösung, da sie die Normativität des demokratischen Verfassungsbegriffs nicht mehr angemessen präsent halten. Im Gegenteil wirkt der Konstitutionalisierungsdiskurs direkt an der transnationalen Governance mit, indem er sie mit dem Konzept der Konstitutionalisierung belegt und so den Anschein normativer Ressourcen als »Gütesiegel« erweckt, ${ }^{19}$ die jedoch in den verselbstständigten Apparaten systematisch abwesend sind.

Deshalb plädiert Maus dafür, den Verfassungsbegriff für die Weltgesellschaft aufzugeben und zur Rechtsfigur des Vertrages zurückzukehren. So werde wenigstens »eine faktische Rückkopplung überstaatlicher und globaler Politik an die demokratisch prozeduralisierten Entscheidungswege in Nationalstaaten gewährleistet ${ }^{20}$. Diese Hinwendung zum nationalen Verfassungsstaat ist ein wenig irritierend, da sie in ihrer Studie zur Demokratietheorie Kants kritisch feststellt, dass das Kant'sche Modell »noch von keiner realexistierenden Demokratie eingeholt wurde « ${ }^{21}$. Aber scheinbar finden sich in den nationalstaatlichen Verfassungen noch diejenigen Horizonte eines demokratischen Rechts, das jetzt als Widerstandsbastion gegen die Refeudalisierung des Verfassungsbegriffs dienen soll. Diese Konstitutionalisierungskritik macht auf die Selbstermächtigungen aufmerksam, indem sie die transnationale Governance an den demokratischen Idealen Kants und Rousseaus misst. Darin besteht ihre beeindruckende Leistung. Sie zeigt das Scheitern der demokratischen Verfassung an den gesellschaftlichen Verhältnissen. Wenn die Logiken einzelner Sozialbereiche sich von demokratischen Prozeduren abkoppeln, bleibt es bei einer nüchtern-negativen Bewertung, die Maus früher in ihrer Rechtstheorie für den nationalstaatlich regulierten Industriekapitalismus ausgestellt hatte: Die in der Demokratietheorie der Aufklärung angelegte »demokratische Allgemeinheit des Gesetzes aber scheitert ebenso wie der Universalismus prozeduraler Ethik am gegenwärtigen Zustand der Gesellschaft ${ }^{22}$.

\section{Formwandel der Demokratie}

Sofort fällt hier auf, dass es an einer gesellschafts- und insbesondere staatstheoretischen Grundierung in diesen Überlegungen mangelt. Gegen die

19 | VgI. I. Maus, "Verfassung oder Vertrag", S. 381.

20 | Ebenda.

21 | Dies., Zur Aufklärung der Demokratietheorie, S. 15.

22 | Dies.: "Verrechtlichung, Entrechtlichung und der Funktionswandel von Institutionen ", in: dies., Rechtstheorie und politische Theorie im Industriekapitalismus (1986),

S. 277-331, hier S. 322. 
Engführung von Modernisierung und demokratischem Rechtsstaat sind genau diejenigen Argumente einzubringen, die in der Auseinandersetzung mit der Konstitutionalisierungsthese eine Rolle gespielt haben. Die moderne Gesellschaft ist eben nicht nur von den politischen Geltungsüberschüssen der bürgerlichen Revolutionen geprägt, sondern genauso von funktionaler Differenzierung, kapitalistischer Modernisierung und policeylichen Sicherheitsdispositiven. Wenn Ökonomie, Recht und Politik eine Neuanordnung erleben, erlischt eventuell das kritische Potential einer territorial eingegrenzten Volksdemokratie. Sie kann ihren Anspruch einer demokratischen Selbststeuerung nicht mehr einlösen, selbst wenn sie es wollen würde. Gegen globalisierte Funktionssysteme können nationalstaatliche Selbstbestimmungsprozeduren nur noch wenig ausrichten. Dies wäre einzig möglich, wenn die weltweiten Sozialbeziehungen so zurückgebaut werden, dass Interdependenzen begrenzt sind. Nur so wäre eine Zentralstellung des politischen Gemeinwesens darstellbar. Die nationale Rückzugsbastion ist bisher deswegen nicht problematisch, da der Staat im linkskantianischen Verständnis verschwindet. Es besteht die (kontrafaktische) Annahme, dass er als Personenverband Ausdruck einer demokratischen Assoziierung gleicher und freier Staatsbürger ist, die mit der Exekutive und der Judikative ein Subsystem ausdifferenzieren, dem die Gesetzesanwendung und Gesetzesauslegung obliegt. ${ }^{23}$

Hier fehlt ein Erklärungsansatz, der den roten Faden des Maus'schen Werks erhellt: dass die Moderne eben nicht als das Zeitalter der strikten Bindung der Exekutive an ein inhaltlich bestimmtes Gesetz gelten kann. Sie ist das Zeitalter einer dynamischen Verrechtlichung, der Grenzbeziehungen des Staates zu Wirtschaft und Gesellschaft, der Macht der Administration und der Generalklauseln. ${ }^{24}$ Insofern kann Maus nur eine Kritik üben, die ein bestimmtes demokratisches Ideal gegen die schlechte Faktizität der modernen Gesellschaft mobilisiert. Findet in der Weltgesellschaft ein Formwandel der Verfassungsevolution statt, verblassen auch die Erinnerungen an die radikaldemokratischen Ideale Kants und Rousseaus und die republikanischen Errungenschaften zunehmend. Was dann bleibt, ist ein begriffsrealistisches Verfahren, das die Errungenschaften der Volkssouveränität beansprucht und auf »Nachrufe« auf die

23 | Vgl. dies., "Verfassung oder Vertrag“, S. 366, siehe zu diesem Aspekt auch Rödl, Florian: "Demokratische Verrechtlichung ohne Verstaatlichung. Kollisionsrecht statt Globalstaat", in: Eberl, Transnationalisierung der Volkssouveränität (2011), S. 271294, hier S. 272.

24 | Maus führt das Neumann'sche Programm eines Funktionswandels des Gesetzes in der modernen Gesellschaft aus der kritischen Rechtsstaatslehre der Frankfurter Schule weiter, siehe Neumann, Franz L.: "Der Funktionswandel des Gesetzes im Recht der bürgerlichen Gesellschaft“ (1937), in: ders., Demokratischer und autoritärer Staat, Frankfurt a. M.: Europäische Verlagsanstalt 1967, S. 7-57. 
demokratische Verfassung beschränkt bleibt. ${ }^{25}$ Demgegenüber ist es fraglich, ob das Demokratieprinzip noch entlang der Selbstbestimmung eines nationalen Staatsvolks fassbar ist und ob es in seiner bürgerlich-revolutionären Spielart die Letztentscheidung über die Geschichte und Zukunft der Demokratie fällt. ${ }^{26}$

\section{Abschied von der Volkssouveränität?}

Nachdem also gesellschafts- und staatstheoretische Einwände mobilisiert wurden, soll diskutiert werden, ob die Volkssouveränität noch als Grundlage dafür dienen kann, die Idee der demokratischen Verfassung in der Weltgesellschaft zu aktualisieren. Es geht somit ein weiteres Mal um die Verknüpfung von Demokratieprinzip und Volkssouveränität - nicht die luzide Beobachtung, dass in der Weltgesellschaft eine problematische »Dissoziation zwischen demokratischen Verfahren und ausgelagerter, expertokratischer Entscheidungsfindung ${ }^{27}{ }^{27}$ stattfindet. Maus expliziert das Volk der Volkssouveränität streng entlang der Idee eines Personenverbands freier und gleicher Staatsbürger, den sie aus Kants Anthropologie gewinnt. Hier hatte Kant das Volk als »vereinigte Menge auf einem Landstrich« definiert:

"Unter dem Wort Volk (populus) versteht man die in einem Landstrich vereinigte Menge, in so fern sie ein Ganzes ausmacht. Diejenige Menge oder auch der Teil derselben, welcher sich durch gemeinschaftliche Abstammung für vereinigt zu einem bürgerlichen Ganzen erkennt, heißt Nation (gens) «"28.

Dann ist Maus bemüht, das in der Passage aufscheinende Kriterium »gemeinschaftlicher Abstammung « nochmal so zur Kant'schen Demokratietheorie in Beziehung zu setzen, dass der Volksbegriff gänzlich von Substantialitäten (etwa blutsmäßiger oder kultureller Identität) gereinigt ist. Das Volk der Volkssouveränität ist nicht »Natur, sondern nur das Kunstprodukt des pactum unionis « ${ }^{29}$. Im Willensakt der Verfassungsgebung konstituiert sich das Volk überhaupt erst als Bürgerbund. Die Nation ist eine Staatsbürgernation, der keine partikulare kulturelle Identität zu Grunde liegt. Diese Konzeptualisierung basiert auf einer Engführung von demos und Staatsvolk. Dies wird auf drei Ebenen deutlich:

25 | Vgl. I. Maus, "Verfassung und Verfassungsgebung", S. 60.

26 | Einen Überblick über ihre Vielgestaltigkeit bietet Keane, John: The Life and Death of Democracy, London: Simon \& Schuster 2009.

27 | I. Maus, "Verfassung oder Vertrag", S. 358.

28 I. Kant, Anthropologie in pragmatischer Hinsicht, zitiert nach I. Maus, Zur Aufklärung der Demokratietheorie, S. 206.

29 | Ebenda, S. 208. 
(1) Territorium: Das Volkskonzept basiert auf einer räumlichen Dimension, die eben doch auf ein klar abgrenzbares Territorium hinausläuft, auf dem sich ein Staatsvolk in kollektiver Selbstbestimmung übt. »Die auf einem Landstrich vereinigte Menge « transformiert sich in ein Staatsvolk des Landstrichs. Insofern schwingt hier eine spezifische, vom westfälischen Nationalstaat her geprägte Raumauffassung mit. Daher unterstreicht Maus konsequenterweise die räumlichen Näheverhältnisse, die für eine demokratische Ausübung der Volkssouveränität, für Deliberation und Öffentlichkeit zwingend erforderlich sind. ${ }^{30}$ Sie besteht auf der Figur des Personenverbandes, der eine Bewegung »raum-zeitlicher Entgrenzung « ${ }^{31}$ in Gang setzt. Diese Entgrenzung versteht sie allerdings im Sinne eines jus solis und der Offenheit demokratischer Republiken für Einwanderungsbewegungen. Letztlich läuft alles doch auf einen politisch konstituierten Raum, auf ein überschaubares Territorium mit klaren Grenzen hinaus, auch wenn die Grenzen »nichts anderes mehr als den Geltungsradius der demokratischen Verfassung darstellen ${ }^{32}$. Auch dies ist eine Folge der räumlichen Dimension: Man muss nämlich klar zwischen auf dem Territorium lebenden Staatsbürgern, Staatsbürgern anderer Nationalstaaten und Reisenden unterscheiden. Das Exklusionskriterium der radikaldemokratischen Republik ist nicht das Blut. Es ist die Grenze. In der radikalen Demokratietheorie ist eine solche Grenzziehung nicht problematisch, da sie weiterhin von einer Selbststeuerung des politischen Gemeinwesens ausgeht. Das klassische Problem negativer Externalitäten und Betroffenheiten außerhalb des Territoriums soll dadurch gelöst werden, dass auch alle anderen Staaten zu demokratischen Republiken werden. Die Betroffenen können dort ihre Interessen einspeisen, und auf Weltebene organisiert ein verrechtlichter Staatenbund mögliche Problemlösungen. Peter Niesen hat dies mit der Normativität eines »Kosmopolitismus in einem Land $\aleph^{33}$ auf den Punkt gebracht.

Damit kommt eine Annahme ins Spiel, die vor dem Hintergrund einer funktional ausdifferenzierten Weltgesellschaft problematisch erscheint: dass der Raum der Weltgesellschaft von nationalstaatlichen Grenzen strukturiert ist. Demgegenüber muss davon ausgegangen werden, dass in der Weltgesellschaft neue Strukturierungen vorliegen. Wenn globale Funktionssysteme den Raum der Weltgesellschaft markieren, liegen vielfältige Grenzbeziehungen in einer komplexen räumlichen Strukturierung vor: zwischen den globalisierten Funktionssystemen, zwischen den Zonen der Inklusion und der Exklusion,

30 | Vgl. dies., "Verfassung oder Vertrag", S. 370.

31 | Dies., Über Volkssouveränität, S. 381.

32 | Ebenda, S. 379.

33 | Vgl. Niesen, Peter: "Kosmopolitismus in einem Land", in: ders. (Hg.), Transnationale Gerechtigkeit und Demokratie. Frankfurt a. M./ New York: Campus 2012, S. 311339. 
zwischen den Räumen nationalstaatlicher und transnationaler Institutionen. ${ }^{34}$ Wiederum müsste das Programm radikaler Demokratie auf einen voluntaristischen Rückbau dieser Grenzbeziehungen hinauslaufen. Bleibt es allerdings bei einer Verbindung von Demokratietheorie und sozialer Evolution, dann gilt es das Demokratieprinzip komplexitätsadäquat zu reformulieren. Der Raum der Demokratie in der Weltgesellschaft übersteigt das Territorium schon heute: Das »Volk« des Cyberspace, das »Volk« der weltweiten Umweltflüchtlinge, das prekarisierte »Volk« der globalen scientific community - das Volk erlebt eine räumliche Dezentrierung. ${ }^{35}$

(2) Staatsbürgerschaft: In der Mitgliedschaftsdimension tauchen ähnliche Grenzbeziehungen auf, die das Konzept des Personenverbands prekär erscheinen lassen. Die Mitgliedschaftsdimension der Volkssouveränität geht davon aus, dass die Menschen auf einem begrenzten Territorium in einem politischen Willensakt das Staatsvolk konstituieren. So entsteht eine umfangslogische Bestimmung des Volks als populus nach dem Maß der Zahl: Alle Menschen auf einem Territorium bilden einen Personenverband, unabhängig von sozialem Status und Herkunft. Auch hier macht die soziale Evolution der Volkssouveränität einen Strich durch die Rechnung. Wenn es sich nämlich beim Gesellschaftsvertrag um eine Fiktion handelt und die beteiligten Personen in bestehende Funktionssysteme inkludiert sind, die sie als Personen anerkennen, muss gezeigt werden, wieso die Mitgliedschaftsdimension des politischen Systems zum zentralen Ort der Sozialintegration werden kann. Letztlich muss die Volkssouveränitätstheorie davon ausgehen, dass die im Personenverband vereinigten Mitglieder ihre personale Identität zuerst über ihre Rolle als Staatsbürger herstellen. Wenn allerdings Personen der Ort sind, an dem unterschiedlichen Linien der Inklusion und Exklusion zusammenlaufen, ist die politische Achse eine unter vielen. Darüber hinaus treten in den letzten Jahrzehnten in der Weltgesellschaft Personengruppen auf, die sich systematisch einer Mitgliedschaftsperspektive in einem territorial gebundenen Personenverband entziehen. Insbesondere die größer werdende Gruppe der Staatenlosen macht darauf aufmerksam, dass das Volkskonzept zunehmend sozialen Gruppen überhaupt

34 | Serhat Karakayali und Vassilis Tsianos zeigen beispielsweise, dass die Innen/Außen-Unterscheidung die räumliche Struktur des europäischen Migrationsregimes nicht fassen kann: dies.: "Das Regieren der Migration. Jenseits von Inklusion und Exklusion", in: Soziale Systeme 14/ 2 (2008), S. 329-348.

35 Paul S. Berman beobachtet beispielsweise unterschiedliche "normative communities", die je eigene Normbestände - auch auf transnationalem Terrain - produzieren. Er unterscheidet "state, international and non-state normative communities", ders.: "Global Legal Pluralism«, in: Southern California Law Review 80/6 (2007), S. 1155-1237, hier S. 1159. 
keine Mitgliedschaftsperspektive mehr anbieten kann ${ }^{36}$ - es sei denn im Rahmen globaler Menschenrechtsgeltung und global citizenship, die allerdings weit von einer volkssouveränistischen Perspektive entfernt sind.

(3) Subjektivierung als citoyen: In den bisherigen Ausführungen klingt der Umstand an, dass die Volkssouveränität mit einer spezifischen Subjektivierungsdimension einhergeht. Die Menge wird zum Volk freier und gleicher Staatsbürger. Dadurch richtet der politische Prozess mit seiner Zentralstellung die Subjekte als citoyens des pactum unionis zu. Sie entscheiden als Staatsbürger über die gesellschaftlichen Angelegenheiten, geben als Staatsbürger ihre Stimmen $\mathrm{ab}$ und begründen ihre politischen Anliegen durch ein Universalisierungsrelais, das auf einen allgemeinen Volkswillen ausgerichtet ist. Bei Maus hat diese Stilisierung freilich eine kritische Funktion: Indem sie die frühbürgerliche Subjektivierung als citoyen zum Ausgangspunkt wählt, übt sie gleichzeitig Kritik an der Dominanz der bourgeoisen Subjektivierung der individuellen Nutzenmaximierung am kapitalistischen Markt und der damit einhergehenden Instrumentalisierung politisch-rechtlicher Institutionen für spezifische Zwecke der bürgerlichen Klasse. Was aber, wenn die Subjektivierungsweise des citoyen schon das Problem darstellt und Marx in seiner Kritik der beschränkt-politischen Emanzipation der bürgerlichen Idealdemokratie doch Recht behältt? ${ }^{37}$ Indem die auf einem Landstrich versammelte Menge sich zum Bürgerbund erhebt, entsteht ein Schleier der Gleichheit über den sozialen Konflikten. Das Volk verkehrt sich von der »Quelle der Gesetzgebung « $^{38}$ zur Legitimationsfigur für die Nutzenmaximierung solcher sozialen Klassen, die privilegierten Zugriff auf die Definition des allgemeinen Willens haben.

Im umfangslogisch, nach dem Maß der Zahl gedachten Volk interagieren Staatsbeamte, Parlamentarier und Wahlberechtigte als Gleiche, obwohl sie je unterschiedlichen Zugriff auf Machtressourcen haben. Die Verselbstständigung der Exekutivapparate zeitigt nur Konsequenzen auf der Ebene der Gesetzesform. Am Wahltag sind alle gleich. Das Universalisierungsrelais der Gesetzesform bleibt die einzige Vorkehrung für die gruppenegoistische Überwältigung des demos. Die Volkssouveränität transformiert die Menge in autonome Subjekte des demokratischen Staats. ${ }^{39}$ Damit geht eine Abstraktion der Einzelnen von den kollektiven Lebenslagen der gesellschaftlichen Verhältnis-

36 | Etwa die perspektivisch massiv anwachsende Gruppe der Umweltflüchtlinge, siehe dazu L. Kreck, "Möglichkeiten und Grenzen des rechtlichen Schutzes für Umweltflüchtlinge".

37 | Vgl. K. Marx, "Zur Judenfrage", S. 351.

38 | I. Maus, Über Volkssouveränität, S. 8.

39 | Zum Recht als modernem Subjektivierungsregime siehe S. Buckel, Subjektivierung und Kohäsion. Hier werden die Subjektivierungsanalysen marxistischer Rechtstheorie in Anlehnung an Eugen Paschukanis "Allgemeiner Rechtslehre" (vgl. ders.: Allgemeine 
se einher, mehr noch: der Staat selbst ist der Ort, von dem aus die privilegierte Subjektivierung der auf einem Territorium versammelten Menschen stattfindet. Die Hoffnungen aufs Universalisierungsrelais verkennen, dass unter Bedingungen politischer Repräsentation und sozioökonomischer Machtkonzentration das Zusammenspiel von Verallgemeinerung und Individualisierung zum Gegenteil führen kann, nämlich zur diskursiven Verallgemeinerung der Interessen von Machtgruppen, die sich auf diesem Wege mit dem Vokabular des allgemeinen Willens sogar noch zusätzliche Legitimationsressourcen sichern. Insofern kann sich eine »republican domination ${ }^{40}$ einstellen: Gerade allgemeine und unparteiliche Verfahren können unter Bedingungen von Machtasymmetrien verstärkend wirken, indem sie die Widersprüche zwischen oben und unten, zwischen »Volk« und »Funktionären« verwischen. ${ }^{41}$

Die Programmierung der Exekutive von der gesellschaftlichen Basis her bleibt einem Legitimationskettenmodell verhaftet. Dagegen ist der differenztheoretische Befund zu bemühen, dass keine authentische, vollständige Repräsentation des Volkswillens stattfinden kann, da die citoyens ihre Interessen stets unter konstitutiver Anwesenheit der sie repräsentierenden Institutionen und Funktionäre bilden. Es gibt keinen reinen Ursprung, keinen jungfräulichen Moment, der die Machtasymmetrien vollständig außer Kraft setzt. Die Repräsentanten wirken an der Identität der zu Repräsentierenden mit. Es liegt an der »Essenz« des Repräsentationsverhältnisses (hier die Ausdifferenzierung von Gewalten, denen die Rechtssetzung- und -anwendung obliegt), »dass der Repräsentant zur Identität des zu Repräsentierenden beitragen muss « ${ }^{42}$. In diesem Sinne gibt es keine umfangslogisch vollständige gesellschaftliche Basis, die voluntativ auf Distanz zur sozialen Evolution gehen könnte, um von dort aus den demokratischen Prozess als Ganzen zu programmieren. Zu klären wäre, welchen Möglichkeitsspielraum die fundamentale Spannung zwischen (nie vollzähligem) Volk und Organen für die positive Ausübung der konstituierenden Macht des Volkes überhaupt aufspannt.

Rechtslehre und Marxismus [1929], Freiburg: 2003) und die Studien Michel Foucaults zu Subjektivierungseffekten der Machtverhältnisse zusammengeführt.

40 | Vgl. J. P. McCormick, Machiavellian Democracy, S. 165 ff.

41 Das ist eine Unterscheidung, die Ingeborg Maus selbst immer wieder bemüht, das Volk wird als Gesamtheit der "Nicht-Funktionäre" definiert; vgl. dies.: "Basisdemokratische Aktivitäten und rechtsstaatliche Verfassung. Zum Verhältnis von institutionalisierter und nichtinstitutionalisierter Volkssouveränität", in: Thomas Kreuder (Hg.), Der orientierungslose Leviathan. Verfassungsdebatte, Funktion und Leistungsfähigkeit von Recht und Verfassung, Marburg: Schüren 1992, S. 99-116, hier S. 115. Die Frage ist natürlich, wie es dazu kommen soll, dass die Nichtfunktionäre nicht sofort verstaatlicht werden, sondern ihre Autonomie erhalten.

42 | E. Laclau, Emanzipation und Differenz, S. 128. 
In allen drei Dimensionen - Raumdimension, Inklusionsdimension, Subjektivierungsdimension - ist deutlich geworden, dass das normative Programm der Volkssouveränität an Kraft verliert. Während die Diagnose zur verselbstständigten Dissoziation zwischen demokratischen Verfahren und expertokratischer Entscheidungsfindung durchaus nachvollziehbar ist, bleibt die Therapie einer Rückkehr zur Volkssouveränität äußerst fragwürdig. Was auf dem Spiel steht, sind nichts weniger als das Demokratieprinzip und die konstituierende Macht des Volkes: Sollten sich diese konstitutiven Ideale der westlichen Rechtstradition eventuell als Anomalie erweisen ${ }^{43}$ Bleibt im Übergang zur Weltgesellschaft nicht mehr übrig als die liberale, herrschaftsformende Verfassung einer transnationalen Policey oder gar ein Rückfall in mittelalterliche Muster der Ständeverfassung, die ihre Anbindung an die konstituierende Macht keinesfalls mehr darstellen können? Muss es bei der Klage über die neuartige Hegemoniekonstellation bleiben oder ist die Idee der demokratischen Verfassung gänzlich zu verabschieden?

\section{Destituierende Macht}

Man muss von der umfangslogischen Variante der konstituierenden Macht den nötigen Abstand gewinnen und den Konflikt der Verfassung mit sich selbst zum Ausgangspunkt für die Suche nach demokratischer Konstitutionalisierung in der Weltgesellschaft machen. Die Leistung der demokratischen Verfassung besteht darin, dass sie den irreduziblen Konflikt zwischen Herrschaftsausübung und Herrschaftskritik, pouvoir constitué und pouvoir constituant, auf Dauer stellt. Dies kann auch so verstanden werden, dass ein schwellender Dissens eine Institutionalisierung erfährt. So entsteht freilich eine andere Lesart der Volkssouveränität, wie sie insbesondere Claude Lefort in seinen radikaldemokratischen Überlegungen profiliert. Diese Herangehensweise kann, wie noch zu zeigen ist, aussichtsreicher auf die hegemonialen Regime reagieren.

Die demokratische Revolution und das daraus erwachsende Dispositiv der demokratischen Verfassung erscheint - so wie bei Maus - als »das Ereignis schlechthin ${ }^{44}$, das die Moderne auf den Weg bringt. Jedoch steht nicht die Selbstregierung des Volkes im Medium des Rechts im Mittelpunkt, sondern die Teilung der Gesellschaft in Kreisläufe der Herrschaftsausübung und der Herrschaftskritik. Die demokratische Verfassung kann nicht auf ein Zusammenspiel aus »rechtlich-politischen Institutionen, freien Wahlen, Mehrpartei-

43 | N. Luhmann, Das Recht der Gesellschaft, S. 586.

44 | Marchart, Oliver: Die politische Differenz. Zum Denken des Politischen bei Nancy, Lefort, Badiou, Laclau und Agamben, Berlin: Suhrkamp 2010, S. 122. 
ensystem, Kontrolle der Regierung durch das Parlament ${ }^{45}$ reduziert werden; vielmehr bezeichnet sie einen fundamentalen Wandel der Ordnung, entlang derer die Gesellschaft ihre Selbstinstituierung ausrichtet. Wurde in vordemokratischen Herrschaftsformen die Gesellschaft als einheitlicher Körper imaginiert, der durch den Körper des Königs repräsentiert wird, vollzieht die demokratische Verfassung einen »Bruch mit der Repräsentation der Gesellschaft als Körper « ${ }^{46}$. Statt einen neuen, einheitlichen Körper zu bilden, findet in der Demokratie eine »Entkörperung (désincorporation) « statt. ${ }^{47}$ Indem Grund- und Menschenrechte und das Demokratieprinzip es jederzeit ermöglichen, die bestehende Form der Selbstinstituierung zu bestreiten, zerfällt der einheitliche Gesellschaftskörper in dissentierende Teile, die niemals das Ganze repräsentieren können, ohne selbst repressiv und totalitär zu werden. Der Ort der Macht so das wohl berühmteste Zitat Leforts - bleibt in der demokratischen Verfassung leer. Zwar »gründet sich die Legitimität der Macht auf das Volk, aber die Vorstellung der Volkssouveränität verbindet sich mit einem leeren Platz, der unmöglich zu vereinnahmen ist ${ }^{48}$. Diese Leere allerdings beruht darauf, wie in Demokratien soziale Praktiken der Herrschaftskritik und der Herrschaftsausübung zusammenspielen. Sie ist weder als eine liberale Gewaltenteilungslehre misszuverstehen noch als einfacher Pluralismus. Lefort begreift das symbolische Dispositiv der Demokratie vom Wechselspiel zwischen den Subverfassungen der Herrschaftsausübung und Herrschaftskritik her. Dabei transformiert sich die konstituierende Macht des Volkes in ein destituierendes Potential, das an herrschaftskritische Kommunikationskreisläufe und die Positionalität des Unterworfen-Seins gebunden ist, nicht notwendig an das Volk in einem umfangslogischen Sinne. ${ }^{49}$

45 | Lefort, Claude: „Préface“, in: ders., L'invention démocratique. Les limites de la domination totalitaire (1981), Paris: Fayard 1994, S. I-IX, hier S. IV - Übers. d. Verf.

46 | Ebenda, S. I - Übers. d. Verf.

47 | Ders.: "Droits de l'homme et politique», in: ders., L'invention démocratique (1994), S. 43-83, hier S. 64.

48 | Ders.: "La logique totalitaire", in: ders., L'invention démocratique (1994), S. 85106, hier S. 92; siehe auch ders.: "Die Frage der Demokratie", in: Ulrich Rödl (Hg.), Autonome Gesellschaft und libertäre Demokratie, Frankfurt a. M.: Suhrkamp 1990, S. 281-357, hier S. 293; vgl. auch die Rekonstruktion bei Raimondi, Francesca: Die Zeit der Demokratie. Politische Freiheit nach Carl Schmitt und Hannah Arendt, Konstanz: Konstanz University Press 2014, S. 117 ff.

49 | Ich beziehe mich im Folgenden insbes. auf Claude Leforts Frühschriften und auf sein Buch zu Machiavelli, ders.: Le travail de l'œuvre Machiavel (1972), Paris: Gallimard 1986. Mir scheint sich hier doch ein alternativer Zugang zur Frage der Demokratie abzuzeichnen, der in einer gewissen Spannung zum stärker liberaldemokratischen Verständnis in seinen späteren Schriften steht. 


\section{Konstitution und Destitution}

Den Übergang von der konstituierenden Macht des Volkes zu einer destituierenden Macht gewinnt Lefort aus einer Rekonstruktion der politischen Philosophie Niccolò Machiavellis und einer Analyse der Ordnungskämpfe in der römischen Republik..$^{50}$ Lefort liest das Werk Machiavellis nicht populärwissenschaftlich als machttechnisches Handbuch. Machiavelli erscheint als Theoretiker des sozialen Konflikts, der die Frage aufwirft, wie der Widerspruch zwischen Noblen und Subalternen, zwischen den grandi und dem populo so institutionalisiert werden kann, dass er das Gemeinwesen nicht in den Bürgerkrieg stürzt. ${ }^{51}$ Der schon in Machiavellis »Il Principe explizierte Ausgangspunkt ist der Widerspruch zwischen zwei unterschiedlichen Momenten, die in Gemeinwesen stets aufeinanderprallen, nämlich dem Begehren des Volks, nicht beherrscht zu werden, und dem Begehren der grandi, Herrschaft auszuüben:

"Denn in jeder Stadt finden sich diese zwei unterschiedlichen Gesinnungen, was daher rührt, dass sich das Volk von den Großen weder beherrschen noch unterdrücken lassen will, die Großen aber das Volk beherrschen und unterdrücken wollen; aus diesen verschiedenen Bedürfnissen entsteht in den Städten jeweils eine von drei möglichen Wirkungen: entweder die Fürstenherrschaft oder die Freiheit oder die Anarchie.. ${ }^{52}$

Demnach ist das Gemeinwesen nicht als identitäre Einheit darstellbar. Es ist zwischen zwei Affektökonomien der Herrschaftsausübung und der Herrschaftskritik geteilt. Und die Frage ist aufgeworfen, wie die hier wirkenden gesellschaftlichen Kräfte aufeinander bezogen und ihr Konflikt eingerichtet wird. Als historisches Beispiel für eine gelingende, halbwegs freiheitliche Institutionalisierung des sozialen Konflikts dient Machiavelli in seinen »Discorsi« die Blütezeit der römischen Republik. Hier scheint es gelungen zu sein, die beiden Momente so zu institutionalisieren, dass sie halbwegs positive Effekte erzielten.

50 | Vgl. ebenda; zentral dabei der Machiavelli, Niccolò: II Principe (1532), Stuttgart: Reclam 2003, und ders.: Discorsi (1531), Frankfurt a. M. / Leipzig: Insel-Verlag 2000.

51 | Vgl. J. P. McCormick, Machiavellian Democracy; Vatter, Miguel: Between Form and Event. Machiavellis Theory of Political Freedom, Dordrecht: Kluwer Academic Publishers 2000. Demgegenüber sieht die englische Cambridge School eher ein liberalrepublikanisches Freiheitsverständnis in der "atlantischen " Tradition angelegt, siehe Pocock, J. G. A.: The Machiavellian Moment. Florentine Political Thought and the Atlantic Republican Tradition, Princeton: Princeton University Press 1975.

52 | N. Machiavelli, Der Fürst, Kap. IX. Die Übersetzung als "Gesinnungen « ist missverständlich, da es sich ja gerade nicht um explizite Überzeugungen handelt, sondern um eher diffuse Gemütszustände. 
Die Einführung des Volkstribunats und die Erweiterung seiner Rechte hat den sozialen Konflikt zwischen Plebs und Patriziern in die Verfassung eingeschrieben: »Die Uneinigkeit zwischen römischem Volk und Senat führte zur Freiheit und Macht der Republik. ${ }^{53}$ Weit von einem autoritären Ordnungsdenken entfernt liegt der innovative Kern der Machiavelli'schen Argumentation im Lob des Plebs. Die Gegenmachtaktionen der Plebejer, ihre politischen Streiks, ihre Auszüge aus der Stadt auf den Heiligen Berg, Mons sacer (secessio plebis), die Volkstribunen, das Wechselspiel zwischen ihrer kollektiven potestas und spontanen Tumulten haben die Blüte der römischen Republik ermöglich. Erst wenn die herrschaftskritischen Gesinnungen den grandi sozusagen »im Nacken sitzen« und ihren Ausdruck in politisch-rechtlichen Formen finden, kann die Ordnung als stabil gelten. Sonst droht die Gefahr einer verselbstständigten Klasse der politisch Herrschenden, die sich systematisch selbst überschätzen. Und der Zusammenbruch der sozialen Basis der Republik droht, da die affektiven Gesinnungen unproduktive Ausdrucksformen finden. ${ }^{54}$

Lefort baut dieses Motiv aus und löst es dabei zunehmend von den konkreten Kollektivakteuren. Die beiden umori (Gemütszustände) übersteigen jede politische Form, auch die Institutionalisierung im Tribunat. Die umori vagabundieren wild in der Gesellschaft umher und sind nur vorläufig zähmbar. Sie erscheinen »symbolisch « auf der Bühne der gesellschaftlichen Instituierung und doch sind sie nie vollständig mit sich selbst identisch. Im Gegensatz zum umfangslogischen Volksbegriff im Sinne von populus avanciert das Volk als Plebs in dieser verfassungstheoretischen Linie zu einem herrschaftskritischen Gegenprinzip. ${ }^{55}$ Das Volk tritt auf den Plan, wenn die Herrschaftsunterworfenen ihr Begehren zum Ausdruck bringen, nicht regiert zu werden. Mit dem Tribunat installieren sie, nach ihrem initialen Auszug auf den heiligen Berg, ein eigenes »Organ der Negativität « ${ }^{56}$. Dadurch entsteht eine Teilung des Volkes:

"[E]s zeigt sich, dass der Begriff des ,Volkes، eine Opposition überdeckt. Oder, um es anders zu sagen, im Innern des Volkes, der vermeintlichen Gemeinschaft, auf die sich die Identität des Staates beruft, zeigt sich eine Masse der Ohnmächtigen - ,Volkı in genau demjenigen Sinne, der es der fiktiven Einheit entzieht, welche die politische Sprache inm aufnötigt. . ${ }^{57}$

53 | Ders., "Discorsi“, S. $27 \mathrm{ff}$.

54 | Siehe dazu N. Machiavelli, „Discorsi“, S. 38 ff.

55 | Vgl. zum Verhältnis von Plebs und populus insbes. Vatter, Miguel: „The Quarrel between Populism and Republicanism: Machiavelli and the Antinomies of Plebeian Politics", in: Contemporary Political Theory 11/3 (2012), S. 242-263.

56 | Vgl. C. Lefort, Le travail de l'œuvre Machiavel, S. 476.

57 | Ebenda, S. 382 - Übers. d. Verf.: "[I]I s'avère que le concept du peuple، recouvre une opposition. Ou, pour le dire autrement, à l'intérieur du peuple, communauté appa- 
Demnach sind also zwei Varianten des demos zu unterscheiden. Einerseits die umfangslogische Bestimmung des demos als populus. Sie ruft eine »vermeintliche Gemeinschaft« herbei und droht auf diesem Wege genau diejenigen machtverzerrenden Effekte zu erzielen, die schon in der Auseinandersetzung mit der Volkssouveränität eine Rolle spielten. Andererseits bezeichnet das Volk ebenfalls die »Masse der Ohnmächtigen«, die ihre negative, plebejische Macht gegen die grandi in Stellung bringen. Die Bestimmung des Volks als Plebs nimmt damit nicht das Maß der Zahl und die Grenze des Territoriums zum Ausgangspunkt. Die Positionalität des Unterworfen-Seins ist derjenige prägende Ausgangspunkt, von dem aus herrschaftskritische Kommunikationsmuster emanieren. Die konstituierende Macht des Volks stellt eine negative Macht dar, die eine bestehende Herrschaft bestreitet und mit dem Begehren nach Herrschaftsfreiheit konfrontiert. ${ }^{58}$ Sie ist nicht mit der bestehenden Sozialordnung identisch. Sie »nimmt eine gewisse Distanz zur geltenden Ordnung ein« und bezieht seine »Stiftungsleistung [...] nicht so sehr auf einen einmaligen Gründungsakt als vielmehr auf die stets aktuelle, mit eigener Zeitlichkeit auftretende Intervention in bestehende Zusammenhänge « ${ }^{59}$. Die konstituierende Macht artikuliert sich als destituierende Macht. ${ }^{60}$

\section{Paradoxe Verfassung}

Hatte Lefort in seinen Studien zur politischen Philosophie Machiavellis diesen grundlegenden Herrschaftskonflikt herausgearbeitet, erwächst in seinen späteren Überlegungen zur modernen Demokratie daraus ein neuer Zugang zum Problem kollektiver Selbstregierung. Für Lefort bringen die demokratischen

rente à laquelle l'Etat assigne son identité, se découvre la masse des sans-pouvoirs 'peuple، au sens précis qui le soustrait à l'unité fictive que le langage politique lui impose."

58 | Das heißt auch, dass die konstituierende Macht, wenn sie sich materialisiert und zu einer konstituierten Macht wird, sich stets nochmal der Befragung einer konstituierenden Macht unterziehen muss. Die Teilung der Gesellschaft schließt auch eine Teilung der konstituierenden Macht selbst in den nie vollständig erreichbaren Standpunkt der Herrschaftskritik und der konstituierten Ordnung plebejischer Organe ein, vgl. K. Möller, "Herrschen und Regieren".

59 | Wagner, Andreas: Recht - Macht - Öffentlichkeit. Elemente demokratischer Staatlichkeit bei Jürgen Habermas und Claude Lefort, Stuttgart: Steiner-Verlag 2010, S. 133. 60 | Ein ähnlicher Zug taucht in der Verfassungstheorie der Französischen Revolution auf. Olivier Beaud zeigt, wie auch hier das Plädoyer für ein "Recht zum Aufstand" mit einem vorgängigen, negativen droit préconstitutionel einhergeht, vgl. ders.: La Puissance de l'Etat, Paris: Presses Universitaires des France 1994, S. 223 ff. 
Revolutionen ein vollständig neues Dispositiv in die Welt. Weit über die positivrechtlichen Verfahren des demokratischen Rechtsstaats hinaus findet eine veränderte und wesentlich komplexere Symbolisierung von Macht statt. Die demokratische Verfassung dekonstruiert den Körper des Königs. Sie etabliert eine neue Form (mise en form) der gesellschaftlichen Instituierung und schafft eine veränderte Bühne (mise en scène), auf der die Sichtbarmachung und Verbergung gesellschaftlicher Macht stattfindet. ${ }^{61}$ Das Machtsymbol durchläuft eine irritierende, geradezu paradoxe Entkörperung. Während im Körper des Königs die Repräsentation der Gesellschaft in einem einheitlichen Macht-, Wissens- und Gesetzeskomplex zusammenfallen, treten die jeweiligen Komponenten auseinander. Sie diffundieren in die Gesellschaft.

"Die moderne demokratische Gesellschaft [erscheint - d. Verf.] als Gesellschaft, wo die Macht, das Recht und das Wissen durch eine radikale Unbestimmtheit auf die Probe gestellt werden, eine Gesellschaft, die die Bühne eines unbeherrschbaren Abenteuers geworden ist; das, was sich instituiert sieht, ist niemals etabliert; das Bekannte wird vom Unbekannten 'gewurmt [ [...]; ein Abenteuer, dessen Suche nach Identität sich nur durch die Erfahrung der Teilung/Spaltung entäußert « ${ }^{62}$.

Dieses Auseinandertreten sucht die Volkssouveränität der demokratischen Verfassung heim. Sie kann nur noch »symbolisch « verstanden werden, da eine vollständige Identität von Rechtsadressaten und Rechtsautoren nicht realisierbar (oder nur um den Preis des Totalitarismus, also einer Besetzung des Machtsymbols zu haben) ist. In der demokratischen Verfassung wandert die Souveränität vom König aufs Volk, erlebt dort aber in der Verbindung mit Grund- und Menschenrechten, der Gewaltenteilung und dem Rechtsprinzip eine paradoxe Wendung. Einerseits gründet die Legitimität der Macht auf dem Volk, andererseits sorgt der demokratische Prozess dafür, dass der Ort der Macht stets leer bleibt, nie vollständig vereinnahmt und »verkörpert« werden kann. ${ }^{63}$ Insofern entfaltet die Verfassung ein Paradox. Sie gibt vor, die Gesellschaft zu repräsentieren, und repräsentiert sie doch nie ganz.

61 | Vgl. C. Lefort, "Die Frage der Demokratie", S. 284.

62 | Ders.: "L'image du corps et le totalitarisme", in: ders., L'invention démocratique (1994), S. 159-176, hier S. 174.

63 | Eine ähnliche Unterscheidung zwischen demokratischem und autoritärem Souveränitätsverständnis nimmt Andreas Kalyvas (ders.: "Constituent Power", in: Political Concepts. A Critical Lexicon [http://www.politicalconcepts.org/constituentpower/], S. 1-13, hier S. 2, Herv. i. 0.) vor: "In positive terms, democracy qua constituent power discloses a different idea of sovereignty, not only historically prior but also analytically distinct from the legal paradigm, opposed and antagonistic to it: the power of the people to constitute." 
Das heißt mithin auch, dass keine Auflösung möglich ist und das demokratische Regime jede Einheitsfiktion unterläuft. Ein offener Modus des Sozialen entsteht, da sich der politische Prozess nie vollständig für neue Thematisierungen und Praktiken schließen kann. Die Unmöglichkeit der Gesellschaft, mit sich selbst identisch zu sein, findet ihren Ausdruck im Demokratieprinzip. Es ist eine Weise, den sozialen Konflikt einzurichten, eine andauernde, nie zur Ruhe kommende Spannung zwischen den herrschaftskritischen und herrschaftsausübenden Momenten im politischen Gemeinwesen.

In gewisser Weise transponiert Lefort diesen Zentralkonflikt des Sozialen von seiner Machiavelli-Lektüre in den Horizont der Französischen Revolution und der modernen demokratischen Verfassung. Die dauerhaften Organe der Negativität treten zu Gunsten einer unbeherrschbaren Öffentlichkeit zurück, in der sich Kritik artikulieren kann. ${ }^{64}$ Die berühmte Passage zum »leeren Ort der Macht« ist in diesem Lichte weiterhin so zu verstehen, dass ein Kräfteverhältnis zwischen Herrschaftsausübung und Herrschaftskritik besteht, das es unmöglich macht, ihn zu besetzen und damit eine totalitäre Verkörperung der Gesellschaft einzuleiten. Institutionelle Verfahren der Demokratie (Wahlen, Repräsentation) und die Gewaltenteilung sind als Ausdruck dieses Kräfteverhältnisses zu begreifen, nicht als bloßes Verbot einer Besetzung der Macht. ${ }^{65}$ Fraglich ist, ob Lefort mit diesem Modell einer umherschweifenden Herrschaftskritik nicht das Problem aus dem Blickfeld verliert, dass die im demokratischen Regime angelegte Potentialität auch in sozialen Konflikten dauerhaft aktualisiert werden muss bzw. auf Kräfteverhältnissen aufruht, die auch institutionelle Verdichtungen, Organe und Gewalten (etwa Parteien, Gewerkschaften, Netzwerke, Zeitungen) benötigen. Aufgerufen wäre die Frage, die Lefort bei Machiavelli mit dem plebejischen Tribunat identifiziert: nach einer angemessenen mise en forme einer destituierenden Macht, einer Art Form 1 (Selbstorganisierung des Plebs), ohne die eine republikanische Form 2 (demokratische Verfassung) nicht dauerhaft lebensfähig wäre - oder, um die Unterscheidung aus der Auseinandersetzung mit dem Postmarxismus Laclaus wieder aufzunehmen: keine Konstitutionalisierung popularer Leere (demokratische Verfassung, Form 2) ohne die Konstitutionalisierung plebejischer Leere (Selbstorganisierung des Plebs, Form 1).

64 | Siehe die Parallelen zu Habermas bei A. Wagner, Recht - Macht - Öffentlichkeit, S. $151 \mathrm{ff}$.

65 | Wagner geht einer ähnlichen Deutung nach (ebenda, S. 136), geht den Weg aber über die existierende Demokratie. 


\section{Staat und Zivilgesellschaft}

Demgegenüber passt Lefort den sozialen Konflikt recht reibungslos in das Verhältnis von Staat und Zivilgesellschaft ein. Der Staat wird tendenziell mit der Herrschaftsausübung identifiziert, die Zivilgesellschaft mit der Herrschaftskritik. Leforts Zivilgesellschaft ist nicht die bürgerliche Gesellschaft des ökonomischen Marktes von Marx und Hegel. Lefort beobachtet »die Entfesselung einer gesellschaftlichen Sphäre der speziellen Aktivität, die notwendig an die Ausübung des Konflikts gebunden ist ${ }^{66}$. Indem die Grund- und Menschenrechte grundlegende Autonomien der Staatsbürger schützen, entsteht der Spielraum für die Befragung staatlicher Herrschaft. Insofern arbeitet Lefort das Konzept der Zivilgesellschaft und der Grund- und Menschenrechte radikaldemokratisch um. Das Dispositiv der Demokratie basiert auf einem schwelenden Dissens zwischen Staat und Zivilgesellschaft. Die Zivilgesellschaft tritt hier nicht als bürgerliche Gesellschaft der Marktteilnehmer auf, streng genommen auch nicht als deliberative Bürgergesellschaft, die im Schleier des Nichtwissens über die allgemeine Gerechtigkeit berät. Sie ist als kritisches Gegenprinzip zur Verselbstständigung der Organe zu verstehen. Ihre Triebfedern sind politische Handlungsformen, die den Schleier des Nichtwissens ablegen und mit dem Wissen um die Tendenzen zur Verstaatlichung der Gesellschaft dem Begehren nach Nichtbeherrschung zum Ausdruck verhelfen. Insofern nimmt Lefort eine Eingrenzung derjenigen Praktiken vor, die als zivilgesellschaftlich gelten können.

Zentral für dieses Spannungsverhältnis von Staatsmacht und Zivilgesellschaft sind die Grund- und Menschenrechte. Sie beugen einem totalisierenden Zugriff der Staatsmacht vor. Als kollektives Recht dient beispielsweise die Meinungsfreiheit dazu, eine Öffentlichkeit zu schaffen, in der auch solche »Kommunikationsweisen « entstehen, »deren Auswirkungen unbestimmt sind und die sich aus demselben Grunde dem Zugriff der Macht entziehen « ${ }^{67}$. Die Menschenrechte haben einen intrinsisch-politischen Charakter. Sie eröffnen den Raum des Politischen für alternative Existenz, Handlungs- und Kommunikationsweisen. Sie sind eminent positive Rechte und verfügen über eine ausgesprochen kollektive Dimension. Indem Rechte eingefordert werden, entsteht zudem ein Zusammenhang der Forderbarkeit von Rechten überhaupt. Damit fällt das epistemische Privileg der Macht, über das zu urteilen, was gefordert werden kann. Es gibt ein Recht auf Rechte. ${ }^{68}$ Das bedeutet aber auch, dass das

66 | Lefort, Claude: "L'impensée de l'union de la gauche“, in: ders., L'invention démocratique (1994), S. 129-158, hier S. 152 - Übers. d. Verf.

67 | Ders., "Droits de l'homme et politique", S. 65 - Übers. d. Verf.

68 Arendt, Hannah: Elemente und Ursprünge totaler Herrschaft, München: Piper 2009, S. 614. 
Verhältnis von Staat, Zivilgesellschaft und Menschenrechten stets umkämpft ist. Im Zentrum der demokratischen Verfassung steht die Institutionalisierung dieses Kräftemessens.

Hier wird jedoch auch deutlich, dass Lefort zwar eine für unsere Zwecke interessante Eingrenzung solcher $\gg$ Spontanbereiche ${ }^{69}$ vornimmt, die für demokratische Prozesse zwingend erforderlich sind. Er überführt den Widerspruch zwischen Herrschaftsausübung und Herrschaftskritik allerdings zu schnell in das Verhältnis von Staat und Zivilgesellschaft. Der Einwand, dass die Zivilgesellschaft doch in Analogie zur Marx'schen Kritik als eine beschränkte, verzerrende bis hin zu einer repressiven Freiheitsinstitutionalisierung zu verstehen ist, wird von Lefort mit einer Gegenhypothese konfrontiert. ${ }^{70}$ Zudem stellt sich die Frage, ob die herrschaftskritischen umori unvermittelt auf die Sphäre der Zivilgesellschaft übergreifen oder nicht auch die Anmerkung erlaubt sein muss, dass die Menschenrechte allein sowohl repressiv als auch freiheitsermöglichend wirken können. Im Frühwerk Leforts zu Machiavelli ist ein Hinweis aufzufinden, der zum Supplement führt, das für eine nichtrepressive Freiheitsinstitutionalisierung nötig ist: die Emergenz plebejischer Politikformen und ihrer Organe der Negativität, eine mise en forme 1, die der Punkt ist, von dem aus die mise en forme 2 stets wieder in die Gesellschaft zurückgenommen werden kann.

\section{Ein demokratisches Dispositiv für die Regime}

Das Volk der Demokratie ist eine paradoxe Einheit aus umfangslogischem und subaltern-positioniertem Volk, während die Souveränität des Volkes die paradoxe Einheit aus demokratischer Letztentscheidung und ständiger Anfechtbarkeit jeder Entscheidung darstellt. Dabei ist die eine Seite der Paradoxie vor der anderen privilegiert: Das subaltern-positionierte Volk verhilft letztlich in seinem Handeln demjenigen herrschaftskritischen Begehren zum Ausdruck, ohne das ein demokratisches Dispositiv niemals entstanden wäre. Es sind herrschaftskritische Gegenkreisläufe, die eine Schließung der politischen Ordnung verhindern und die Entkörperung des Machtsymbols aufrechterhalten. Die Seite der Herrschaftsausübung muss sich vor einem ständigen Tribunal behaupten. Sie kann sanktioniert und in die Gesellschaft zurückgenommen werden.

Jetzt lässt sich der Transferschritt entwickeln, auf den die Argumentation zugelaufen ist: Indem man die demokratische Verfassung als Institutiona-

69 | G. Teubner, "Privatregimes", S. 448.

70 | Dabei entgeht Leforts Antimarxismus allerdings vollkommen, dass seine Verfassungstheorie im Grunde der Marx'schen Konflikttheorie der Verfassung aus der "Kritik des Hegelschen Staatsrechts" in vielerlei Hinsicht entspricht. 
lisierung des Herrschaftskonflikts versteht, in der die Seite der Herrschaftskritik das Privileg besitzt, die andere Seite zurückzunehmen, kann sie auch auf Ordnungsbildungen jenseits des Nationalstaates übertragen werden. »Demokratische Konstitutionalisierung « wäre so zu verstehen, dass in den Eigenverfassungen der Regime ein Dispositiv entsteht, das die Kreisläufe der Herrschaftsausübung und der Herrschaftskritik aufeinander bezieht. Dabei müsste die Seite der Herrschaftskritik wirksam sein, indem sie eine privilegierte Macht der Rücknahme und Blockade über die Seite der Herrschaft ausübt. Die demokratische Konstitutionalisierung findet ihre Orientierungspunkte nicht in einer übergreifenden Weltverfassung. Sie ist auf die hegemonialen Regime und ihre ökologischen Hegemonieverhältnisse umzustellen. Dies schließt gleichermaßen eine Abkehr vom einzelnen Bürger als zentralem Lokus der Demokratie mit ein und leitet hin zur Frage, wie gegenhegemoniale Kommunikationsstrukturen auf Dauer eine destituierende Macht ausüben können.

\section{Leere}

Zunächst besteht die Herausforderung für eine so verstandene destituierende Macht darin, die Regimeverfassungen zu entleeren. Die bisherigen Betrachtungen legen nahe, dass die populare Leere, die mit der demokratischen Verfassung verknüpft war, stets von einer plebejischen Leere zehrte. Sie hatte ein hintergründiges Rücknahmeszenario präsent gehalten, das die populare Leere der konstituierten Gewalten überhaupt zu einer Möglichkeit gemacht hatte. Erst wenn das herrschaftskritische Moment auch einen Ausdruck in eigenen Organen der Negativität findet, kann eine demokratische Entkörperung der Macht stattfinden. Leere ist hier somit nicht als einfache Beliebigkeit zu verstehen. Die vom Rechtspositivismus apostrophierte Offenheit der Rechtsform wird als Effekt lesbar, den die Kämpfe sozialer Bewegungen im 19. und 20. Jahrhundert erzeugt haben. Die Offenheit des Rechts, wonach »es [...] kein menschliches Verhalten« gibt, »das als solches, kraft seines Gehalts, ausgeschlossen wäre, zum Inhalt einer Rechtsnorm zu werden « ${ }^{71}$, erscheint in einem anderen Licht. Sie ist Ausdruck einer Konstellation, in der unterschiedliche Varianten der Gesellschaftsverfassung aufeinandertrafen und sich nicht verallgemeinern konnten. Damit war der Boden für die populare Leere als konstitutioneller Effekt bereitet, der aus dem sozialen Konflikt hervorgeht.

Dieser Effekt zehrt aber von einer plebejischen Leere, die sich in eigenen Organen der Negativität verdichtet. Die Figur der destituierenden Macht überbrückt den Abstand zwischen den herrschaftskritischen umori (Machiavelli) und der Verfassung. Ähnlich wie Marx mit seiner These von der Demokratie

71 | Vgl. Kelsen, Hans: Reine Rechtslehre (1934), Tübingen: Mohr Siebeck 2009, S. 64. 
als Wahrheit aller Verfassungen davon ausging ${ }^{72}$ dass mit der Rücknahmedrohung der konstituierenden Macht auf die forces propres der Gesellschaft verwiesen wird, knüpft die destituierende Macht an jene Möglichkeit der Kritik und Distanznahme an, die bisher als Quellen gesellschaftlicher Veränderung angenommen wurden. Dies läuft nicht auf ein eindeutiges moralisches oder politisches Programm hinaus, es ist aber normativ nicht vollkommen beliebig: Eine destituierende Macht, die sich von Beginn an von der Möglichkeit der eigenen Befragung abschneidet (etwa, indem sie ein bloßes Zusammengehörigkeitsgefühl zum Ausgangspunkt wählt und lediglich akklamiert wie die verfassungsgebende Gewalt bei Schmitt), simuliert sie nur. ${ }^{73}$

Die plebejische Leere entzieht sich freilich einer vollständigen, »restlosen« Verrechtlichung. ${ }^{74}$ Im Gegensatz zu neueren Versuchen, den Begriff der destituierenden Macht auf einen vollständigen Exit aus Politik und positivem Recht hinauslaufen zu lassen ${ }^{75}$ wird hier aber ein anderer Weg eingeschlagen: Die destituierende Macht überführt die herrschaftskritischen umori in eine Form der Gegenmacht. Sie wird erst dann sichtbar, wenn sie nicht nur potentia, sondern auch potestas ist, die in Verfassungskämpfe eingreift und die Rücknahmedrohung zum Ausdruck bringt. Damit hat die destituierende Macht eine Form. Will sie zu einer dauerhaften Gegenmacht werden, wird sie auf den rechtlichen Formalismus zurückkommen, um sich selbst eine Form zu verleihen.

\section{Opposition und Kontestation}

Diese Herangehensweise weist offensichtlich einige Überschneidungen mit jüngeren Überlegungen zur Rolle von Kontestation im Völkerrecht und in den internationalen Beziehungen auf. Auch sie setzen den Untersuchungsschwerpunkt dort an, wo Offenheit und Befragbarkeit der Ordnungen jenseits des Staates eintreten. In der republikanischen Demokratietheorie wird sogar schon länger der Versuch unternommen, von kollektiver Selbstbestimmung auf rückwirkende Befragung umzustellen: ${ }^{76}$ Demnach ist der freiheitliche Gehalt demo-

72 | Vgl. K. Marx, "Kritik der Hegelschen Staatsrechts", S. $230 \mathrm{ff.}$

73 | Vgl. Schmitt, Carl: Verfassungslehre (1928), Berlin: Duncker \& Humblot 1993, S. 83.

74 | So äußerte sich schon Ingeborg Maus zur Rolle "nicht-institutionalisierter Volkssouveränität“ in: dies., Basisdemokratische Aktivitäten und rechtsstaatliche Verfassung, S. $115 \mathrm{ff}$.

75 | Vgl. Agamben, Giorgio: "What is a Destituent Power?«, in: Environment and Planning D: Society and Space $32 / 1$ (2014), S. 65-74.

76 | Vgl. Pettit, Philip: Republicanism. A Theory of Freedom and Government, Oxford: Oxford University Press 1997; Rosanvallon, Pierre: La contre-démocratie. La politique à l'âge de la défiance, Paris: Points 2008; siehe auch die Beiträge in: Niederberger, And- 
kratischer Ordnungsbildung weniger darin zu sehen, dass die Bürger als Autoren der Gesetze fungieren, sondern als Editoren: Sie müssen nachträglich die Möglichkeit haben, bestehende Entscheidungen anzufechten (kontestieren). Die Kontestationsspielräume sind dabei jedoch stark begrenzt. Die hier vorgeschlagene Destitution setzt zwar auch erst einmal negativ an, geht aber davon aus, dass jede Form der Herrschaftsausübung vom Standpunkt der destituierenden Macht aus bestritten werden kann: Bürger können nur Editoren im demokratischen Sinne sein, wenn sie den Abstand zu einer möglichen Autorschaft abmessen können.

Darüber hinaus wird zunehmend versucht, die Möglichkeitsspielräume von Opposition im Völkerrecht und in den internationalen Beziehungen abzuklären. ${ }^{77}$ Hier stellt sich die Frage, wie und ob bestehende Mechanismen, wie etwa die aufschiebenden Waiver-Ausnahmeregeln in der WTO, schon Keimformen einer »institutionalisierten Alternativität ${ }^{78}$ in sich tragen, die als Oppositionsmöglichkeiten zu kennzeichnen sind. Aus der Perspektive destituierender Macht verschiebt sich die Fragestellung hier: Kann es gelingen, solche Mechanismen zu Einfallstoren zu machen, um die inhaltliche Überformung der Regime zu zersetzen? Und wenn ja, welche Bedingungen müssen erfüllt sein, damit dies auch aussichtsreich ist? Können solche Sonderregelungen auf eine Weise politisch genutzt und aufgeladen werden, so dass sie zu einem Teil einer destituierenden Macht werden? Grundsätzlich sperrt sich die destituierende Macht gegen eine Engführung von spezifischen Akteuren und Institutionen oder Funktionssystemen. Im Kern kommt es auf die Frage an, wie gegenhegemoniale Kommunikationsstrukturen eine dauerhafte Form erlangen und wirksam werden können. Dafür spielen natürlich soziale Bewegungen eine zentrale Rolle genauso wie der Druck aus den Öffentlichkeiten. Man kann in diesem Zusammenhang freilich auch an gegenhegemoniale Regime denken, die einen Gegenpol zu den dominanten marktliberalen Regimen bilden. In den daraus erwachsenden Regimekollisionen könnte sich wenigstens eine gewisse Offenheit abzeichnen und die Möglichkeit eröffnen, die Dominanz der hegemonialen Regime zu blockieren. Zwar hatte der Argumentationsgang den nationalen Wettbewerbsstaat als Hüter der Demokratie verworfen, im Kontext einer destituierenden Macht könnten jedoch auch Staatenallianzen eine Rolle spielen, wenn sie damit beginnen, postneoliberale Kooperationsmöglichkeiten zu erschließen, oder konzertiert in den Regimen als politische Kraft auftreten.

reas/Schink, Philipp (Hg.): Republican Democracy: Liberty, Law and Politics, Edinburg: Edinburgh University Press 2013.

77 | Vgl. Wiener, Antje: A Theory of Contestation, Berlin/Heidelberg: Springer 2014;; Wolff, Jonas/Zimmermann, Lisbeth: "Between Banyans and Battle Scenes: Contestation and Democracy“, unveröffentlichtes Manuskript.

78 | I. Ley, Opposition im Völkerrecht, S. 190. 
Bisher ist der transnationale Konstitutionalismus weit von einem demokratischen Dispositiv entfernt. Eine kritische Befragung der Programme und Codes von innen her ist schwer möglich. Erst recht erscheint dort keine destituierende Macht, die auf Rücknahme drängt. Auch hat die Weltgesellschaft bisher nicht diejenigen radikaldemokratischen Geschichtszeichen hervorgebracht, die es erlauben würden, schwache Mechanismen der Mitbestimmung mit herrschaftskritischen Ambitionen zu überfluten und sie sich von der Seite der destituierenden Macht her anzueignen. Das Wechselspiel zwischen Herrschaftsausübung und Herrschaftskritik, wie es für die demokratische Verfassung kennzeichnend ist, findet in den postdemokratischen Regimen kaum Anknüpfungspunkte. Die Regimeverfassungen sind eben nicht entkörpert. Ihre Machtsymbole sind besetzt. Zwar ist hier nicht die Weltgesellschaft als übergreifender sozialer Köper repräsentiert, es liegen jedoch partiale Verkörperungen vor, die versuchen, sich mit dem Ganzen der Weltgesellschaft zu identifizieren.

Der Weg zu einem demokratischen Dispositiv wird also nur über eine Entleerung des Konstitutionalismus führen. Dies ist der Kern der demokratischen Herausforderung. Es gilt, die Orte der Macht frei zu räumen. Handlungsformen und politische Selbstorganisierungen, die darauf gerichtet sind (und in diesem Sinne selbst substantiell werden müssen), sind als Platzhalter der Demokratie zu begreifen. ${ }^{79}$ Da die demokratische Verfassung in der Weltgesellschaft ihre Haltepunkte weder im Nationalstaat oder in einer übergreifenden Weltverfassung noch in den Regimeverfassungen findet, sind es vorläufig gegenhegemoniale Kommunikationsstrukturen, die mit ihrer destituierenden Macht eine relativ klar umrissene Aufgabe haben: als destituierende Macht auf der Bühne der Weltgesellschaft zu erscheinen und die Besatzer des Machtsymbols anzufechten, indem sie es zu okkupieren versuchen. ${ }^{80}$ Damit könnte die Fülle des transnationalen Konstitutionalismus einer ausstehenden Leere weichen.

79 | In diesem Sinne wird nicht behauptet, dass politisches Handeln nur "negativ" sein darf. Im Gegenteil ist der Unterschied zwischen Beobachter- und Teilnehmerperspektive entscheidend: Eine destituierende Macht muss aus der Perspektive der Teilnehmer durchaus positiven und inhaltlichen Charakter besitzen, um überhaupt vom plebejischen Moment aus ins Politische überzugehen. Der Beobachterstandpunkt sollte jedoch vorsichtig sein, in die oftmals prekären Widerstände umfassende Programme hineinzulegen.

$\mathbf{8 0}$ | So hat die jüngere Occupy-Bewegung in ihrer Kurzlebigkeit doch einen wichtigen Kern. 



\section{Epilog: Verfassungskämpfe langer Dauer und die Wiederkehr des Plebejischen}

Schließlich legt die These vom Formwandel der Verfassung nahe, unser Nachdenken über die demokratische Verfassung folgenreich umzustellen. Das Imaginäre der Volkssouveränität, das noch für Marx, Maus, Habermas und den späten Lefort den Horizont markiert, hilft nur noch bedingt weiter. Denn dort erschien die konstituierende Macht des Volkes als verfassungsgebende Gewalt, die im Zuge der Revolution eine alte Ordnung als Ganze zersetzt und eine neue Ordnung geschaffen hatte. Die fragmentierte Hegemoniekonstellation der Weltgesellschaft ist jedoch nicht das Resultat einer demokratischen Revolution. Das umfangslogische Volk, das selbst noch für Lefort am Wahltag auf den Plan tritt, findet kein funktionales Äquivalent: Weder ist es als solches »konstituiert« noch fällt es übergreifende weltweit geltende Letztentscheidungen. Freilich gibt es in der Weltgesellschaft den Standpunkt des demos. Er ist allerdings als herrschaftskritischer »Anteil der Anteillosen « ${ }^{1} \mathrm{zu}$ begreifen. Der Standpunkt des demos ist keine fest umrissene, soziologische Einheit. Mit dem »Anteil der Anteillosen« entsteht ein symbolischer Ort, der die demokratische Verfassungsidee in der Weltgesellschaft präsent hält. Dies gilt jedoch nur - und hier ist die jüngere Euphorie für die faktische Unverfügbarkeit dieses Standpunkts zu korrigieren -, wenn er eine immanente Aktualisierung erfährt, wenn Organe der Negativität entstehen, die diesen Standpunkt in Anspruch nehmen, wenn die herrschaftskritische potentia kommunikativer Macht eine transnationale potestas als verfasste Gegenmacht ausbildet. Dabei ist das demokratische Imaginäre einem Formwandel zu unterziehen. Es sind Perioden von Ordnungskämpfen langer Dauer, die eher als Folie dienen können, um der Verfassungsevolution in der Weltgesellschaft gerecht zu werden. Die Parallele zu den Ordnungskämpfen der römischen Republik liegt auf der Hand.

Die plebejischen Sezessionen, der Auszug des Plebs auf den Heiligen Berg, Mons sacer, die Überlieferungen zufolge 494 v. Chr., 450 v. Chr. und 287 v. Chr.

1 | J. Rancière, Das Unvernehmen, S. 24. 
stattfanden, ${ }^{2}$ haben nicht nur das Mittel eines politischen Streiks genutzt, um der Herrschaftsordnung ihre Grundlage zu entziehen. Genauso ist ein Selbstorganisierungsprozess erkennbar, der seinen Ausdruck auch in einer Verfassung des Plebs gefunden hat: Sie bilden eine »Parallelordnung« aus, die ihre plebejischen Institutionen vor Angriffen schützt; sie »konstituieren sich als Gegensouverän gegen die herrschende Ordnung « ${ }^{3}$. Dabei beeiden sie ihre Verfassung als leges sacratae, als heilige und in diesem Sinne höherrangige Gesetze. Sie sind die Grundlage dafür, dass es dem Plebs schrittweise gelingt, Zugeständnisse zu erringen und die Volkstribunen als Verfassungsinstitution der römischen Republik zu etablieren. ${ }^{4}$ Hier greift das, was Cornelia Vismann einst als »Sog « beschrieben hat: »Dieser Sog zur Veröffentlichung, zur Offenlegung (hier: in der Selbstorganisation des Plebs - d. Verf.) zieht die Gemeinschaft in die Sphäre des Rechts. $\ll^{5}$

Dieser historischen Periode sind Hinweise auf die Frage zu entnehmen, wie in der postdemokratischen Verfasstheit des Transnationalen doch noch eine destituierende Macht aufscheinen kann. Es sind plebejische Politikformen, ihre Organe der Negativität (Form 1), die das Projekt einer demokratischen Konstitutionalisierung (Form 2) noch angemessen vertreten. Die »Kostüme«, »Schlachtparolen « und »altehrwürdigen Verkleidungen ${ }^{6}$ müssten so allerdings von der bürgerlichen Revolutionsepoche auf Verfassungskämpfe langer Dauer umgestellt werden. Es kommt dann auf »Praktiken der Teilung des Volks« an, die ein »zusätzliches Volk « konstituieren. Aber auch dieses »zusätzliche Volk«, der transnationale Plebs, wird eine Verfassung ausbilden, wenn er zu einer potestas

2 | Vgl. die Überlieferung von Livius, Titus: Römische Geschichte. Von der Gründung der Stadt an, Wiesbaden: matrix-Verlag 2009.

3 | Koschorke, Albrecht/Lüdemann, Susanne/Frank, Thomas/Mazza, Ethel Matala de: Der fiktive Staat. Konstruktionen des politischen Körpers in der Geschichte Europas, Frankfurt a. M.: Fischer 2007, S. 27.

4 | Siehe dazu auch I. Lorey, Figuren des Immunen, S. 281 ff. Sie zeigt, dass die vom italienischen Philosophen Giorgio Agamben bemühte Figur des "Homo Sacer" eine Immunisierungsstrategie des Plebs darstellt und nicht einfach die Keimform einer ausschließenden Souveränitätsmaschine darstellt (ebenda, S. 17). Lorey schreckt in ihrer poststrukturalistisch inspirierten Lesart der leges sacratae allerdings vor dem Verfassungsbegriff zurück und sieht vor allem eine konstituierende potentia am Werk (ebenda, S. 59); ähnlich spontan auch: M. Breaugh, The Plebeian Experience.

5 | Vismann, Cornelia: "St. Benedict, Inc. Zur Rechtsförmigkeit von Gemeinschaft", in: dies., Das Recht und seine Mittel. Ausgewählte Schriften, Frankfurt a. M.: Fischer, S. 365-393, hier S. 386.

6 | K. Marx, "Der achtzehnte Brumaire des Louis Bonaparte", S. 115.

7 | So allerdings in Bezug auf den Nationalstaat Rancière, Jacques: Der Hass der Demokratie, Berlin: August-Verlag 2012, S. 92. 
avancieren will. Die Leere der Verfassung als Form sorgt dafür, dass sie nicht auf die transnationalen Regime festgelegt ist. 



\section{Literaturverzeichnis}

Abendroth, Wolfgang: »Zum Begriff des demokratischen und sozialen Rechtsstaates im Grundgesetz der Bundesrepublik Deutschland« (1954), in: Michael Buckmiller/Joachim Perels/Uli Schöler (Hg.), Gesammelte Schriften Band 2, Hannover: Offizin-Verlag 2008, S. 338-357.

Abensour, Miguel: Democracy against the State. Marx and the Machiavellian Moment, Cambridge: Polity Press 2011.

Abouharb, M. Rodwan/Cingranelli, David: Human Rights and Structural Adjustment, Cambridge: Cambridge University Press 2007.

Ackerman, Bruce: »Constitutional Politics/Constitutional Law«, in: Yale Law Journal 99/3 (1989), S. 453-547.

Adorno, Theodor W.: Negative Dialektik (= Gesammelte Schriften. Band 6), Frankfurt a. M.: Suhrkamp 2003.

Adorno, Theodor W.: Philosophische Elemente einer Theorie der Gesellschaft (1964), Frankfurt a. M.: Suhrkamp 2008.

Agamben, Giorgio: »What is a Destituent Power?«, in: Environment and Planning D: Society and Space 32/1 (2014), S. 65-74.

Agamben, Giorgio: Höchste Armut. Ordensregeln und Lebensform, Frankfurt a. M.: S. Fischer Verlag 2012.

Agamben, Giorgio: Homo Sacer. Die souveräne Macht und das nackte Leben, Frankfurt a. M.: Suhrkamp 2002.

Aglietta, Michel: Ein neues Akkumulationsregime. Die Regulationstheorie auf dem Prüfstand, Hamburg: VSA-Verlag 2000.

Allott, Philip: »The Emerging Universal Legal System«, in: International Law Forum du Droit International 3/1 (2001), S. 12-17.

Alter, Karen J./Meunier, Sophie: »The Politics of International Regime Complexity«, in: Perspectives on Politics 7/1 (2009), S.13-24.

Amstutz, Marc: »Der zweite Text. Für eine Kritische Systemtheorie des Rechts«, in: ders./Andreas Fischer-Lescano (Hg.), Kritische Systemtheorie. Zur Evolution einer normativen Theorie, Bielefeld: transcript 2013, S. 365-395.

Amstutz, Marc: »Métissage - Zur Rechtsform in der Weltgesellschaft«, in: Fischer-Lescano/Rödl/Schmid, Europäische Gesellschaftsverfassung (2009), S. 333-351. 
Amstutz, Marc/Fischer-Lescano, Andreas (Hg.): Kritische Systemtheorie. Zur

Evolution einer normativen Theorie, Bielefeld: transcript 2013.

Angermüller, Johannes: Nach dem Strukturalismus, Bielefeld: transcript 2007. Angermüller, Johannes/Nonhoff, Martin/Herschinger, Eva/Macgilchrist, Felicitas/Reisigl, Martin/Wedl, Juliette/Wrana, Daniel/Ziem, Alexander (Hg.): Diskursforschung. Ein interdisziplinäres Handbuch, Bielefeld: transcript 2014.

Archibugi, Daniele: »Immanuel Kant, Cosmopolitan Law and Peace«, in: European Journal of International Relations 1/4 (1995), S. 429-456.

Arendt, Hannah: Elemente und Ursprünge totaler Herrschaft, München: Piper 2009 .

Aristoteles: Politik. Schriften zur Staatstheorie, Stuttgart: Reclam 2010.

Bachur, Joao Paulo: Kapitalismus und funktionale Differenzierung, BadenBaden: Nomos 2013.

Balibar, Etienne: Die Grenzen der Demokratie, Hamburg: Argument-Verlag 1993.

Balibar, Etienne: »On the Politics of Human Rights«, in: Constellations 20/1 (2013), S.18-26.

Barr, Michael S./Miller, Geoffrey P.: »Global Administrative Law. The View from Basel«, in: European Journal of International Law 17/1 (2006), S.1546.

Bauer, Otto: »Das Gleichgewicht der Klassenkräfte« (1924), in: Hans-Jörg Sandkühler/Rafael de la Vega (Hg.), Austromarxismus. Texte zu »Ideologie und Klassenkampf«, Frankfurt a. M.: Europäische Verlagsanstalt 1970, S. 79-97. Beaud, Olivier: La Puissance de l'Etat, Paris: Presses Universitaires des France 1994.

Behrens, Maria: »Global Governance«, in: Arthur Benz (Hg.), Governance Regieren in komplexen Regelsystemen, Wiesbaden: VS-Verlag 2010, S. 104124 .

Bellamy, Richard: Political Constitutionalism. A Republican Defence of the Constitutionality of Democracy, Cambridge: Cambridge University Press 2007.

Benhabib, Seyla: Another Cosmopolitanism, New York: Oxford University Press 2006.

Benjamin, Walter: »Zur Kritik der Gewalt« (1921), in: ders., Gesammelte Schriften II.1., Frankfurt a. M.: Suhrkamp 1991, S. 179-203.

Berman, Harold J.: Recht und Revolution. Die Bildung der westlichen Rechtstradition. Frankfurt a. M.: Suhrkamp 1991.

Berman, Paul S.: »Global Legal Pluralism«, in: Southern California Law Review 80/6 (2007), S. 1155-1237. 
Biebricher, Thomas/Vogelmann, Frieder: »Die Zukunft Europas zwischen Demokratie und Kapitalismus«, in: Politische Vierteljahresschrift 55/1 (2014), S. 1-17.

Bieling, Hans-Jürgen: »Die Konstitutionalisierung der Weltwirtschaft als Prozess hegemonialer Verstaatlichung«, in: Sonja Buckel/Andreas FischerLescano (Hg.), Hegemonie gepanzert mit Zwang. Zivilgesellschaft und Politik im Staatsverständnis Antonio Gramscis, Baden-Baden: Nomos 2007, S. $143-160$.

Bieling, Hans-Jürgen/Jäger, Johannes: »Global Finance and the European Economy. The Struggle over Banking Regulation«, in: Bastian Apeldoorn/Jan Drahokoupil/Laura Horn (Hg.), Contradictions and Limits of Neoliberal European Governance. From Lisbon to Lisbon, London: Palgrave Macmillan 2008, S. 87-105.

Blecher, Michael: Zu einer Ethik der Selbstreferenz oder: Theorie als Compassion. Möglichkeiten einer Kritischen Theorie der Selbstreferenz von Gesellschaft und Recht, Berlin: Duncker \& Humblot 1991.

Böckenförde, Ernst-W.: »Die Zukunft politischer Autonomie. Demokratie und Staatlichkeit im Zeichen von Globalisierung, Europäisierung und Individualisierung«, in: ders., Staat, Nation, Europa, Frankfurt a. M.: Suhrkamp 1999, S. 103-126.

Bogdandy, Armin von/Dann, Philipp/Goldmann, Matthias: »Völkerrecht als öffentliches Recht: Konturen eines rechtlichen Rahmens für Global Governance«, in: Der Staat 49/1 (2010), S. 23-50.

Bohlender, Matthias: Metamorphosen des liberalen Regierungsdenkens: Politische Ökonomie, Polizei und Pauperismus, Weilerswist: Velbrück 2007.

Boyer, Robert/Saillard, Yves (Hg.): Regulation Theory. The State of the Art, London/New York: Routledge 2001.

Brand, Ulrich/Görg, Christoph/Wissen, Markus: »Verdichtungen zweiter Ordnung. Die Internationalisierung des Staates aus einer neo-poulantzianischen Perspektive«, in: Prokla - Zeitschrift für kritische Sozialwissenschaften 147/2 (2007), S. 217-234.

Breaugh, Martin: The Plebeian Experience. A Discontinuous History of Political Freedom, New York: Columbia University Press 2013.

Brock, Lothar: »Zauberlehrlinge, oder: Die List der (Un-)Vernunft in den internationalen Beziehungen«, in: Zeitschrift für Internationale Beziehungen 14/1 (2007), S. 165-174.

Bröckling, Ulrich/Feustel, Robert (Hg.): Das Politische denken. Zeitgenössische Positionen, Bielefeld: transcript 2010.

Brunkhorst, Hauke: Critical Theory of Legal Revolutions. Evolutionary Perspectives, New York u.a.: Bloomsbury 2014.

Brunkhorst, Hauke: Das doppelte Gesicht Europas. Zwischen Kapitalismus und Demokratie. Berlin: Suhrkamp 2014. 
Brunkhorst, Hauke (Hg.): Demokratie in der Weltgesellschaft, Baden-Baden: Nomos 2009.

Brunkhorst, Hauke: »Kommentar«, in: ders. (Hg.), Karl Marx, Der 18. Brumaire des Louis Bonaparte, Frankfurt a. M.: Suhrkamp 2007, S. 133-328.

Brunkhorst, Hauke: »Legitimationsverhältnisse. Replik auf Ingeborg Maus«, in: Eberl, Transnationalisierung der Volkssouveränität (2011), S. 317-348.

Brunkhorst, Hauke: »Machbarkeitsillusionen, feierliche Erklärungen und Gesänge - Zum Verhältnis von Evolution und Revolution im Recht«, in: Calliess et al., Soziologische Jurisprudenz (2009), S. 447-464.

Brunkhorst, Hauke: Solidarität. Von der Bürgerfreundschaft zur globalen Rechtsgenossenschaft, Frankfurt a. M.: Suhrkamp 2002.

Brunkhorst, Hauke: »The Return of Crisis«, in: Kjaer/Teubner/Febbrajo, The Financial Crisis in Constitutional Perspective (2011), S. 133-171.

Brunkhorst, Hauke: »There will be Blood«, in: ders., Demokratie in der Weltgesellschaft (2009), S. 99-123.

Buckel, Sonja: Subjektivierung und Kohäsion. Zur Rekonstruktion einer materialistischen Theorie des Rechts, Weilerswist: Velbrück 2007.

Buckel, Sonja: »Von der Selbstorganisation zur Gerechtigkeitsexpertokratie. Zum Wandel der Prozeduralisierung des Allgemeinen«, in: Eberl, Transnationalisierung der Volkssouveränität (2011), S. 33-56.

Buckel, Sonja/Wissel, Jens: »State Project Europe: The Transformation of the European Border Regime and the Production of Bare Life «, in: International Political Sociology 4/1 (2010), S. 33-49.

Buck-Morss, Susan: Hegel und Haiti. Für eine neue Universalgeschichte, Berlin: Suhrkamp 2011.

Bung, Jochen: »Das Bett des Karneades. Zur Metakritik der Paradoxologie«, in: Winfried Brugger/Ulfried Neumann/Stephan Kirste (Hg.), Rechtsphilosophie im 21. Jahrhundert, Frankfurt a. M.: Suhrkamp 2008, S. 72-89.

Butler, Judith: Das Unbehagen der Geschlechter, Frankfurt a. M.: Suhrkamp 1991.

Calliess, Gralf-Peter/Fischer-Lescano, Andreas/Wielsch, Dan/Zumbansen, Peer (Hg.): Soziologische Jurisprudenz. Festschrift für Gunther Teubner, Berlin: De Gruyter 2009.

Candeias, Mario: Neoliberalismus. Hochtechnologie. Hegemonie. Grundrisse einer transnationalen kapitalistischen Produktions- und Lebensweise, Berlin/Hamburg: Argument-Verlag 2009.

Cass, Deborah Z.: The Constitutionalization of the World Trade Organisation. Legitimacy, Democracy, and Community in the International Trading System, New York: Oxford University Press 2005.

Castel, Robert: Die Metamorphosen der sozialen Frage. Eine Chronik der Lohnarbeit, Konstanz: UVK 2000. 
Chimni, B. S.: »Between Co-option and Resistance: Two Faces of Global Administrative Law«, in: NYU Journal of International Law and Politics 37/4 (2005), S.799-827.

Chimni, B. S.: »International Institutions Today: An Imperial Global State in the Making«, in: European Journal of International Law 15/1 (2004), S. 1-37.

Christodoulidis, Emilios: »Of Boundaries and >Tipping Points $<$ A Response to Gunther Teubner«, in: Social \& Legal Studies 20/2 (2011), S. 238-243.

Cohen, Jean L.: Globalization and Sovereignty. Rethinking Legality, Legitimacy, and Constitutionalism, New York: Cambridge University Press 2012.

Colliot-Thélène, Catherine: La Démocratie sans »demos«, Paris: Presses Universitaires de France 2011.

Cox, Robert W.: Production, Power and World Order. Social Forces in the Making of History, New York: Columbia University Press 1987.

Crotty, James: »Structural Causes of the Global Financial Crisis. A Critical Assessment of the New Financial Architecture«, in: Cambridge Journal of Economics 33/4 (2009), S. 563-580.

Crouch, Colin: Das befremdliche Überleben des Neoliberalismus, Frankfurt a. M.: Suhrkamp 2011.

Crouch, Colin: Post-democracy, Cambridge: Polity Press 2005.

Critchley, Simon: »Is there a Normative Deficit in the Theory of Hegemony?«, in: ders./Oliver Machart (Hg.), Laclau - A Critical Reader, New York: Routledge 2004, S. 113-122.

Cutler, Claire: »Legal Pluralism as the >Common Sense< of Transnational Capitalism«, in: Oñati Socio-Legal Series 3/4 (2013), S. 719-740.

Cutler, Claire: Private Power and Global Authority. Transnational Merchant Law in the Global Political Economy, Cambridge: Cambridge University Press 2003.

Cutler, Claire A./Gill, Stephen (Hg.): New Constitutionalism and World Order, Cambridge: Cambridge University Press 2014.

Daase, Christopher/Deitelhoff, Nicole: Zur Rekonstruktion globaler Herrschaft aus dem Widerstand, Frankfurt a. M.: Working-Paper Projekt »Internationale Dissidenz«, 1/2014.

Danvivathana, Pornchai: »Thailand's Experience in the WTO Dispute Settlement System, Challenging the WTO Sugar Regime«, in: Gregory C. Shaffer/Ricardo Meléndez-Ortiz (Hg.), Dispute Settlement in the WTO. The Developing Country Experience, New York: Cambridge University Press 2010, S. 210-229.

Deleuze, Gilles/Guattari, Félix: Tausend Plateaus. Kapitalismus und Schizophrenie, Berlin: Merve 1997.

Demirovic, Alex (Hg.): Komplexität und Emanzipation. Kritische Gesellschaftstheorie und die Herausforderung der Systemtheorie, Münster: Westfälisches Dampfboot 2001. 
Demirovic, Alex: »Neoliberalismus und Hegemonie«, in: Christoph Butterwegge/Bettina Lösch/Ralf Ptak (Hg.), Neoliberalismus. Analysen und Alternativen, Wiesbaden: VS-Verlag 2008, S. 17-33.

Derrida, Jacques: Gesetzeskraft. Der mystische Grund der Autorität, Frankfurt a. M.: Suhrkamp 1991.

Derrida, Jacques: Schurken. Zwei Essays über die Vernunft, Frankfurt a. M.: Suhrkamp 2003.

Dimitrova, Petja/Egermann, Eva/Holert, Tom/Kastner, Jens/Schaffer, Johanna: Regime. Wie Dominanz organisiert und Ausdruck formalisiert wird, Münster: edition assemblage 2012.

Dobner, Petra: »More Law, Less Democracy? Democracy and Transnational Constitutionalism «, in: dies./Loughlin, The Twilight of Constitutionalism? (2010), S. 141-161.

Dobner, Petra/Loughlin, Martin (Hg.): The Twilight of Constitutionalism?, New York: Oxford University Press 2010.

Dolzer, Rudolf/Stevens, Margarete: Bilateral Investment Treaties, Den Haag: Martinus Nijhoff Publishers 1995.

Douzinas, Costas: The End of Human Rights, Oxford: Hart Publishing 2000.

Douzinas, Costas: »The Paradoxes of Human Rights«, in: Constellations 20/1 (2013), S. 51-67.

Draper, Hal: Karl Marx's Theory of Revolution III. The »Dictatorship of the Proletariat«, New York: Monthly Review Press 1986.

Eberl, Oliver: Demokratie und Frieden. Kants Friedensschrift in den Kontroversen der Gegenwart, Baden-Baden: Nomos 2008.

Eberl, Oliver: »Die Gewaltentrennung. Sieyes' Begründung eines >französischen Modells< der vertikalen Gewaltenteilung«, in: Ulrich Thiele (Hg.), Volkssouveränität und Freiheitsrechte. Emmanuel Joseph Sieyes' Staatsverständnis, Baden-Baden: Nomos 2009, S. 191-210.

Eberl, Oliver (Hg.): Transnationalisierung der Volkssouveränität. Radikale Demokratie diesseits und jenseits des Staates, Stuttgart: Steiner-Verlag 2011.

Eberl, Oliver/Rödl, Florian: »Kritische Politische Ökonomie und radikale Demokratietheorie. Eine Begegnung auf der Suche nach der postneoliberalen Weltrechtsordnung «, in: Kritische Justiz 43/4 (2010), S. 416-430.

Elster, Jon: Ulysses and the Sirens. Studies in Rationality and Irrationality, Cambridge: Cambridge University Press 1979.

European Comission: European Governance - A White Paper, COM(2001) 428, Brussels 2001.

Farzin, Sina: Inklusion und Exklusion. Entwicklungen und Probleme einer systemtheoretischen Unterscheidung, Bielefeld: transcript 2006.

Farzin, Sina/Opitz, Sven/Stäheli, Urs (Hg.): Theorien der Inklusion/Exklusion: Rhetorik - Körper - Macht (= Soziale Systeme 14/2), Stuttgart: Lucius \& Lucius 2008. 
Fassbender, Bardo: The United Nations Charta as the Constitution of the International Community, Leiden/Boston: Martinus Nijhoff Publishers 2009.

Feichtner, Isabel: The Law and Politics of WTO Waivers. Stability and Flexibility in Public International Law, Cambridge: Cambridge University Press 2011.

Femia, Pasquale: »Infrasystemische Subversion«, in: Amstutz/Fischer-Lescano, Kritische Systemtheorie (2013), S. 305-326.

Fischer-Lescano, Andreas: Globalverfassung: Die Geltungsbegründung der Menschenrechte, Weilerswist: Velbrück 2005.

Fischer-Lescano, Andreas: »Kritische Systemtheorie Frankfurter Schule«, in: Gralf-Peter Calliess /Andreas Fischer-Lescano/Dan Wielsch/Peer Zumbansen (Hg.), Soziologische Jurisprudenz, Berlin: De Gruyter 2009, S. 49-68.

Fischer-Lescano, Andreas: Rechtskraft, Berlin: August-Verlag 2013.

Fischer-Lescano, Andreas/Buckel, Sonja: »>Democrazia operaia<? Hegemonietheoretische Überlegungen für ein aktualisiertes Recht auf politischen Streik«, in: Jochen Bung/Brian Valerius/Sascha Ziemann (Hg.): Normativität und Rechtskritik (=Archiv für Rechts- und Sozialphilosophie Beiheft 114), Stuttgart: Steiner-Verlag 2007, S. 238-256.

Fischer-Lescano, Andreas/Christensen, Ralph: »Auctoritatis Interpositio. Die Dekonstruktion des Dezisionismus durch die Systemtheorie«, in: Der Staat 44/2 (2005), S. 213-241.

Fischer-Lescano, Andreas /Möller, Kolja: Der Kampf um globale soziale Rechte. Zart wäre das Gröbste, Berlin: Wagenbach 2012.

Fischer-Lescano, Andreas/Rödl, Florian/Schmid, Christoph (Hg.): Europäische Gesellschaftsverfassung. Zur Konstitutionalisierung sozialer Demokratie in Europa, Baden-Baden: Nomos 2009.

Fischer-Lescano, Andreas/Teubner, Gunther: »Cannibalizing Epistemes: Will Modern Law Protect Traditional Cultural Expressions?«, in: Christoph Beat Graber/Mira Burri-Nenova (Hg.), Intellectual Property and Traditional Cultural Expressions in a Digital Environment, Cheltenham: Edward Elgar 2008, S. $17-45$.

Fischer-Lescano, Andreas/Teubner, Gunther: Regime-Kollisionen. Zur Fragmentierung des globalen Rechts, Frankfurt a. M.: Suhrkamp 2006.

Fögen, Marie Theres: Das Lied vom Gesetz, München: Carl Friedrich von Siemens Stiftung 2007.

Foucault, Michel: Der Wille zum Wissen (= Sexualität und Wahrheit I), Frankfurt a. M.: Suhrkamp 1987.

Foucault, Michel: Dits et Ecrits 3, Frankfurt a. M.: Suhrkamp 2003.

Foucault, Michel: »Gespräch mit Michel Foucault«, in: ders., Dits et Ecrits 3 (2003), S. 186-213.

Foucault, Michel: »Mächte und Strategien«, in: ders., Dits et Ecrits 3 (2003), S. $538-550$. 
Foucault, Michel: Sicherheit, Territorium, Bevölkerung (= Geschichte der Gouvernementalität 1), Frankfurt a. M.: Suhrkamp 2004.

Fraenkel, Ernst: »Die politische Bedeutung des Arbeitsrechts« (1932), in: ders.: Reformismus und Pluralismus, Hamburg: Hoffmann und Campe 1973, S. 60-72.

Frankenberg, Günter: »Partisanen der Rechtskritik. Critical Legal Studies etc.«, in: Sonja Buckel/Andreas Fischer-Lescano/Ralph Christensen (Hg.), Neuere Theorien des Rechts, Stuttgart: Lucius \& Lucius 2006, S. 97-116.

Fraser, Nancy: Scales of Justice. Reimagining Political Space in a Globalized World, New York: Columbia University Press 2010.

Frowein, Jochen A.: »Konstitutionalisierung des Völkerrechts«, in: Berichte der Deutschen Gesellschaft für Völkerrecht, Band 39 (2000), S. 427-448.

Gaus, Daniel: »Rational Reconstruction as a Method of Political Theory between Social Critique and Empirical Political Science«, in: Constellations 20/4 (2013), S. 553-570.

Gill, Stephen: »Constitutionalizing Inequality and the Clash of Globalizations«, in: International Studies Review 4/2 (2002), S. 47-65.

Gill, Stephen: »European Governance and New Constitutionalism: Economic and Monetary Union and Alternatives to Disciplinary Neoliberalism in Europe«, in: New Political Economy 3/1 (1998), S. 5-26.

Gill, Stephen: »New Constitutionalism, Democratisation and Global Political Economy«, in: Pacifica Review: Peace, Security \& Global Change 10/1 (1998), S. 23-38.

Goldmann, Matthias: Internationale öffentliche Gewalt. Handlungsformen internationaler Institutionen im Zeitalter der Globalisierung, Heidelberg: Springer 2015.

Goncalves, Guilherme L.: Il Rifugio delle Aspettative. Saggio sulla Certezza del Diritto, Lecce/Rovato: Pensa Multimedia, 2013.

Gramsci, Antonio: Gefängnishefte (= kritische Gesamtausgabe), hg. v. Klaus Bochmann/Wolfgang Fritz Haug, Hamburg: Argument-Verlag $1991 \mathrm{ff}$.

Gregorrato, Federica: Il doppio volto della comunicazione. Normatività, dominio e critica nell'opera di Jürgen Habermas, Mailand/Udine: Mimesis 2013.

Grimm, Dieter: Die Zukunft der Verfassung, Frankfurt a. M. Suhrkamp 1991.

Grimm, Dieter: Die Zukunft der Verfassung II, Berlin: Suhrkamp 2012.

Grimm, Dieter: Souveränität. Herkunft und Zukunft eines Schlüsselbegriffs, Berlin: Berlin University Press 2009.

Grimm, Dieter: »The Achievement of Constitutionalism in a Changed World «, in: Dobner/Loughlin, The Twilight of Constitutionalism? (2010), S.3-22. 
Günther, Klaus: »Rechtspluralismus und universaler Code der Legalität: Globalisierung als rechtstheoretisches Problem«, in: Lutz Wingert/Klaus Günther (Hg.), Die Öffentlichkeit der Vernunft und die Vernunft der Öffentlichkeit. Festschrift für Jürgen Habermas, Frankfurt a. M.: Suhrkamp 2001, S. 539-567.

Habermas, Jürgen: Die postnationale Konstellation. Politische Essays, Frankfurt a. M.: Suhrkamp 1998.

Habermas, Jürgen: Faktizität und Geltung, Frankfurt a. M.: Suhrkamp 1992.

Habermas, Jürgen: »Hat die Konstitutionalisierung des Völkerrechts noch eine Chance?«, in: ders., Der gespaltene Westen, Frankfurt a. M.: Suhrkamp 2004, S. 113-193.

Habermas, Jürgen: »Naturrecht und Revolution« (1963), in ders., Theorie und Praxis. Sozialphilosophische Studien, Frankfurt a. M.: Suhrkamp 1972, S. 89-127.

Habermas, Jürgen: Stichworte zu einer Diskurstheorie des Rechts und des demokratischen Rechtsstaats, in: ders. (Hg.), Im Sog der Technokratie, Berlin: Suhrkamp 2013, S. 67-81.

Habermas, Jürgen: Strukturwandel der Öffentlichkeit, Frankfurt a. M.: Suhrkamp 1962.

Habermas, Jürgen: Theorie des kommunikativen Handelns I, Frankfurt a. M.: Suhrkamp 1984 .

Habermas, Jürgen: Theorie des kommunikativen Handelns II (1981), Frankfurt a. M.: Suhrkamp 1995.

Habermas, Jürgen: Zur Rekonstruktion des historischen Materialismus, Frankfurt a. M.: Suhrkamp 1976.

Habermas, Jürgen: Zur Verfassung Europas, Berlin: Suhrkamp 2011.

Hall, Stuart: »Cultural Identity and Diaspora«, in: Jonathan Rutherford (Hg.): Identity. Community, Culture, Difference, London: Lawrence \& Wishart 1990, S. 222-237.

Haltern, Ulrich: »Internationales Verfassungsrecht? Anmerkungen zu einer kopernikanischen Wende«, in: Archiv des Öffentlichen Rechts 128/4 (2003), S. 511-557.

Hardt, Michael/Negri, Antonio: Commonwealth, Cambridge: Harvard University Press 2009.

Hart, H. L. A.: The Concept of Law (1961), Oxford: Oxford University Press 2012. Hasenclever, Andreas/Mayer, Peter/Rittberger, Volker: Theories of International Regimes, Cambridge: Cambridge University Press 1997.

Hayek, Friedrich A.: The Constitution of Liberty, Chicago: Chicago University Press 1978.

Hegel, Georg W. F.: Grundlinien der Philosophie des Rechts (1821) (= Werke. Band 7), Frankfurt a. M.: Suhrkamp 1986. 
Held, David/Archibugi, Daniele (Hg.): Cosmopolitan Democracy. An Agenda for a New World Order, Cambridge: Polity Press 1995.

Hirsch, Michael: Die zwei Seiten der Ent-Politisierung. Zur politischen Theorie der Gegenwart, Stuttgart: Steiner-Verlag 2007.

Hirschl, Ran: »The Political Origins of the New Constitutionalism«, in: Indiana Journal of Global Legal Studies 11/1 (2004), S. 71-108.

Hirschl, Ran: Towards Juristocracy. The Origins and Consequences of New Constitutionalism, Cambridge/London: Harvard University Press 2004.

Hitzel-Cassagnes, Tanja: Die Verfassung des Transnationalen, Baden-Baden: Nomos 2012.

Holmes, Pablo: Verfassungsevolution in der Weltgesellschaft. Differenzierungsprobleme des Rechts und der Politik im Zeitalter der Global Governance, Baden-Baden: Nomos 2013.

Honneth, Axel: Das Recht der Freiheit. Grundriß einer demokratischen Sittlichkeit, Berlin: Suhrkamp 2011.

Höpner, Martin/Schäfer, Armin: Die Politische Ökonomie der europäischen Integration, Frankfurt a. M./New York: Campus 2008.

Horkheimer, Max: Zur Kritik der instrumentellen Vernunft, Frankfurt a. M.: Fischer-Verlag 1967.

Horst, Johan: »Politiken der Entparadoxierung: Versuch einer Bestimmung des Politischen in der funktional ausdifferenzierten Weltgesellschaft «, in: Amstutz/Fischer-Lescano, Kritische Systemtheorie (2013), S.189-212.

Howarth, David R./Norval, Aletta J./Stavrakakis, Yannis: Discourse Theory and Political Analysis. Identities, Hegemonies and Social Change, Manchester: Manchester University Press 2000.

ICSID, Aguas del Tunari S.A. v. Republic of Bolivia (ICSID Case No. ARB / O2/3); CMS Gas Transmission Company v. Argentine Republic (ICSID Case No. ARB /O1/8); Compañía de Aguas del Aconquija S.A. and Vivendi Universal S.A. v. Argentine Republic (ICSID Case No. ARB/97/3).

ILC Study Group (Hg.): Fragmentation of International Law: Difficulties Arising from the Diversification and Expansion of International Law, Genf 2006.

Illing, Marc/Paulin, Graydon: »Basel II and the Cyclicality of Bank Capital«, in: Canadian Public Policy 31/2 (2005), S. 161-180.

Isaac, Jeffrey C.: »The Lion's Skin of Politics. Marx on Republicanism«, in: Polity 22/3 (1990), S. 59-85.

Iseli, Andrea: »Bonne Police«. Frühneuzeitliches Verständnis von der guten Ordnung eines Staates in Frankreich, Epfendorf: bibliotheca academica Verlag 2003.

Iseli, Andrea: Gute Policey. Öffentliche Ordnung in der frühen Neuzeit, Stuttgart: UTB 2009 . 
Jäger, Johannes: Bankenregulierung in der Krise (= Working Paper Series by the University of Applied Sciences bfi Vienna 59/2010), Wien 2010. Jessop, Bob: The Future of the Capitalist State, Cambridge: Polity Press 2002. Jessop, Bob: »Zur Relevanz von Luhmanns Systemtheorie und von Laclau und Mouffes Diskursanalyse für die Weiterentwicklung der materialistischen Staatstheorie«, in: Joachim Hirsch/John Kannankulam/Jens Wissel (Hg.), Der Staat der bürgerlichen Gesellschaft. Zum Staatsverständnis von Karl Marx, Baden-Baden: Nomos 2008, S. 157-179.

Joerges, Christian: »Recht und Politik in der Krise Europas«, in: Merkur 66/11 (2012), S. 1013-1024.

Joerges, Christian/Trubek, David M. (Hg.): Critical Legal Thought. An American-German Debate, Baden-Baden: Nomos 1989.

Joseph, Sarah: Blame it on the WTO? A Human Rights Critique, Oxford: Oxford University Press 2011.

Justi, Johann Heinrich Gottlob von: Grundsätze der Policeywissenschaft, Göttingen: W. Vandenhoek 1782.

Kalyvas, Andreas: »Constituent Power«, in: Political Concepts. A Critical Lexicon (http://www.politicalconcepts.org/constituentpower/), S. 1-13.

Kannankulam, John/Georgi, Fabian: Die europäische Integration als materielle Verdichtung von Kräfteverhältnissen. Hegemonieprojekte im Kampf um das »Staatsprojekt Europa (= Arbeitspapier der Forschungsgruppe Europäische Integration an der Philipps-Universität 30), Marburg 2012.

Kant, Immanuel: Zum Ewigen Frieden (1796), in: ders., Werke. Band 9, Darmstadt: Wissenschaftliche Buchgesellschaft 1964.

Kantorowitz, Ernst H.: The King's Two Bodies. A Study in Mediaeval Political Theology, Princeton: Princeton University Press 1957.

Kapstein, Ethan B.: »Resolving the Regulator's Dilemma. International Coordination of Banking Regulations«, in: International Organization 43/2 (1989), S. 323-347.

Karakayali, Serhat/Tsianos, Vassilis: »Das Regieren der Migration. Jenseits von Inklusion und Exklusion«, in: Soziale Systeme 14/2 (2008), S. 329-348.

Karavas, Vagias: »Governance of Virtual Worlds and the Quest for a Digital Constitution«, in: Christoph Beat Graber/Mira Burri-Nenova (Hg.), Governance of Digital Game Environments and Cultural Diversity. Transdisciplinary Enquiries, Cheltenham: Edward Elgar 2009, S.153-169.

Keane, John: The Life and Death of Democracy, London: Simon \& Schuster 2009.

Kelsen, Hans: Reine Rechtslehre (1934), Tübingen: Mohr Siebeck 2009.

Kelsen, Hans: Vom Wesen und Wert der Demokratie, Tübingen: Mohr Siebeck 1920.

Kennedy, David: »Law and the Political Economy of the World«, in: Leiden Journal of International Law 26/1 (2013), S. 7-48. 
Kennedy, Duncan: A Critique of Adjudication, Cambridge/London: Harvard University Press 1997.

Kennedy, David: »The International Human Rights Movement: Part of the Problem?, in: Harvard Human Rights Journal 15 (2002), S. 101-125.

Kennedy, Duncan: »A Left Phenomenological Critique of the Hart/Kelsen Theory of Legal Interpretation«, in: Kritische Justiz 40/3 (2007), S. 296-305.

Kennedy, Duncan: »Comment on Rudolf Wiethölter's >Materialization and Proceduralization in Modern Law<, and >Proceduralization of the Category of Law« (1989), in: German Law Journal 12/1 (2011), S. 474-487.

Keohane, Robert O./Macedo, Stephen/Moravscik, Andrew: »Democracy Enhancing Multilateralism«, in: International Organization 63/1 (2009), S. 1-31.

Kessler, Oliver: Die internationale Politische Ökonomie des Risikos. Eine Analyse am Beispiel der Diskussion um die Reformierung der Finanzmärkte, Wiesbaden: VS-Verlag 2008.

King, Michael R./Sinclair, Timothy J.: »Private Actors and Public Policy. A New Requiem for the New Basel Accord «, in: International Political Science Review 24/3 (2003), S. 345-362.

Kirchheimer, Otto: »Zur Staatslehre von Sozialismus und Bolschewismus«, in: Wolfgang Luthardt (Hg.), Von der Weimarer Republik zum Faschismus: Die Auflösung der demokratischen Rechtsordnung, Frankfurt a. M.: Suhrkamp 1976, S. 32-52.

Kjaer, Poul F.: Constitutionalism in the Global Realm. A Sociological Approach, London/New York: Routledge 2014.

Kjaer, Poul F.: »The Metamorphosis of the Functional Synthesis: A Continental European Perspective on Governance, Law and the Political in the Transnational Space«, in: Wisconsin Law Review 2010/2 (2010), S. 489-534.

Kjaer, Poul F./Teubner, Gunther/Febbrajo, Alberto (Hg.): The Financial Crisis in Constitutional Perspective. The Dark Side of Functional Differentiation, Oxford: Hart Publishing 2011.

Kleinlein, Thomas: Konstitutionalisierung im Völkerrecht. Konstruktion und Elemente einer idealistischen Völkerrechtslehre, Berlin: Springer 2012.

Kohler-Koch, Beate/Quittkat, Christine: Die Entzauberung partizipativer Demokratie. Zur Rolle der Zivilgesellschaft bei der Demokratisierung von EU-Governance, Frankfurt a. M./New York: Campus 2010.

Koschorke, Albrecht/Lüdemann, Susanne/Frank, Thomas/Mazza, Ethel Matala de: Der fiktive Staat. Konstruktionen des politischen Körpers in der Geschichte Europas, Frankfurt a. M.: Fischer 2007.

Koselleck, Reinhart: Begriffsgeschichten. Studien zur Semantik und Pragmatik der politischen und sozialen Sprache, Frankfurt a. M.: Suhrkamp 2006. 
Koskenniemi, Martti: »Constitutionalism as Mindset. Reflections on Kantian Themes about International Law and Globalization«, in: Theoretical Inquiries in Law 8/1 (2007), S. 9-36.

Koskenniemi, Martti: From Apology to Utopia. The Structure of International Legal Argument, Cambridge: Cambridge University Press 2005.

Koskenniemi, Martti: »Hegemonic Regimes«, in: Margaret A. Young (Hg.), Regime Interaction in International Law, Cambridge: Cambridge University Press 2012, S. 305-324.

Koskenniemi, Martti: »Hierarchy in International Law. A Sketch«, in: European Journal of International Law 8/4 (1997), S. 566-582.

Koskenniemi, Martti: »International Law and Hegemony. A Reconfiguration«, in: Cambridge Review of International Affairs 17/2 (2004), S. 197-218.

Koskenniemi, Martti: The Gentle Civilizer of Nations, Cambridge: Cambridge University Press 2002.

Koskenniemi, Martti: »The Politics of International Law«, in: European Journal of International Law 1/1 (1990), S. 4-32.

Koskenniemi, Martti: »The Politics of International Law - 20 Years Later«, in: European Journal of International Law 20/1 (2009), S. 7-19.

Koskenniemi, Martti: »What Should International Lawyers Learn from Karl Marx?«, in: Leiden Journal of International Law 17/2 (2004), S. 229-246.

Koskenniemi, Martti: »What Use for Sovereignty Today?«, in: Asian Journal of International Law 1/1 (2011), S. 61-70.

Krajewski, Markus: Verfassungsperspektiven und Legitimation des Rechts der Welthandelsorganisation, Berlin: Duncker \& Humblot 2001.

Krajewski, Markus: Wirtschaftsvölkerrecht, Heidelberg: C. F. Müller 2009.

Krasner, Stephen D.: »Structural Causes and Regime Consequences: Regimes as Intervening Variables«, in: International Organization 36/2 (1982), S. $185-205$.

Kratochwil, Friedrich: The Status of Law in World Society. Meditations on the Role and the Rule of Law, Cambridge: Cambridge University Press 2014.

Kreck, Lena: »Möglichkeiten und Grenzen des rechtlichen Schutzes für Umweltflüchtlinge«, in: Kritische Justiz 44/2 (2011), S. 178-184.

Kreide, Regina: »Re-embedding the Market Through Law?« in: Christian Joerges/Josef Falke (Hg.), Karl Polanyi. Globalization and the Potential of Law in Transnational Market, Oxford/Portland: Hart Publishing, S. 42-64.

Kriegel, Blandine: The State and the Rule of Law, Princeton: Princeton University Press 1995 .

Krisch, Nico: Beyond Constitutionalism. The Pluralist Structure of Postnational Law, Oxford: Oxford University Press 2010.

Kumm, Mattias: »The Cosmopolitan Turn in Constitutionalism. An Integrated Conception of Public Law«, in: Indiana Journal of Global Legal Studies 20/2 (2013), S. 605-628. 
Laclau, Ernesto: Emanzipation und Differenz, Wien: Turia + Kant 2002.

Laclau, Ernesto: »Ethics, Normativity and the Heteronomy of Law«, in: ders., The Rhetorical Foundations of Society (2014), S.127-138.

Laclau, Ernesto: New Reflections on the Revolution of our Time, London/New York: Verso 1990.

Laclau, Ernesto: On Populist Reason, London/New York: Verso 2005.

Laclau, Ernesto: »On the Names of God«, in: ders., The Rhetorical Foundations of Society (2014), S. 37-52.

Laclau, Ernesto: »The Death and the Resurrection of the Theory of Ideology«, in: ders., The Rhetorical Foundations of Society (2014), S. 11-36.

Laclau, Ernesto: The Rhetorical Foundations of Society, London/New York: Verso 2014 .

Laclau, Ernesto: »Was haben leere Signifikanten mit Politik zu tun?«, in: ders., Emanzipation und Differenz (2002), S. 65-78.

Laclau, Ernesto/Mouffe, Chantal: Hegemonie und radikale Demokratie. Zur Dekonstruktion des Marxismus, Wien: Passagen-Verlag 1991.

Ladeur, Karl-Heinz: »Die Evolution des Rechts und die Möglichkeit eines >globalen Rechts< jenseits des Staates - zugleich eine Kritik der >Selbstkonstitutionalisierungsthese «, in: ancilla iuris (2012), S. 220-255.

Ladeur, Karl-Heinz/Viellechner, Lars: »Die transnationale Expansion staatlicher Grundrechte. Zur Konstitutionalisierung globaler Privatrechtsregimes«, in: Archiv des Völkerrechts 46/1 (2008), S. 42-73.

Lang, Andrew: World Trade after Neoliberalism. Reimagining the Global Economic Order, Oxford: Oxford University Press 2011.

Lefort, Claude: »Die Frage der Demokratie«, in: Ulrich Rödl (Hg.), Autonome Gesellschaft und libertäre Demokratie, Frankfurt a. M.: Suhrkamp 1990, S. 281-357.

Lefort, Claude: »Droits de l'homme et politique«, in: ders., L'invention démocratique (1994), S. 43-83.

Lefort, Claude: »La logique totalitaire«, in: ders., L'invention démocratique (1994), S. 85-106.

Lefort, Claude: Le travail de l'œuvre Machiavel (1972), Paris: Gallimard 1986.

Lefort, Claude: »L'image du corps et le totalitarisme«, in: ders., L'invention démocratique (1994), S.159-176.

Lefort, Claude: »L'impensée de l'union de la gauche«, in: ders., L'invention démocratique (1994), S. 129-158.

Lefort, Claude: L'invention démocratique. Les limites de la domination totalitaire (1981), Paris: Fayard 1994.

Lefort, Claude: »Préface«, in: ders., L'invention démocratique (1994), S. I-IX.

Ley, Isabelle: Opposition im Völkerrecht. Ein Beitrag zur Legitimation internationaler Rechtserzeugung, Heidelberg u.a.: Springer 2015. 
Lindahl, Hans: »Constituent Power and Reflexive Identity. Towards an Ontology of Collective Self-hood«, in: Martin Loughlin/Neil Walker (Hg.), The Paradox of Constitutionalism. Constituent Power and Constitutional Form, Oxford: Oxford University Press 2007, S. 9-24.

Liste, Philip: Völkerrecht-Sprechen. Die Konstruktion demokratischer Völkerrechtspolitik in den USA und der Bundesrepublik Deutschland, BadenBaden: Nomos 2012.

Livius, Titus: Römische Geschichte. Von der Gründung der Stadt an, Wiesbaden: matrix-Verlag 2009.

Loick, Daniel: Kritik der Souveränität, Frankfurt a.M./New York: Campus 2012.

Lorey, Isabelle: Figuren des Immunen. Elemente einer politischen Theorie, Zürich: diaphanes 2011.

Loughlin, Martin: The Idea of Public Law, Oxford: Oxford University Press 2004.

Luhmann, Niklas: Das Recht der Gesellschaft, Frankfurt a. M.: Suhrkamp 1993.

Luhmann, Niklas: Die Gesellschaft der Gesellschaft I, Frankfurt a. M.: Suhrkamp 1998.

Luhmann, Niklas: Die Gesellschaft der Gesellschaft II, Frankfurt a. M.: Suhrkamp 1998.

Luhmann, Niklas: Die Kunst der Gesellschaft, Frankfurt a. M.: Suhrkamp 1997.

Luhmann, Niklas: »Die Paradoxie der Form«, in: Dirk Baecker (Hg.), Kalkül der Form, Frankfurt a. M.: Suhrkamp 1993, S. 197-215.

Luhmann, Niklas: Die Politik der Gesellschaft, Frankfurt a.M.: Suhrkamp 2000.

Luhmann, Niklas: »Die Weltgesellschaft« (1971), in: ders., Soziologische Aufklärung 2. Aufsätze zur Theorie der Gesellschaft, Wiesbaden: VS-Verlag 2005, S. 63-88.

Luhmann, Niklas: »Einige Probleme mit >reflexivem Recht«, in: Zeitschrift für Rechtssoziologie 6/1 (1985), S.1-18.

Luhmann, Niklas: Grundrechte als Institution (1965), Berlin: Duncker \& Humblot 1999 .

Luhmann, Niklas: »Inklusion und Exklusion« (1995), in: ders., Soziologische Aufklärung 6. Die Soziologie und der Mensch, Wiesbaden: VS-Verlag 2008, S. 226-251.

Luhmann, Niklas: »Jenseits der Barbarei«, in: ders., Gesellschaftsstruktur und Semantik. Studien zur Wissenssoziologie der modernen Gesellschaft, Frankfurt a. M.: Suhrkamp 1999, S. 138-150.

Luhmann, Niklas: »Kausalität im Süden«, in: Soziale Systeme 1/1 (1995), S. 7-28. 
Luhmann, Niklas: »Observing Re-entries«, in: Graduate Faculty Philosophy Journal 16/2 (1993), S. 485-498.

Luhmann, Niklas: Protest. Systemtheorie und Soziale Bewegungen, hg. v. Kai Uwe-Hellmann, Frankfurt a. M.: Suhrkamp 1996.

Luhmann, Niklas: Soziale Systeme. Grundriß einer allgemeinen Theorie, Frankfurt a. M.: Suhrkamp 1984 .

Luhmann, Niklas: »Systemtheoretische Argumentationen. Eine Entgegnung auf Jürgen Habermas«, in: Jürgen Habermas/Niklas Luhmann, Theorie der Gesellschaft oder Sozialtechnologie, Frankfurt a. M.: Suhrkamp 1971, S. 291-405.

Luhmann, Niklas: »Verfassung als evolutionäre Errungenschaft«, in: Rechtshistorisches Journal 9 (1990), S. 176-220.

Luxemburg, Rosa: »Massenstreik, Partei und Gewerkschaften« (1906), in: dies., Politische Schriften I, Frankfurt a.M.: Europäische Verlagsanstalt 1967, S. 135-228.

Machiavelli, Niccolò: Discorsi (1531), Frankfurt a. M./Leipzig: Insel-Verlag 2000.

Machiavelli, Niccolò: Il Principe/Der Fürst (1532), Stuttgart: Reclam 2003.

Majone, Giandomenico: Dilemmas of European Integration. The Ambiguities and Pitfalls of Integration by Stealth, Oxford: Oxford University Press 2005.

Majone, Giandomenico: Regulating Europe, London/New York: Routledge 1996.

Marchart, Oliver: Das unmögliche Objekt. Eine postfundamentalistische Theorie der Gesellschaft, Berlin: Suhrkamp 2013.

Marchart, Oliver: Die politische Differenz. Zum Denken des Politischen bei Nancy, Lefort, Badiou, Laclau und Agamben, Berlin: Suhrkamp 2010.

Marchart, Oliver: »Gesellschaft ohne Grund. Laclaus Theorie des Post-Foundationalism«, in: Laclau, Emanzipation und Differenz (2002), S. 7-18.

Marchart, Oliver: »Politik ohne Fundament. Das Politische, der Staat und die Unmöglichkeit der Gesellschaft bei Ernesto Laclau und Chantal Mouffe«, in: Michael Hirsch/Rüdiger Voigt (Hg.), Der Staat in der Postdemokratie. Staat, Politik, Demokratie und Recht im neueren französischen Denken, Stuttgart: Steiner-Verlag 2009, S. 133-144.

Marcuse, Herbert: »Repressive Toleranz«, in: Robert Paul Wolff/Barrington Moore/ders., Kritik der reinen Toleranz, Frankfurt a. M.: Suhrkamp 1966, S. 91-128.

Margulis, Matias E.: »The Regime Complex for Food Security: Implications for the Global Hunger Challenge«, in: Global Governance: A Review of Multilateralism and International Organizations 19/1 (2013), S. 53-67.

Marks, Susan: »False Contingency«, in: Current Legal Problems 62/1 (2009), S. 1-21. 
Marks, Susan: The Riddle of all Constitutions. International Law, Democracy, and the Critique of Ideology, New York: Oxford University Press 2000.

Marx, Karl: »Das Kapital« (1864), in: ders./Engels, Friedrich, Werke. Band 23, Berlin: Dietz 1972.

Marx, Karl: »Der achtzehnte Brumaire des Louis Bonaparte« (1852), in: ders./ Friedrich Engels, Werke. Band 8, Berlin: Dietz 1960, S.111-207.

Marx, Karl: »Die Deutsche Ideologie« (1846), in: ders./Friedrich Engels: Werke. Band 3, Berlin: Dietz 1969, S. 5-530.

Marx, Karl: »Kritik des Hegelschen Staatsrechts« (1843), in: ders./Engels: Werke. Band 1, Berlin: Dietz 1976, S. 203-333.

Marx, Karl: »Zur Judenfrage« (1843), in: ders./Engels: Werke. Band 1 (1976), S. 347-377.

Marx, Karl: »Zur Kritik der politischen Ökonomie« (1859), in: ders./Friedrich Engels, Werke. Band 13, Berlin: Dietz 1971, S. 3-160.

Marx, Karl/Engels, Friedrich: Werke. Band 1, Berlin: Dietz 1976.

Mattei, Ugo/Nader, Laura: Plunder. When the Rule of Law is Illegal, Oxford: Blackwell Publishing 2008.

Maus, Ingeborg: »Basisdemokratische Aktivitäten und rechtsstaatliche Verfassung. Zum Verhältnis von institutionalisierter und nichtinstitutionalisierter Volkssouveränität«, in: Thomas Kreuder (Hg.), Der orientierungslose Leviathan. Verfassungsdebatte, Funktion und Leistungsfähigkeit von Recht und Verfassung, Marburg: Schüren 1992, 99-116.

Maus, Ingeborg: Bürgerliche Rechtstheorie und Faschismus. Zur sozialen Funktion und aktuellen Wirkung der Theorie Carl Schmitts, München: Wilhelm Fink Verlag 1980.

Maus, Ingeborg: »Die Basis als Überbau oder >Realistische< Rechtstheorie«, in: dies., Rechtstheorie und politische Theorie im Industriekapitalismus (1986), S. 247-276.

Maus, Ingeborg: »Menschenrechte als Ermächtigungsnormen internationaler Politik oder der zerstörte Zusammenhang von Menschenrechten und Demokratie«, in: Hauke Brunkhorst/Wolfgang R. Köhler/Matthias LutzBachmann (Hg.), Recht auf Menschenrechte. Menschenrechte, Demokratie und internationale Politik, Frankfurt a. M.: Suhrkamp 1999, S. 276-292.

Maus, Ingeborg: Rechtstheorie und politische Theorie im Industriekapitalismus, München: Wilhelm Fink Verlag 1986.

Maus, Ingeborg: Über Volkssouveränität. Elemente einer Demokratietheorie, Berlin: Suhrkamp 2011.

Maus, Ingeborg: »Verfassung oder Vertrag. Zur Verrechtlichung globaler Politik«, in: Peter Niesen/Benjamin Herborth (Hg.), Anarchie der kommunikativen Freiheit. Jürgen Habermas und die Theorie der internationalen Politik, Frankfurt a. M.: Suhrkamp 2007, S. 350-382. 
Maus, Ingeborg: »Verfassung und Verfassungsgebung. Zur Kritik des Theorems einer $>$ Emergenz< supranationaler und transnationaler Verfassungen «, in: Regina Kreide/Andreas Niederberger (Hg.), Staatliche Souveränität und transnationales Recht, München: Mering: Hampp 2010, S. 27-70.

Maus, Ingeborg: »Verrechtlichung, Entrechtlichung und der Funktionswandel von Institutionen«, in: dies., Rechtstheorie und politische Theorie im Industriekapitalismus (1986), S. 277-331.

Maus, Ingeborg: Zur Aufklärung der Demokratietheorie. Rechts- und demokratietheoretische Überlegungen im Anschluss an Kant, Frankfurt a.M.: Suhrkamp 1992.

McCormick, John P.: Machiavellian Democracy, Cambridge: Cambridge University Press 2011.

Menke, Christoph: »Die sandre Form < der Herrschaft. Marx' Kritik des Rechts«, in: Rahel Jaeggi/Daniel Loick (Hg.), Nach Marx. Philosophie, Kritik, Praxis, Berlin: Suhrkamp 2013, S. 273-295.

Menke, Christoph: »Einleitung«, in: ders./Raimondi, Die Revolution der Menschenrechte (2011), S. 247-252.

Menke, Christoph: Recht und Gewalt, Berlin: August-Verlag 2011.

Menke, Christoph/Raimondi, Francesca (Hg.): Die Revolution der Menschenrechte. Grundlegende Texte zu einem neuen Begriff des Politischen, Berlin: Suhrkamp 2011.

Mestmäcker, Ernst-Joachim: Wirtschaft und Verfassung in der Europäischen Union, Baden-Baden: Nomos 2003.

Meyer, John W.: Weltkultur. Wie die westlichen Prinzipien die Welt durchdringen, Frankfurt a. M.: Suhrkamp 2005.

Miles, Kate: The Origins of International Investment Law. Empire, Environment and the Safeguarding of Capital, Cambridge: Cambridge University Press 2013.

Möller, Kolja: »Herrschen und Regieren. Zur Doppelstruktur der konstituierenden Macht«, in: Thore Prien (Hg.), Das Staatsverständnis des Postoperaismus, Baden-Baden: Nomos 2015, S. 95-117.

Möller, Kolja: »Rechtskritik und Systemtheorie«, in: Albert Scherr (Hg.), Systemtheorie und Differenzierungstheorie als Kritik. Perspektiven im Anschluss an Niklas Luhmann, Weinheim/Basel: Beltz Juventa 2015, S. 186210.

Möller, Kolja: »Subalterne Konstitutionalisierung. Zur Verfassung von Revolution und Evolution in der Weltgesellschaft«, in: Amstutz/Fischer-Lescano, Kritische Systemtheorie (2013), S. 169-188.

Möllers, Christoph: »Verfassunggebende Gewalt - Verfassung - Konstitutionalisierung «, in: Armin von Bogdandy/Jürgen Bast (Hg.): Europäisches Verwaltungsrecht, Heidelberg: Springer 2009, S. 227-277. 
Moosa, Imad A.: »Basel II as a Casualty of the Global Financial Crisis«, in: Journal of Banking Regulation 11/2 (2010), S. 95-114.

Mouffe, Chantal: The Democratic Paradox, London/New York: Verso 2000.

Mouffe, Chantal: Über das Politische, Frankfurt a. M.: Suhrkamp 2007.

Müller, Harald: »Staatlichkeit ohne Staat? Ein Irrtum aus der europäischen Provinz«, in: Nicole Deitelhoff/Jens Steffek (Hg.), Was bleibt vom Staat? Demokratie, Recht und Verfassung im globalen Zeitalter, Frankfurt a. M.: Campus 2009, S. 221-258.

Mutua, Makua: »Savages, Victims, and Saviors: The Metaphor of Human Rights«, in: Harvard International Law Journal 41/1 (2001), S. 201-245.

Nassehi, Armin: »Inklusion, Exklusion, Ungleichheit«, in: Thomas Schwinn (Hg.), Differenzierung und soziale Ungleichheit. Die zwei Soziologien und ihre Verknüpfung, Frankfurt a. M.: Humanities Online 2004, S. 323-352.

Naucke, Wolfgang: »Vordringen des Polizeigedankens im Recht, d.i.: Vom Ende der Metaphysik im Recht«, in: Gerhard Dilcher/Bernhard Diestelkamp (Hg.), Recht, Gericht, Genossenschaft und Policey. Studien zu Grundbegriffen der germanistischen Rechtshistorie, Berlin: Erich Schmidt Verlag 1986, S. 177-187.

Negri, Antonio: Insurgencies: Constituent Power and the Modern State, Minneapolis: University of Minnesota Press 1999.

Negri, Antonio: »The Law of the Common«, in: Finnish Yearbook of International Law 21 (2010), S. 16-25.

Neumann, Franz L.: »Der Funktionswandel des Gesetzes im Recht der bürgerlichen Gesellschaft« (1937), in: ders., Demokratischer und autoritärer Staat, Frankfurt a. M.: Europäische Verlagsanstalt 1967, S. 7-57.

Neumann, Franz L.: »Die soziale Bedeutung der Grundrechte in der Weimarer Verfassung« (1930), in: ders., Wirtschaft, Staat, Demokratie. Aufsätze 19301954, Frankfurt a. M.: Suhrkamp 1978, S. 57-75.

Neves, Marcelo: Transconstitutionalism, Portland/Oxford: Hart Publishing 2013 .

Niederberger, Andreas: Demokratie unter Bedingungen der Weltgesellschaft, Berlin: De Gruyter 2009.

Niederberger, Andreas /Schink, Philipp (Hg.): Republican Democracy: Liberty, Law and Politics, Edinburg: Edinburgh University Press 2013.

Niesen, Peter: »Deliberation oder Demokratie? Zur Konstruktion von Legitimität jenseits des Nationalstaats«, in: Regina Kreide/Andreas Niederberger (Hg.), Transnationale Verrechtlichung. Nationale Demokratien im Kontext globaler Politik, Frankfurt a. M.: Campus 2008, S. 240-259.

Niesen, Peter: »Internationale Politische Theorie: Eine disziplinengeschichtliche Einordnung«, in: Zeitschrift für internationale Beziehungen 17/2 (2010), S. 267-277. 
Niesen, Peter: »Kosmopolitismus in einem Land«, in: ders. (Hg.), Transnationale Gerechtigkeit und Demokratie. Frankfurt a. M./New York: Campus 2012, S. 311-339.

Niesen, Peter: Von verfassungsgebender Gewalt zu konstituierender Autorität: ein Grundbegriff für die Internationale Politische Theorie. Antrittsvorlesung Universität Hamburg, Manuskript, 2014.

Nonhoff, Martin: Politischer Diskurs und Hegemonie. Das Projekt »Soziale Marktwirtschaft«, Bielefeld: transcript 2006.

Nowotny, Stefan/Raunig, Gerald: Instituierende Praxen. Bruchlinien der Institutionskritik, Wien: Turia + Kant 2008.

Nowrot, Karsten: Normative Ordnungsstruktur und private Wirkungsmacht. Konsequenzen aus der Beteiligung transnationaler Unternehmen im internationalen Wirtschaftssystem, Berlin: Berliner Wissenschaftsverlag 2006.

Oberndorfer, Lukas/Buckel, Sonja: »Die lange Inkubationszeit des Wettbewerbs der Rechtsordnungen - Eine Genealogie der Rechtsfälle Viking/ Laval/Rüffert/Luxemburg aus der Perspektive einer materialistischen Europarechtstheorie«, in: Fischer-Lescano/Rödl/Schmid, Europäische Gesellschaftsverfassung (2009), S. 277-296.

Opitz, Sven: An der Grenze des Rechts. Inklusion/Exklusion in Zeiten der Sicherheit, Weilerswist: Velbrück 2012.

Opitz, Sven: »Ausnahme mit System. Giorgio Agamben und Niklas Luhmann an der Grenze zum Anderen des Rechts«, in: Kritische Justiz 44/4 (2010), S. 436-449.

Opitz, Sven: »Gibt es einen normativen Eigensinn der (R)Evolution? Über Streit und Ästhetik in der Soziologie des Politischen«, in: Soziale Welt 63/3 (2012), S. 283-292.

Paschukanis, Eugen: Allgemeine Rechtslehre und Marxismus (1929), Freiburg: 2003 .

Patberg, Markus: »Supranational Constitutional Politics and the Method of Rational Reconstruction«, in: Philosophy \& Social Criticism 40/6 (2014), S. 501-521.

Peters, Anne: »Dual Democracy«, in: Jan Klabbers/Anne Peters/Geir Ulfstein (Hg.), The Constitutionalization of International Law, Oxford: Oxford University Press 2009, S. 263-341.

Petersmann, Ernst-Ulrich: The GATT/WTO Dispute Settlement System, London/Den Haag/Boston: Kluwer Law International 1997.

Petersmann, Ernst-Ulrich: »The WTO-Constitution and Human Rights«, in: Journal of International Economic Law 3/1 (2000), S. 19-25.

Pettit, Philip: »A Republican Law of Peoples«, in: European Journal of Political Theory 9/1 (2010), S. 70-94.

Pettit, Philip: Republicanism. A Theory of Freedom and Government, Oxford: Oxford University Press 1997. 
Pocock, J. G. A.: The Machiavellian Moment. Florentine Political Thought and the Atlantic Republican Tradition, Princeton: Princeton University Press 1975 .

Polanyi, Karl: The Great Transformation (1944), Boston: Beacon Press 2001.

Poulantzas, Nicos: Die Internationalisierung der kapitalistischen Produktionsverhältnisse und der Nationalstaat, Berlin: Merve 1973.

Preuss, Ulrich K.: »Der Begriff der Verfassung«, in: ders. (Hg.), Zum Begriff der Verfassung. Die Ordnung des Politischen, Frankfurt a. M.: Fischer 1994 , S. 7-36.

Preuss, Ulrich K.: »Disconnecting Constitutions from Statehood. Is Global Constitutionalism a Viable Concept?«, in: Dobner/Loughlin, The Twilight of Constitutionalism? (2010), S. 23-46.

Preuss, Ulrich K.: Legalität und Pluralismus. Beiträge zum Verfassungsrecht der BRD, Frankfurt a. M.: Suhrkamp 1973.

Preuss, Ulrich K.: »Zum Strukturwandel politischer Herrschaft im bürgerlichen Verfassungsstaat«, in: Claudio Pozzoli (Hg.), Rahmenbedingungen und Schranken staatlichen Handelns. Zehn Thesen, Frankfurt a. M.: Suhrkamp 1976, S. 71-88.

Prien, Thore: Fragmentierte Volkssouveränität. Recht, Gerechtigkeit und der demokratische Einspruch in der Weltgesellschaft, Baden-Baden: Nomos 2010.

Prien, Thore: »Kosmopolitismus und Gewalt. Fragen an die Weltinnenpolitik mit Blick auf Vertreibung, Landgrabbing und die Kämpfe der Subalternen«, in: Franziska Martinsen/Oliver Flüger (Hg.), Gewaltbefragungen. Beiträge zur Theorie von Politik und Gewalt, Bielefeld: transcript 2013, S.165-183.

Raimondi, Francesca: Die Zeit der Demokratie. Politische Freiheit nach Carl Schmitt und Hannah Arendt, Konstanz: Konstanz University Press 2014.

Rajagopal, Balakrishnan: International Law from Below. Development, Social Movements and Third World Resistance, Cambridge: Cambridge University Press 2003.

Rancière, Jacques: Das Unvernehmen. Politik und Philosophie, Frankfurt a. M.: Suhrkamp 2002.

Rancière, Jacques: Der Hass der Demokratie, Berlin: August-Verlag 2012.

Rancière, Jacques: »Who is the Subject of the Rights of Man?«, in: South Atlantic Quarterly 103/2, 3 (2004), S. 297-310.

Renner, Moritz: »Death by Complexity. The Crisis of Law in World Society«, in: Kjaer/Teubner/Febbrajo, The Financial Crisis in Constitutional Perspective (2011), S. 93-112.

Renner, Moritz: »Transnationale Wirtschaftsverfassung«, in: Rabels Zeitschrift für ausländisches und internationales Privatrecht 78/4 (2014), S. 750-783.

Renner, Moritz: Zwingendes transnationales Recht. Zur Struktur der Wirtschaftsverfassung jenseits des Staates, Baden-Baden: Nomos 2011. 
Riedel, Eibe: »Menschenrechte der dritten Generation«, in: Europäische Grundrechte-Zeitschrift 16 (1989), S. 9-21.

Rödl, Florian: »Demokratische Verrechtlichung ohne Verstaatlichung. Kollisionsrecht statt Globalstaat«, in: Eberl, Transnationalisierung der Volkssouveränität (2011), S. 271-294.

Rödl, Florian: »EU im Notstandsmodus«, in: Blätter für deutsche und internationale Politik 5 (2012), S. 5-8.

Rosanvallon, Pierre: La contre-démocratie. La politique à l'âge de la défiance, Paris: Points 2008.

Ruda, Frank: »Alles verpöbelt sich zusehends! Namenlosigkeit und generische Inklusion«, in: Soziale Systeme 14/2 (2008), S. 210-228.

Ruggie, John G.: »International Regimes, Transactions and Change: Embedded Liberalism in the Postwar Economic Order«, in: International Organization 36/2 (1982), S. 379-415.

Salacuse, Jeswald W.: The Law of International Investment Treaties, Oxford: Oxford University Press 2010.

Santos, Alvaro: »Carving Out Policy Autonomy for Developing Countries in the World Trade Organization. The Experience of Brazil and Mexico«, in: Virginia Journal of International Law 52/3 (2012), S. 551-632.

Santos, Boaventura de Sousa: »The World Social Forum and the Global Left«, in: Politics and Society 36/2 (2008), S. 247-270.

Santos, Boaventura de Sousa: The World Social Forum. A User's Manual, Madison 2004 (http://www.ces.uc.pt/bss/documentos/fsm_eng.pdf 2004).

Sassen, Saskia: Territory, Authority, Rights. From Medieval to Global Assemblages, Princeton: Princeton University Press 2006.

Scharpf, Fritz W.: Regieren in Europa. Effektiv und demokratisch?, Frankfurt a. M./New York: Campus 1999.

Schimank, Uwe: »Die Moderne: eine funktional differenzierte kapitalistische Gesellschaft«, in: Berliner Journal für Soziologie 19/3 (2009), S. 327-351.

Schmitt, Carl: Die Tyrannei der Werte (1967), Berlin: Duncker \& Humblot 2011. Schmitt, Carl: Verfassungslehre (1928), Berlin: Duncker \& Humblot 1993.

Schneiderman, David: Constitutionalizing Economic Globalization. Investment Rules and Democracy's Promise, Cambridge: Cambridge University Press 2008.

Schwöbel, Christine J.: »Situating the Debate on Global Constitutionalism«, in: International Journal of Constitutional Law 8/3 (2010), S. 611-635.

Shalakany, Amr A.: »Arbitration and the Third World. A Plea for Reassessing Bias Under the Scepter of Neo-Liberalism«, in: Harvard International Law Journal 41/2 (2000), S. 419-468.

Silver, Beverly J.: Forces of Labor. Arbeiterbewegung und Globalisierung seit 1870, Berlin: Assoziation A 2005. 
Simma, Bruno/Pulkowski, Dirk: »Of Planets and the Universe: Self-contained Regimes in International Law«, in: European Journal of International Law 17/3 (2006), S. 483-529.

Simon, Thomas: »Gute Polizei«. Ordnungsleitbilder und Zielvorstellungen des politischen Handelns in der Frühen Neuzeit, Frankfurt a. M.: Vittorio Klostermann 2004 .

Sinzheimer, Hugo: Grundzüge des Arbeitsrechts, Jena: Gustav Fischer 1927.

Slaughter, Anne-Marie: A New World Order, Princeton: Princeton University Press 2004.

Slaughter, Anne-Marie/Burke-White, William: »An International Constitutional Moment«, in: Harvard International Law Journal 43/1 (2002), S. 1-22.

Somek, Alexander: »Administration without Sovereignty«, in: Dobner/Loughlin, The Twilight of Constitutionalism? (2010), S. 267-287.

Somek, Alexander: »Demokratie als Verwaltung. Wider die deliberativ halbierte Demokratie«, in: Brunkhorst, Demokratie in der Weltgesellschaft (2009), S. 323-348.

Sorel, George: Über die Gewalt (1906), Frankfurt a. M.: Suhrkamp 1981.

Spivak, Gayatari: Righting Wrongs - Unrecht richten, Zürich/Berlin: diaphanes 2008.

Stäheli, Urs: »Gesellschaftstheorie und die Unmöglichkeit ihres Gegenstandes«, in: Schweizerische Zeitschrift für Soziologie 21/2 (1995), S. 361-390.

Stäheli, Urs: »Politik der Entparadoxierung. Zur Artikulation von Hegemonie- und Systemtheorie«, in: Oliver Marchart (Hg.), Das Undarstellbare der Politik. Zur Hegemonietheorie Ernesto Laclaus, Wien: Turia + Kant 1998, S. 52-66.

Stäheli, Urs: Sinnzusammenbrüche. Eine dekonstruktive Lektüre von Niklas Luhmanns Systemtheorie, Weilerswist: Velbrück 2000.

Stevenson, Robert Louis: Dr. Jekyll \& Mr. Hyde, Frankfurt a. M./Leipzig: InselVerlag.

Stichweh, Rudolf: Die Weltgesellschaft. Soziologische Analysen, Frankfurt a. M.: Suhrkamp 2000.

Stichweh, Rudolf: »The Eigenstructures of World Society and the Regional Cultures of the World «, in: Ino Rossi (Hg.), Frontiers of Globalization Research. Theoretical and Methodological Approaches, New York: Springer 2007, S. 133-149.

Stolleis, Michael: Geschichte des öffentlichen Rechts in Deutschland. 1. Band: Reichspublizistik und Policeywissenschaft, München: C. H. Beck 1988.

Stolleis, Michael: »Öffentliches Recht und Privatrecht im Prozeß der Entstehung des modernen Staates«, in: Wolfgang Hoffmann-Riem/Eberhard Schmidt-Aßmann (Hg.), Öffentliches Recht und Privatrecht als wechselseitige Auffangordnungen, Baden-Baden: Nomos 1996, S. 41-61. 
Stolleis, Michael (Hg.): Policey im Europa der frühen Neuzeit, Frankfurt a. M.: Vittorio Klostermann 1996.

Streeck, Wolfgang: Gekaufte Zeit. Die vertage Krise des demokratischen Kapitalismus, Berlin: Suhrkamp 2013.

Süßmann, Johannes: »Die Wurzeln des Wohlfahrtsstaats - Souveränität oder Gute Policey?«, in: Historische Zeitschrift 285 (2007), S. 19-47.

Sweet, Alec Stone: »Constitutionalism, Legal Pluralism, and International Regimes«, in: Indiana Journal of Global Legal Studies 16/2 (2009), S. 621-645.

Tams, Christian J.: »Konstitutionalisierungstendenzen im Recht des internationalen Investitionsschutzes«, in: Christian Tietje/Karsten Nowrot (Hg.), Verfassungsrechtliche Dimensionen des Internationalen Wirtschaftsrechts, Stuttgart u.a.: Boorberg, S. 229-251.

Ten Brink, Tobias: Geopolitik. Geschichte und Gegenwart kapitalistischer Staatenkonkurrenz, Münster: Westfälisches Dampfboot 2008.

Teubner, Gunther: »A Constitutional Moment? The Logics of >Hitting the Bottom«, in: Kjaer/Teubner/Febbrajo, The Financial Crisis in Constitutional Perspective (2011), S. 9-51.

Teubner, Gunther: »>And God laughed ...< Indeterminacy, Self-Reference and the Paradox in Law« (1989), in: German Law Journal 12/1 (2011), S. 376-406.

Teubner, Gunther: »Das Projekt der Verfassungssoziologie. Irritationen des nationalstaatlichen Konstitutionalismus«, in: Zeitschrift für Rechtssoziologie $32 / 2$ (2011), S. 189-204.

Teubner, Gunther: »Die anonyme Matrix: Menschenrechtsverletzungen durch >private< transnationale Akteure«, in: Der Staat 45/2 (2006), S.161-187.

Teubner, Gunther: »Exogene Selbstbindung: Die Konstitutionalisierung von Gründungsparadoxien gesellschaftlicher Teilsysteme«, in: Zeitschrift für Rechtssoziologie 35 (2015), S.1-21.

Teubner, Gunther: »Globale Bukowina: Zur Emergenz eines transnationalen Rechtspluralismus«, in: Rechtshistorisches Journal 15 (1996), S. 253-255.

Teubner, Gunther: »Globale Zivilverfassungen: Alternativen zur staatszentrierten Verfassungstheorie«, in: Zeitschrift für ausländisches öffentliches Recht und Völkerrecht 63 (2003), S. 1-28.

Teubner, Gunther: »Privatregimes: Neo-Spontanes Recht und duale Sozialverfassungen in der Weltgesellschaft«, in: Dieter Simon/Manfred Weiss (Hg.), Zur Autonomie des Individuums. Liber Amicorum Spiros Simitis, BadenBaden: Nomos 2000, S. 437-453.

Teubner, Gunther: »Selbstsubversive Gerechtigkeit: Kontingenz- oder Transzendenzformel des Rechts?«, in: Zeitschrift für Rechtssoziologie 29/1 (2008), S. 9-36.

Teubner, Gunter: »Societal Constitutionalism and the Politics of the Common«, in: Finnish Yearbook of International Law 21 (2010), S. 2-15. 
Teubner, Gunther: »Societal Constitutionalism without Politics? A Rejoinder«, in: Social \& Legal Studies 20/2 (2011), S. 248-252.

Teubner, Gunther: Verfassungsfragmente. Gesellschaftlicher Konstitutionalismus in der Globalisierung, Berlin: Suhrkamp 2012.

Thornhill, Chris: A Sociology of Constitutions. Constitutions and State Legitimacy in Historical-Sociological Perspective, Cambridge: Cambridge University Press 2011.

Thornhill, Chris: »Contemporary Constitutionalism and the Dialectic of Constituent Power«, in: Global Constitutionalism 1/3 (2012), S. 369-404.

Tomuschat, Christian: »Die internationale Gemeinschaft«, in: Archiv des Völkerrechts (1995), S. 1-20.

Trachtman, Joel P.: »The Constitutions of the WTO«, in: European Journal of International Law 17/3 (2006), S. 623-646.

United Nations Conference on Trade and Development (UNCTAD) (Hg.): World Investment Report. Towards a New Generation of Investment Policies 2012.

Underhill, Geoffrey: »Foreword«, in: Wood, Governing Global Banking (2005), S. vi-vii.

UN Generalversammlung, Resolution der UN Generalversammlung A/ $\operatorname{Res} / 60 / 1$.

UN Special Representative on Human Rights and Transnational Corporations (The Ruggie Report) (Hg.): Report of the Special Representative of the Secretary-General (SRSG) on the Issue of Human Rights and Transnational Corporations and Other Business Enterprises, Mapping International Standards of Responsibility and Accountability for Corporate Acts, UN Doc A/HRC/4/035 v 9.2.2007.

Vatter, Miguel: Between Form and Event. Machiavellis Theory of Political Freedom, Dordrecht: Kluwer Academic Publishers 2000.

Vatter, Miguel: »The Quarrel between Populism and Republicanism: Machiavelli and the Antinomies of Plebeian Politics«, in: Contemporary Political Theory $11 / 3$ (2012), S. 242-263.

Viellechner, Lars: »Berücksichtigungspflicht als Kollisionsregel. Zu den innerstaatlichen Wirkungen von völkerrechtlichen Verträgen und Entscheidungen internationaler Gerichte, insbesondere bei der Auslegung und Anwendung von Grundrechten«, in: Nele Matz-Lück/Mathias Hong (Hg.), Grundrechte und Grundfreiheiten im Mehrebenensystem - Konkurrenzen und Interferenzen, Berlin u.a.: Springer 2012, S.109-160.

Viellechner, Lars: Transnationalisierung des Rechts, Weilerswist: Velbrück 2013 .

Vismann, Cornelia: »Das Recht erklären. Zur gegenwärtigen Verfassung der Menschenrechte«, in: Kritische Justiz 29/3 (1996), S. 321-335. 
Vismann, Cornelia: »St. Benedict, Inc. Zur Rechtsförmigkeit von Gemeinschaft«, in: dies., Das Recht und seine Mittel. Ausgewählte Schriften, Frankfurt a. M.: Fischer 2012, S. 365-393.

Vogl, Joseph: »Staatsbegehren. Zur Epoche der Policey«, in: Deutsche Vierteljahrsschrift 74/4 (2000), S. 600-626.

Volk, Christian: »Zwischen Entpolitisierung und Radikalisierung. Zur Theorie von Demokratie und Politik in Zeiten des Widerstands«, in: Politische Vierteljahresschrift 54/1 (2013), S. 75-110.

Vorländer, Hans: Die Verfassung. Idee und Geschichte, München: C. H. Beck 1999.

Wagner, Andreas: Recht - Macht - Öffentlichkeit. Elemente demokratischer Staatlichkeit bei Jürgen Habermas und Claude Lefort, Stuttgart: SteinerVerlag 2010.

Weir, Lorna: »The Concept of Truth Regime«, in: Canadian Journal of Sociology 33/2 (2008), S. 367-390.

Wiener, Antje: A Theory of Contestation, Berlin/Heidelberg: Springer 2014.

Wiener, Antje: »Zur normativen Wende in den IB: Triangulation of a Different Kind«, in: Zeitschrift für internationale Beziehungen 17/2 (2010), S. 335354 .

Wiener, Antje/Lang, Anthony F./Tully, James / Maduro, Miguel Poiares / Kumm, Mattias: »Global Constitutionalism: Human Rights, Democracy and the Rule of Law«, in: Global Constitutionalism 1/1 (2012), S. 1-15.

Willke, Helmut: Atopia. Studien zur atopischen Gesellschaft, Frankfurt a. M.: Suhrkamp 2001.

Willke, Helmut: Politische Strukturbildung der Weltgesellschaft. Symbolordnung und Eigenlogik lateraler Weltsysteme, in: Mathias Albert/Rudolf Stichweh, Weltstaat und Weltstaatlichkeit. Beobachtungen globaler Strukturbildung, Wiesbaden: VS-Verlag 2007, S. 133-156.

Willke, Helmut: Stand und Kritik der neueren Grundrechtstheorie. Schritte zu einer normativen Systemtheorie, Berlin: Duncker \& Humblot 1975.

Wissel, Jens: Die Transnationalisierung von Herrschaftsverhältnissen. Zur Aktualität von Nicos Poulantzas' Staatstheorie, Baden-Baden: Nomos 2007. Wolff, Jonas/Zimmermann, Lisbeth: »Between Banyans and Battle Scenes: Contestation and Democracy«, unveröffentlichtes Manuskript.

Wolzendorff, Kurt: Der Polizeigedanke des modernen Staates (1918), Aalen: Scientia Verlag 1964.

Wood, Duncan R.: Governing Global Banking. The Basel Committee and the Politics of Financial Globalisation, Aldershot: Ashgate 2005.

WTO DSU, DS 58, United States - Import Prohibition of Certain Shrimp and Shrimp Products.

WTO DSU, DS 265, 266 und 283 European Communities - Export Subsidies on Sugar. 
Ziltener, Patrick: Strukturwandel der europäischen Integration, Münster: Westfälisches Dampfboot 1999.

Žižek, Slavoj: »Against the Populist Temptation«, in: Critical Inquiry $32 / 3$ (2006), S. 551-574.

Žižek, Slavoj: Die Tücke des Subjekts, Frankfurt a. M.: Suhrkamp 2001.

Zürn, Michael/Binder, Martin/Ecker-Ehrhardt, Matthias: »International Authority and its Politicization«, in: International Theory - A Journal of International Politics, Law and Philosophy 4/1 (2012), S. 69-106.

Zürn, Michael/Binder, Martin/Ecker-Ehrhard, Matthias/Radtke, Katrin: »Politische Ordnungsbildung wider Willen«, in: Zeitschrift für internationale Beziehungen 15/1 (2008), S. 129-164. 



\section{Danksagung}

Das vorliegende Buch ist eine überarbeitete Variante meiner Dissertation, die ich 2013 an der Universität Flensburg eingereicht habe. Es war ein großes Glück, dieses Projekt verfolgen zu können. Die beiden Betreuer Hauke Brunkhorst und Andreas Fischer-Lescano haben die Arbeit stets mit kritischer Solidarität begleitet. Sie standen mir als Gesprächspartner zur Verfügung und haben mich immer wieder darin bestärkt, meine Gedankengänge konsequent bis zum Ende durchzuarbeiten. Ihre Arbeiten und insbesondere ihr wissenschaftlicher Stil sind, wie der Leser des Buches sicherlich feststellen wird, nicht folgenlos an der Arbeit vorbeigezogen, auch wenn ich an entscheidenden Stellen andere inhaltliche Weichenstellungen vornehme. Peter Niesen verdanke ich nicht nur das Drittgutachten, sondern auch eine Reihe von weiterführenden Hinweisen und Kommentaren zum Problem eines transnationalisierten pouvoir constituant.

Das Projekt hat unterschiedliche Kontexte durchlaufen: zunächst den Sonderforschungsbereich »Staatlichkeit im Wandel« an der Universität Bremen und das Projekt »Judizialisierung der internationalen Streitbeilegung « sowie schließlich ein Fellowship am Graduiertenkolleg »Verfassung jenseits des Staates« an der Berliner Humboldt-Universität. Der Studienstiftung des deutschen Volkes danke ich für die Aufnahme in die Promotionsförderung und für ein großzügiges Stipendium, das es mir ermöglicht hat, intensiv am Projekt zu arbeiten. Schließlich konnte ich das Manuskript am Exzellenzcluster »Normative Orders« der Universität Frankfurt in einem stimulierenden intellektuellen Umfeld überarbeiten und auf eine finanzielle Förderung der Publikation zurückgreifen.

So eine Qualifikationsarbeit ist auch immer ein kollektives Unternehmen. Ohne inhaltliche Diskussionen, hilfreiche Fragen oder konkrete Hilfe in Krisenfällen und die nötige Zerstreuung geht es natürlich nicht. Besonders bedanken möchte ich mich deshalb bei Vanessa Aab, Johannes Buchner, Sergio Costa, Hannah Franzki, Guilherme Leite Goncalves, Jan Harms, Jonas Heller, Pablo Holmes, Johan Horst, Joachim Jainta, Lena Kreck, Katja Kipping, Jan Hauke Plassmann, Manuel Bastias Saavedra, Jörg Schindler, Philipp Schink, Jasmin Siri, Thore Prien, Benedict Vischer und Inge Walter-Möller, die entwe- 
der Teile der Dissertation kommentiert haben oder an entscheidenden Stellen für mich da waren. Nicht zuletzt sind Beiträge von Teilnehmern der Tagungen in Minneapolis und Brasilia eingeflossen, wo ich meine Überlegungen vorgestellt habe, ebenso wie Kommentare und Einwände von Jürgen Habermas, Federica Gregoratto und Regina Kreide auf einer Konferenz in Bad Homburg. Sie haben mich insbesondere dazu veranlasst, noch einmal ausführlicher auf die Normativität einer »destituierenden Macht« einzugehen, wie ich sie im Buch vorschlage. Bei Jan Wenke bedanke ich mich für ein sorgfältiges Lektorat, das den Text lesbarer und besser gemacht hat. Für das Glück mit meiner Tochter Natalja Anaïs fehlen mir hier alle Worte.

Die übliche Widmung bleibt, ganz im Sinne des Buches, vorläufig leer.

Kolja Möller, Frankfurt, 2.3.2015 


\section{Edition Politik}
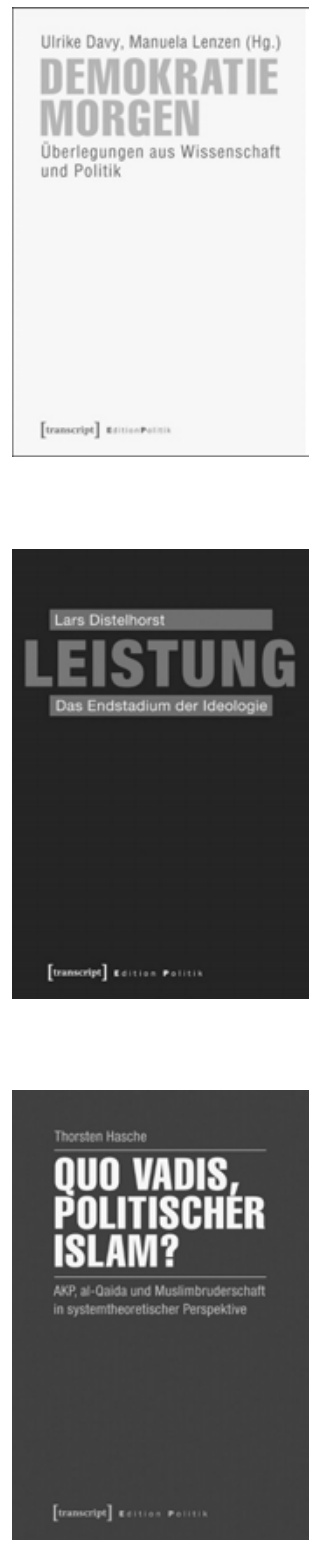

Ulrike Davy, Manuela Lenzen (Hg.)

Demokratie morgen

Überlegungen aus Wissenschaft und Politik

20I3, I20 Seiten, kart., I6,80€,

ISBN 978-3-8376-2387-I

Lars Distelhorst

Leistung

Das Endstadium der Ideologie

20I4, I92 Seiten, kart., 22,99€,

ISBN 978-3-8376-2597-4

Thorsten Hasche

Quo vadis, politischer Islam?

AKP, al-Qaida und Muslimbruderschaft in systemtheoretischer Perspektive

April 2015, 390 Seiten, kart., 39,99 €,

ISBN 978-3-8376-3I20-3 


\section{Edition Politik}

Marcus Koch

\section{Das}

utopische Europa

Die Vertrăge der politischen

Integration Europas und

ihre utopischen Elemente

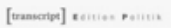

Timmo Krüger

Das Hegemonie-

projekt der

ökologischen

Modernisierung

Die Konflikte um Carbon Capture and Storage (CCS) in der

internationalen Klimapolitik

[rascoive] :

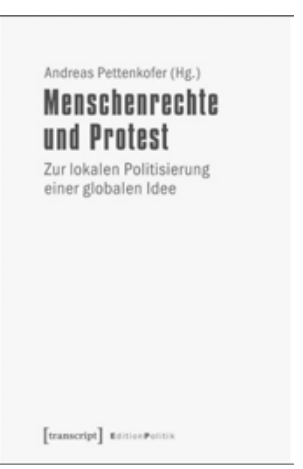

\section{Marcus Koch}

Das utopische Europa

Die Verträge der politischen Integration Europas und ihre utopischen Elemente

Januar 20I5, I62 Seiten, kart., 24,99€, ISBN 978-3-8376-2958-3
Timmo Krüger

Das Hegemonieprojekt der ökologischen

Modernisierung

Die Konflikte um Carbon Capture and Storage (CCS) in der internationalen Klimapolitik

Mai 20I5, 428 Seiten, kart., 34,99€,

ISBN 978-3-8376-3233-0

Andreas Pettenkofer (Hg.)

Menschenrechte und Protest

Zur lokalen Politisierung einer globalen Idee

Dezember 20I5, ca. 250 Seiten, kart., ca. $28,80 €$, ISBN 978-3-8376-2II2-9 


\section{Edition Politik}

Karin Bischof

Global Player EU?

Eine ideologiekritische

Metaphernanalyse

Mai 20I5, 242 Seiten, kart., 34,99€,

ISBN 978-3-8376-3II5-9

\section{Ahmet Cavuldak}

Gemeinwohl und Seelenheil

Die Legitimität der Trennung

von Religion und Politik in

der Demokratie

Januar 20I5, 632 Seiten, kart., 49,99 €,

ISBN 978-3-8376-2965-I

\section{Lucyna Darowska}

Widerstand und Biografie

Die widerständige Praxis

der Prager Journalistin Milena Jesenská gegen den Nationalsozialismus

20I2, 528 Seiten, kart., 39,80€,

ISBN 978-3-8376-I783-2

Michael Daxner,

Hannah Neumann (Hg.)

Heimatdiskurs

Wie die Auslandseinsätze der

Bundeswehr Deutschland verändern

20I2, 340 Seiten, kart., zahlr. Abb., 32,80 €,

ISBN 978-3-8376-2219-5

Stefan Luft, Peter Schimany (Hg.)

20 Jahre Asylkompromiss

Bilanz und Perspektiven

20I4, 332 Seiten, kart., zahlr. Abb., 29,99€, ISBN $978-3-8376-2487-8$

\section{Hendrik Meyer}

Was kann der Staat?

Eine Analyse der rot-grünen

Reformen in der Sozialpolitik

20I3, 282 Seiten, kart., 32,80 €,

ISBN 978-3-8376-23I2-3
Werner J. Patzelt (Hg.)

Die Machbarkeit politischer Ordnung

Transzendenz und Konstruktion

2013, 472 Seiten, kart., $38,80 €$,

ISBN $978-3-8376-2247-8$

Shamim Rafat

Ethik und Qualität

in der Politikberatung

Zur Entwicklung von professionellen Standards und Grundsätzen

20I2, 272 Seiten, kart., zahlr. Abb., 32,80 €, ISBN 978-3-8376-2085-6

Jana Trumann

Lernen in Bewegung(en)

Politische Partizipation und Bildung in Bürgerinitiativen

2013, 298 Seiten, kart., $29,80 €$,

ISBN 978-3-8376-2267-6

Bärbel Heide Uhl

Die Sicherheit der Menschenrechte Bekämpfung des Menschenhandels zwischen Sicherheitspolitik und

Menschenrechtsschutz

20I4, 238 Seiten, kart., 34,99 €,

ISBN 978-3-8376-2640-7

Hans Vorländer (Hg.)

Demokratie und Transzendenz

Die Begründung politischer

Ordnungen

20I3, 534 Seiten, kart., 39,80€,

ISBN 978-3-8376-2278-2

Zentrum für Ethik und Nachhaltigkeit (ZEN-FHS) (Hg.)

Herausforderungen für die Politik

und die Ethik

Moral - Terror - Globalisierung -

Demokratie

2014, 94 Seiten, kart., I6,99 €,

ISBN 978-3-8376-26I2-4 
